\title{
TEST SYSTEM DEVELOPMENT FOR THE PERFORMANCE TESTING OF ASPHALT CONTAINING DIFFERENT MINERAL FILLERS
}

\author{
By \\ Domenic Valle \\ B.Eng. Civil Engineering, Ryerson University, Toronto 2004
}

A thesis
presented to Ryerson University
in partial fulfillment of the
requirements for the degree of
Master of Applied Science

(Civil Engineering)

\section{PROPERTY OF \\ Ryerson University Library}

Toronto, Ontario, Canada, 2008

$M P=2009$

(C) Domenic Valle, 2008 


\section{AUTHOR'S DECLARATION}

I hereby declare that I am the sole author of this thesis.

I authorize Ryerson University to lend this thesis to other institutes or individuals for the purpose of scholarly research.

Author's signature

Date -

I further authorize Ryerson University to reproduce this thesis by photocopying or by other means, in total or in part, at a request of other institutions or individuals for the purpose of scholarly research.

Author's signature

Dat $\epsilon$

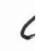




\section{BORROWER'S PAGE}

Borrowers undertake to give proper credit for any use made of the thesis. Ryerson

University requires the signatures of all persons using or photocopying this thesis.

Please sign below and give address and date.

\begin{tabular}{|c|c|c|c|}
\hline Name & Signature of Borrower & Address & Date \\
\hline & & & \\
\hline & & & \\
\hline & & & \\
\hline & & & \\
\hline & & & \\
\hline & & & \\
\hline & & & \\
\hline & & & \\
\hline & & & \\
\hline & & & \\
\hline & & & \\
\hline & & & \\
\hline & & & \\
\hline
\end{tabular}




\title{
TEST SYSTEM DEVELOPMENT FOR THE PERFORMANCE TESTING OF ASPHALT CONTAINING DIFFERENT MINERAL FILLERS
}

\author{
Domenic Valle \\ Master of Applied Science, Department of Civil Engineering \\ RYERSON UNIVESRITY, Canada, 2008
}

\begin{abstract}
This research project identifies the materials and equipment needed to implement Simple Performance Testing (SPT) on Superpave asphalt mixtures. This project can be used as a guide or manual for others who would like to evaluate the performance of Hot Mix Asphalt (HMA) mixtures. This thesis outlines both physical and mechanical SPT requirements and applies them to the performance testing of asphalt mixtures incorporating different types of mineral fillers. Furthermore, this research evaluates the dynamic modulus of asphalt containing various mineral fillers. The results have shown a small increase in dynamic modulus values when $4 \%$ fly ash is used as mineral filler when compared to limestone dust (control mix). Portland cement has also shown an increase in dynamic modulus over the control mix although the increase was less than that observed with the use of fly ash. The higher moduli associated with the use of fly ash can be viewed as beneficial in terms of rutting resistance, but require further investigation for fatigue resistance.
\end{abstract}




\section{ACKNOWLEDGEMENTS}

This thesis is mainly based on the work done from September 2005 - to - May 2008, in the TARBA Highway Materials Lab, Department of Civil Engineering at Ryerson University, Canada. This thesis is an analysis of the performance of hot mix asphalt made using various mineral fillers.

I would like to express my sincere gratitude and appreciation to my thesis advisor, Dr. Medhat Shehata, for his guidance, support and patience during the development of this thesis. At every turn, his enthusiastic support played a key role in my successful completion of this thesis.

Furthermore, I would like to thank the following individuals for their input and expertise in their respected areas: Larry Mullins (InterTechnology), Terry Hawkly (MTS) for their help with the acquisition of MPT software, I would also like to thank Ryerson University (Department of Civil Engineering) for their gracious support in the funding of some critical pieces of equipment. And last but not least I would like to thank the Canadian Foundation for Innovation (CFI) for providing the funds to purchase the MTS series 810 load frame and environmental chamber. Lastly, special gratitude goes to my family $\&$ friends who have helped me through this process and who have supported my continued dedication to education. And last but not least a special thank you to my many proof readers who have helped make this thesis what it is today. 


\section{DEDICATION}

This thesis is dedicated to my family and friends who have helped and supported me through all my years of study. 


\section{TABLE OF CONTENTS}

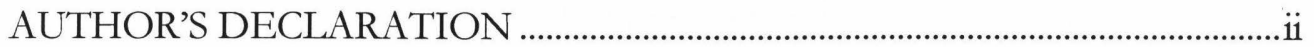

BORROWER'S PAGE.......................................................................................................iii

ABSTRACT .......................................................................................................................

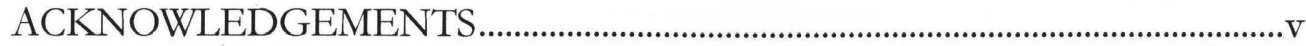

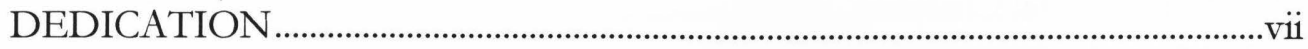

TABLE OF CONTENTS ....................................................................................... vii-ix

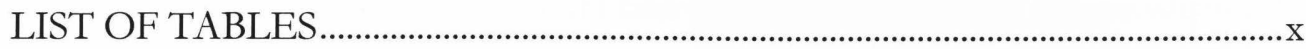

LIST OF FIGURES ...........................................................................................

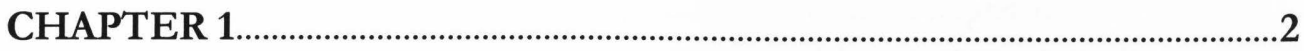

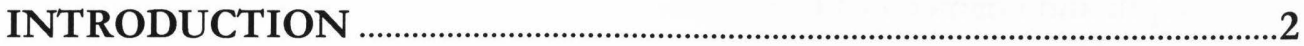

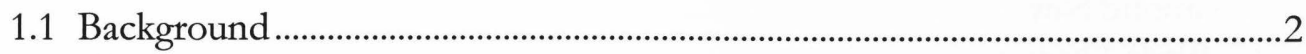

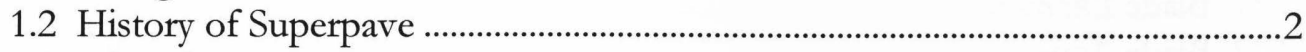

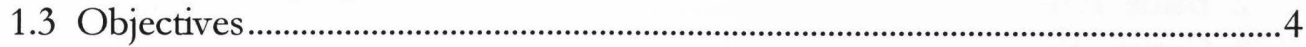

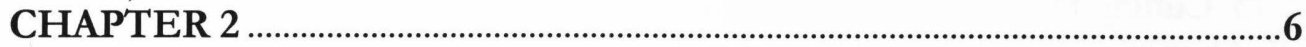

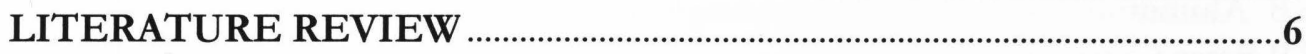

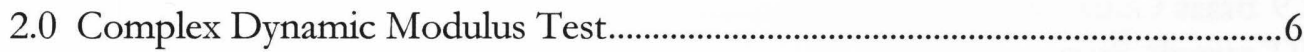

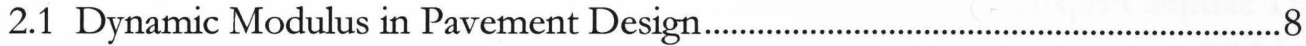

2.2 Dynamic Modulus as a Performance Test .............................................................10

2.3 Dynamic Test Studies and Protocols ....................................................................11

2.4 Dynamic Modulus vs. Master Curves ……….....................................................12

2.5 Variability in Past Test Studies and Protocols .....................................................12

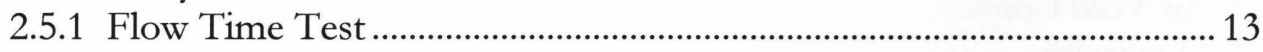

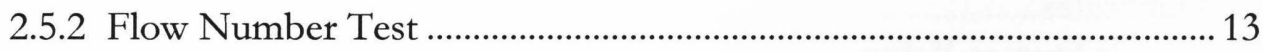

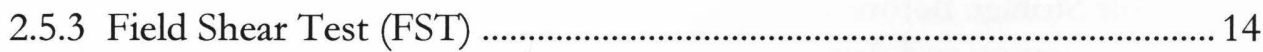

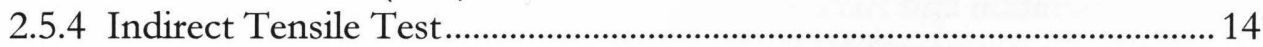

2.6 Wheel Load Testers ..............................................................................................15

2.61 Georgia Wheel Load Tester (GWLT) ….................................................. 15

2.6.2 Asphalt Pavement Analyzer (APA) .......................................................... 17

2.6.4 Hamburg Wheel Tracking Device (HWTD) ........................................... 18

2.7 Simple Performance Testing Procedures ...............................................................19

2.7.1 Testing Program Frequencies and Temperatures (ASTM) ........................19

2.7.2 Testing Program Frequencies and Temperatures (NCHRP) ....................20

2.7.3 Similarities and Differences ASTM \& NCHRP........................................22

2.8 Dynamic Modulus for Permanent Deformation .................................................24

2.8.1 Repeated Load and Uni-axial Compression ...............................................25

2.8.3 Static Creep/Flow Time of HMA ......................................................................26

2.9 Common HMA Distress Mechanisms ...............................................................27

2.9.1 Permanent Deformation...........................................................................27

2.9.2 Low Temperature Cracking ............................................................................29

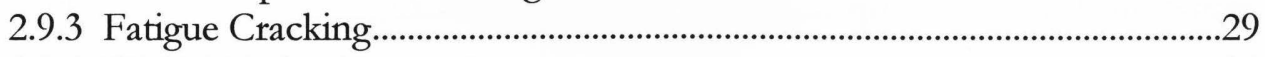

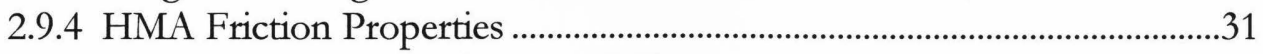

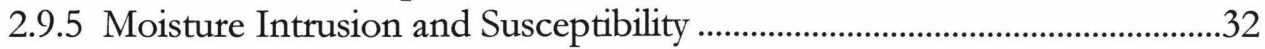

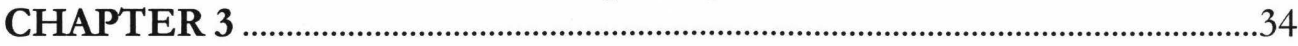




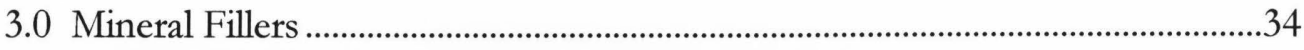

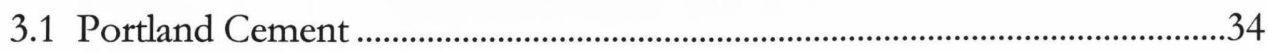

3.1.2 Fly Ash Type C and Type F.....................................................................34

3.1.3 Bag House Dust ................................................................................................

3.2 Equipment Requirements...................................................................................35

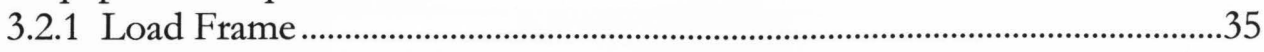

3.2.2 Environmental Chamber.............................................................................37

3.2.3 Gyratory Compactor ..................................................................................38

3.2.4 Displacement Transducers (LVDT) and Hardware.....................................39

3.2.5 Data Acquisition Equipment.........................................................................4

3.2.6 Coring Rig and Accessories ............................................................................4

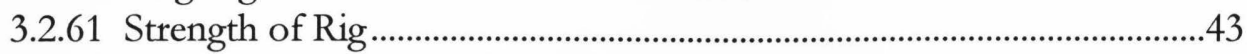

3.2.62 Depth and Diameter of Coring Bit............................................................43

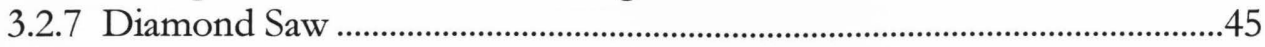

3.2.71 Blade Diameter .............................................................................................46

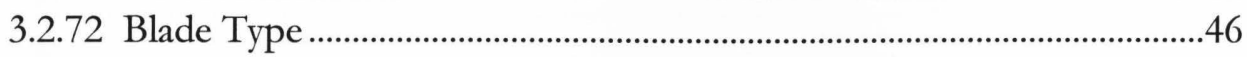

3.2.73 Cutting Process .........................................................................................4

3.2.8 Aluminum Cylinder for Phase Angle Verificaion .................................... 46

3.2.9 Brass Gauge Bars ......................................................................................... 47

3.3 SPT sample Preparation.........................................................................................

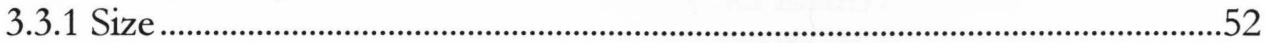

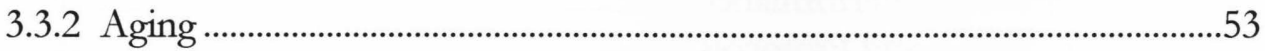

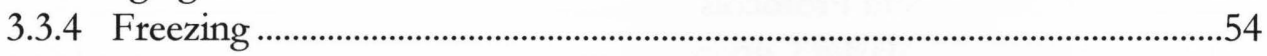

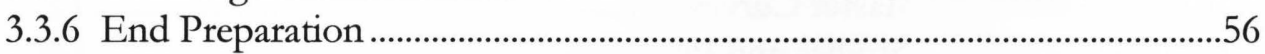

3.3.7 Air Void Content ……………………………………………………….....56

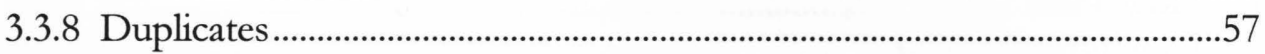

3.3.9 Sample Storage Before Testing …………………………………………....57

3.4 Sample Preparation and Accessories.....................................................................57

3.4.1 Sample Accessories (LVDT mounting hardware) .......................................57

3.4.2 Time requirements..........................................................................................

3.4.21 Sample Preparation ...................................................................................59

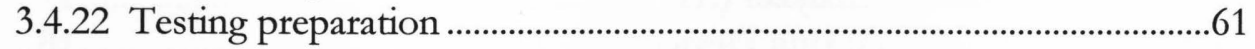

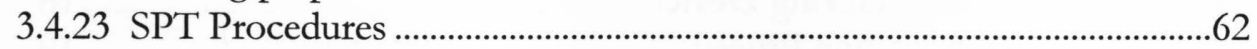

3.4.3 Pre-Test Sample Conditioning .......................................................................62

3.4.4 Sample Preparation Weigh Cards ..................................................................63

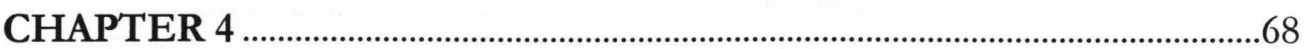

RESULTS AND ANALYSIS......................................................................68

4.1 Mix Properties ..................................................................................................6

4.1.1 Results from SPT Testing ……………………………………………......68

4.1.3 Mix Property Comparison..................................................................................

4.1.4 Temperature and Frequency Effects on Filler Type .....................................74

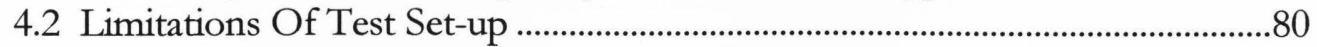


CHAPTER 5 .82

CONCLUSIONS.

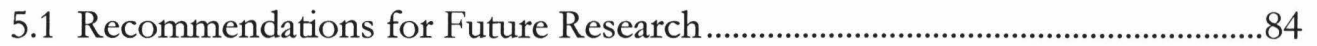

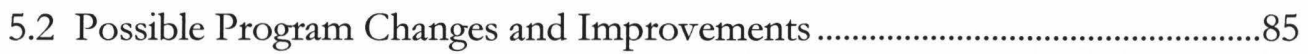

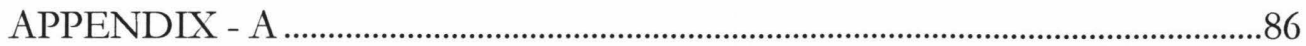

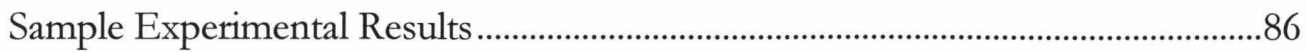

APPENDIX - B .............................................................................. 1367-145

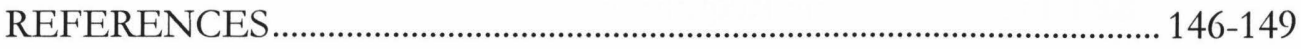




\section{LIST OF TABLES}

Table 1: Sample Activity Time Requirements __ 60

Table 2: Testing Activity Time Requirements __ 61

Table.3: $\quad$ SPT Procedure Time Requirements __ 62

Table 4: $\quad$ Control Mix Weigh Card __ 64

Table 5: $\quad$ Fly Ash Type C Mix Weigh Card __ 65

Table 6: $\quad$ Fly Ash Type F Mix Weigh Card __ 66

Table 7: $\quad$ Portland Cement Mix Weigh Card __ 67

Table 8: $\quad$ Mix properties

Table 9: Control Mix Dynamic Moduli __ 70

Table 10: $\quad$ Fly Ash Type F Mix Dynamic Moduli __ 71

Table 11: Portland Cement Mix Dynamic Moduli __ 71

Table 12: $\quad$ Fly Ash Type C Mix Dynamic Moduli __ 72 


\section{LIST OF FIGURES}

Figure 2.1: Typical Dynamic Modulus Test Waveform 6

Figure 2.2: Temperature Superposition Dynamic Values vs. Log Time_9

Figure 2.3: Typical Master Curve for a sample data set 9

Figure 2.4: Relationship Between Dynamic Modulus and Rutting for the FHWA Pavement Testing Facility 11

Figure 2.5: Indirect Tensile Testing Apparatus 15

Figure 2.6: Georgia Wheel Tester from the

Georgia Institute of Technology 16

Figure 2.7: Full size Asphalt Pavement Analyzer 17

Figure 2.8: Hanburg Wheel Tester 18

Figure 3.1: $\quad$ Load Frame 36

Figure 3.2: $\quad$ Filling Process 37

Figure 3.3: Nitrogen Gas Dewer 37

Figure 3.4: Gyratory Compactor 38

Figure 3.5a: LVDT Schematic 40

Figure 3.5b: LVDT Used in this study 40

Figure 3.6: Data Acquisition System 42

Figure 3.7: $\quad$ Coring Rig 44

Figure 3.8a: Puck Holder Device (side view) 44

Figure 3.8b: Puck Holder Device (top view) 45 
Figure 3.9: Diamond Blade Rock Saw 46

Figure 3.91: Aluminum Alloy Round for Phase Shift Verification 48

Figure 3.91a: Sinusoidal Stress and Strain Waves vs. time in Asphalt 50

Figure 3.91b: Sinusoidal Stress and Strain Waves vs. Time in Aluminum Alloy 50

Figure 3.92a: Brass Gauge Bars Mounted on Asphalt Specimen 52

Figure 3.92b: Brass Gauge Bars Mounted on Aluminum Specimen 52

Figure 3.10: Convection Oven used for aging 53

Figure 3.11: Brovold Gyratory Compactor 54

Figure 3.12: Commercial Freezer 55

Figure 3.13: LVDT Fasteners 58

Figure 4.1: Load vs. AVG displacement 69

Figure 4.2: $\quad$ Solved Example for one Data Set 70

Figure 4.3: Indirect Tensile Strength Results 73

Figure 4.4: Tensile Strength Ratio test Results 74

Figure 4.5: Dynamic Modulus vs. Frequency $\left(@-9^{\circ} \mathrm{C}\right)$ 75

Figure 4.6: Dynamic Modulus vs. Frequency $\left(@ 4.4^{\circ} \mathrm{C}\right)$ 75

Figure 4.7: Dynamic Modulus vs. Frequency $\left(@ 21.1^{\circ} \mathrm{C}\right)$ 76

Figure 4.8: Dynamic Modulus vs. Frequency $\left(@ 37.8^{\circ} \mathrm{C}\right)$ 76

Figure 4.9: Dynamic Modulus vs. Temperature (@10Hz) 77

Figure 4.10: Dynamic Modulus vs. Temperature (@5.0Hz) 77

Figure 4.11: Dynamic Modulus vs. Temperature (@1.0Hz) 78

Figure 4.12: Dynamic Modulus vs. Temperature (@0.5Hz) 78 
Figure 4.13: Dynamic Modulus vs. Temperature (@0.1Hz) 79 


\section{CHAPTER 1}

\section{INTRODUCTION}

\subsection{Background}

Superpave Mix design and analysis method was developed more than a decade ago under the Strategic Highway Research Program otherwise known as SHRP. Since then many departments of transportation have decided to adopt and follow certain common guidelines which SHRP had set forth. One of the most popular and widely accepted criteria is SUPERPAVE methodology which includes performance grade binder specification and volumetric mix design method. Since its inception SUPERPAVE has been scrutinized and reviewed many times. The main concern with SUPERPAVE or volumetric mix design is that the methodology is all based on volumetric properties of HMA (Hot Mix Asphalt) mixtures and thus does not run any tests to evaluate the true characteristics of a mixture.

Since the late sixties various institutions and government bodies began conducting extensive experimentation and testing on HMA, this testing still continues today. Through the analysis of these extensive studies, namely WesTrack, and National Cooperation Highway Research Program or NCHRP Superpave Project 9-7 (Field Procedures and Equipment to implement SHRP Asphalt Specifications), as well as other experimental projects the main question was whether Superpave volumetric mix design alone would be enough to ensure good performance over a wide range of trouble areas. With the intent to better understand the problems at hand, under the blanket of NCHRP Superpave Project 9-19 (Simple Performance Test for Superpave Mix Design) numerous tests have been developed and adopted

over the last couple of decades. After extensive testing the pool of knowledge acquired by US projects such as MnRoad, FHWA-ALF, and WesTrak, most 
departments of transportation agreed and recommend SPT's for permanent deformation testing as well as dynamic modulus and repeated load resistance. This research will review and apply simple methodology to a series of HMA samples in attempts to reveal long term performance characteristics. This study will deal primarily with the testing of a series of case specific HMA mixes enhanced by mineral fillers. The mineral fillers used have been implemented in the HMA to increases strength as well as material resilience. If successful this approach would decrease binder consumption through the production of thinner pavements. The minerals used were Fly Ash types F \& C (low and high calcium), as well as Portland Cement.

\subsection{History of Superpave}

Superpave mix design and analysis hit the mainstream research and testing society in the early 1990's under the guidance and support of the Strategic Highway Research Program (SHRP). Originally Superpave design criterion only really outlined three areas, namely material selection, aggregate blending and gradation, and volumetric properties for gyratory compacted specimens. It was the original intention of the scientific community and SHRP to have a fourth step or method which could be used to directly analyze complex mixture properties. The analysis of these properties was performed to determine the potential for long term HMA performance. The problem was that at that point in time no such method existed.

To date most American highway agencies as well as their Canadian counterparts have adopted the volumetric mix design approach. In other words the majority of our asphalt producers are currently using volumetric mix designs. However as mentioned earlier at the time there was still no real performance test to compliment volumetric mix design or Superpave methodology. Comparatively speaking the older tests namely Marshall and Hveem both had comprehensive 
strength testing programs and capability which did not exist in SUPERPAVE. At the time there was some dispute among the scientific community about the accuracy and effectiveness of the old testing practices, although no one would deny that the old ways did in fact provide useful descriptive information about HMA mixtures. The common argument was that Marshall and Hveem tests were merely empirical but at the end of the day they still did provide many years of mixture quality estimation and can still be used today if needed. Considering the problems at hand and the millions of tones of asphalt that are laid each year something definitely needed to change. Everyone searched for the king of all methods and everyone agreed that the test method selected did not need to be perfect but rather only be available in the near future to assure good mix performance.

Eventually the situation worsened, research from WesTrack NCHRP 9-7 (Field Procedures and Equipment to Improve SHRP Asphalt Specifications) and other experimental construction projects began to show that Superpave volumetric mix design method alone was not sufficient to ensure the production of reliable mixes over a wide range of materials, traffic loading, and environmental conditions. At this point in time there was no avoiding the fact that controlling volumetric properties alone could not sufficiently ensure the long term performance of an HMA mixture. The other conclusion was that a simple performance test was needed to ensure better long term pavement performance.

There were mainly five identifiable distress areas where Superpave fell short; these areas included fatigue cracking, surface friction loss, rutting, thermal or low temperature cracking, as well as moisture susceptibility. All of the mentioned distress mechanisms have been accepted and are known to cause performance degradation over time.

Due to the imminent and immediate need for new evaluation criteria the NCAT board of directors stepped in and provided some vague details on performance 
testing until something better came along. With the inception of NCHRP 1-37A and 9-19, the wheels were in motion and the train of knowledge seemed to be heading in the right direction. After many years of deliberation and research in the year 2000 NCHRP began a streamlined approach to better the current yet vague guidelines previously set forth. Finally by 2002 NCHRP released a report entitled Simple Performance Test for Superpave Mix Design. This report although riddled with its own problems was still better than anything that had been seen to date. Currently this report in conjunction with ASTM guidelines can be used to gain reasonable approximations about long term performance of a wide variety of HMA mixtures.

\subsection{Objectives}

The objectives of this research are as follows:

1. Develop a suitable method of finding the dynamic modulus of HMA materials through the modification of a universal test frame under the guidance of ASTM, AASHTO and NCHRP practices.

2. Develop an inexpensive alternative for measuring axial deformations in asphalt specimens at high and low temperatures and frequencies while decreasing negative side effects such as sag attenuation.

3. Test a series of asphaltic specimens with different types of mineral fillers, namely fly ash Type $\mathrm{C}$ and Type $\mathrm{F}$ as well as Portland cement and limestone dust.

4. Develop a suitable compromise to achieve required compaction and target air voids using only the available compaction equipment.

5. Develop a suitable method for coring HMA specimens with minimal damage to the core while following the strict tolerances set forth by AASHTO, NCHRP, and ASTM. 
6. Develop a method of preparing HMA sample ends in accordance with strict surface and squareness tolerances set forth by AASHTO, NCHRP, and ASTM.

7. Evaluate the response of hot mix asphalts made with different mineral fillers when exposed to dynamic loading. 


\section{LITERATURE REVIEW}

\subsection{Complex Dynamic Modulus Test}

The complex dynamic modulus test is used to determine various HMA material properties. Dynamic modulus testing is one of the oldest and best documented testing procedures which can be traced back to the 1970's. This test has the ability to relate the stress and strain of almost any visco-elastic material especially asphalt to the materials long term performance. The complex dynamic modulus is unique since it involves both real and imaginary parts. The real and imaginary components of this modulus represent both the viscous and the elastic responses of an HMA mix. The various components of this test are measured and calculated using a series of haversine load applications under stringent data acquisition. The result of dynamic testing yields a waveform similar to that shown in Figure 2.1. (NCHRP Report 513).

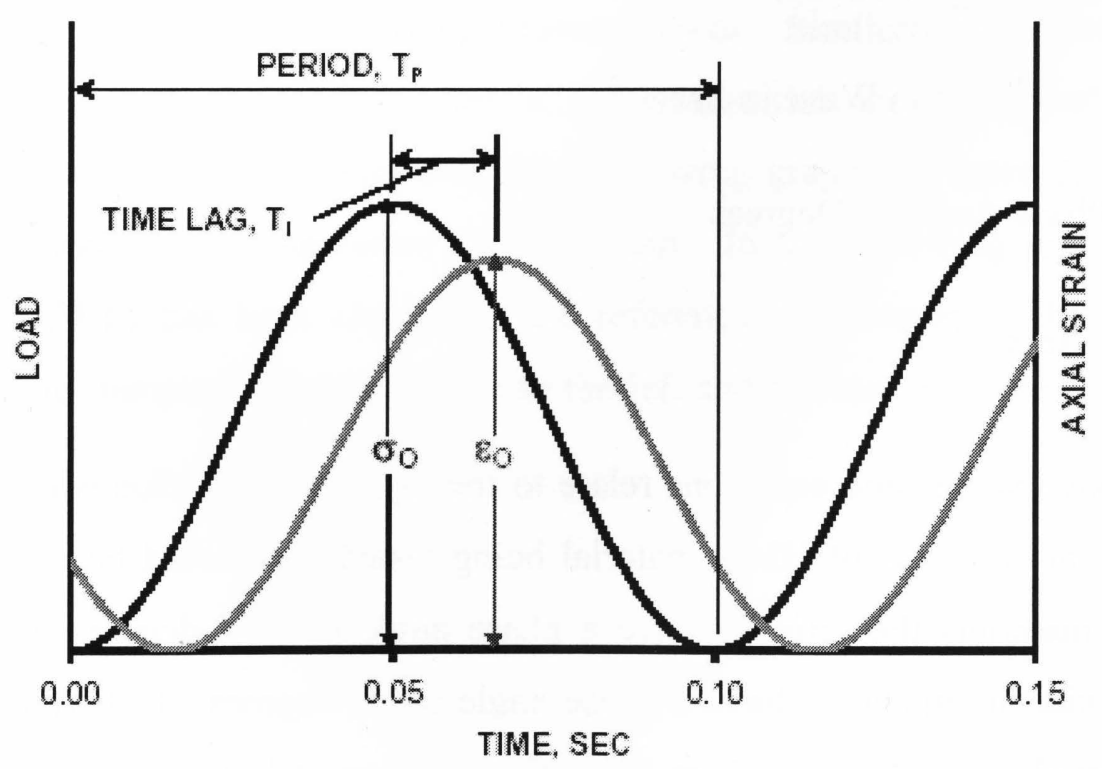

Figure 2.1: Typical Dynamic Modulus Test Waveform (NCHRP Report 513) 
The determination of the Complex Modulus requires certain elemental equations. These equations have been depicted below alongside their definitions.

Main Complex Modulus Equations (AASHTO, 2005)

$\left|E^{*}\right|=\frac{\sigma_{0}}{\varepsilon_{0}}$

$$
\phi=\left(\frac{T_{l}}{T_{p}}\right) X 360
$$

Where,

$\left|E^{*}\right|=$ Dynamic Modulus

$\boldsymbol{E}_{0}=$ Amplitude of Resulting Strain

$T_{l}=$ Time Lag in Seconds

$T_{p}=$ Period of Sin Wave in Seconds

$\phi \quad=$ Phase Angle in Degrees

$\sigma_{0} \quad=$ Stress

The above values and equations relate to the Dynamic Modulus which refers to the overall stiffness of HMA material being tested. It should be noted that all elastic materials theoretically have a phase angle of zero degrees where as all purely viscous materials have a phase angle of 90 degrees. In HMA mixes the phase angle can vary anywhere from five degrees at lower temperatures to 40 degrees at higher temperatures. This is to be expected as HMA exhibits solid characteristics when very cold and more liquid characteristics when very hot. 


\subsection{Dynamic Modulus in Pavement Design}

There are many accepted design guides which are used in Canada and across the continental US. Flexible pavements in general consist of layers which are composed of better material on the surface and weaker materials below. Due to this layering process these systems cannot be analyzed easily as they are neither solid nor liquid nor are they completely homogeneous masses. The first to notice pavement systems are made of layers rather than a single mass and develop a method of analysis was (Burmister, 1945). His research eventually went on to develop the layered theory. Throughout his life Burmister developed a two layer system and eventually a three layer system to explain asphalt pavement systems (Burmister, 1945). Later in history with the inception of computer technology the base theories developed by Burnister were applied to more complex multilayer systems (Huang, 1967). In all these mechanical systems stresses and strains were computed using the linear elastic theory. The strength of the elastic theory lies in the fact that it can be used in conjunction with material dynamic modului and temperature superposition to develop Master Curves. Similarly by knowing the Master Curve and shift factors for a given material the modulus at any temperature can also be determined. The following graph in Figure 2.2 below shows an example of temperature superposition. In the following graph $21^{\circ} \mathrm{C}$ (shown as $70^{\circ} \mathrm{F}$ ) has been chosen as the reference temperature. The idea is simple, colder temperatures are shifted to the left and warmer ones are shifted to the right. 


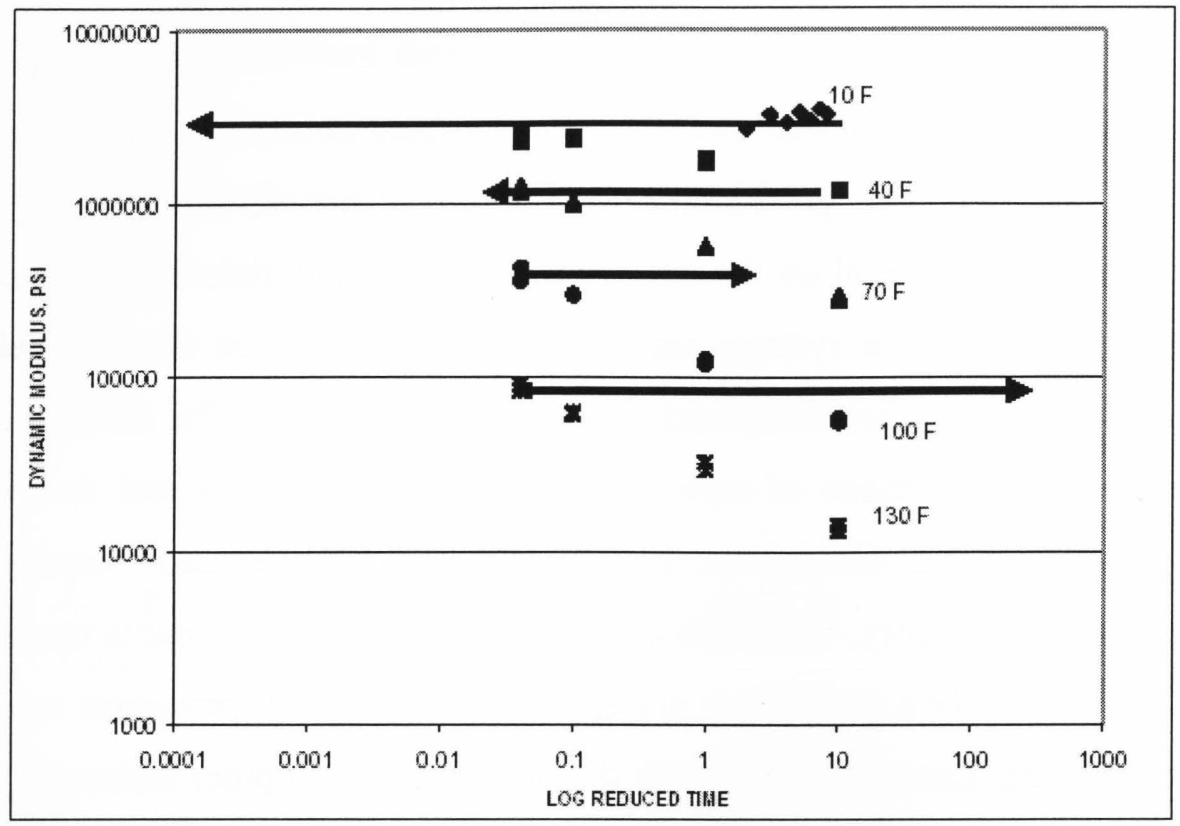

Figure 2.2: Temperature Superposition from Dynamic Values vs. Log Reduced Time (NCAT,01-05)

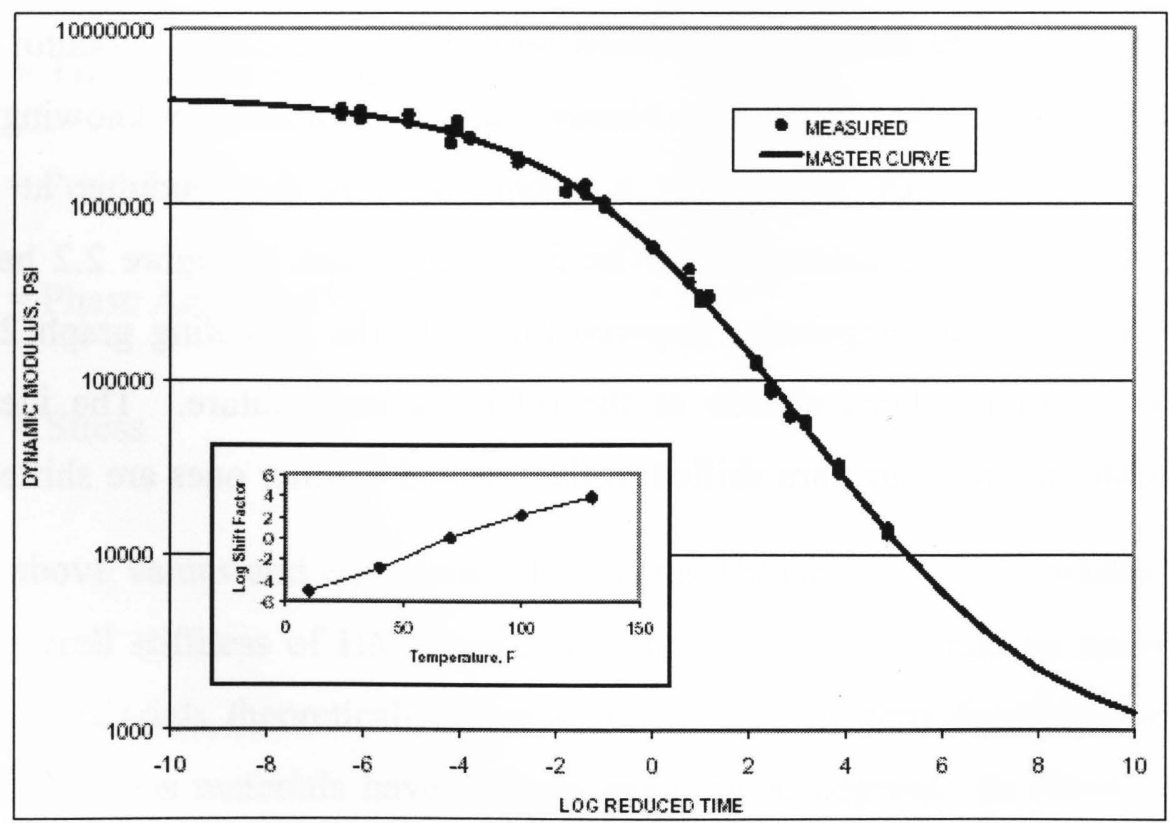

Figure 2.3: Typical Master Curve for a Sample Data Set (NCAT,01-05) 
In Figure 2.3 below an example of a typical Master Curve for an arbitrary set of data has been provided. This methodology can be applied to almost any HMA material to gain relatively good results.

This method and a further explanation of the process can be found in almost any design guide for asphalt mixtures. The following equations represent a general Master Curve as well as the shift function used to superimpose the temperatures shown in Eq. 1.

$$
\log \left(E^{*}\right)=\delta+\frac{\alpha}{1+e^{\beta+\gamma(\log t r)}}
$$

Where:

$\mathrm{E}^{*}=$ Dynamic Modulus

$\operatorname{tr}=$ time of loading at the reference temperature

$\delta=$ minimum dynamic modulus value

$\delta+\alpha=$ maximum dynamic modulus value

$\beta, \gamma, \alpha=$ parameters describing the shape and the sigmoidal function

$\log (\operatorname{tr})=\log (\mathrm{t})-\mathrm{c}[\log (\eta)-\log (\eta \mathrm{tr})]$

Where:

$\operatorname{tr}=$ time of loading at the reference temperature

$\mathrm{t}=$ time of loading at maximum force

$\eta=$ binder viscosity at temperature of interest

$\eta \operatorname{tr}=$ viscosity at the reference temperature

\subsection{Dynamic Modulus as a Performance Test}

In NCHRP Project 9-19 samples were tested at $37.8^{\circ} \mathrm{C}$ and $54.4^{\circ} \mathrm{C}\left(100^{\circ} \mathrm{F}\right.$ and $\left.130^{\circ} \mathrm{F}\right)$. According to this report a good correlation was noted between dynamic 
modulus figures and rutting resistance for the sections tested. Figure 2.4 illustrates this relationship. This report also included data for the various experimental sections included in MNRoad, WesTrack as well as FHWA pavement testing facilities. According to this same report as the dynamic modulus at high temperatures increased so did the materials resistance to rutting. To date the ideal test temperatures and minimum dynamic modulus values are still being determined for different materials in order to satisfactorily design mixes which will resist rutting. According to the NCHRP Project 9-19 the research found a fair correlation between cracking observed in each of the experimental sections (Bonaquist et al, 2003).

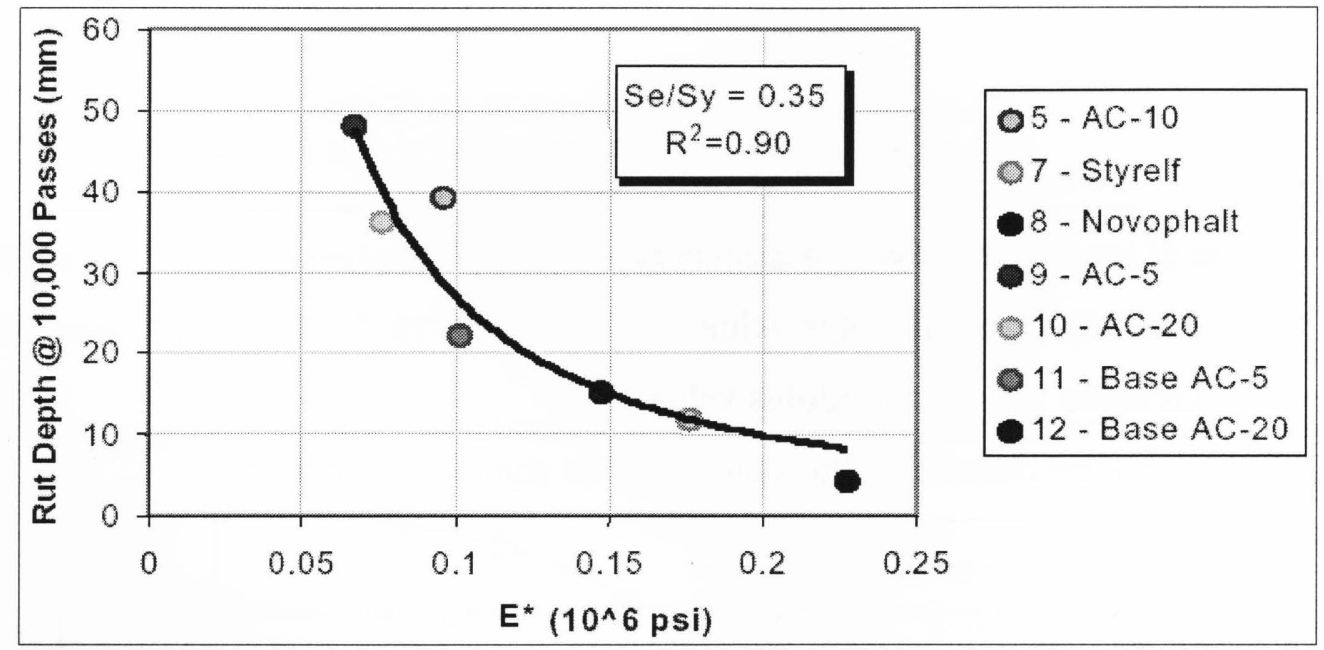

Figure 2.4: Relationship Between Dynamic Modulus and Rutting for the FHWA Pavement Testing Facility (Mehta, 2005)

\subsection{Dynamic Test Studies and Protocols}

Similar to Project 9-19, project 1-37A had similar achievements. The NCHRP 137A Draft Test Method DM-1, Standard Test Method for Dynamic Modulus of Asphalt Concrete Mixtures was based on the established ASTM D-3497 standards. In this particular test the samples were continuously loaded following a haversine waveform at specific temperatures and loading rates. The measured stresses and strains were used to calculate the dynamic modulus and phase angle for each unique mix. This project used temperatures of $14,40,70,100,130{ }^{\circ} \mathrm{C}$ 
and frequencies of $0.1,0.5,1.0 .5,10,25 \mathrm{~Hz}$, respectively. The resulting 30 dynamic modulus values obtained were used along with the principle of superposition to generate Master Curves for each of the mixes tested.

\subsection{Dynamic Modulus vs. Master Curves}

The main method for using dynamic modulus values as a principle performance test for rutting and fatigue cracking can be found in NCHRP Report 465. The main difference between the dynamic modulus approach and the generation of Master Curves is the number of required measurements. In simple performance testing, the tests are done at specific effective temperatures for rutting and cracking performance which are representative of a pavements location. In this type of testing a specific load rate is used throughout the process which is heavily dependant on the expected traffic speeds in the area of interest.

\subsection{Variability in Past Test Studies and Protocols}

Variability is a phenomenon that is inherent in all research, especially in the analysis of HMA materials due to the complexity of their visco-elastic behavior. In NCHRP Report 513 two dynamic modulus determination approaches were compared. Tests were conducted on specimens that contained two different maximum aggregate sizes, as well as six different loading frequencies in two different laboratories using three different temperatures. In Report 523 the variability was analyzed and compared using standard deviations, and coefficients of variation. The study also looked at the mean values for specimen dynamic modulus as well as phase angle. In essence this study followed general trends in dynamic modulus data to conclude that both the modulus values and phase shift data were consistent with the materials tested. The overall variability of the dynamic modulus data produced with the two devices was reasonable, with coefficients of variation for various conditions ranging from $5 \%$ to $15 \%$ 
(Bonaquist et al., 2003). This research and analysis prove that dynamic testing is reproducible in different environments and conditions while still yielding good results. Some may argue that dynamic modulus testing is often one of the most time and cost intensive approaches but past research clearly shows the success of such experimentation in the analysis of HMA material characteristics.

\subsubsection{Flow Time Test}

This test is simply a compressive creep test. In this test a static load is applied to a specimen and the resulting strains are recorded as a function of time. The flow time test can be run on a variety of machines since it only requires a small load frame and minor data acquisition capability. NCHRP has defined this test in Project 9-19 as the time when the minimum rate of change occurs during a creep test. Furthermore, flow time is determined by the differentiation of the strain versus time curve (NCHRP, 2003). In Project 9-19 the flow time was found to have a close relation to the rutting resistance of certain HMA mixtures, namely the mixtures used in MNRoad, WesTrack, and FHWA Pavement Testing Facility. For tests at a given temperature, axial stress, confining stress, the rutting resistance of the mixture increases as the flow time increases (Bonaquist et al.,2003).

\subsubsection{Flow Number Test}

In this test haversine axial load is axially applied to HMA specimens. The load is held for $0.1 \mathrm{sec}$ followed by a $0.9 \mathrm{sec}$ rest period. The permanent axial deformation is measured at the end of each rest period during repeated loading and then converted to strain by dividing by the original specimen length. Ultimately, the flow number generated by this test refers to the number of load pulses when a minimum rate of change in permanent deformation occurs. Flow number is similar to Flow Time in that it is determined by differentiating between 
permanent strain and the number of load cycles. Similar to flow time, flow number is apparently related to the rutting resistance of HMA section tested in WesTrack and FHWA.

\subsubsection{Field Shear Test (FST)}

This device was initially developed during NCHRP Project 9-7 as a simple device for performing in situ quality control testing on HMA specimens. It was designed to be a replacement for Superpave shear test or SST. The original field shear test had a lot of good qualities. The advantages include small size, ruggedness, and ease of use. The main problem with the device was the fact that it had a lot of variability problems. Unfortunately, measurement variability and quality control are not meant to co-exist and thus this test eventually disappeared into the archives.

\subsubsection{Indirect Tensile Test}

This test is a very popular test used to determine specific HMA mixture characteristics. Properties measured using indirect tension testing have been successfully used for the evaluation of moisture damage and fracture distress mechanisms in asphalt pavements. Indirect tensile testing of samples requires exposure to a series of sinusoidal loading cycles. This test mainly involves a series of load applications over a $1000 \mathrm{sec}$ period. During the loading horizontal deformation measurements are taken and recorded. It is believed that in some cases creep compliance with respect to a material's ITT results has been strongly correlated to the thermal cracking phenomena. The indirect tensile testing apparatus looks very similar to Figure 2.5. 


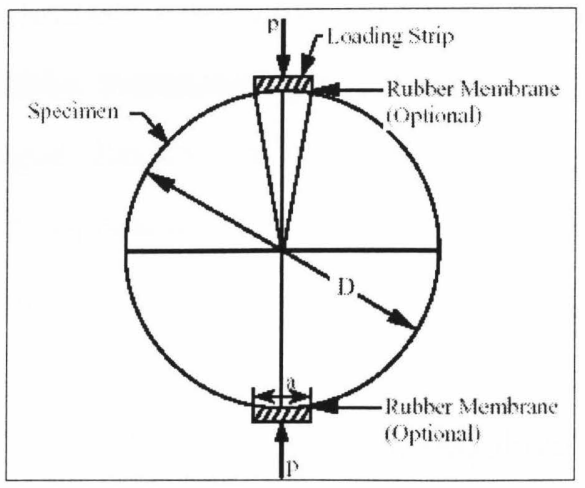

Figure 2.5 Indirect Tensile Testing Apparatus (NCHRP 513)

\subsection{Wheel Load Testers}

Wheel Load Testers are performance tests on Asphalt concrete primarily used to rank mixtures (Cooley et al, 2000). There are an increasing number of these machines in labs across the US. These systems have seen more than their fare share of scrutiny in the US and in Canada. In the US these testers can be found in many states. For example Georgia has its own unique system called the GLWT. Many US DOT also house many other forms of modified wheel testers, namely the APA or Asphalt Pavement Analyzer as well as Hanburg Wheel Tracking Device otherwise known as the HWTD. Another substantial US investment was the Mobile Load Simulator or the MMLS3 for short. There are many different sizes and types of wheel testers and in this research some of the less significant machines have been disregarded. The following sub sections shall include small definitions of the above mentioned wheel testers.

\subsection{Georgia Wheel Load Tester (GWLT)}

This piece of equipment was first developed in the 1980's through a cooperative research study between the department of transportation and the Georgia Institute 
of technology. A full size GWLT wheel tester has been depicted on the next page in Figure 2.6.

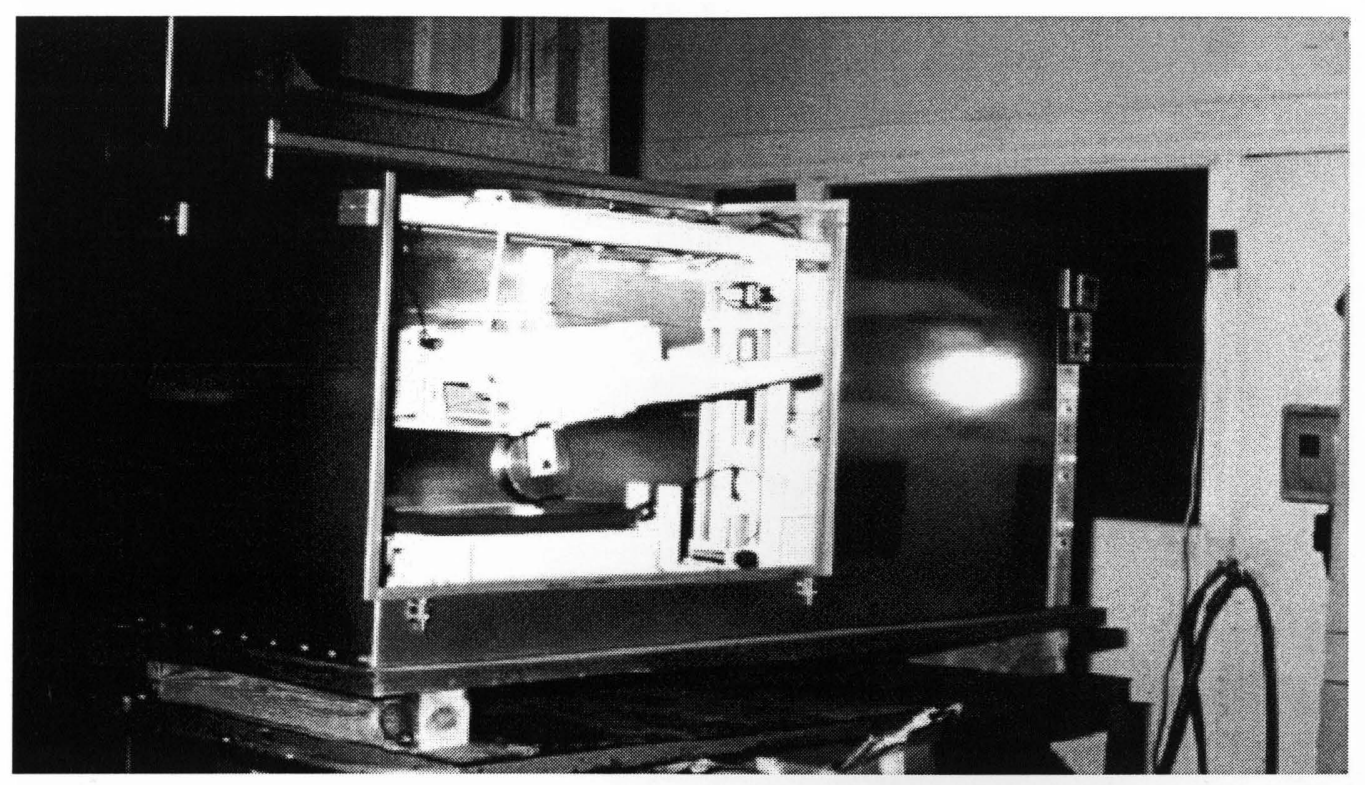

Figure 2.6: Georgia Wheel Tester from the Georgia Institute of Technology

This particular tester is very versatile as it has the ability to test both HMA beams as well as cylinders. This test involves the application of a $100 \mathrm{lb}$ load through a pneumatic hose which is continuously pressurized to $100 \mathrm{psi}$. This test can accommodate a large variety of specimen dimensions. This test has been praised for its adaptability as it can accommodate test specimens ranging from 4 to $7 \%$ air voids. The load is applied through a steel wheel which rolls over a hose placed on the surface of the sample being tested. This type of test is usually run for about 8000 loading cycles. One cycle involves the steel roller passing over the sample and then returning to its rest position. The rut depth after testing using this machine has been correlated to the rutting performance of the HMA being tested. 


\subsubsection{Asphalt Pavement Analyzer (APA)}

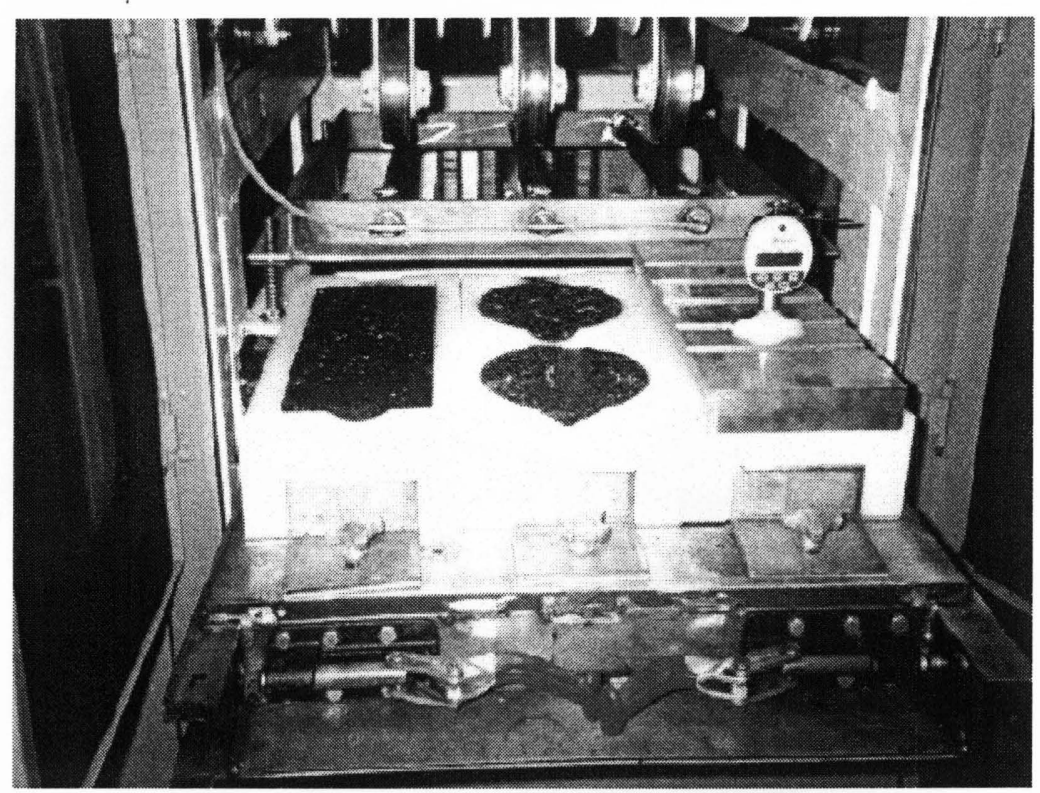

Figure2.7: Full size Asphalt Pavement Analyzer

The APA is basically a modified version of a Georgia Loading Wheel Tester. It was first manufactured in 1996 by Pavement Technology Inc. A full size APA is depicted in Figure 2.7.

This particular machine runs virtually the same test procedure as the GWLT. The main difference between the APA and GWLT is that the APA has the ability to

apply the pneumatic force to samples while they are submersed in water. This test has been thought to vaguely determining rutting, fatigue, as well as moisture resistance in certain HMA mixes. 


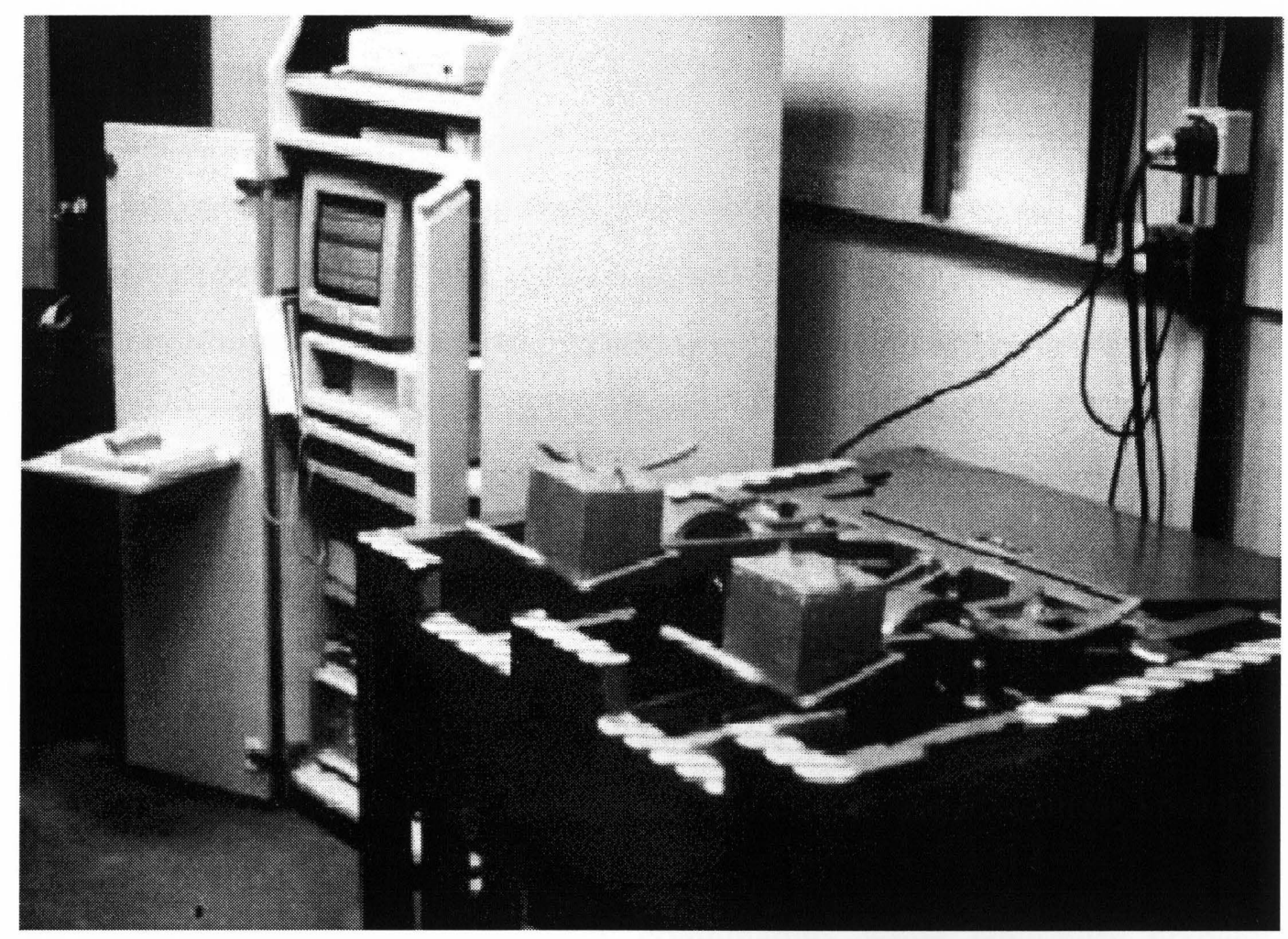

Figure 2.8: Hanburg Wheel Tester and Data Acquisition System

\subsubsection{Hamburg Wheel Tracking Device (HWTD)}

The Hamburg Wheel Tracking Device was developed by Helmut-Wind Incorporated which is located in Hanburg Germany. It was initially developed for the testing of the heavy traffic roadways across Germany to evaluate rutting and stripping. In Figure 2.8 there is a picture of a Hanburg Wheel Tester in a laboratory aside its data acquisition and control system.

The Hamburg device is a very restrictive apparatus especially in regards to the size of the specimens. In this test the specimen has to be a pre-defined size and have a specific amount of air in order to be tested. The Hamburg device test samples must be 10.2 " $\times 12.6$ " 1.6 ". The target air voids for this test are $7 \%+/-$ $1 \%$ which can be hit in the lab but is very difficult to obtain accurately in the field. These requirements are usually met through the use of a linear kneading 
compactor, although some testing has also been done using gyratory compacted specimens. The testing in this device is often done under water between 25 and $70^{\circ} \mathrm{C}\left(77^{\circ} \mathrm{F}\right.$ and $\left.158^{\circ} \mathrm{F}\right)$. Most tests are conducted at $50^{\circ} \mathrm{C}$ under a $705 \mathrm{~N}$ load for up to 20,000 passes, or until $20 \mathrm{~mm}$ of deformation have occurred. The wheel used for loading travels at a fixed rate of about $340 \mathrm{~mm} / \mathrm{sec}$ and thus sample testing time can vary from sample to sample but is ultimately limited by the samples size

\subsection{Simple Performance Testing Procedures}

\subsubsection{Testing Program Frequencies and Temperatures (ASTM)}

The uni-axial Dynamic Modulus test was first standardized in 1979 under the umbrella of ASTM D 3479, "Standard Test for Dynamic Modulus of Asphalt Concrete Mixes" and then later re-approved in 2003 under D 3497-79 and entitled "Standard Test Method for Dynamic Modulus of Asphalt Mixtures".

The test consists of applying a uni-axial sinusoidal or haversine compressive stress to an un-confined cylindrical HMA test specimen. Before its inception in 1979 the basis of this type of testing was presented at the fourth International Conference on the Structural Design of Asphalt Pavements by L.Francken, with his study named "Permanent Deformation Law of Bituminous Road Mixes in Repeated Triaxial Compression". In the early stages of development the accepted practice was simple know as the repeated load test. The main difference in procedure specification is that today's dynamic modulus test is much more difficult to perform and requires a very accurate measuring system.

The current ASTM standardized test calls for certain specific requirements. Namely a testing machine capable of producing sinusoidal loading functions over a range of frequencies from 0.1 to $20 \mathrm{~Hz}$. The load frame in question should be capable of sweeping over a range from 0 to $13.3 \mathrm{kN}$. This method also calls for 
an environmental system capable of producing stable temperature controlled atmospheres from -9 to $50{ }^{\circ} \mathrm{C}+/-0.5{ }^{\circ} \mathrm{C}\left(-48.2^{\circ} \mathrm{F}\right.$ to $\left.122^{\circ} \mathrm{F}+/-33^{\circ} \mathrm{F}\right)$. Temperature control units should also be capable of holding up to 6 specimens for group conditioning. The loading device should be equipped with a strain measuring device linked to a data acquisition as well as an electronic load cell to verify maximum load points. This test involves laboratory molded specimens which are in accordance with ASTM D3496. The specimens should be produced in house or cored to have a diameter of $100 \mathrm{~mm}$ and a minimum height to with ratio of 2:1 (H:DIA). Most samples are made $200 \mathrm{~mm} \times 100 \mathrm{~mm}$. ASTM testing involves the application of haversine loading without impact using loads varying between 0 and 35 psi through each load case for a minimum of 30 seconds and not exceeding 45 seconds at set temperatures of 5,25 , and $40^{\circ} \mathrm{C}(41,77$, and $104^{\circ} \mathrm{F}$ ) while being loaded at frequencies of $1,4,16 \mathrm{~Hz}$ for each temperature.

The standard also specifies if field cored specimens are used to test six samples for each temperature and frequency combination, while laboratory prepared specimens only require three samples. The testing is straight forward, to reduce the amount of damage between tests the sample need to be loaded first with the lowest temperatures and highest frequencies. By keeping the samples cold and applying the quicker loads first the samples are conserved and the amount of relative damage to the sample is significantly reduced. The conclusion of this test is to record the resulting recoverable axial strain of each mix and load temperature combination and then compute the average dynamic moduli for each temperature and frequency.

\subsubsection{Testing Program Frequencies and Temperatures (NCHRP)}

NCHRP otherwise known as the National Co-operative Highway Research Program has been a strong driving force in the attempt to discover the cause and effect of pavement distresses as well as discovering and applying reliable performance testing practice for decades. NCHRP Report 465 actually stemmed from Project 9-19. The experimental plans for these projects were very straight 
forward. The goal was to use a combination of lab and field projects which covered a diverse range of distress mechanisms to select test methods which had the greatest correlation to both rutting and fatigue cracking. In order to have a pavement stand the test of time it would need to be flexible enough to resist fracture and stiff enough to resist permanent deformation or rutting. Although the goal seems simple, researchers have been struggling to achieve the perfect balance in their mixes for many years. In order to best predict asphalt distresses NCHRP analysis covered a wide range of material, climates as well as pavement structures. This experimentation was designed to quantify the correlation between mixture response and HMA distresses.

The current NCHRP tests call for certain specific requirements. Namely a testing machine capable of producing sinusoidal loading functions over a range of frequencies from 0.1 to $30 \mathrm{~Hz}$. The loading functions should have the ability to sweep over a maximum of $25 \mathrm{kN}$ in some instances. This method also calls for an environmental chamber capable of producing stable temperature controlled atmospheres from -20 to $60{ }^{\circ} \mathrm{C}+/-0.5{ }^{\circ} \mathrm{C}\left(-68\right.$ to $\left.140^{\circ} \mathrm{F}+/-32.9^{\circ} \mathrm{F}\right)$. The temperature control unit should also be capable of holding 6 specimens. The loading device should be equipped with a strain measuring device or LVDT as well as a data acquisition system and electronic load cell to verify maximum load points. According to the report NCHRP 465, this test involves laboratory molded specimens which are short term aged for 4 hours in accordance with AASHTO PP2, "Standard Practice for Short Term Aging of Hot Mix Asphalt". The specimens should be produced in house or cored to have a diameter of $100 \mathrm{~mm}$ and a minimum height to diameter ratio of 1.5:1 (H:DIA). Most samples are cored from gyratory compacted pucks which are 4 " x 6 " to samples that are 150 $\mathrm{mm} \times 100 \mathrm{~m}$ in accordance with a study conducted by the Superpave models team.

Similar to ASTM, NCHRP Simple Performance Tests also involve the application of haversine loading without impact using loads which vary between 0 and 100 
psi through each load case for a minimum of 30 seconds and not exceeding 45 seconds at set temperatures of 4.4, 9, 21.2, 37.8 and $54.4^{\circ} \mathrm{C}(40,48,70,100$ and $130^{\circ} \mathrm{F}$ ) while being loaded at frequencies of $0.1,0.5,1,5,10,25$ for each temperature. Much like the standard the report also specifies each load, temperature, and frequency combination. The testing is straight forward, to reduce the amount of damage between tests the samples need to be loaded first with the lowest temperatures and highest frequencies while progressing to the hotter temperatures. By keeping the samples cold and applying the quicker loads first the samples are conserved and the amount of relative damage to the samples is significantly reduced. This method of testing requires at least two samples to be made for each mix type. The resulting recoverable axial strain was recorded for each mix as well as the temperatures and frequency combination. The average dynamic modulus was then computed using first principles for each temperature, frequency, and load category.

\subsubsection{Similarities and Differences ASTM \& NCHRP}

The similarities between these two methods of testing are remarkable, as they are both based on the same first principles. Both these tests have deeply rooted elements of material mechanics which have been slightly modified for their application to HMA materials.

Both these methods seem to share the same initial basis, since an HMA material's dynamic modulus is determined by dividing the maximum dynamic stress by the peak recoverable axial strain. Where these tests substantially differ can be seen in the testing procedure. In ASTM the loading frequencies range from $0.1-20 \mathrm{~Hz}$ where as in NCHRP the range was increased by 10 to make a range from 0.1-30 Hz. After careful consideration this testing program has omitted all the ranges of measurement between 25 and $30 \mathrm{~Hz}$ since they proved to be very difficult to attain. Stable readings at high oscillations were very difficult to capture, even 
after a long conditioning periods and thus have been avoided. This frequency adoption can be seen in NCHRP report 513. Another difference between these tests can be seen in the maximum load requirements, NCHRP demands a machine capable of $0-25 \mathrm{kN}$ of force where as ASTM only specifies $0-13 \mathrm{kN}$. In the end though NCHRP only used testing loads within ASTM specifications anyway. High loads were also avoided, since they propagated specimen damage before any good data could be collected. Both NCHRP and ASTM required temperature control for specimens to be tested, ASTM requires 0 to $50^{\circ} \mathrm{C}\left(32\right.$ to $\left.122^{\circ} \mathrm{F}\right)$ where as NCHRP specifies a higher range from -20 to $60^{\circ} \mathrm{C}\left(-68\right.$ to $\left.140^{\circ} \mathrm{F}\right)$. This action appears justified in the fact that NCHRP specifications cover a wide variety of tests including low temperature cracking which is commonly carried out at temperatures below the freezing mark. Almost all the specified details between these two tests differ in one way or another. Even the specifications used to prepare the samples are different. This is evident since NCHRP follows AASHTO PP2 and ASTM follows ASTM-D3496.

The greatest difference between these two methods is the specimen height to diameter ratios. NCHRP in Report 465 state "The sample preparation was based on the conclusions of an extensive study on sample geometry and aggregate size conducted during NCHRP Project 9-19." where apparently "It was found that a minimum height to diameter ratio of 1.5 was required in order to insure that the response of a sample evaluated in either the dynamic modulus or permanent deformation tests represents a fundamental engineering property". This minimum requirement was very beneficial for the production of asphalt specimens created in gyratory compaction devices since most of them are not capable of producing the ASTM height requirement of $200 \mathrm{~mm}$.

The remaining differences between these two tests lie in the loading frequencies, sample temperatures, number of samples. In ASTM frequencies of $1,4,16 \mathrm{~Hz}$ were used where as in NCHRP a wider range of frequencies were applied namely $0.1,0.5,1,5,10,25 \mathrm{~Hz}$. Similarly, in ASTM samples were tested at temperatures 
of 5,25 , and $40^{\circ} \mathrm{C}\left(41,77,104^{\circ} \mathrm{F}\right)$ where as in NCHRP samples were tested at temperatures of $4.4,9,21.2,37.8^{\circ} \mathrm{C}\left(40,48,70,100^{\circ} \mathrm{F}\right)$. Both of these tests involve numerous samples which raises the demand for time and funds. ASTM recommends 6 field cored samples or 3 laboratory samples where as NCHRP makes it possible to conserve funds by allowing the program to test only two samples per mix design. Furthermore, sample end preparation was also different, in NCHRP certain minimum tolerances were set for cored and sawed samples in terms of smoothness and verticality where as ASTM uses a combination of sulfur mortar capping similar to that of concrete cores following Method C617. ASTM also uses Hardened Steel Disks to transfer load from the actuator to the samples being tested where as NCHRP has no real specification in this area.

\subsection{AVAILABLE TESTING USING SPT CRITERIA}

\subsubsection{Dynamic Modulus for Permanent Deformation}

This test method deals with testing asphalt concrete to determine the dynamic modulus of the material as well as its reaction to external stressors which cause permanent deformation. This test was designed to test HMA compliance in terms of dynamic modulus, phase angle, and effective temperature as well as loading frequency. This test has been praised for its usefulness in the characterization of asphalt concrete for use in various pavement projects across the US and Canada. This test yields values which aid designers with thickness design as well as long term performance analysis. It also provides a long term evaluation of permanent deformation phenomena that exist in HMA mixes.

This test is performed by applying a haversine compressive stress in the form of a load directly to the surface of cylindrical specimens. This stress is applied at a set temperature and loading frequency. The applied load and recoverable or elastic strain response of the sample is then measured and recorded. The values obtained are used to calculate the dynamic modulus and phase angle for the sample tested. 
The test is significant in that the dynamic modulus obtained through this test at a specific temperature can be used as performance criteria to build permanent deformation resistance in new mixes. According to Project 9-19, dynamic modulus test results at high temperatures correlated very well with test sections at MNRoad, Wes-Track, and FHWA (NCHRP 465, 2002). These reports show that dynamic modulus testing is a unique and powerful tool for the design and analysis of current and future Superpave volumetric mix designs.

In order to perform this test a Dynamic Modulus test system is needed. In this case the test system consists of a load frame with axial loading capability for the sample height being used, as well as an environmental chamber to change the specimen temperature according to the desired test temperature. And lastly, a data acquisition

system is needed to record the results of the testing, namely the horizontal and vertical deformations as well as the temperature at different loads. For more information on the equipment please refer to Appendix B.

\subsubsection{Repeated Load and Uni-axial Compression}

This test method deals the application of uni-axial compression to cylindrical HMA specimens. This test yields specific hot mix resilience in terms of material compliance as the specimen is subjected to repeated loading conditions. This test has been praised for its increased accuracy and field imitation since it is commonly run in a tri-axial state of compression. This loading represents the true field conditions since the strains incurred by the sample cannot be lost to the environment as the sample is completely restrained from every surface allowing the full extent of the loads to be felt. If the cylindrical test specimen is not restrained the sample has the ability to transfer load effort and strain and convert it to a change in diameter. This change can be visually noted as a bulge or slight 
increase in cross sectional area near the center of the sample during unrestrained conditions.

This test like the majority of simple performance tests, involves the preparation of at least two cylindrical samples of bituminous paving material. The mixtures are compacted and then subjected to uni-axial load. The procedure uses a total loading cycle of 1 second. The sample is loaded by applying load for a period of 0.1 seconds load, and then allowed to rest for 0.9 seconds. Throughout this cycle both permanent axial and radial strains are recorded. After numerous repetitions under constant volume before shear deformation begins the analyst is able to find the flow number for each mix used. This test is significant because it yields a flow number. The flow number can be used to compare different mixes in terms of their resistance to deformation and shear resistance. The reason for the rest period is to promote the maximum amount of damage to the specimen by allowing the specimen to return to its rest position before the application of the next load.

In order to perform this test a loading frame is needed. In this case the test system consists of a load frame with axial loading capability for the sample height being used which is in most cases between 150 to $200 \mathrm{~mm}$, as well as an environmental chamber to change the specimen temperature according to the desired test requirements. With this particular test it is recommended that a confining pressure device be used to better simulate in situ strains. And lastly a data acquisition system is needed to record the results of the testing, namely the

permanent axial and radial strains as well as the temperature at different load intervals.

\subsubsection{Static Creep/Flow Time of HMA}

This test method deals with testing asphalt concrete to determine its creep and flow time while under tri-axial compression. This test yields an HMA material 
compliance in terms of creep and flow for a range of set temperatures and stress levels. In this test, asphalt specimens are subjected to static axial loading. While under load, permanent axial and radial strains are captured and recorded. These tests are useful in analyzing creep and flow time in terms of their compliance through various effective temperatures.

This test involves the preparation of cylindrical specimens made of HMA which are compacted using a gyratory compactor and then subjected to static axial load. This test is very versatile as it can be performed with or without confining pressure, but it is much more accurate if the specimen is confined. Confinement increases the quality of this test since the sample would better represent in situ stress conditions. The flow time is known as the estimated time it takes before shear deformation occurs in a constant volume of HMA material. Basically in this test the applied stress and resulting permanent axial strain is measured and used to calculate the flow time.

In order to perform this test a loading frame is needed. In this case the test system consists of a load frame with axial loading capability for the sample height being used, as well as an environmental chamber to change the specimen temperature according to the desired test requirements. With this particular test it is also recommended that a confining pressure device such as a tri-axial cell be used to better simulate in situ conditions. Lastly, a data acquisition system is needed to record the results of the testing, namely the horizontal and vertical deformations as well as the temperature at different loads.

\subsection{COMMON HMA DISTRESS MECHANISMS}

\subsubsection{Permanent Deformation}

Permanent deformation in HMA refers to the accumulation of minute amounts of unrecoverable strain in response to repeated loading. Permanent deformation is 
commonly referred to as rutting due to the visual effects of this distress mechanism on the surface of HMA pavements. Rutting appears as small depressions in asphalt most predominantly visible in the wheel path, these small depressions highly resemble "ruts" or valleys thus the acceptance of the term "rutting". Rutting occurs as a result of a wide range of environmental and repetitive loading effects which cause small depressions which start between 1 to $3 \mathrm{~mm}$ and can continue until the end of the pavements service life. On occasion the rutting progresses can quickly and prematurely produce depressions upward of $4 \mathrm{~mm}$; this degree of degradation is often blamed on material problems rather than just traffic and weather alone. The common misdiagnosis is that rutting only occurs on the road surface, but this is not the case.

Rutting can happen due to HMA problems but also due to sub grade failure as well as unbound base course. In most cases the focus of experimentation and testing is on the HMA. In these cases the sub grades are ignored or considered capable of supporting any applied loads. Permanent deformation which occurs in asphalt is believed to stem from the lateral movement or consolidation of particles due to the applied loads from vehicular traffic. Shear failure of HMA courses generally occurs in the top $100 \mathrm{~mm}$ of pavement surfaces (Nevelt et.al 1988). Rutting in asphalt pavement is not usually an instantaneous problem, in most cases the visual and physical signs of deformation appear gradually over time. The degree of rutting which can be visually identified by physical depressions in the wheel paths and sometimes small upheavals to the sides are often worsened as the amount of load and number of repetitions increases. It should be noted that deformation rarely occurs due to volume change or densification but rather by shear deformation in the HMA or unbound materials beneath the HMA. Rutting is mainly caused by deformation flow rather than volume change (Eisman, et.al 1992). 


\subsubsection{Low Temperature Cracking}

Low temperature cracking as the name indicates is a pavement distress which is primarily caused by internally induced unbearable material strains generated by severe temperature gradients. The main cause of damage in this distress mechanism has been severe cold but it can be greatly worsened by repeated heavy traffic loading. Thermal cracking is characterized by intermittent transverse cracks perpendicular to the direction of traffic (McGuiness et al. 1994). In simple terms cold temperature causes HMA to shrink, this shrinkage causes a buildup of tensile strain. At any time during the cold period the tensile stress can exceed past the tensile strength of the material leading to a cracks. This phenomenon can be seen from a single cold spell unlike some other distresses which need many cyclic repetitions. Similar to other pavement distresses low temperature cracking can be worsened by repeated cycles of temperature. Many hot and cold cycles in HMA cause low temperature cracking due to the temperature and cracking in general due to fatigue. It is believed that pavement rigidity or stiffness is the greatest contributor to the low temperature cracking phenomena. HMA is greatly affected by temperature, especially extremes. In essence a stiffer mix will perform better in hot weather and a softer mix will perform better in cold weather. The key is to balance economical design while maintaining acceptable performance in every environment. Recent developments in binder technology in regards to PG ratings for binder have made much advancement in low temperature environment performance in HMA's.

\subsubsection{Fatigue Cracking}

Repeated loading is the root of many problems associated with material deterioration. Fatigue occurs when a material is stressed beyond its fatigue limit or life due to repeated loading. The visual appearance of fatigue cracking in HMA is very distinctive. Fatigue cracking is sometimes called alligator cracking since it resembles the line pattern on an alligators back. During the design process HMA materials and thickness are specified to support a predefined 
number of repeated loads of a designated weight. In general, fatigue cracking occurs when the number and degree of load surpasses the design parameters. Asphalt pavement structures are very capable of supporting loads assuming all the systems components are pulling their weight.

Fatigue cracking may be worsened by certain factors. Fatigue can be worsened if there are pre-existing sub grade problems as well as poor quality control both in the plant and in the field. One common problem exists in the drainage of oncoming water. In some cases pavement foundation layers can become saturated and loose strength, this in turn decreases the amount of support available to the surface structure and leads to accelerated damage. The increased stress in the HMA can cause the surface to fail prematurely. Fatigue can also be prematurely seen in pavements which are loaded by the illegal use of overweight trucks. Premature fatigue is also immanent when contractors fail to implement good quality and thickness control measures during construction. In advanced fatigue environments, pavement will crack, ravel, and progressively produce pot holes which lead to a complete loss of surface material as well as complete structural failure.

Fatigue in pavements is a structural integrity problem rather than a material problem. Both structural and material traits heavily affect the development of distress mechanisms. Structurally, poor sub grade and drainage design leads to weak pavement which stems to advanced fatigue deterioration very quickly under vehicular traffic. In early pavement structures experts believed that asphalt failure stems from cracking which would begin at the bottom of the structure and migrate upwards, where in fact, cracking has actually been observed starting at the surface and moving down. Furthermore, for thin pavement structures cracking begins at the bottom of the HMA. Contrarily, in very thick pavements, namely perpetual pavement systems, cracking starts at the surface and migrates downward. Typical fatigue behavior is often misdiagnosed as the sole lack of surface material due to poor quality control where as these properties are only a secondary effect at most. 


\subsubsection{HMA Friction Properties}

Virtually every highway agency across the globe is concerned with the safety of the people who use their roadways. This concern stems from the liability involved when serious accidents occur. When there are major accidents one of the first components tested is the skid resistance of the road surface. Skid resistance is directly correlated to the ease of which a vehicle on a road can loosen or break its frictional bond. In the field certain factors govern how fast a driver can decelerate during an emergency maneuver. Due to the significant correlation between skid resistance and safety we currently have a set of minimum acceptable values for the skid resistance of our highways. Skid resistance is mainly the amount of friction on the surface of the HMA structure in any given weather.

Generally friction can be defined as the relation between both vertical and horizontal force developed by a still tire held by a vehicles brake while a vehicle is still in motion. The friction of pavement is a function of the surface texture which is divided into two components, micro texture and macro texture. (Leu, et al 1978). Regular HMA provides small escape channels which carry water away from the surface, as the water travels away from the wheel path there is less water on the surface to act as a lubricant increasing surface friction as well as skid resistance. In recent studies researches in conjunction with transportation agencies have been looking at SMA materials as well as improved drainage layers to facilitate the movement of water away from the wheel path in attempts to increase skid resistance. Surface friction means better and quicker stops for the driver, which extends to a safer road way for all.

From a design engineer's perspective, friction is a very important HMA surface property which can be facilitated through proper material selection as well as proper design and construction. From a pavement management perspective 
friction can be seen as measure of serviceability. In other words the longer a road can provide a safe amount of surface friction to the user the less money would be consumed in surface rehabilitation and the lower the life cycle cost for the material.

The following friction characteristics are desirable in a good pavement (NCHRP Synthesis 14, 1972):

1) High friction during weather extremes. Ideally the friction when wet should be as high as possible when compared to that of the dry pavement.

2) Little or no decrease of the friction with increased speed. The friction of dry pavement is nearly independent of speed, but this is not the case for wet pavement.

3) No reduction in friction with time, from polishing or other causes.

4) Resistance to wear by abrasion of aggregate, attrition of binder or mortar, or loss of particles.

As time passes more and more ministries are beginning to see how important the skid resistance is to the safety of the roadway. Hopefully the future will bring pavements that are safer and stronger which last longer.

\subsubsection{Moisture Intrusion and Susceptibility}

Moisture susceptibility in HMA materials is mainly affected by various environmental factors namely temperature and moisture. Moisture problems in any material are usually propagated by environmental conditions. This distress mechanism can be worsened by the accumulation of other distresses. There are three mechanisms by which moisture can degrade the integrity of a hot mix asphalt matrix:

1) Loss of cohesion of asphalt film that may be due to several mechanisms; 
2) Failure of the adhesion between the aggregate and asphalt

3) Degradation or fracture of individual aggregate particles when subjected to freezing (SHRP-A-404, 1994).

Stripping is the main reason for moisture problems. Basically, when the aggregate in the mixture has a high affinity for water the asphalt can be stripped away. Usually asphalt mixes avoid aggregates which tend to absorb great deals of water since stripping leads to a loss in binder to the aggregate. The more binder consumed or absorbed by the aggregate means less binder availability to hold together the materials stone matrix which means less strength and material quality. The loss of HMA material performance can lead to pre-mature rutting, raveling, as well as cracking. 


\section{H A P T E R 3}

\section{EQUIPMENT AND MATERIAL EXPERIMENTAL DETAILS}

\subsection{MINERAL FILLERS}

\subsection{Portland Cement}

Portland cements are commonly known as materials composed of hydraulic calcium silicates that set and harden by reacting chemically with water through a process called hydration. A popular material in the HMA area is PCBD otherwise known as Portland cement bypass dust. According to past research PCBD has been know to positively influence the anti-stripping properties of HMA mixes. Asphalt mixes with PCBD filler, has significant improvements on Marshall Properties including stabilities and flow (Aljassar, 2004). Common practice has been to substitute between 2 to 5\% of HMA fines with Portland cement. According to Amer, and Ramzi (2002) the optimum percentage of cement should be equal or less than $5 \%$ filler by weight.

The problem with using cement as filler is obviously the associated cost. In today's market, asphaltic product costs have been skyrocketing due to the rising crude costs. The reason for adding fillers to HMA is simple; we wish to achieve acceptable performance and reduce cost. For the purposes of this research it is understood that the cost of adding cement to asphalt is a hindrance to the economics of a project. However, there may be a time when the benefits far outweigh the costs, as using cement reduces binder demand.

\subsubsection{Fly Ash (Type C and Type F)}

Fly ash is mostly made of silicate glass which is composed of silica, alumina, iron and calcium. It also has very small amounts of magnesium, sulfur, sodium, potassium, and carbon as well as some crystalline compounds. Fly ash is a fine 
powder that looks like cement which is a combustion by-product which is produced when ever coal is used to power industrial processes. In general Type $\mathrm{C}$ fly ashes have higher calcium contents $(10$ to $30 \% \mathrm{CaO})$ where as Type $\mathrm{F}$ fly ashes are considered low calcium (less than $8 \% \mathrm{CaO}$ ). If recycled fly ash would have a more positive environmental and industrial effect. Unlike fly ash cement requires an enormous amount of energy to produce which makes it very harmful to the environment in terms of Carbon dioxide and ecosystem destruction during the mining process required to claim raw material.

\subsubsection{Bag House Dust}

Bag house dust, also known as limestone dust, is plainly as the name implies. This dust is composed of extremely fine limestone particles which are the natural byproduct of aggregate crushing. Bag house dust is generated from the movement and transportation of limestone aggregates during asphalt mix production, as well as the grinding method associated with the crushing process.

\subsection{Equipment Requirements}

\subsubsection{Load Frame}

Load frames are the back bone of most axial loading devices, as they provide the essential load needed to perform performance tests. Load frames vary in size and capacity, and can range from one pound to millions of pounds. The development of the asphalt testing system at Ryerson University involved careful equipment selection which was riddled with many tedious tasks. These tasks include space, equipment requirements and hydraulic and electric power supply demands as well as strict safety protocol which push for proper ventilation as well as safe working conditions. The current system set up in the TARBA highway materials laboratory at Ryerson University has a MTS load frame. The MTS load frame is 
composed of a Model $810100 \mathrm{ken}$ load system. The maximum load frame requirement for most simple performance testing is $25 \mathrm{kN}$. From my experience a load cell and frame capable of loading up to $5000 \mathrm{lbs}$ is more than adequate for all HMA testing needs as asphalt is relatively weak, especially at warmer temperatures. Also the load frame should have a long stroke of at least 4" to 6" since simple performance testing changes from standard to standard. For example just changing from NCHRP testing to ASTM can vary the minimum sample height up to $50 \mathrm{~mm}$ which can only be accommodated if the load frame has enough stroke height to compensate for the change.

Simple performance testing calls for dynamic loading capability. Simple performance testing commonly involves loading frequencies which range from 0.1 to $30 \mathrm{~Hz}$. The Simple Performance Testing of HMA materials involve frequencial loading as well as confinement and temperature control. It is recommended that the load frame have enough lateral clearance to accommodate both a tri-axial cell as well as a temperature control device. The load frame used for this particular testing is depicted in Figure 3.1. For the specifications of the device used in this project please refer to Appendix B.

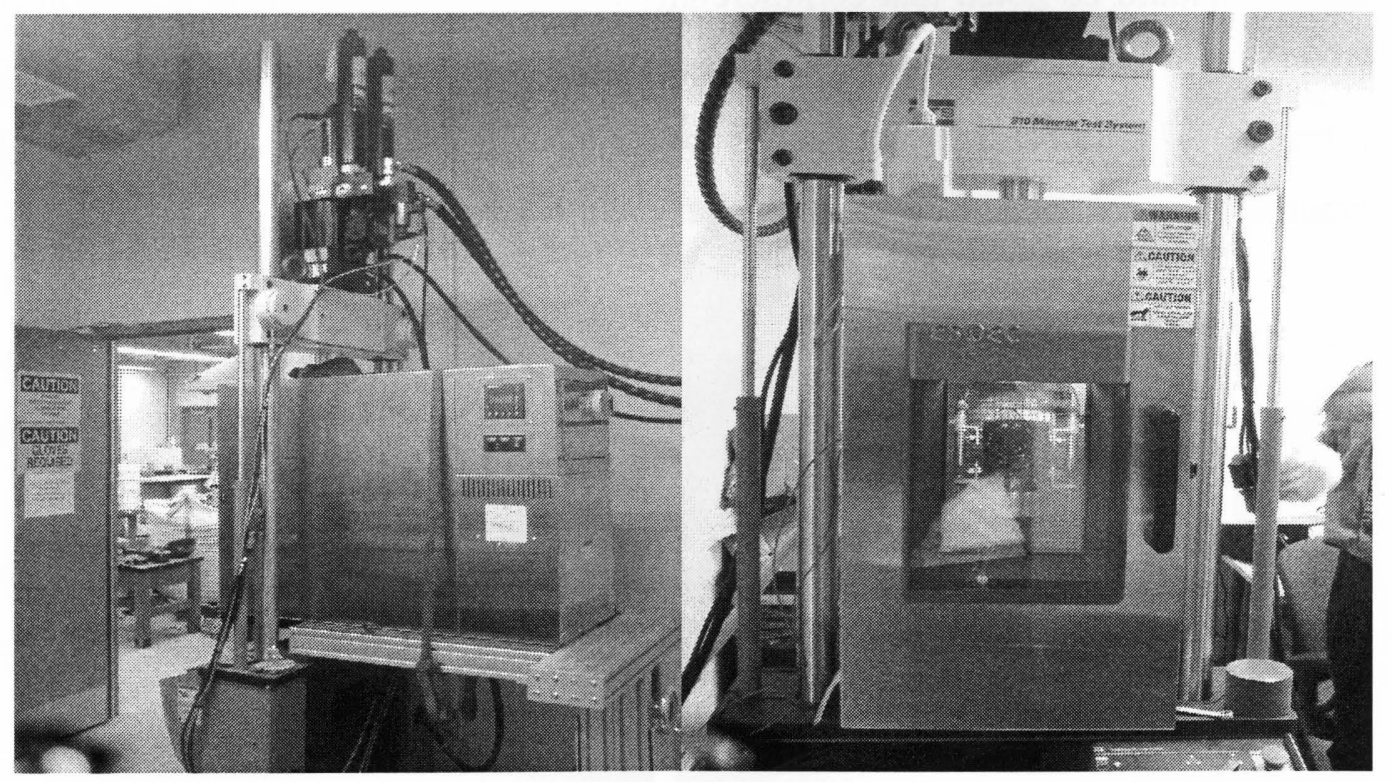

3.1: Load Frame 


\subsubsection{Environmental Chamber}

Simple performance testing was designed to accurately and reliably measure mixture response characteristics in a variety of environmental conditions. In a laboratory setting, it is difficult to come up with an accurate method of conditioning samples as well as maintaining set temperature extremes throughout the duration of the testing cycle without an environmental chamber. Simple performance testing is usually conducted between the temperatures of -9 and $37.8^{\circ} \mathrm{C}\left(-48.2\right.$ and $\left.100^{\circ} \mathrm{F}\right)$ for $\mathrm{NCHRP}$ and 5 to $40.0^{\circ} \mathrm{C}\left(41\right.$ to $\left.104^{\circ} \mathrm{F}\right)$ for $\mathrm{ASTM}$. It should be noted that some tests also involve very low temperature extremes which can dive down to $-20^{\circ} \mathrm{C}\left(-68^{\circ} \mathrm{F}\right)$. Temperature stability is very important in simple performance testing. Proper testing requires that all temperatures be held within $0.5^{\circ} \mathrm{C}\left(32.9^{\circ} \mathrm{F}\right)$ of their respective targets. The chamber used for the testing was a model 651.34 liquid nitrogen cooled chamber. The decision to purchase a LN2 system was based on unit cost, as a regular compressor based unit would be much more expensive. In the future if another system were to be purchased it would be beneficial to steer away from a liquid nitrogen unit since it is very labor intensive procuring, transporting, and connecting nitrogen to the unit. It should be noted that commercially available liquid nitrogen is bought in containment device called dewers, these devices hold upwards of $200 \mathrm{~L}$ of liquid nitrogen. The problem is that the containers actually only last about three weeks whether they are used or not since the gas naturally boils away.

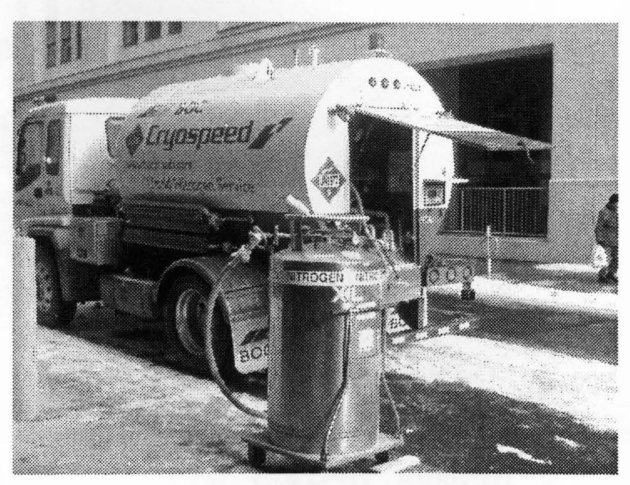

Figure 3.2: Filling Process

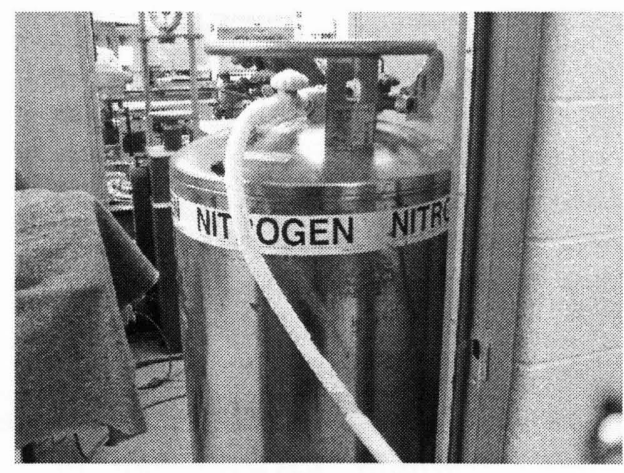

Figure 3.3: Nitrogen Gas Dewer 
The tanks cost about $\$ 300 \mathrm{CAD}$ and will only last about 3 weeks from the date of delivery. The large dewer as well as the filling process is depicted in Figures 3.2 and 3.3 .

\subsubsection{Gyratory Compactor}

The specimens prepared and tested in this research were all made using a gyratory compaction device. In previous studies some people have chosen to use a California kneading compactor but it is believed that gyratory systems perform much better in terms of representing actual field compaction. One main restriction

with using a gyratory compactor is the final specimen height. If test specimen needed has a height to diameter ration of 1.5 to 1 similar to NCHRP testing then a gyratory can be used. It should be noted that it is very difficult to determine the maximum amount of material that will fit into a gyro so that it can be closed. Also the number of gyrations is usually altered when compacting taller samples. The author would only recommend the use of a gyratory compaction system which follows ASTM D3387 if samples can be made to a maximum height of about $160 \mathrm{~mm}$, anything taller that this would have to be made using a California kneading compactor. The gyratory compactor used for this testing is depicted in Figure 3.4.

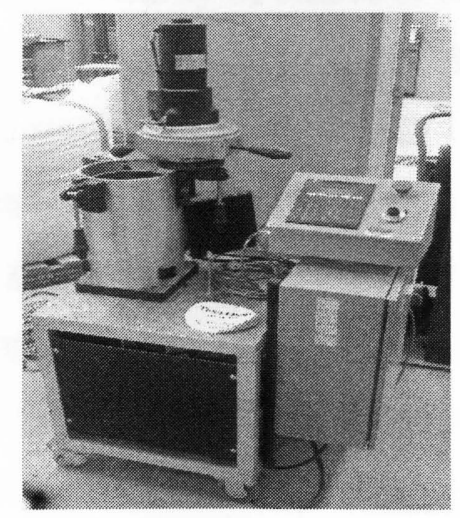

Figure 3.4: Gyratory Compactor 
A gyratory compactor is a device which applies two separate compacting efforts to HMA materials. A Gyratory, as the name indicates gyrates during compaction, which applies a shear or kneading force to the contained material to aid in compaction effort. This type of system also applies a continuous force throughout the compaction period of approximately $600 \mathrm{kPa}$. The combined effort of force and gyration has been thought to better represent in field compaction when compared to other compaction methods such as Marshall and even the California kneading compactor.

All the materials tested in this research were compacted using a Brovold Gyratory compactor, the current owner and distributor of this system is now Pine Instrument Company which is located in Grove City, PA. This particular unit follows SCSC according to AASHTO PP35.

\subsubsection{Liner Variable Displacement Transducers (LVDT) and Hardware}

The key to most performance tests is precise measurement. It is not enough to be able to apply repeated or static load if the sample response cannot be recorded. In the past, performance testing in asphalt called for disposable strain gauges, which where quite difficult to mount and which were quite costly when used in high and low temperature extremes. Today's performance tests rely on a newer form of technology called a linear variable displacement transducers or transformers which we refer to as LVDT's for short. LVDT's work on a fairly simple premise, they are excited by a set voltage and then depending on their position return a fraction of that voltage which is linearly related to their displacement within a predefined range. LVDT's are produced using numerous combinations of $\mathrm{AC}$ and DC input and out put orientations. The internal components of an LVDT look similar to electrical schematic shown in Fig 3.5a. Visually the LVDT's used in this experiment are shown in Figure 3.5b. 


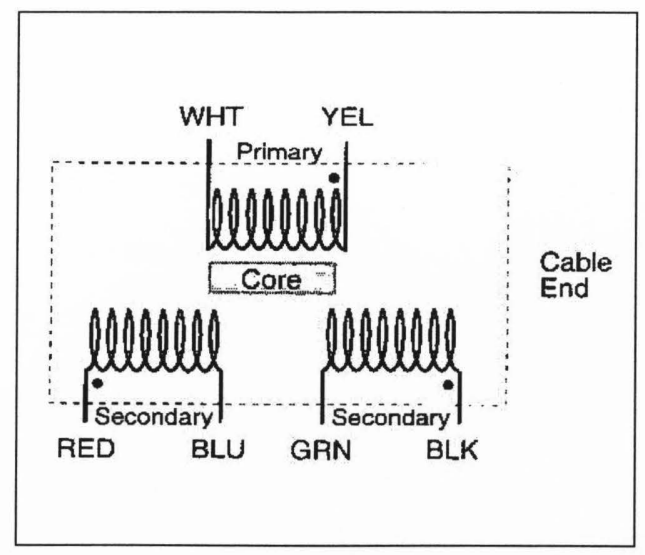

Figure 3.5a: LVDT Schematic (Trans-Tek 2008).

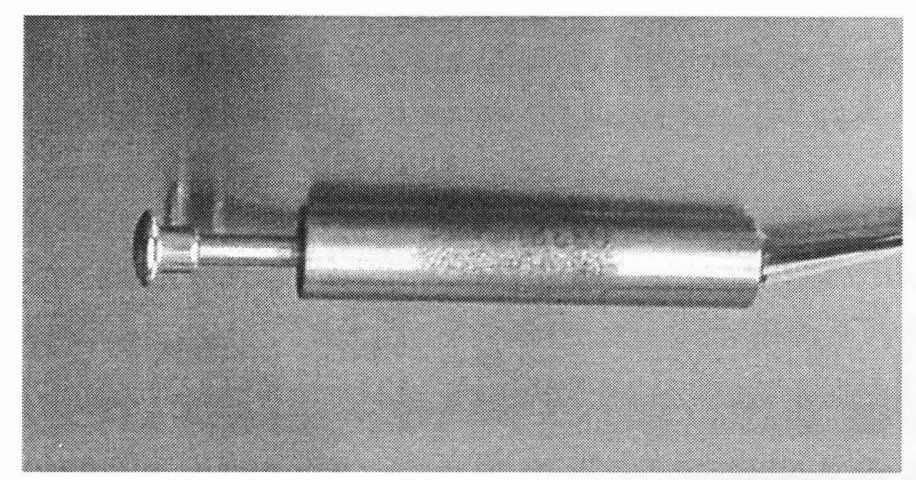

Figure 3.5b: LVDT Used in this study (Manufactured by Trans-Tek Inc.)

The testing of HMA has certain minimum requirements when it comes to LVDT's. Any LVDT used for HMA testing should have a minimum range of 0.02 " as well as an inherent non-linearity of $0.25 \%$ of full scale (NCHRP 465 ). It should be noted that signal conditioners are as important as the LVDT's. Signal conditioners provide the excitation voltage to the LVDT's, receive the unit feedback and provide a clean output signal to be connected to a data acquisition system. The samples tested in this report used 2 Tans-Tek 330 series LVDT's for vertical displacement measurements. Through the development of mounting hardware and various testing set ups it should be noted that it is very important to make sure all components are wired correctly and the connections are soldered and tight so as to avoid any signal noise problems during testing. While fabricating mounting hardware for the testing in this report it was found that the 
hardware used to mount the LVDT's to the specimen should be made of non metallic materials at all costs. If for any reason this is not possible, then ferromagnetic metals should be avoided. All the materials and hardware within an inch of a transducer should be made of non ferrous materials which are poor electrical conductors to avoid directly compromising transducer performance. Any ferromagnetic materials which are within a few $\mathrm{mm}$ of the transducer walls can change the shape of the transducers magnetic field. This change in the core field can lead to signal stability problems as well as measurement error. All the components used in this research to hold the LVDT's were made of Aluminum Alloy, Brass and or plastic so as to avoid any interference issues.

\subsubsection{Data Acquisition Equipment}

Logically, a test can only be validated or rejected if it produces results. The testing of HMA mixtures is no different. In order to understand and predict future performance of a material we need to accurately and efficiently capture and store test data for future review. In most cases a data acquisition system used for conducting a simple performance test should include some form of analog to digital conversion and or digital input storage as well as some form of computational analysis. The system should be capable of measuring and recording very minute changes in material and equipment characteristics during testing. For HMA, the system needs to be capable of measuring and recording repeated applied loads, as well as axial and radial deformations versus time, through a variety of channels. The system used for this testing is shown below in Figure 3.6. The detailed specifications for the system used to test the specimens created for this thesis can be found in Appendix B. 


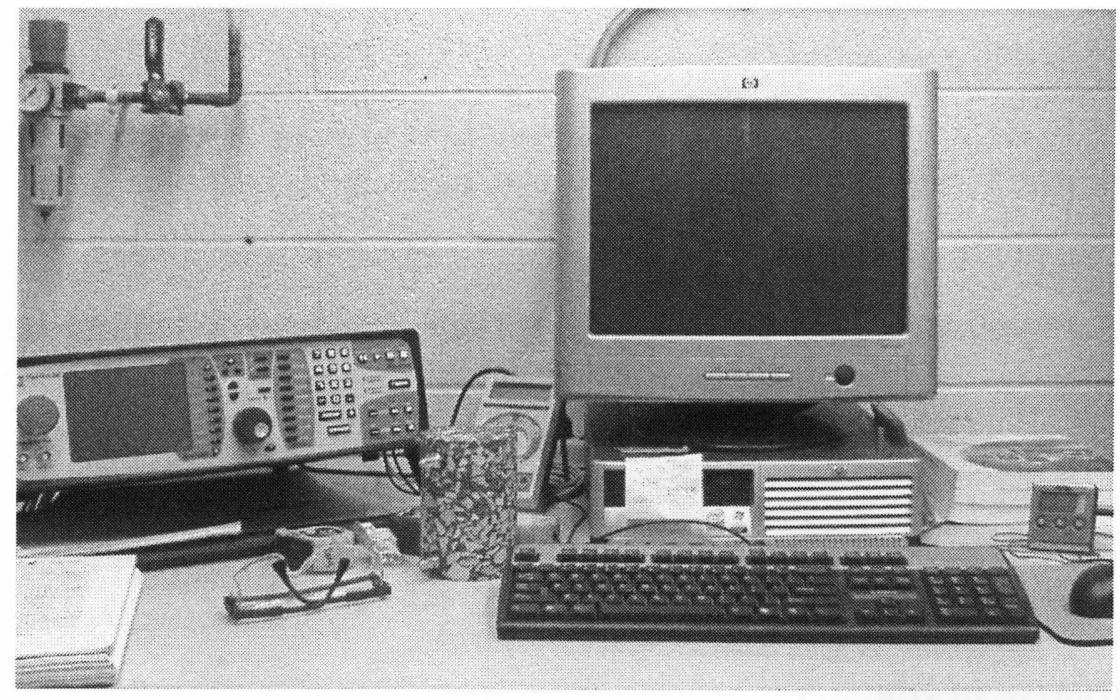

Figure 3.6: Data Acquisition System (Refer to Appendix B for Specs.)

The main advantage to computerized data acquisition is that it has far surpassed the days of the pen and paper approach. Data acquisition systems are capable of recording data points thousands of times a second whereas human capability can hardly record single data point once every few seconds. During the set up of the system used for this testing it has been found that a data acquisition device which combines load, temperature control and data storage is the best option. When the original universal system was purchased for this testing the bare bone software package was not capable of fulfilling the testing program needs. For example, in its original condition the user would have to start and stop the testing process many times in order to achieve certain testing criteria. For example if a user wants to apply a load for 0.1 seconds and then remove it for 0.9 seconds repeatedly this would be almost impossible unless the control software for the load frame had this ability. Since the bare bone software shipped with the universal test frame was not adequate for the testing program it was updated to a more powerful version called MPT (Multi Purpose Test ware). The details for this software can be found on the MTS website which can be easily located through the World Wide Web. 


\subsubsection{Coring Rig and Accessories}

There are many different commercially available coring devices from a wide range of suppliers across the Canada and the US. A decent coring rig can be purchased for about $\$ 2500-\$ 3500$ CAD. There are few minor but important details which should be addressed when selecting a coring rig for asphalt coring, they have been listed below:

\subsubsection{Strength of Rig}

The drilling rig should have the power to turn the desired coring bit at a constant rate for the entire coring period without slowing down or overheating. This is assured by buying a device which has a power rating high enough for your project. For this particular project a 20Amp Milwaukee clutch model drilling unit was used and proved to perform very well.

\subsubsection{Depth and Diameter of Coring Bit}

Simple Performance Testing requires a minimum height to diameter ratio of 1.5:1 and ASTM specifies 2:1 so the coring bit should fulfill both of these requirements in case further research negates one of the two standards in the future. The coring bit should be about 4" in diameter and have a minimum cut depth of 8 ". The coring in this project was made using standard 4" Wet Diamondcore asphalt coring bit and collar. This combination performed very well for this project. Although the depth of most standard coring bits is a little long which emphasizes the eccentricity of the drill at times. This eccentricity can cause small score marks on the sample wall surfaces if special care is not taken. A custom bit can be used which is closer to the maximum sample height to minimize this phenomena. 


\subsubsection{Longevity of Product or Warranty}

The coring rig used for this research was a Milwaukee product which housed a 20 A motor mounted on a 14 " x 16" base. It is shown here in Figure 3.7.

The challenge in the coring process was not the commercially available rig but rather the device used to hold the gyratory compacted puck while it was being cored. To facilitate the coring of the 4" $\mathrm{x} 6$ " puck a small holding device had to be designed and manufactured. This device is shown below in Figures 3.8a and $3.8 b$.
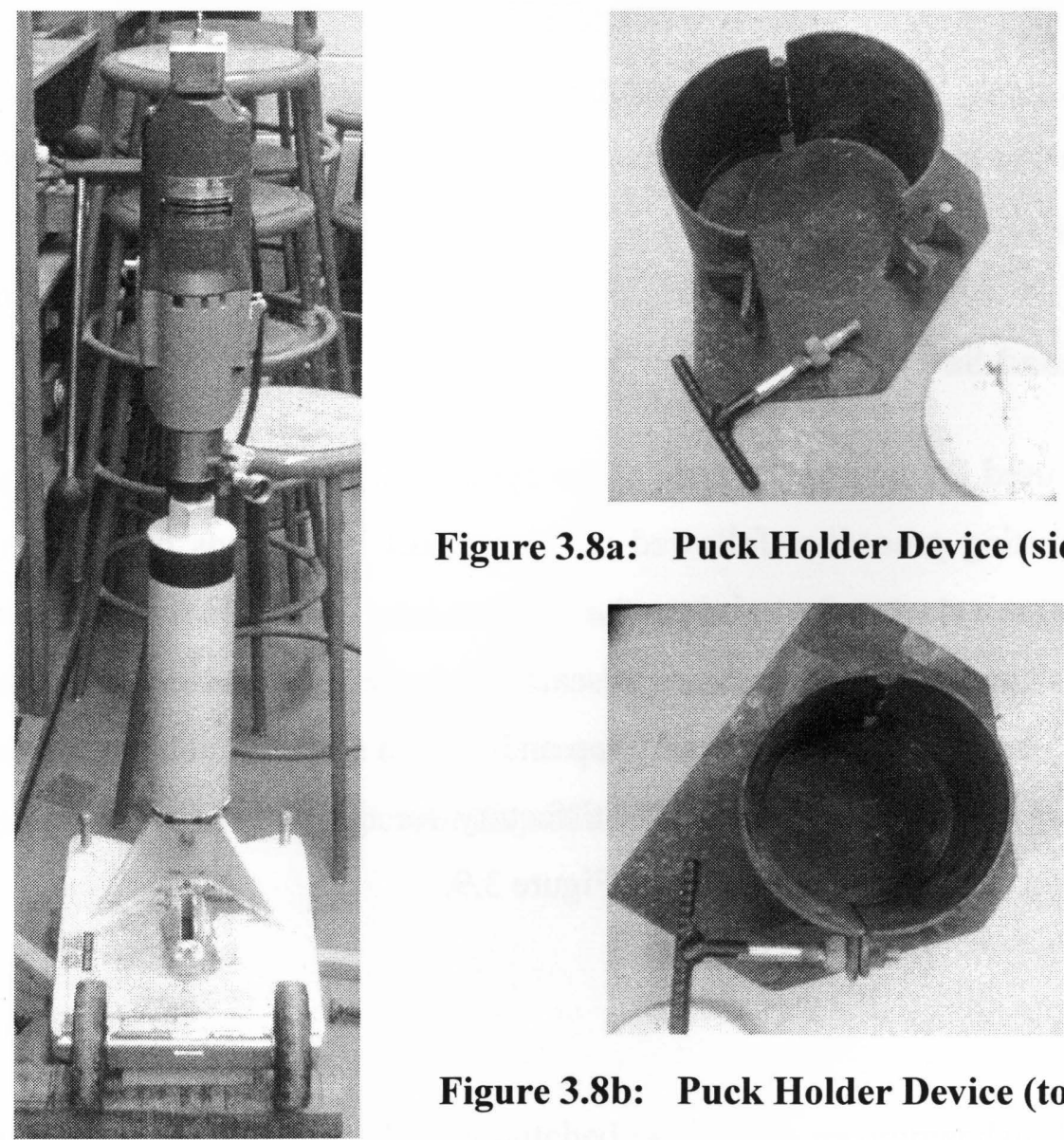

Figure 3.8a: Puck Holder Device (side view)

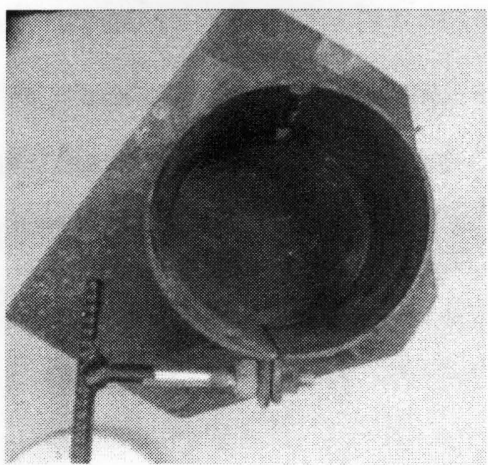

Figure 3.8b: Puck Holder Device (top view)

Figure 3.7: Coring Rig 
The puck holders were made of mild steel which were rolled to the exact sample curvature and retrofitted with a hinge and tightening mechanism which would distribute the holding force around the circumference of the sample being cored. The rig was designed to be strong enough to firmly hold the sample while causing virtually no damage to the original puck; this insures that the sample being extracted remained safe throughout the coring cycle. Small wooden disks were also made and placed below the HMA pucks so as to act as an end indicator for coring. The wooden disks are vital for the protection of diamond coring bit.

The disks were composed of circular plates cut from 3/4" plywood. These disks would suffer mild score marks as the drill bit proceeded to break through the bottom of each sample, however a single disk could be reused repeatedly before replacement was necessary. The purpose of these disks was to insure that the coring bit never hit the steel base of the puck holder where it would be damaged.

\subsubsection{Diamond Saw}

A machine used for sawing the ends of the cylindrical specimens is necessary for the HMA testing procedure followed in this project. The ends of the samples used in this project were cut to insure the surfaces in contact with the platens were square and smooth. In some cases researchers have used double bladed saws separated by spacers to insure parallel top and bottom surfaces. This testing used a single bladed setup which proved satisfactory for the purpose of this project. The saw used can be seen below in the Figure 3.9. 


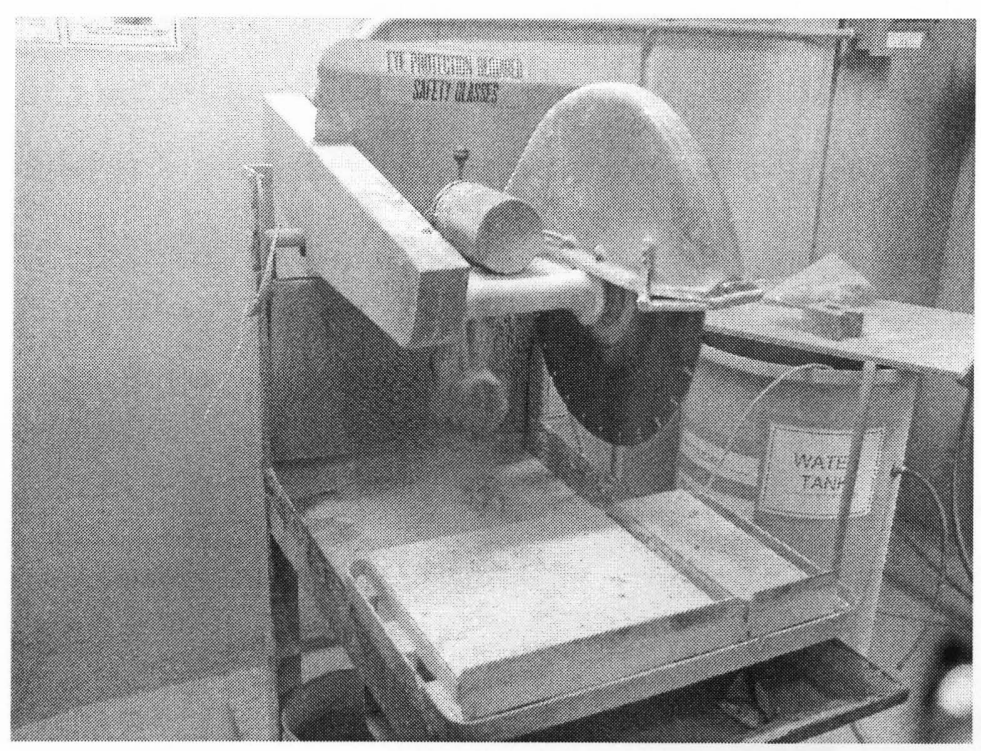

Figure 3.9: Diamond Blade Cutting Saw

The main criteria for a saw or cutting device which can be used for this testing has been listed below:

\subsubsection{Blade Diameter}

The cutting capacity of the blade has to be at least a few inches larger than the maximum specimen diameter to be cut. For example if you are cutting a 4 inch specimen the diameter of the blade would be $4 "+2 "$ (clearance) x $2=12 "$. Therefore, the clear cutting capability of a 12 " blade is about $+/-4$ ".

\subsubsection{Blade Type}

A high grade diamond blade with notched sections is recommended for this type of specimen cutting. The key to cutting asphalt specimens is to keep them as cool as possible throughout the cutting process. A notched blade allows for a cooler cut as the blade will draw more air and water during the cutting process. As an 
overheated blade would promote premature aging of the binder at the loading interfaces of the sample, the cooling capability of the blade allows for the reduction of this occurrence.

\subsubsection{Cutting Process}

A wet cutting process should be used. The samples should be cut with a diamond saw which is water cooled. The specimen should also be cut in a slow steady motion so as to avoid the excessive scoring of the sample ends. In some cases, samples that have uneven surfaces at their cut ends can be end-faced using a diamond grinder if necessary to obtain a smoother finish. Another approach to obtaining an even surface would be to cap the samples using a sulfur capping compound similar to that used for concrete specimens. It should be noted that when cutting a sample from a specimen, a tolerance greater than 3-4 $\mathrm{mm}$ from the extreme ends of the sample should be considered. This tolerance will reduce the presence of blade wash and reduce the chances of the sample being cut at an angle.

\subsubsection{Aluminum Cylinder for Phase Angle Verification}

The determination of the dynamic modulus and phase angle for any material relies heavily on the instrumentation used. In this research an MTS based system was used which is powered hydro-mechanically. Basically, a series of electrically controlled valves regulate the movement of high pressure hydraulic oil into and out of an actuator to apply the required force necessary to run a test. The accuracy and control of new hydraulic test systems is very good when compared to the older mechanical devices. For example, when the controller electrically tells the actuator to apply a force the actuator responds with virtually no lag. In other words when it is told the actuator responds almost instantly, in order for this 
to happen though the actuator needs to be calibrated. New test frames have many pieces of software to aid in calibration and set up. For example the MTS has a function called a PVC or peak valley compensator, this function puts the coarse peaks and valleys of the load and displacement in phase by using the load cell and the LVDT built into the frame.

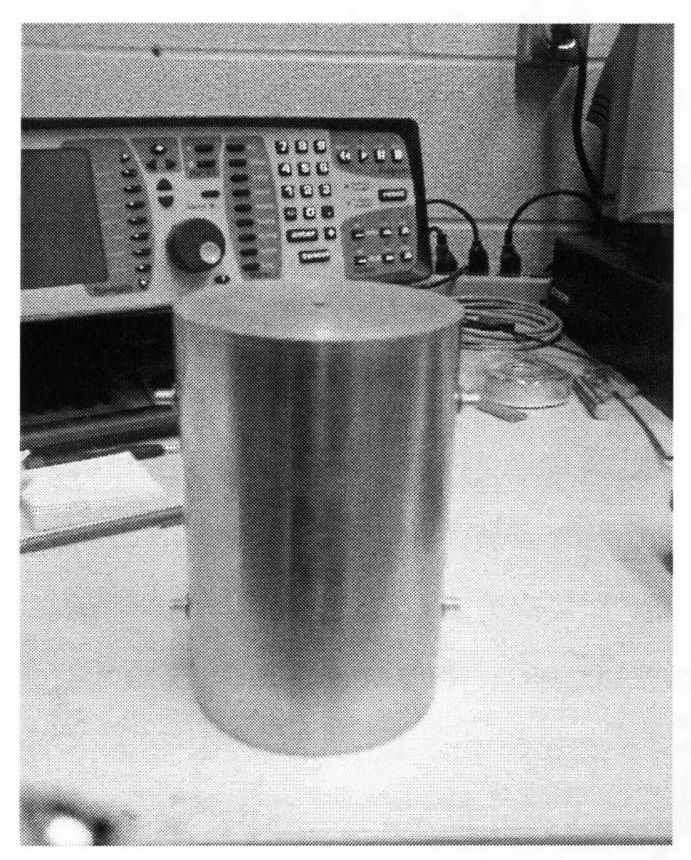

\section{Figure 3.91: Aluminum Alloy Round for Phase Shift Calibration}

The problem in this testing system lies in the fine tuning, as there is no real way to tune the device in terms of load and displacement in units smaller than those controlled by the built in LVDTs. To address this issue an aluminum alloy cylinder was fabricated and fitted with LVDT's just like its asphalt counterpart. This aluminum cylinder can be seen in Fig 3.91. Aluminum alloy was used for four main reasons as listed below:

1. Aluminum alloy is lightweight and easier to machine than brass or steel

2. Aluminum alloy is non-ferrous so it will not interfere with the magnetic field generated by the LVDT's used to determine displacement 
3. Solid aluminum alloy is a metal which is very homogeneous when compared to other materials such as concrete or asphalt

4. Aluminum Alloy also has published values for its coefficients of thermal expansion as well as its moduli of rigidity and elasticity which are the base numbers used in the dynamic modulus \& phase angle calibration of the test frame

5. At room temperature the T6-6061 aluminum alloy used in this research acts purely elastic which is essential in the calibration of the displacement and load sinusoidal waves

Unlike asphalt, at room temperature aluminum alloy is purely elastic as it has no known liquid characteristics at such a low temperature. The aluminum is tested just like the asphalt, it is put through a series of frequencial loads and the displacements are read by the LVDT's. The displacements are then verified from first principles using the selected metals natural properties. In asphalt there is a visible phase difference between the load and the axial strain vs. temperature as shown in Fig 3.91a. To assure that this phase difference is all attributed to the asphalts fluid characteristics aluminum is used to generate a similar graph shown in Fig 3.91b. The ideal difference can be seen in the phase shift. Theoretically aluminum alloy has a phase shift of zero where as asphalt has a shift greater than zero. If this is not the case of any reason then a calibration problem exists in the testing system which needs to be addressed before the next test. 


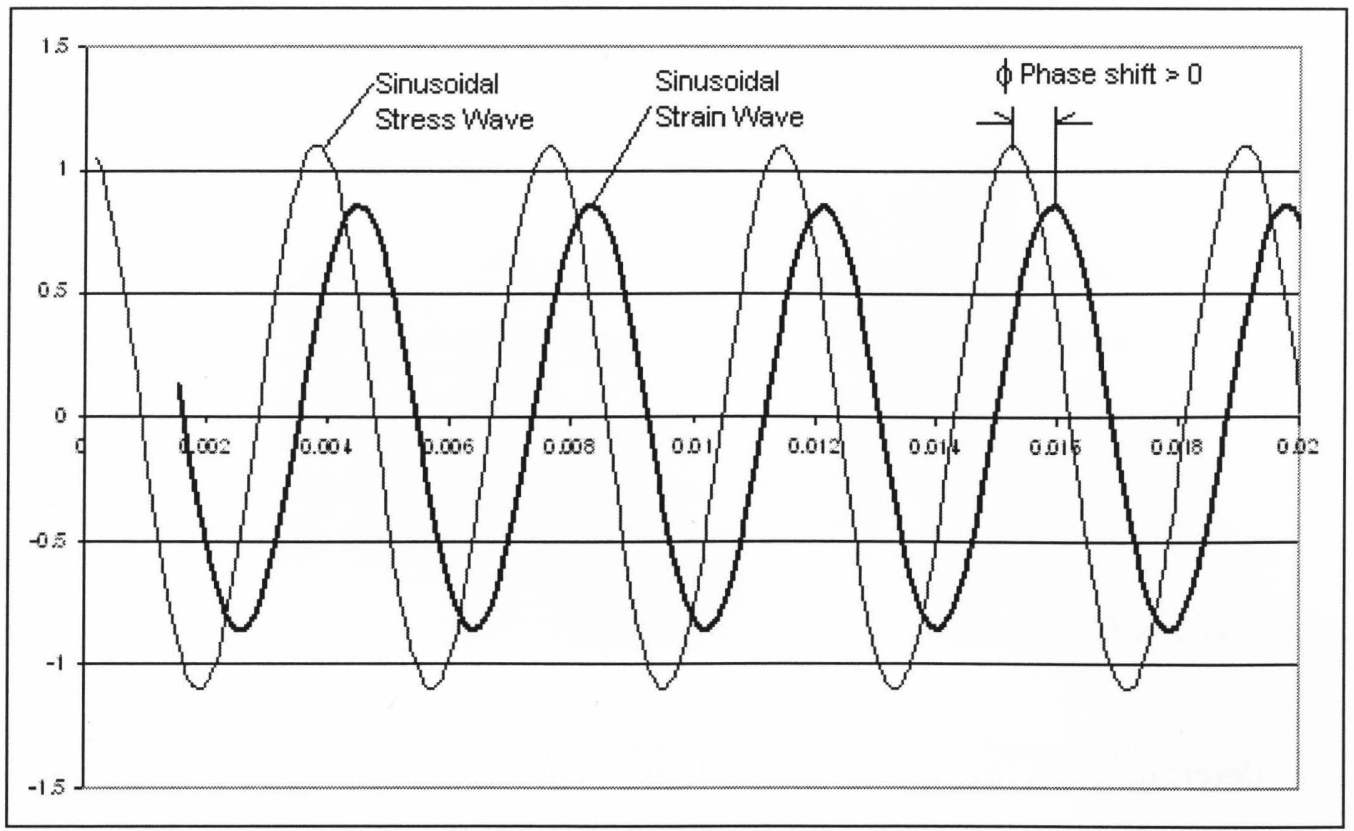

Figure 3.91a: Obtained Sinusoidal Stress and Strain Waves vs. Time in Asphalt (phase shift $>0$ )

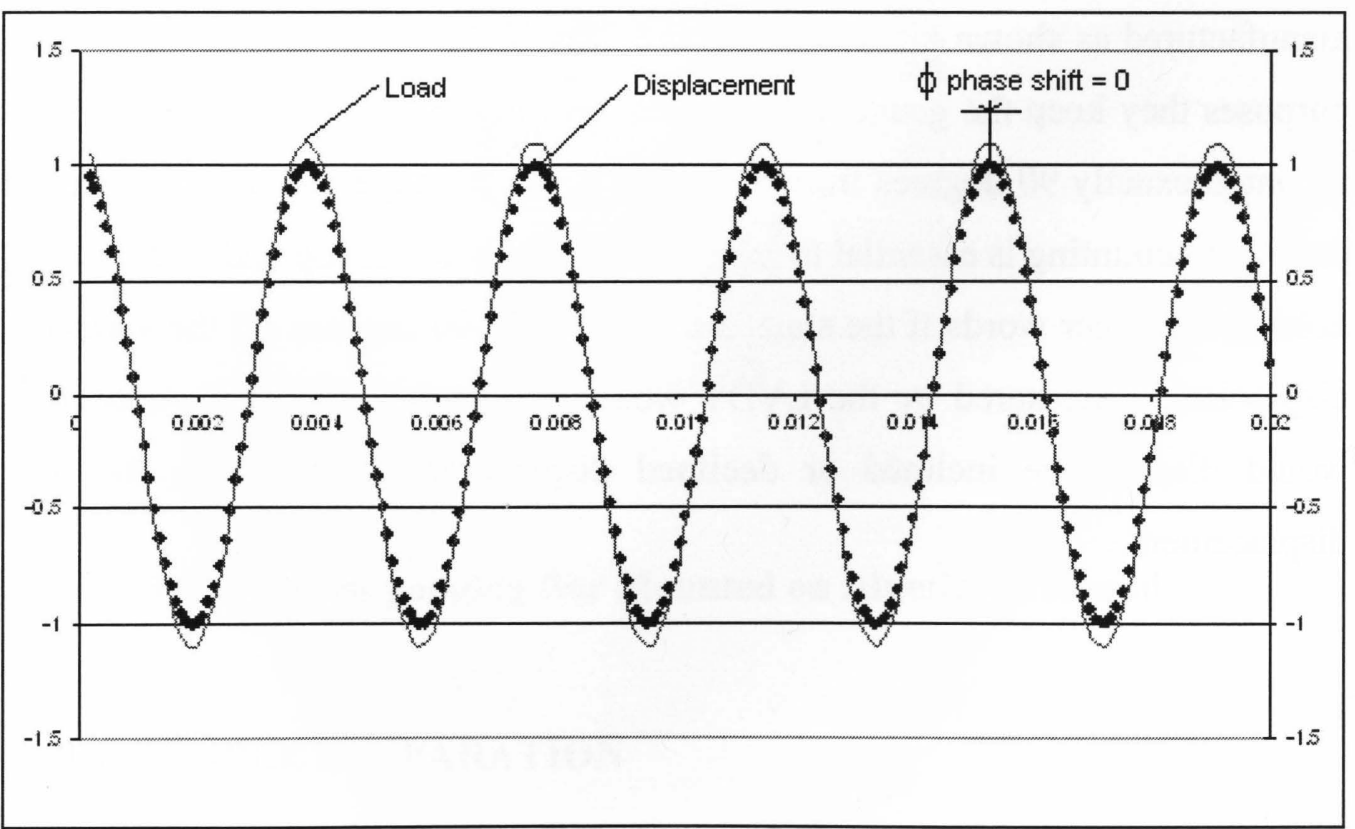

Figure 3.91b: Obtained Sinusoidal Stress and Strain Waves vs. Time in T6-6061 Aluminum Alloy (phase shift $=0$ ) 
This procedure was followed so that any phase shift noticed in the asphalt could be correlated to the materials characteristics rather than equipment error. The initial validation of the approximate linearity of a new LVDT can also be done using the aluminum round, as it provides a stable base for any needed adjustments, as well as rough base line figures to check the functionality of all the instruments.

\subsubsection{Brass Gauging Bars}

The determination of dynamic modulus requires certain calculations, these calculations include a constant value known as the gauge length. The gauge length is denoted as GL in the calculation tables in Appendix A and it refers to the distance between the two LVDT mounting studs. In this testing the gauge length is kept constant on all the samples tested. To achieve this, brass gauge bars were manufactured as shown in Fig 3.92a and 3.92b. These brass bars serve two main purposes they keep the gauge length constant while insuring the LVDT studs are mounted exactly 90 degrees from the surface. Both gauge length combined with precision mounting is essential to insure the linearity of the top and bottom LVDT holders. In other words if the studs are not exactly 90 degrees off the surface the displacement measured by the LVDT would not be accurate as the eccentricity would display the inclined or declined displacement rather than the actual displacement. 


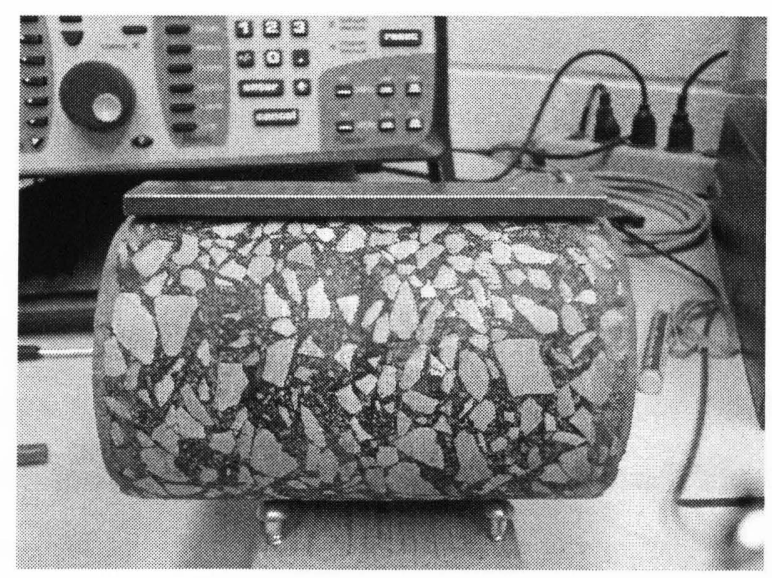

3.92a: Brass gauging Bar Mounted on Asphalt Specimen

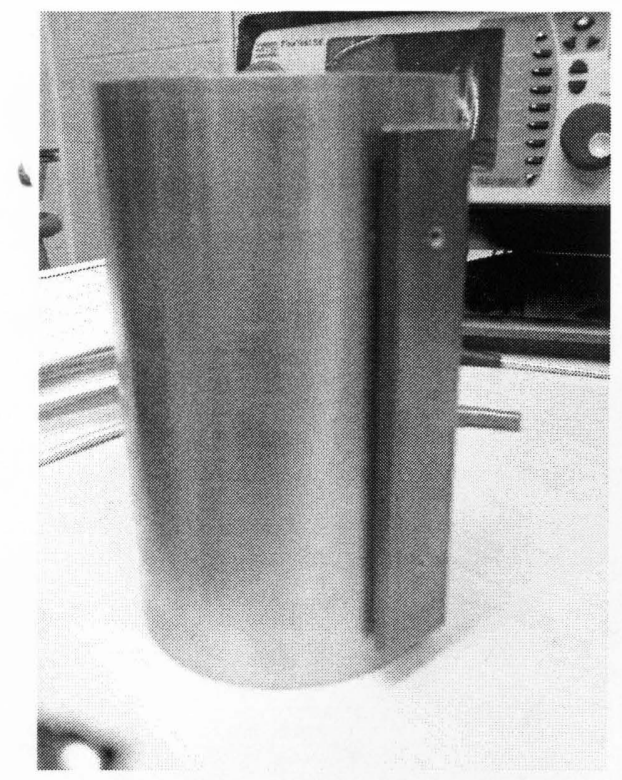

3.92b: Brass gauging Bar Mounted on Aluminum Round

\subsection{SPT SAMPLE PREPARATION}

\subsubsection{Size}

Samples shall have a height to diameter ratio of a minimum of 1.5:1. Samples are usually $100 \mathrm{~mm}$ in diameter with a height of $150 \mathrm{~mm}$. The samples used in this testing were $+/-94 \mathrm{~mm}$ in diameter and $141 \mathrm{~mm}$ in height since standard 4" 
coring bits yield an internal diameter between $93 \mathrm{~mm}$ and $95 \mathrm{~mm}$ not $100 \mathrm{~mm}$ like one would expect.

\subsubsection{Aging}

All samples were short term aged prior to compaction in a convection oven in accordance with the short term aging procedure outlined in AASHTO PP2. The samples were aged in a large capacity $27 \mathrm{cu}$.ft chamber as shown in Figure 3.10 below.

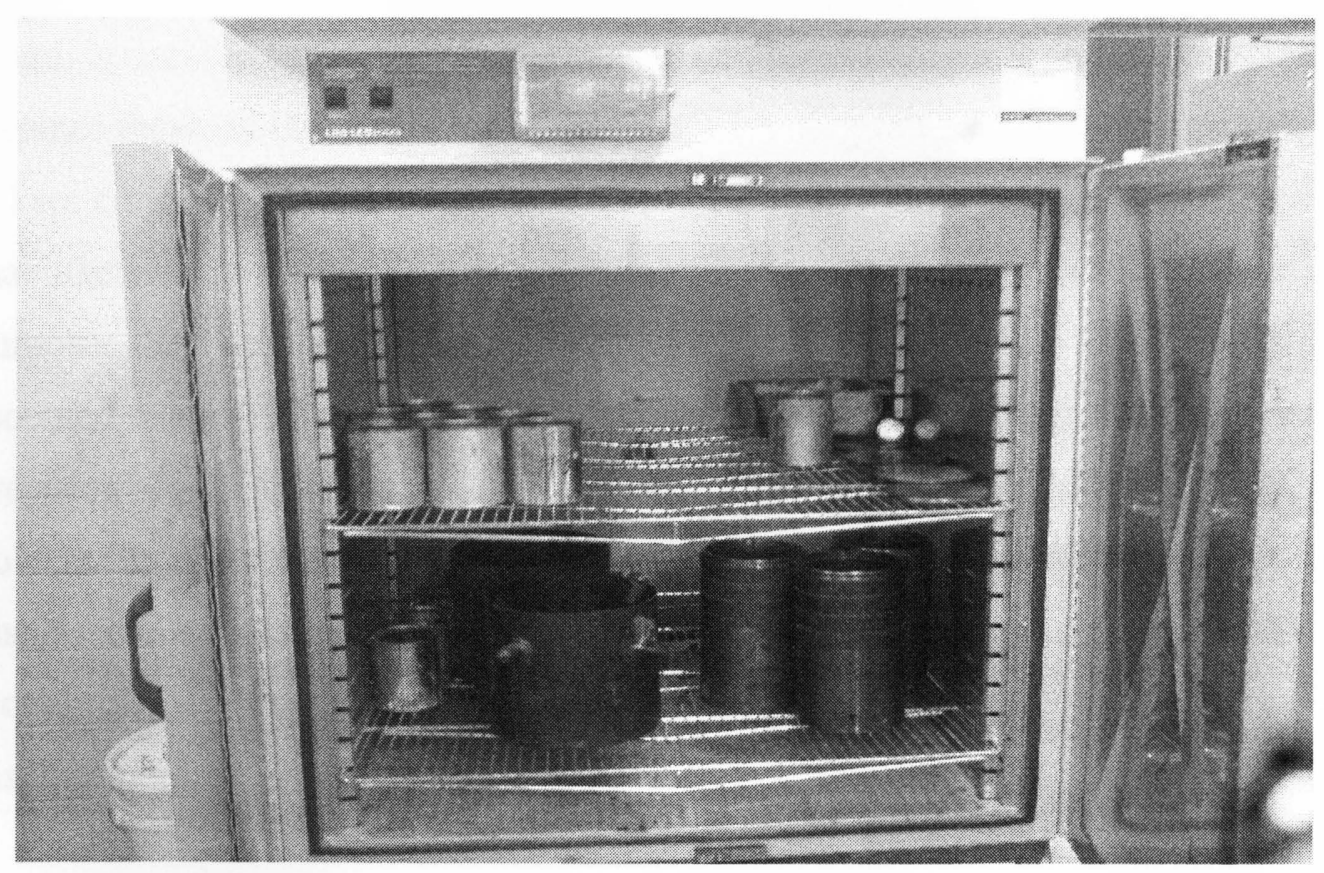

Figure 3.10: Convection Oven used for aging

\subsubsection{Compaction}

All specimens were made using a gyratory compaction device and compacted at the compaction temperatures listed under ASTM D1561 using a device which conforms to ASTM D3387. The compaction device used was not a listed device 
which could produce samples which were $200 \mathrm{~mm}$ in height. For this reason the sample height recommended by NCHRP was used. The gyratory compaction device used for this testing was only capable of achieving suitable sample height with the help of some minor manual tamping. The HMA material was slowly tamped as it was loaded into the gyro to allow for the cover of the apparatus to close. The small manual effort applied has been assumed to be negligible as it is was only enough to insure the material is all level before the gyratory head is closed onto the sample. The gyratory compactor used was a Brovold and it is depicted in Figure 3.11. It has been assumed for the purpose of this project that the energy exerted during the manual tamping is very small when compared to the total compaction effort and thus has been considered negligible.

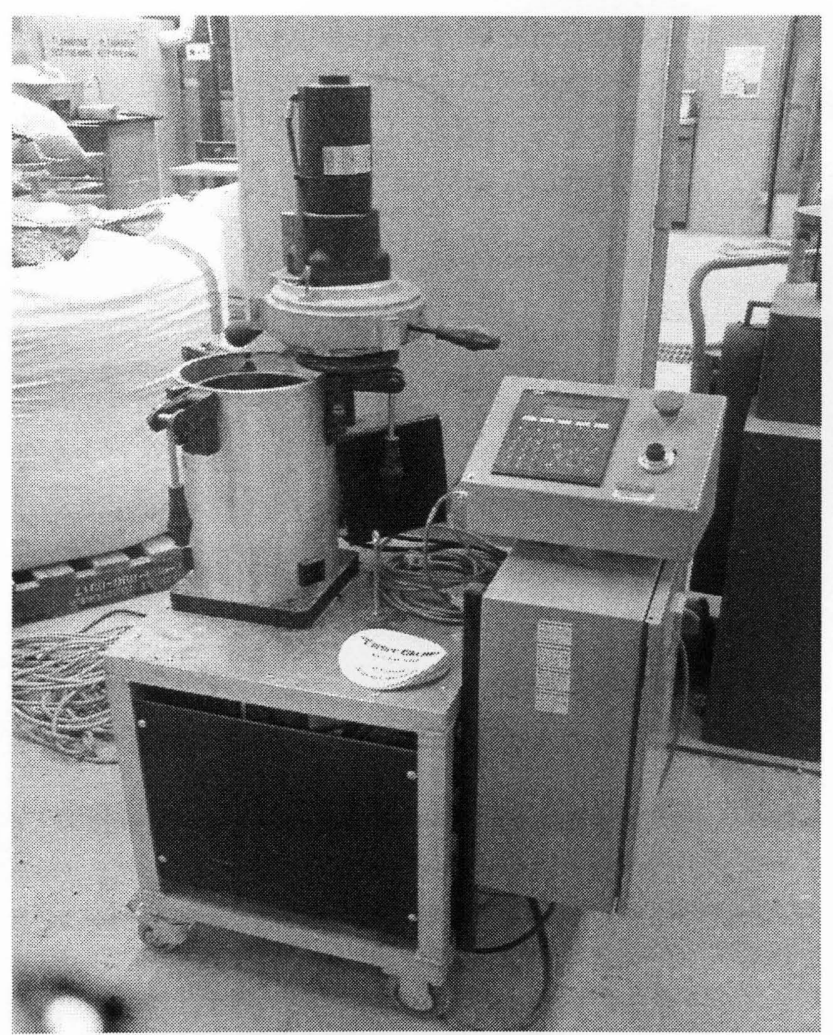

Figure 3.11: Brovold Gyratory Compactor 


\subsubsection{Freezing}

All samples were produced and then allowed to cool to room temperature for one day before being placed in a freezer. The samples were kept in the freezer for a minimum of three hours before they were cored and end cut. This method was used to achieve higher quality cores, and better end cuts. It is understood for the purposes of this paper and has been accepted that by freezing the samples they should be treated as if they had undergone a single winter freeze thaw cycle. To minimize the damage to the samples during the freezing period the samples have been cooled to room temperature in desiccators and were kept away from any water before they were frozen. The samples were all frozen to $-15^{\circ} \mathrm{C}$ and then cored and cut immediately to achieve the greatest benefit from the stiffness gained through the low temperature. The low temperature was achieved using an ordinary commercial freezer as shown in Figure 3.12.

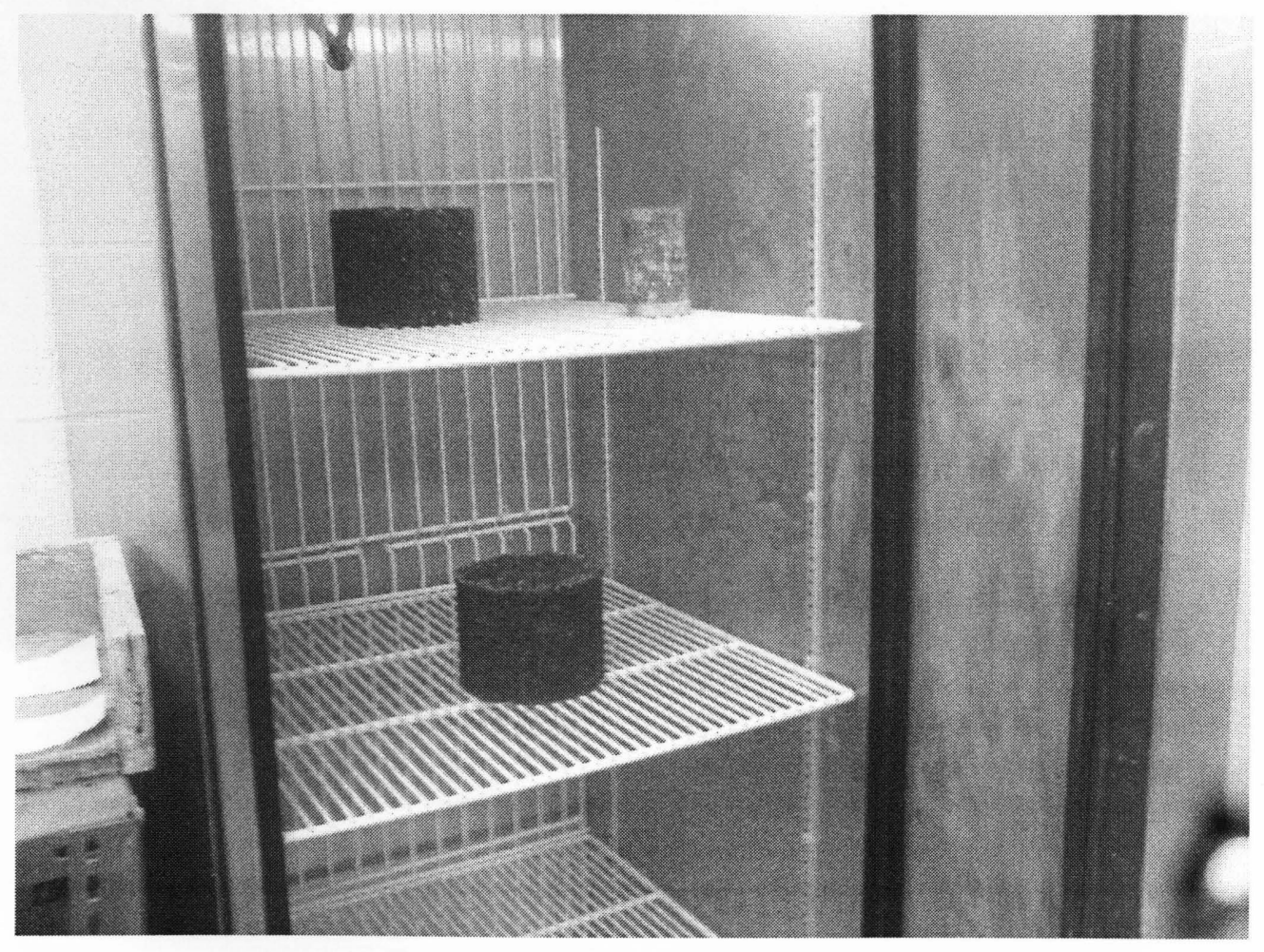

Figure 3.12: Commercial Freezer 


\subsubsection{Diameter}

The diameter of the specimens tested was measured along the mid height to insure they had a maximum run out of $1 \mathrm{~mm}$ or less. Any specimens that had a run out of $2.5 \mathrm{~mm}$ or more were discarded. The diameter of the specimens are very important as they are the attachment surfaces for the LVDT holders, these surfaces can be kept smooth and unscarred by merely freezing the samples and reducing the feed rate of the coring and cutting process.

\subsubsection{End Preparation}

The ends of the samples were cut using a diamond saw while frozen to ensure very smooth surfaces. The samples were then capped using the conventional sulfur capping compound used for concrete applications. This compound was then sanded and burnished to a smooth finish using a belt sander. The specimens were then checked for specific tolerances. The height and waviness of the specimens was measured and kept within $0.5 \mathrm{~mm}$ from the allotted measurement. The best way to check the surface tolerance is through the use of a dial gauge and stand or through the use of a machinists square and feeler gauges.

\subsubsection{Air Void Content}

The specimens were tested for air void content in accordance with AASHTO T296. A great deal of work was done to check the variation in the amount of air in the cored specimens. Any specimens which differed more that $0.5 \%$ were not tested. It should be noted for future reference that the amount of air voids in a core can be 1 to $1.5 \%$ higher when compared to the amount of air voids in an entire puck. 


\subsubsection{Duplicates}

Three samples were made for each test. In accordance with ASTM, one sample was used as a check for air void content, and two samples were used for dynamic testing purposes as outlined by NCHRP.

\subsubsection{Sample Storage Before Testing}

The samples were produced in various batches. As the samples were made they were cored, cut, capped and affixed with LVDT mounting hardware. The samples were then wrapped with cellophane and placed under vacuum until the time of testing. These precautions were implemented to avoid any premature aging problems. This process was used to protect the samples in the event they could not immediately be tested. This process would make it possible to keep a sample in a fresh state for up to two weeks after production.

\subsection{SAMPLE PREPARATION AND ACCESSORIES}

\subsubsection{Sample Accessories (LVDT mounting hardware)}

There are many types and shapes of hardware that have been used in past studies. The hardware used in this test was specially fabricated for this project. The mounting hardware consists of 4 LVDT holders which were machined out of $1 / 4$ ", wall aluminum angle. These devices were modified two times through out this testing program due to their re-design. The first set of holders was made from steel which proved to be too heavy to accommodate high temperature testing. The second set was made from aluminum alloy which was very light, but generated far too much moment at the surface of the sample under testing conditions due to the distance of the LVDT from the surface of the sample. The conventional mounting method involved mounting a brass stud on the asphalt and then mounting the LVDT holders to that brass stud. Previous testing displayed 
the female end of the fastener or the nut mounted on the specimen. This set up started by mounting bolts to the specimen rather than brass studs, eventually when the brackets were redesigned a new aluminum low profile fastener was designed and implemented to insure that the LVDT's were mounted within $5 \mathrm{~mm}$ of the surface of the sample. This was found to be less expensive and easier to replicate. Figure 3.13 shows the fasteners as they were produced. The LVDT holders shown in Fig 3.13 are very small and lightweight. The holders incorporate four brass set screws (two per fixture) used to affix the LVDT to the holder, and two machined adjustment screws (one per fixture) to perform necessary LVDT zero adjustments before calibration.

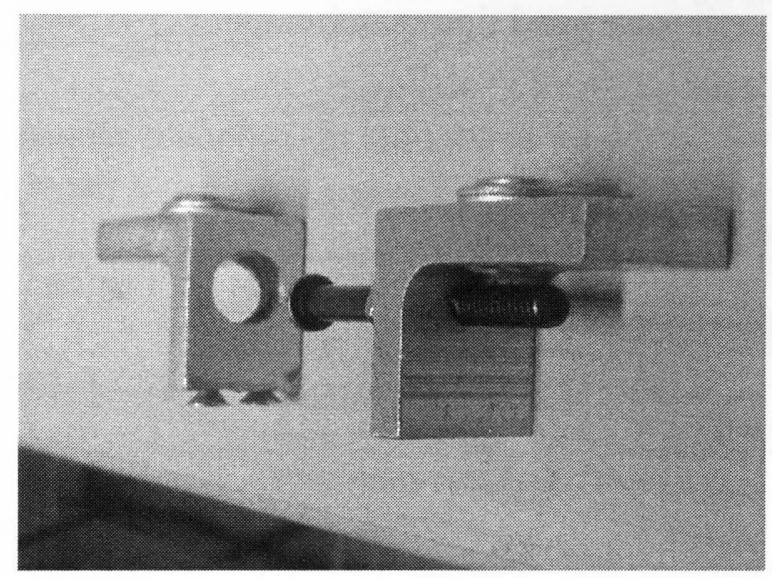

Figure 3.13: LVDT Fasteners

\subsubsection{Time requirements}

Simple performance testing is not as simple as the name would imply as all forms of testing require a great deal of time and precision. In fact simple performance testing actually takes longer that many other conventional testing procedures due to all the inherent precision tasks involved in the process. It is believed that unlike Marshall testing SUPERPAVE simple performance testing requires the use of expensive machines which need to be operated by properly trained personnel to ensure successful results. The time requirements for SPT can be broken down 
into three primary groups. These groups include, sample preparation, test preparation, and physical testing.

\subsubsection{Sample Preparation}

Sample preparation is among the longest and most tedious tasks associated with the testing of materials. A great deal of sample preparation time is consumed making samples which are never performance tested. For example numerous samples are produced for the determination and convergence toward the targeted number of air voids. These samples never make it to the load frame as they are melted down to find MRD \& BRD. Table 1 lists the actions involved in sample preparation and their associated time requirements. 
Table 1: Sample Activity Time Requirements

\begin{tabular}{|c|c|c|}
\hline \multicolumn{2}{|c|}{ Lab Activities for Sample Preparation } & $\begin{array}{l}\text { Estimated Time } \\
\text { Required }\end{array}$ \\
\hline 1 & $\begin{array}{l}\text { Acquire aggregates namely HL3 and HL8 and } \\
\text { ship to downtown location }\end{array}$ & $\begin{array}{l}\text { 3-5 Days depending } \\
\text { on season }\end{array}$ \\
\hline 2 & Dry Aggregate (heavily dependant of facility) & 3-5 Days \\
\hline 3 & $\begin{array}{l}\text { Sieve aggregate stockpile to desired sieve } \\
\text { sizes for all mixes }\end{array}$ & 4 Days \\
\hline 4 & Batching approximately $7100 \mathrm{~g}$ samples & $30 \mathrm{~min} / \mathrm{each}$ \\
\hline 5 & Heat batched aggregate & $6 \mathrm{~h}+$ to Overnight \\
\hline 6 & $\begin{array}{l}\text { Heating Binder (depends on amount of binder } \\
\text { and oven type) }\end{array}$ & about $2 h-4 h$ \\
\hline 7 & Mixing (2stages) & $10 \mathrm{~min}$ \\
\hline 8 & Short Term Aging & $2 \mathrm{~h}+/-5 \mathrm{~min}$ \\
\hline 9 & $\begin{array}{l}\text { Compaction (heavily dependant on specimen } \\
\text { height and number of gyrations) }\end{array}$ & $20-30 \mathrm{~min}$ \\
\hline 10 & $\begin{array}{l}\text { Cool down for extraction (depends on lab } \\
\text { temp) }\end{array}$ & $1-2 \mathrm{~h}$ \\
\hline 11 & Cooling to room temp & $6 \mathrm{~h}+$ to Overnight \\
\hline 12 & Freezing $\left(-5^{\circ} \mathrm{F}\right)$ or $\left(-15^{\circ} \mathrm{C}\right)$ & $3-5 \mathrm{~h}$ to Overnight \\
\hline 13 & Sawing and Coring & $35-40 \mathrm{~min}$ \\
\hline 14 & Getting wet SSD weight & $5 \mathrm{~min}$ \\
\hline 15 & Drying Core & Overnight \\
\hline 16 & Dry weight & $2 \min$ \\
\hline 17 & Obtain MRD & $25 \mathrm{~min}$ \\
\hline
\end{tabular}




\subsubsection{Testing preparation}

Testing preparation refers to the time consumed preparing the physical cored specimens for testing. Ideally once the samples are prepared they are ready for final simple performance testing. The steps involved in testing preparation have been summarized below in Table 2:

Table 2: Testing Activity Time Requirements

\begin{tabular}{|c|c|c|}
\hline \multicolumn{2}{|c|}{ Lab Activities for Testing Preparation } & \multirow{2}{*}{$\begin{array}{l}\begin{array}{l}\text { Estimated } \\
\text { Required }\end{array} \\
\begin{array}{l}5 \mathrm{~min} \text { per } \\
\text { side }\end{array} \\
\end{array}$} \\
\hline 1 & Glue on female type LVDT holder stud & \\
\hline 2 & $\begin{array}{l}\text { Curing Epoxy resin to } 75 \% \text { strength to } \\
\text { insure stability }\end{array}$ & $1 \mathrm{~h}-4 \mathrm{~h}$ \\
\hline 3 & Mounting LVDT brackets & $10 \mathrm{~min}$ \\
\hline 4 & Installing LVDT's in brackets & $10 \mathrm{~min}$ \\
\hline 5 & $\begin{array}{l}\text { Zeroing LVDT using an } \\
\text { oscilloscope }\end{array}$ & $\begin{array}{l}20 \mathrm{~min} / \\
\text { LVDT }\end{array}$ \\
\hline 6 & $\begin{array}{l}\text { Calibrating new zeroed range using } \\
\text { feeler gauges (set max range to } 0.022 ")\end{array}$ & $\begin{array}{l}20 \mathrm{~min} / \\
\text { LVDT }\end{array}$ \\
\hline 7 & $\begin{array}{l}\text { Purging nitrogen dewer and starting } \\
\text { chamber }\end{array}$ & $20 \mathrm{~min}$ \\
\hline 8 & $\begin{array}{l}\text { Pre heating or cooling specimens and } \\
\text { chamber }\end{array}$ & $2-5 \mathrm{~h}$ \\
\hline 9 & $\begin{array}{l}\text { Writing testing program for machine } \\
\text { control }\end{array}$ & $\begin{array}{l}20 \mathrm{~min}- \\
1 \mathrm{~h}\end{array}$ \\
\hline 10 & $\begin{array}{l}\text { Powering up the hydraulic power } \\
\text { unit and chiller }\end{array}$ & $15 \mathrm{~min}$ \\
\hline 11 & $\begin{array}{l}\text { Checking for specimen contact in } \\
\text { chamber }\end{array}$ & $5 \mathrm{~min}$ \\
\hline
\end{tabular}




\subsubsection{SPT Procedures}

Simple Performance Testing covers a wide range of tests and applications. Table 3 illustrates three tests and their estimated time requirements. These tests do not have a total time frame as they can range from days to weeks.

Table 3: SPT Procedure Time Requirements

\begin{tabular}{|l|l|l|}
\hline \multicolumn{2}{|c|}{ Simple Performance Testing Procedures } & $\begin{array}{l}\text { Estimated Time } \\
\text { Required }\end{array}$ \\
\hline \hline 1 & $\begin{array}{l}\text { Dynamic Modulus Testing for one temperature } \\
\text { all frequencies }\end{array}$ & $30 \mathrm{~min}$ \\
\hline 2 & $\begin{array}{l}\text { Dynamic Modulus Testing for five temperatures } \\
\text { all frequencies }\end{array}$ & $3-5$ days \\
\hline 3 & $\begin{array}{l}\text { Verification of Accuracy in Dynamic } \\
\text { Response Using Aluminum Cylinder }\end{array}$ & $30-180 \mathrm{~min}$ \\
\hline
\end{tabular}

\subsubsection{Pre-Test Sample Conditioning}

In most testing environments samples need to be conditioned. Samples are conditioned for many reasons. The two main reasons for conditioning a sample are to achieve stable temperature throughout the specimen, as well as to ensuring the specimen is capable of producing a good response wave to frequencial loading. The amount of time it takes to achieve temperature stability has many controlling variables. These variables include specimen size, chamber heating and coolong capacity as well as sample surface area. It is important in sample testing that a sample be the same temperature through out, this can be assured through the use of an internal temperature probe placed in a dummy sample. In the testing involved in this paper samples were brought to their desired set points in 2 to 5 hours. In general the larger the temperature gradient between the desired specimen temperature and room temperature the longer the conditioning would 
take. It should also be noted that cooling samples often takes longer than heating. In the research presented samples were cooled using liquid nitrogen, although this is a significantly more expensive operating experience, liquid nitrogen is capable of cooling samples much quicker than conventional refrigeration devices. The specimens in this paper were conditioned by applying a small repeated load at the highest testing frequency selected for each testing category for a minimum of 200 cycles before testing.

\subsubsection{Sample Preparation Weigh Cards}

The samples prepared for this paper have been made to strictly conform to the following weigh cards which have been generated with the help of past research and optimization from (Fung 2007.). The samples were prepared by sieving all the materials to each of their respective sizes rather than generally scooping materials in the fine spectrum during the weighing process. All materials were precisely sieved and weighed to ensure reproducibility as well as to insure that any material performance differences discovered between each of the mineral fillers was caused by the fillers and not by any mix variability. The specific values can be found for each of the five mixes in the weigh cards shown in Tables $4-7$. 
Table 4: Control Mix Weigh Card

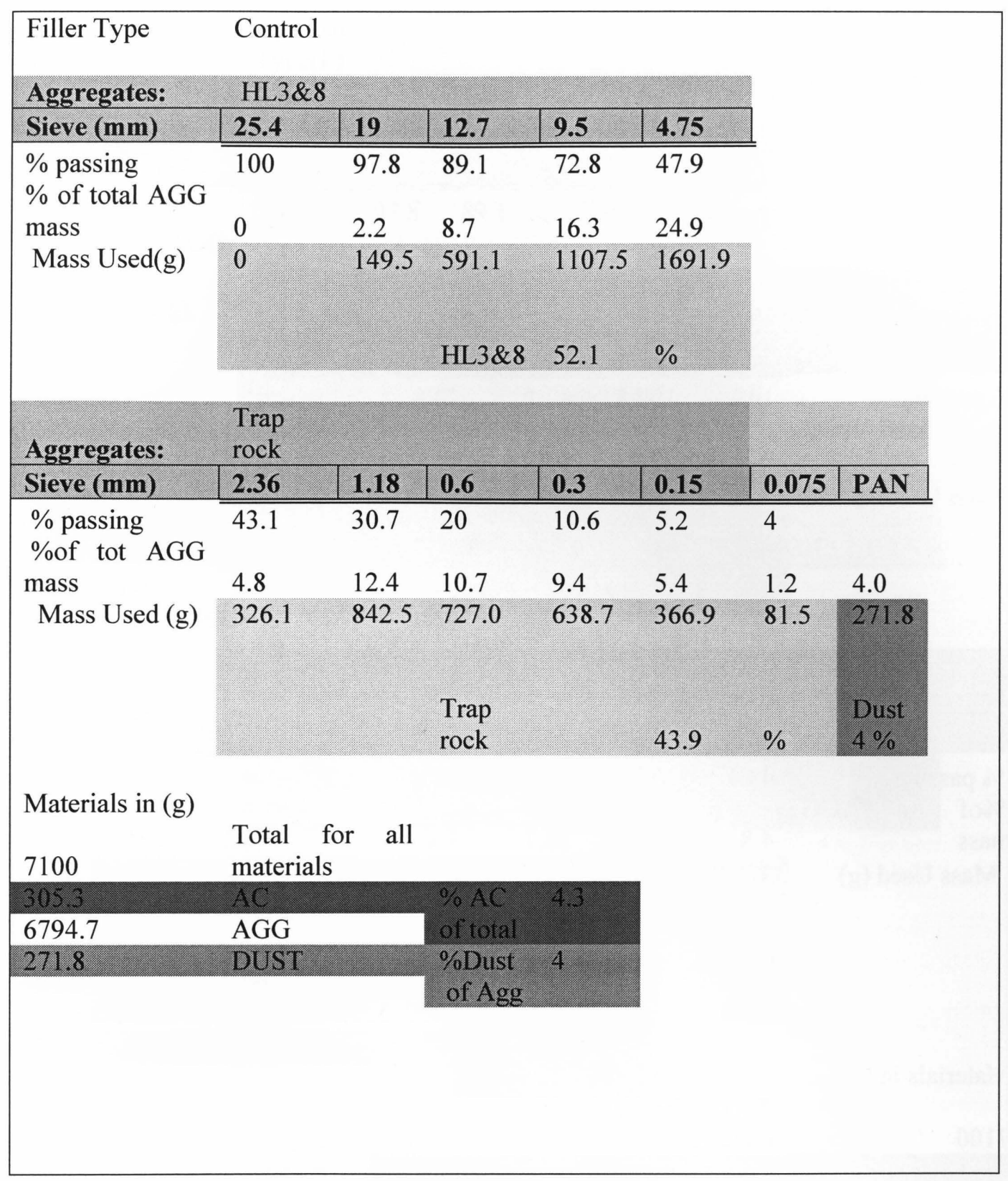


Table 5: $\quad$ Fly Ash Type C Mix Weigh Card

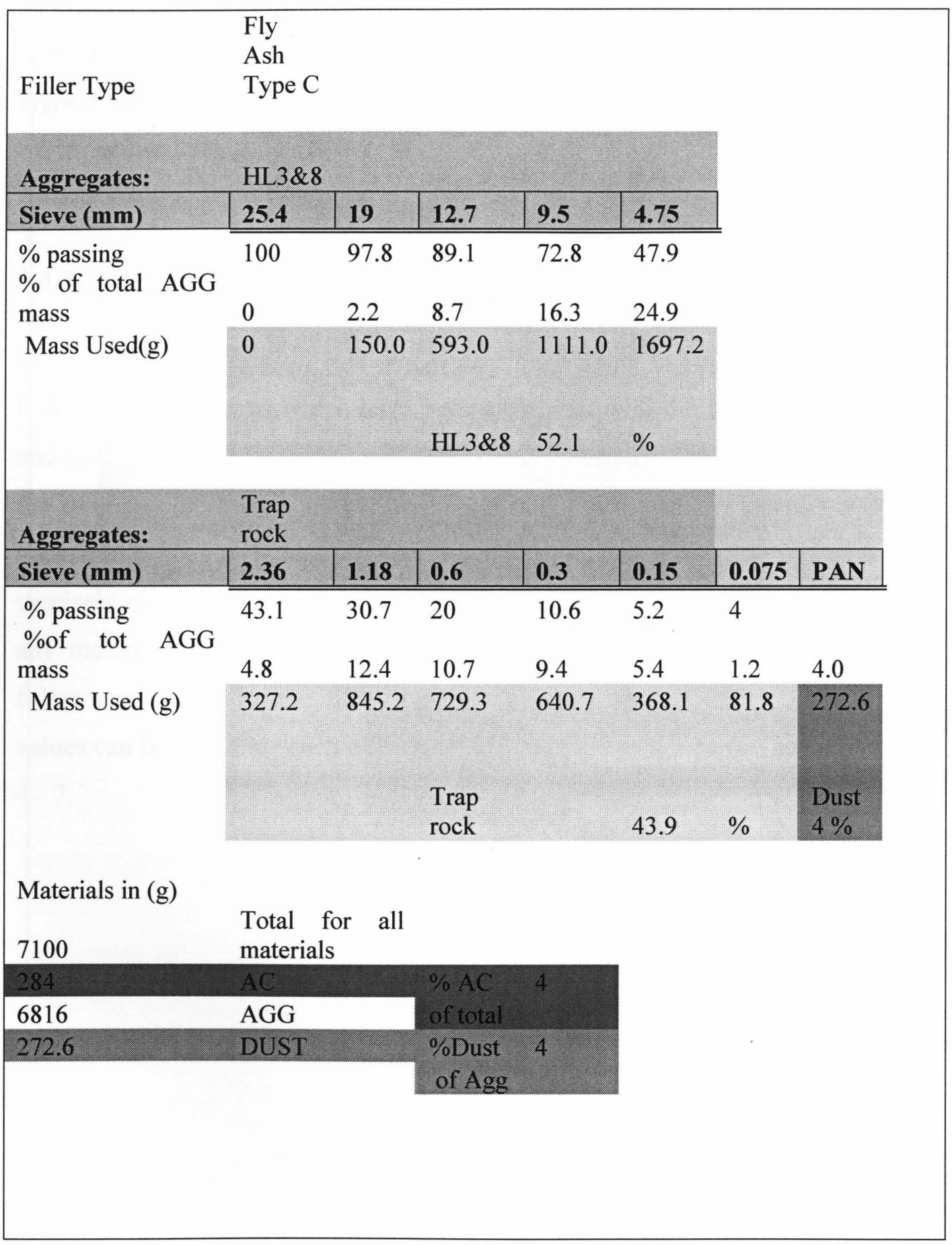


Table 6: Fly Ash Type F Mix Weigh Card

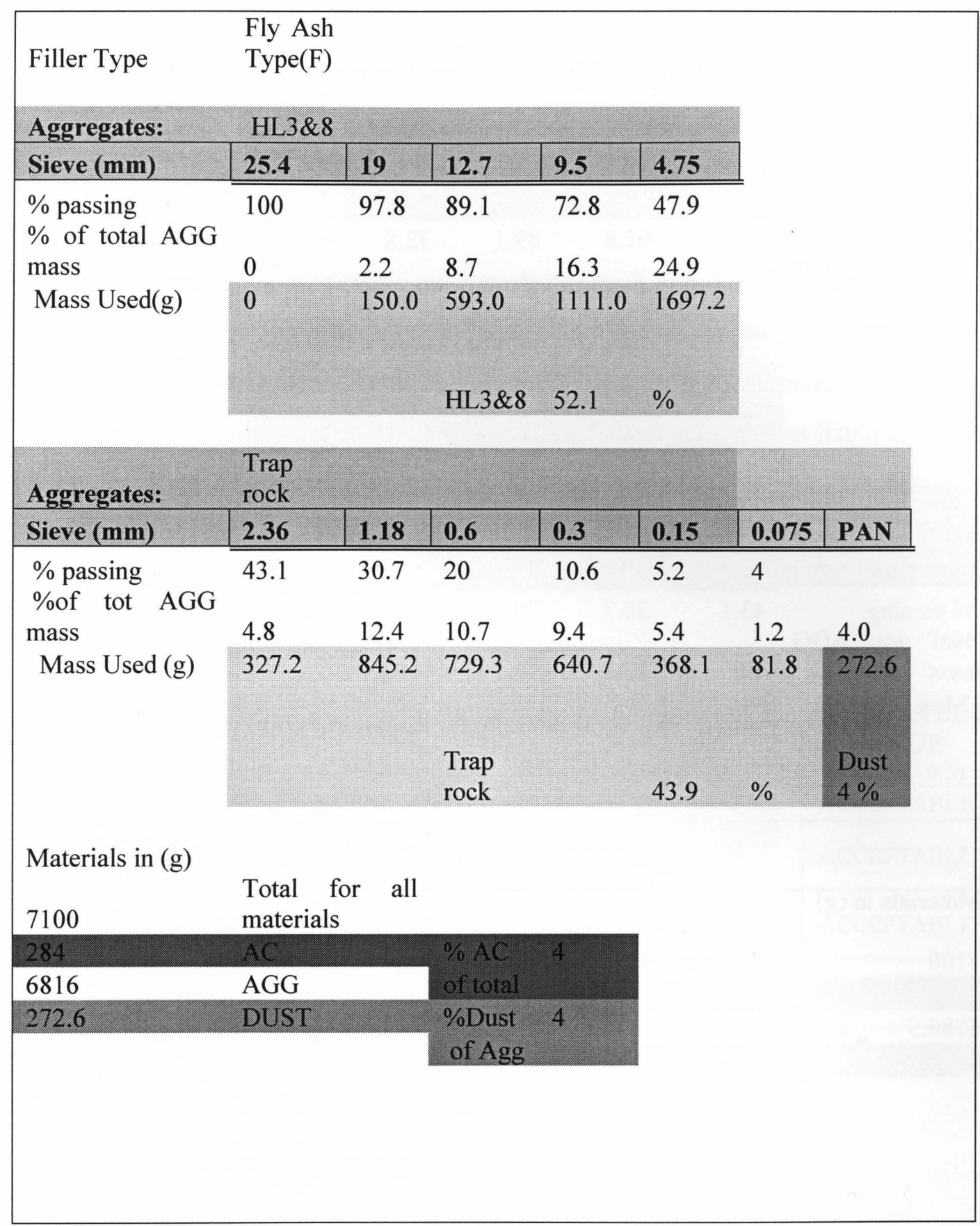


Table 7: $\quad$ Portland Cement Mix Weigh Card

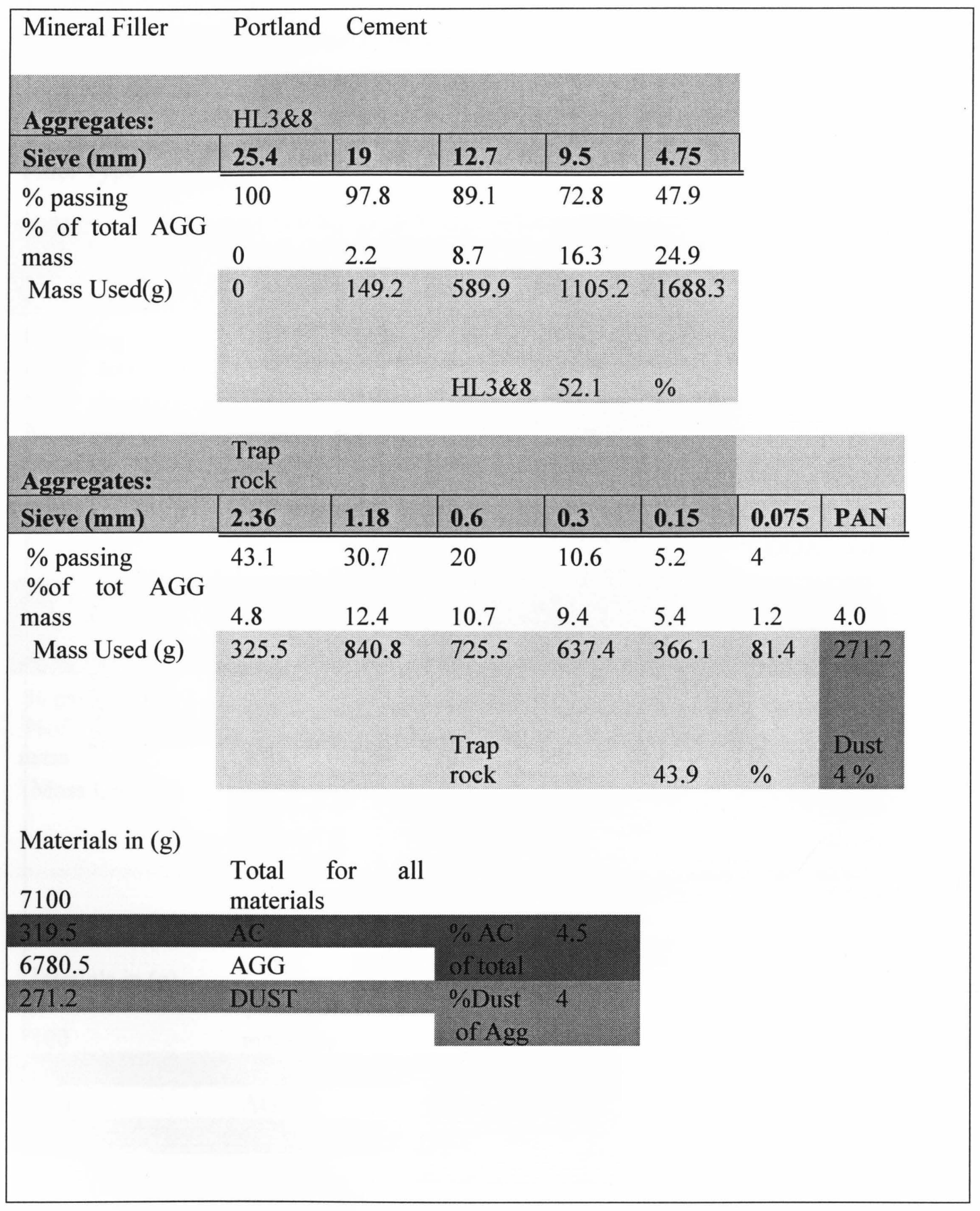




\section{H A P T E R 4}

\section{RESULTS AND ANALYSIS}

\subsection{Mix Properties}

In this program three specimens were made for each mix, one was used to assure compliance in terms of air void content and the other two were tested to determine dynamic modulus values. Table 8 shows the specific mix characteristics of the samples tested in terms of MRD, BRD and Air Voids. The values listed in Table 8 are the average of two specimens. The test variation between the two test samples was small.

Table 8 Mix Properties

\begin{tabular}{|c|c|c|c|c|c|c|}
\hline & AC (\%) & BRD & MRD & $\begin{array}{c}\text { Average Air } \\
\text { Void (\%) }\end{array}$ & $\begin{array}{c}\text { Puck } \\
\text { Reference }\end{array}$ & $\begin{array}{c}\text { ACCEPATBLE } \\
\text { RANGE } \\
(4.0 \%+/-0.5)\end{array}$ \\
\hline Control & 4.5 & 2.477 & 2.584 & 4.14 & 3 CON & ACCEPTABLE \\
\hline $\begin{array}{c}\text { Portland } \\
\text { Cement }\end{array}$ & 4.7 & 2.481 & 2.582 & 3.92 & $3 \mathrm{PC}$ & ACCEPTABLE \\
\hline $\begin{array}{c}\text { Fly Ash } \\
\text { (Type C) }\end{array}$ & 4.2 & 2.483 & 2.588 & 4.05 & $3 \mathrm{FAC}$ & ACCEPTABLE \\
\hline $\begin{array}{c}\text { Fly Ash } \\
\text { (Type F) }\end{array}$ & 4.2 & 2.471 & 2.578 & 4.15 & 3FAF & ACCEPTABLE \\
\hline
\end{tabular}

\subsubsection{Results from SPT Testing}

The experimental results are listed in Tables 9 through 12. These tables depict the test temperatures as well as the corresponding mixture performance as observed through each materials unique dynamic moduli. Mixture performance and dynamic moduli were correlated as the hardness of an HMA mixture relates to its integrity regarding fatigue and rutting. High dynamic modulus values were 
obtained from the testing of harder mixes at lower temperatures. These results imply that the sample may be less capable of resisting fatigue. Where as, lower dynamic moduli from soft mixes portrays an HMA sample that may be more inclined to resist fatigue.

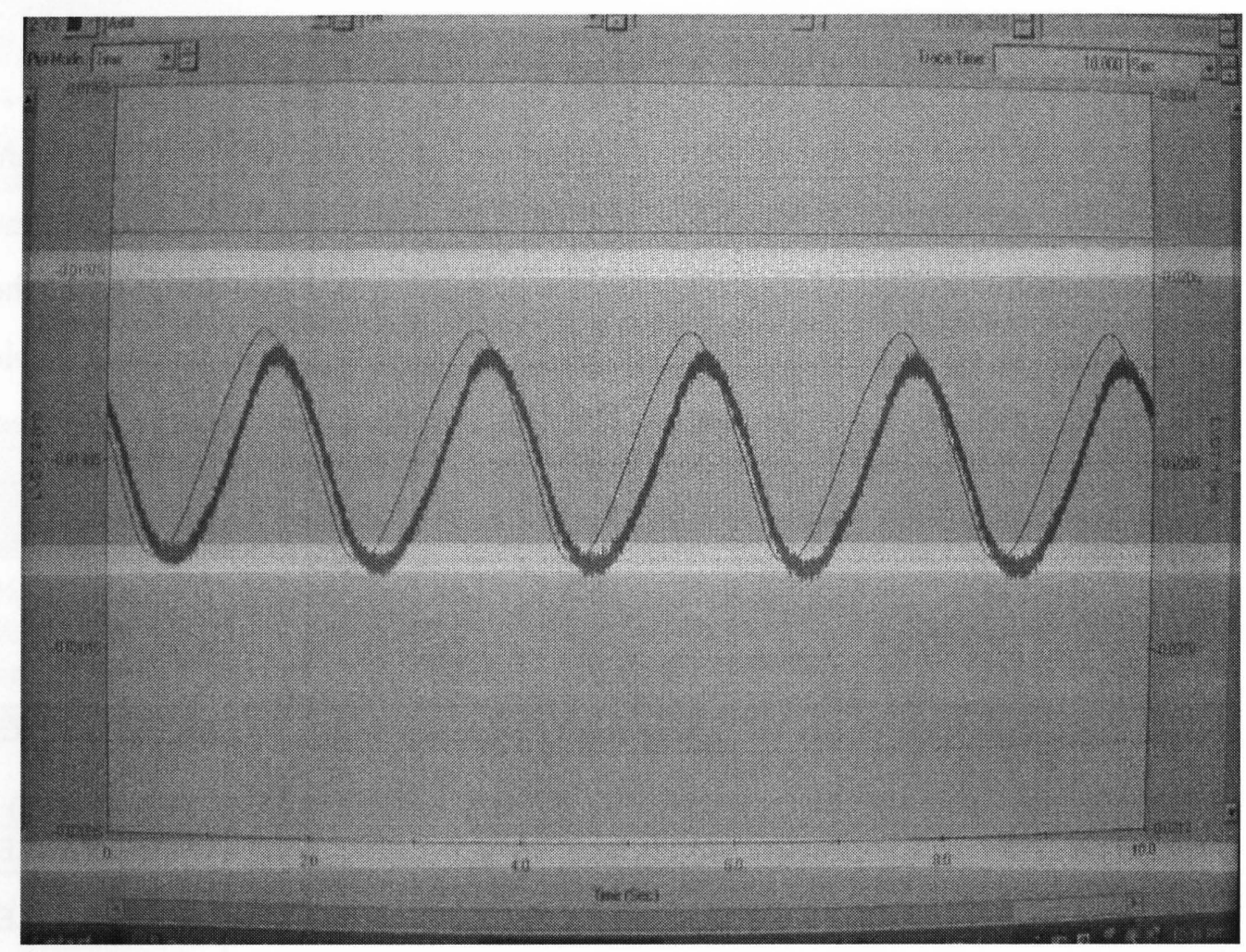

Figure 4.1: Load vs. AVG displacement

The testing pursued for the purposes of this paper has produced a waveform very similar to the ideal wave shown in Figure 4.2. This figure depicts the load and the average LVDT displacement reading for one of the test specimens. Fig 4.1 depicts the actual monitor showing the impulse generated during an actual test. The load is shown as the thin red line in lb- $\mathrm{ft}$ and the displacement is the thicker red line displayed in inches. The scales have been adjusted to yield adequate visual demonstrative performance. 

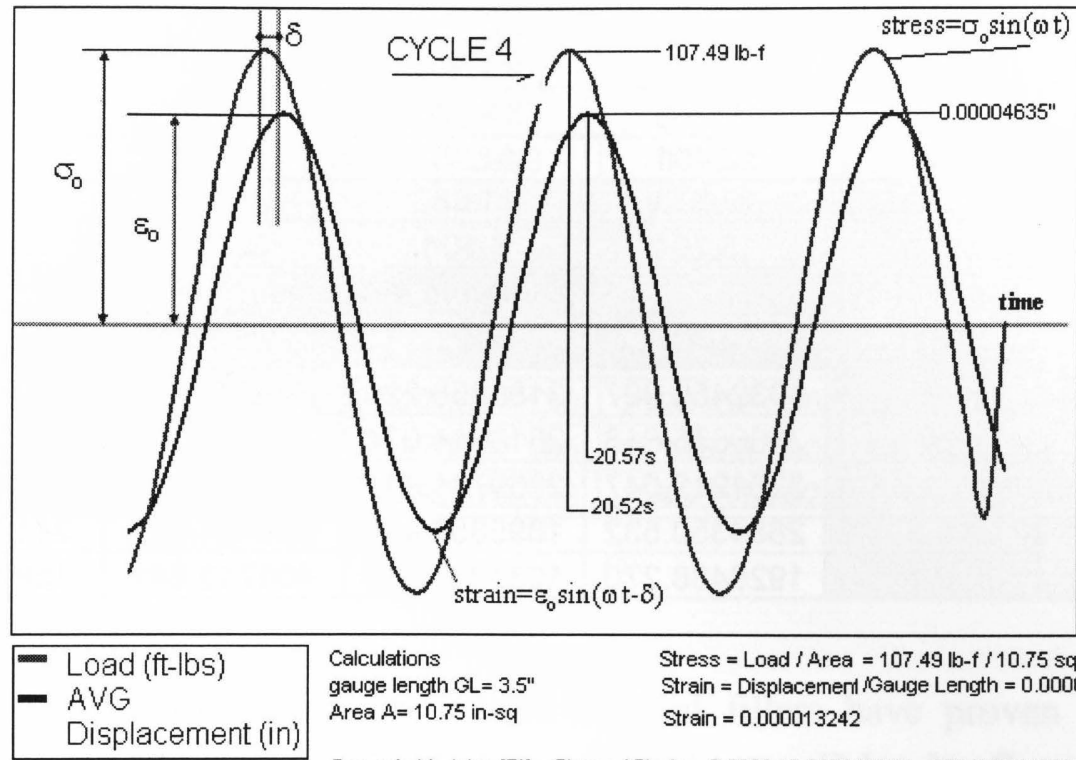
Calculations gauge lencth $\mathrm{GL}=3.5^{\prime \prime}$
Area $\mathrm{A}=10.75 \mathrm{in}-\mathrm{sq}$

Stress $=$ Load $/$ Area $=107.49 \mathrm{lb}-\mathrm{f} / 10.75 \mathrm{sq}$.in $=9.9990$ Strain $=$ Displacemen/Gauge Length $=0.00004635 / 3.5$

Strain $=0.000013242$

Dynamic Modulus $\left[\mathrm{E}^{\star}\right]=$ Stress $/$ Strain $=9.9990 / 0.000013242=755,048.5437 \mathrm{lb} / \mathrm{sq}$.in (psi) $755,048.5437 \mathrm{lb} / \mathrm{sq}$.in (psi) $=5205876.232015 \mathrm{kPa}=5.20 \mathrm{GPa}$

*Please refer to Appendix A for a bigger version of these calculations.

Figure 4.2 Solved Example for One Data Set

Table 9: Control Mix Dynamic Moduli

\begin{tabular}{|c|c|c|c|c|c|}
\hline \multirow{2}{*}{$\begin{array}{l}\text { Mineral } \\
\text { Filler Type } \\
\text { (CONTROL) }\end{array}$} & \multirow{2}{*}{$\begin{array}{c}\text { Frequency } \\
(\mathrm{Hz})\end{array}$} & \multicolumn{4}{|c|}{ Dynamic Modulus (GPa) } \\
\hline & & $-9^{\circ} \mathrm{C}$ & $4.4^{\circ} \mathrm{C}$ & $21.1^{\circ} \mathrm{C}$ & $37.8^{\circ} \mathrm{C}$ \\
\hline \multirow{12}{*}{$\begin{array}{l}\text { Bypass } \\
\text { Dust } \\
\text { Passing } \\
0.75 \mu \mathrm{m} \\
\text { Sieve }\end{array}$} & 10 & 20.029 & 16.047 & 4.914 & 3.108 \\
\hline & 5 & 18.428 & 14.404 & 4.197 & 2.665 \\
\hline & 1 & 15.075 & 13.019 & 3.722 & 2.336 \\
\hline & 0.5 & 13.791 & 12.360 & 3.311 & 2.100 \\
\hline & 0.1 & 9.694 & 9.454 & 2.637 & 1.852 \\
\hline & \multicolumn{5}{|c|}{$\begin{array}{c}\text { Dynamic } \\
\text { Modulus (psi) }\end{array}$} \\
\hline & $(\mathrm{Hz})$ & $-9^{\circ} \mathrm{C}$ & $4.4^{\circ} \mathrm{C}$ & $21.1^{\circ} \mathrm{C}$ & $37.8^{\circ} \mathrm{C}$ \\
\hline & 10 & 2906936.497 & 2328977.323 & 713185.343 & 451155.959 \\
\hline & 5 & 2674561.577 & 2090555.982 & 609160.059 & 386792.304 \\
\hline & 1 & 2188015.216 & 1889555.410 & 540223.912 & 339042.859 \\
\hline & 0.5 & 2001580.476 & 1793928.569 & 480571.126 & 304771.270 \\
\hline & 0.1 & 1406962.565 & 1372123.033 & 382676.606 & 268770.750 \\
\hline
\end{tabular}


Table 10: Fly Ash Type F Mix Dynamic Moduli

\begin{tabular}{|c|c|c|c|c|c|}
\hline \multirow{2}{*}{$\begin{array}{l}\text { Mineral } \\
\text { Filler Type }\end{array}$} & \multirow{2}{*}{$\begin{array}{c}\text { Frequency } \\
(\mathrm{Hz})\end{array}$} & \multicolumn{4}{|c|}{ Dynamic Modulus (GPa) } \\
\hline & & $-9^{\circ} \mathrm{C}$ & $4.4^{\circ} \mathrm{C}$ & $21.1^{\circ} \mathrm{C}$ & $37.8^{\circ} \mathrm{C}$ \\
\hline \multirow{12}{*}{$\begin{array}{l}\text { Fly Ash } \\
\text { Type F } \\
\text { Passing } \\
0.75 \mu \mathrm{m} \\
\text { Sieve }\end{array}$} & 10 & 27.784 & 21.913 & 9.620 & 5.302 \\
\hline & 5 & 25.263 & 18.009 & 7.985 & 3.597 \\
\hline & 1 & 22.401 & 14.261 & 5.750 & 2.445 \\
\hline & 0.5 & 19.873 & 11.683 & 4.192 & 1.454 \\
\hline & 0.1 & 13.294 & 7.104 & 3.216 & 1.091 \\
\hline & Frequency & \multicolumn{4}{|c|}{ Dynamic Modulus (psi) } \\
\hline & $(\mathrm{Hz})$ & $-9^{\circ} \mathrm{C}$ & $4.4^{\circ} \mathrm{C}$ & $21.1^{\circ} \mathrm{C}$ & $37.8^{\circ} \mathrm{C}$ \\
\hline & 10 & 4032459.987 & 3180358.226 & 1396204.977 & 769482.410 \\
\hline & 5 & 3666675.646 & 2613814.074 & 1158937.761 & 522002.237 \\
\hline & 1 & 3251219.047 & 2069781.419 & 834599.460 & 354847.937 \\
\hline & 0.5 & 2884350.532 & 1695657.410 & 608424.895 & 211007.903 \\
\hline & 0.1 & 1929488.270 & 1031080.949 & 466713.241 & 158390.423 \\
\hline
\end{tabular}

Table 11: Portland Cement Mix Dynamic Moduli

\begin{tabular}{|c|c|c|c|c|c|}
\hline \multirow{2}{*}{$\begin{array}{l}\text { Mineral } \\
\text { Filler Type }\end{array}$} & \multirow{2}{*}{$\begin{array}{c}\text { Frequency } \\
(\mathrm{Hz})\end{array}$} & \multicolumn{4}{|c|}{ Dynamic Modulus (GPa) } \\
\hline & & $-9^{\circ} \mathrm{C}$ & $4.4^{\circ} \mathrm{C}$ & $21.1^{\circ} \mathrm{C}$ & $37.8^{\circ} \mathrm{C}$ \\
\hline \multirow{12}{*}{$\begin{array}{l}\text { Type } 10 \\
\text { Portland } \\
\text { Cement } \\
\text { Passing } \\
0.75 \mu \mathrm{m} \\
\text { Sieve }\end{array}$} & 10 & 28.790 & 20.561 & 7.835 & 5.184 \\
\hline & 5 & 25.981 & 18.130 & 7.217 & 3.865 \\
\hline & 1 & 23.460 & 15.938 & 6.763 & 2.564 \\
\hline & 0.5 & 20.408 & 12.872 & 5.943 & 2.026 \\
\hline & 0.1 & 17.203 & 11.897 & 5.080 & 1.459 \\
\hline & Frequency & \multicolumn{4}{|c|}{ Dynamic Modulus (psi) } \\
\hline & $(\mathrm{Hz})$ & $-9^{\circ} \mathrm{C}$ & $4.4^{\circ} \mathrm{C}$ & $21.1^{\circ} \mathrm{C}$ & $37.8^{\circ} \mathrm{C}$ \\
\hline & 10 & 4178488.680 & 2984111.662 & 1137220.524 & 752410.043 \\
\hline & 5 & 3770880.060 & 2631404.692 & 1047510.190 & 560936.651 \\
\hline & 1 & 3404929.107 & 2313151.461 & 981532.766 & 372170.634 \\
\hline & 0.5 & 2961906.303 & 1868275.394 & 862540.683 & 294029.333 \\
\hline & 0.1 & 2496859.461 & 1726699.117 & 737368.436 & 211778.071 \\
\hline
\end{tabular}


Table 12: $\quad$ Fly Ash Type C Mix Dynamic Moduli

\begin{tabular}{|c|c|c|c|c|c|}
\hline \multirow{2}{*}{$\begin{array}{l}\text { Mineral } \\
\text { Filler Type }\end{array}$} & \multirow{2}{*}{$\begin{array}{c}\text { Frequency } \\
(\mathrm{Hz})\end{array}$} & \multicolumn{4}{|c|}{ Dynamic Modulus (GPa) } \\
\hline & & $-9^{\circ} \mathrm{C}$ & $4.4^{\circ} \mathrm{C}$ & $21.1^{\circ} \mathrm{C}$ & $37.8^{\circ} \mathrm{C}$ \\
\hline \multirow{12}{*}{$\begin{array}{l}\text { FLY ASH } \\
\text { Type C } \\
\text { Passing } \\
0.75 \mu \mathrm{m} \\
\text { sieve }\end{array}$} & 10 & 27.6260 & 19.7936 & 9.0136 & 4.5133 \\
\hline & 5 & 25.7096 & 17.6230 & 5.4624 & 3.6109 \\
\hline & 1 & 22.5342 & 14.5115 & 4.5668 & 3.3752 \\
\hline & 0.5 & 19.8363 & 11.8134 & 3.7999 & 2.2324 \\
\hline & 0.1 & 13.0399 & 10.6785 & 2.5297 & 1.6485 \\
\hline & Frequency & \multicolumn{4}{|c|}{ Dynamic Modulus (psi) } \\
\hline & $(\mathrm{Hz})$ & $-9^{\circ} \mathrm{C}$ & $4.4^{\circ} \mathrm{C}$ & $21.1^{\circ} \mathrm{C}$ & $37.8^{\circ} \mathrm{C}$ \\
\hline & 10 & 4009574.504 & 2872794.762 & 1308213.167 & 655046.539 \\
\hline & 5 & 3731436.285 & 2557757.652 & 792796.779 & 524076.554 \\
\hline & 1 & 3270571.138 & 2106162.336 & 662812.282 & 489865.994 \\
\hline & 0.5 & 2878992.185 & 1714575.900 & 551505.418 & 324010.112 \\
\hline & 0.1 & 1892576.338 & 1549851.782 & 367152.115 & 239263.603 \\
\hline
\end{tabular}

According to earlier research, certain mineral fillers have proven to be very beneficial in particular environments. A number of studies have concluded that fly ash makes a very good "asphalt extender", in particular according to (Suheihani 1986). Tables 11 and 13 show an increased modulus through a variety of temperatures. Unfortunately, the high dynamic values associated with the cooler temperatures imply the possibility of the material having fatigue problems. Generally, the more rigid the material at high temperature, the better it will resist rutting; and the more flexible at low temperature, the better it would resist fatigue. In this case, the two fly ash mixes show high modulus values in the cold side of the spectrum and thus would mean they may have low performance in terms of fatigue.

Tables 9 through 12 shows the results for the entire range of mineral fillers used. It appears that Type F Fly ash demonstrated higher dynamic modulus values when compared to Type $\mathrm{C}$ in colder temperatures and Type $\mathrm{C}$ yields higher dynamic modulus values in warmer temperatures. This phenomenon would lead to the belief that Type $\mathrm{C}$ fly ash will perform better in HMA in terms of rutting resistance. Higher dynamic modulus values at high frequency low temperature 
were observed in Type $\mathrm{F}$ when compared to Type $\mathrm{C}$. This leads to believe that Type C fly ash may be a better option than Class $\mathrm{F}$ in terms of fatigue.

\subsubsection{Mix Properties}

The results of this report were consistent with those done earlier at Ryerson. According to (Fung, 2008) the material performance displayed through the dynamic modulus testing conducted here appears to be in harmony of the TSR values performed by (Fung, 2008). According to Fig 4.4 below the substitution of fly ash leads in terms of tensile strength followed by Portland cement and tailed by the control mix. This increase in tensile strength can be seen through the increase present in the dynamic modulus values shown in Tables 10 to 13.

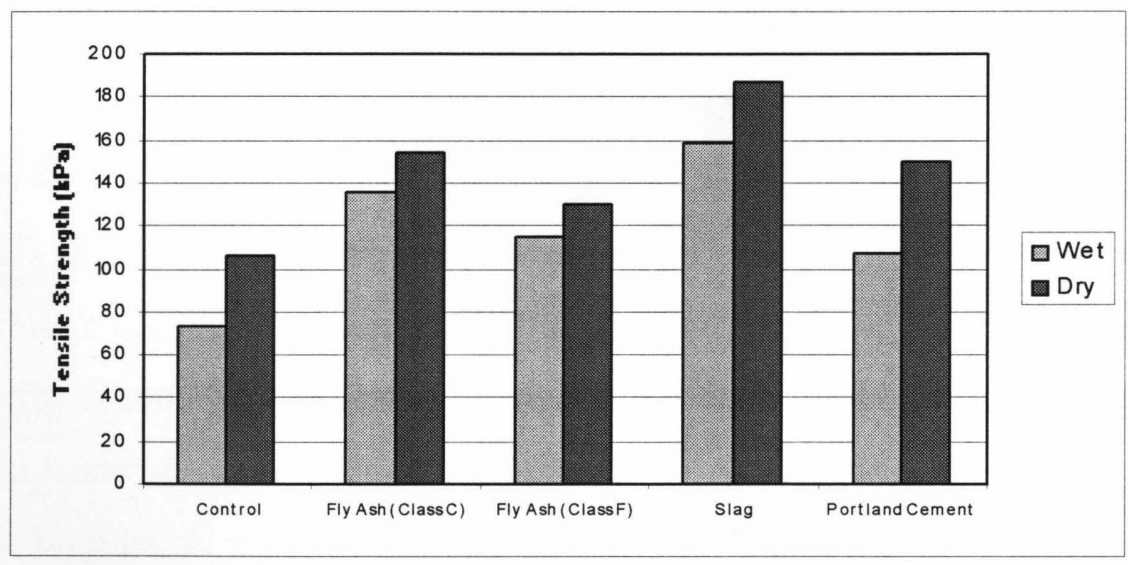

Figure 4.3 Indirect Tensile Strength Test Results (Fung, 2008).

Similar to the indirect tensile strengths shown in Fig 4.3 the TSR values shown here in Fig 4.4 also show an increase in performance when fly ash is used over both the control sample as well as the Portland cement sample. It appears that the TSR values indicate a slightly higher strength in Type F fly ash, where as in the dynamic modulus values it appears Type $\mathrm{F}$ fly ash yields slightly lower values in colder temperatures. However the results showed Fly Ash enhances the moisture 
susceptibility as well as the dynamic modulus of the mixtures tested when compared to bag house dust.

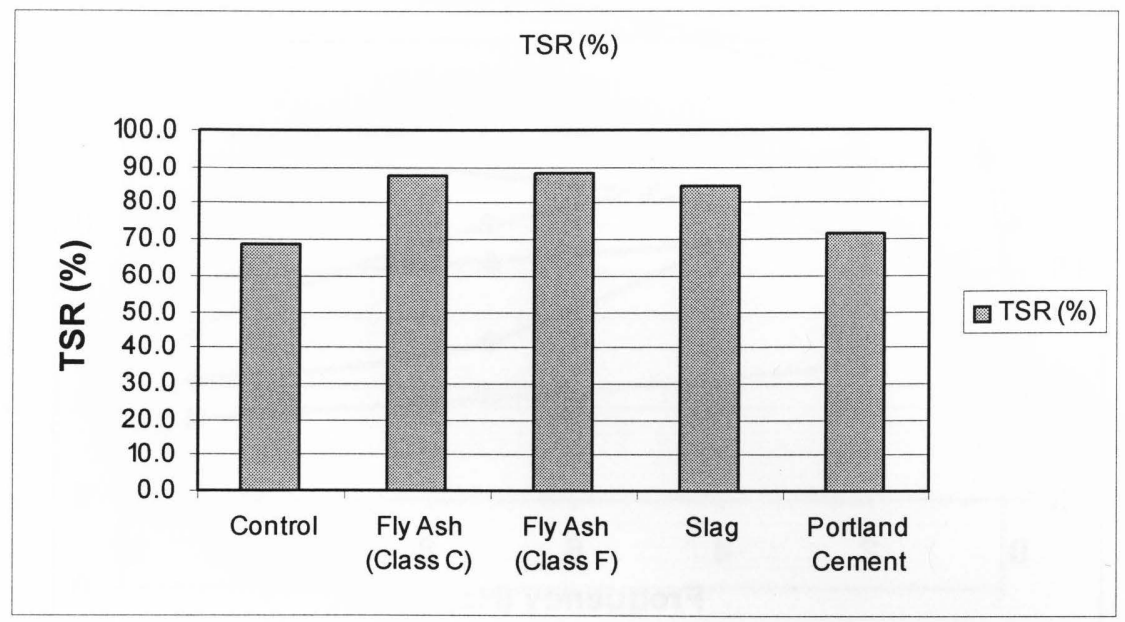

Figure 4.4: Tensile Strength Ratio Test Results (Fung,2008).

\subsubsection{Temperature and Frequency Effects on Filler Type}

Visco-elastic materials can be greatly affected by variations in temperature. As asphalt is visco-elastic it follows certain trends. For example, the warmer an HMA material the softer it is and the colder the stiffer. This phenomenon is visible in the following graphs. The graphs show the affect of mineral fillers on the performance of each unique specimen under temperature change. Figures 4.5 to 4.9 show the individual performance of each mix in different temperatures in terms of their dynamic moduli. 


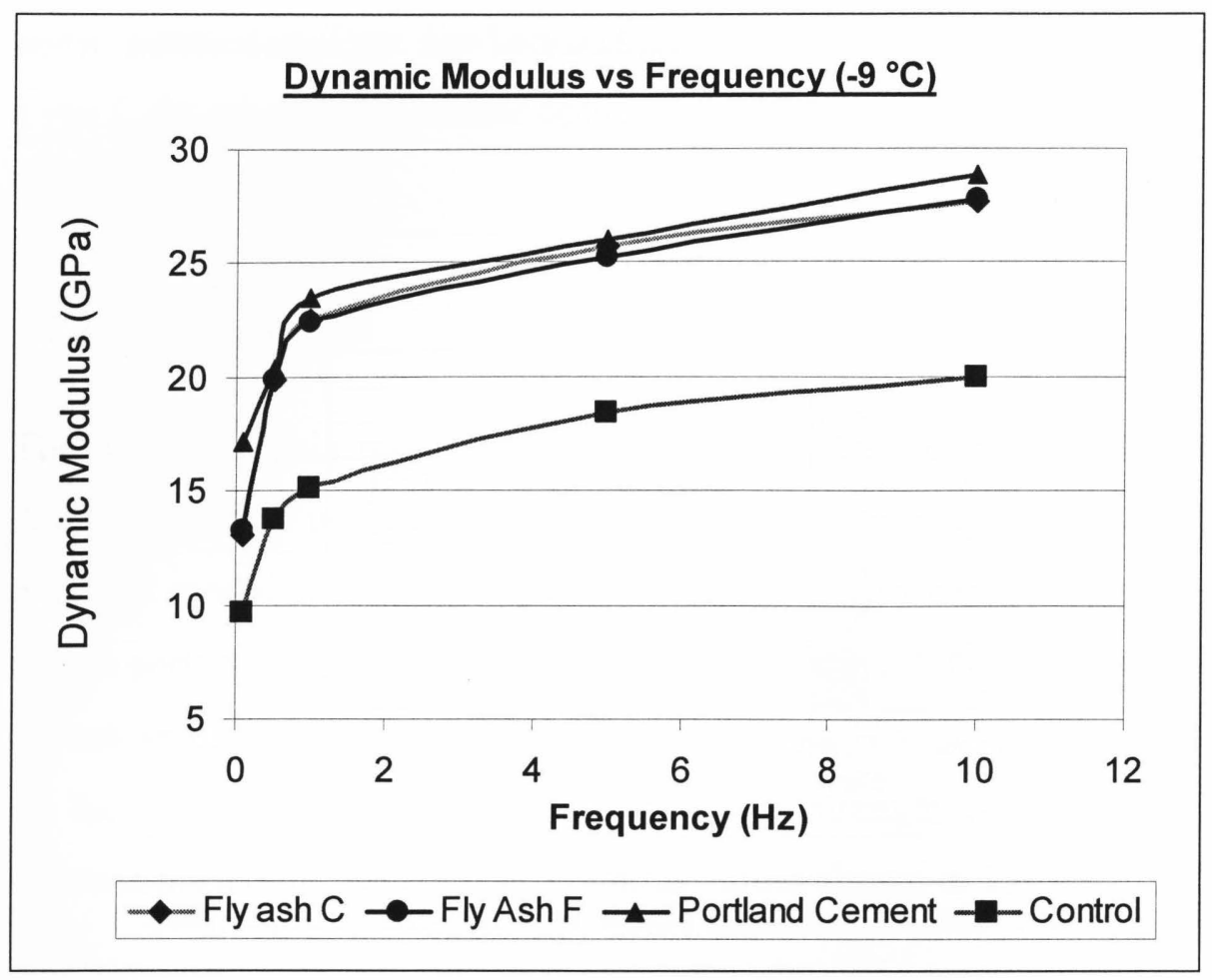

Fig 4.5: Dynamic Modulus vs. Frequency $\left(-9^{\circ} \mathrm{C}\right)$

\section{Dynamic Modulus vs Frequency $\left(4.4^{\circ} \mathrm{C}\right)$}

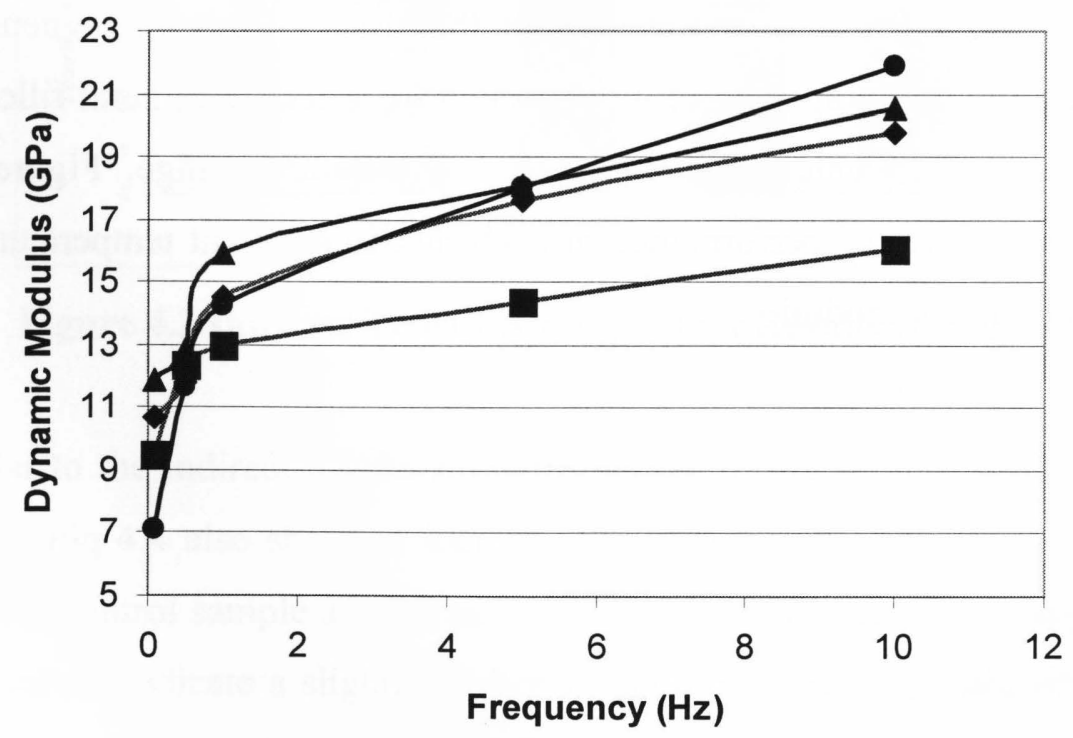

$\multimap$ Fly ash C $\rightarrow$ Fly Ash F $\rightarrow$ Portland Cement $\rightarrow$ - Control

Fig 4.6: Dynamic Modulus vs. Frequency $\left(4.4^{\circ} \mathrm{C}\right)$ 


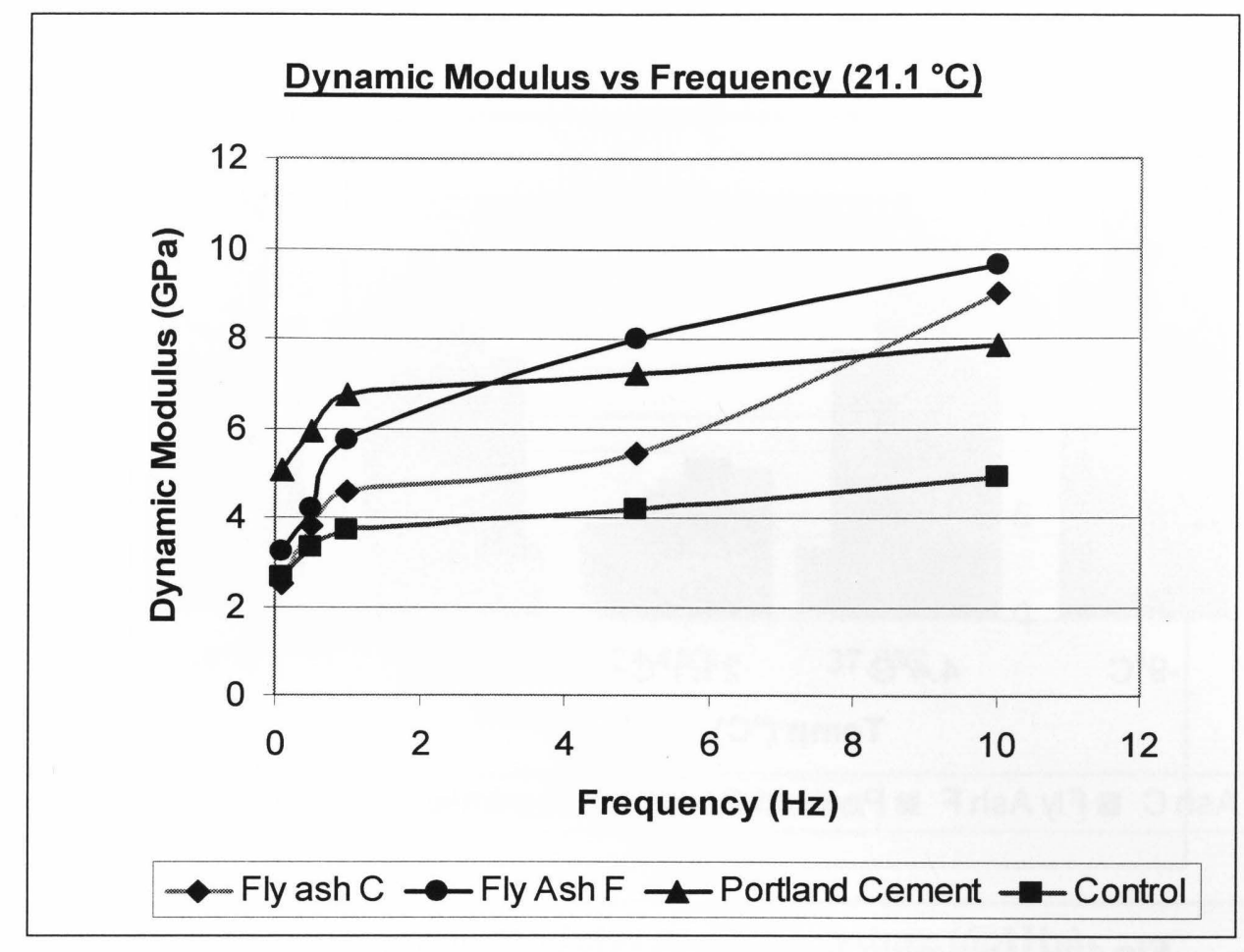

Fig 4.7: Dynamic Modulus vs. Frequency $\left(21.1^{\circ} \mathrm{C}\right)$

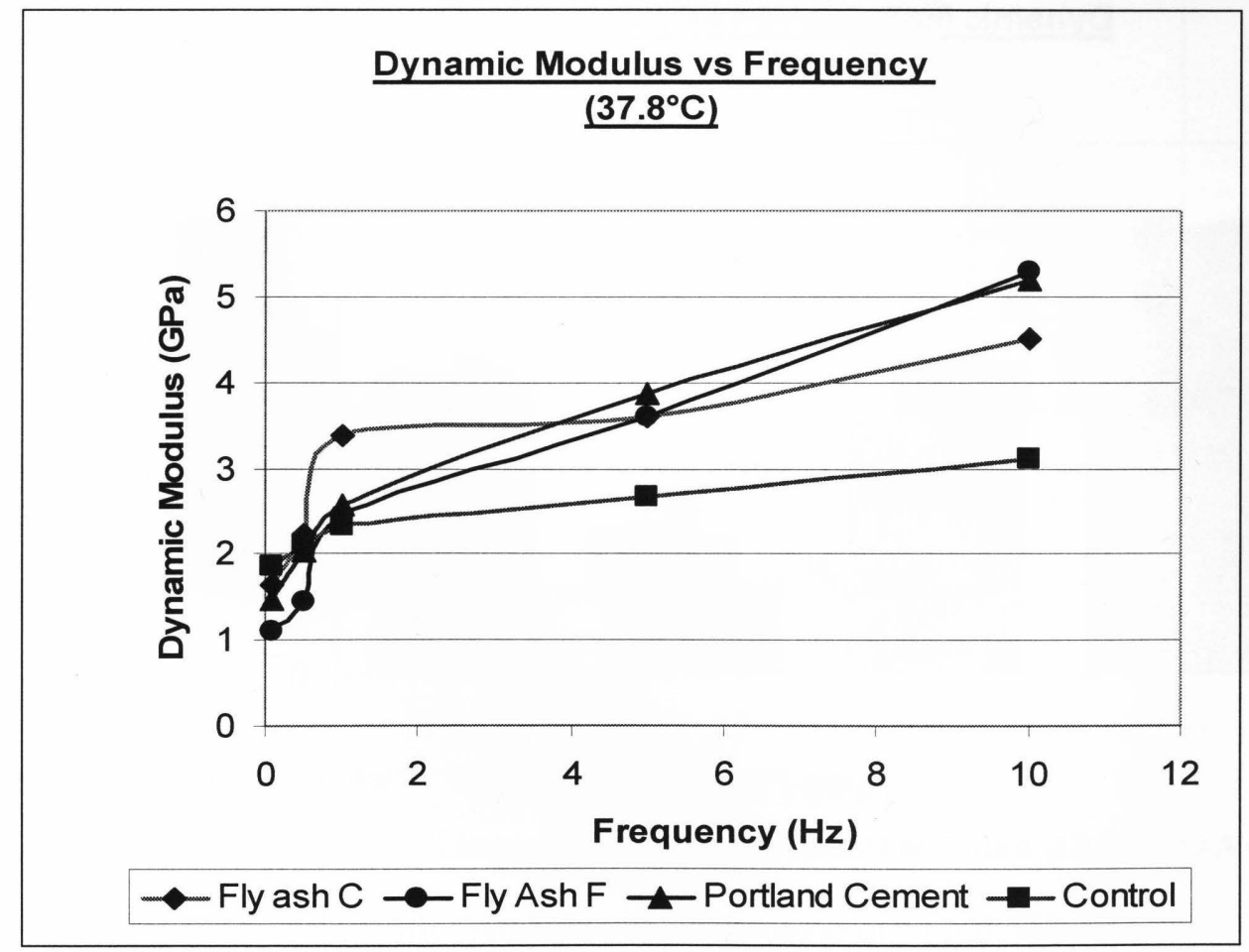

Fig 4.8: Dynamic Modulus vs. Frequency $\left(37.8^{\circ} \mathrm{C}\right)$ 


\section{Dynamic Modulus vs Temperature @10 $10 \mathrm{~Hz}$}

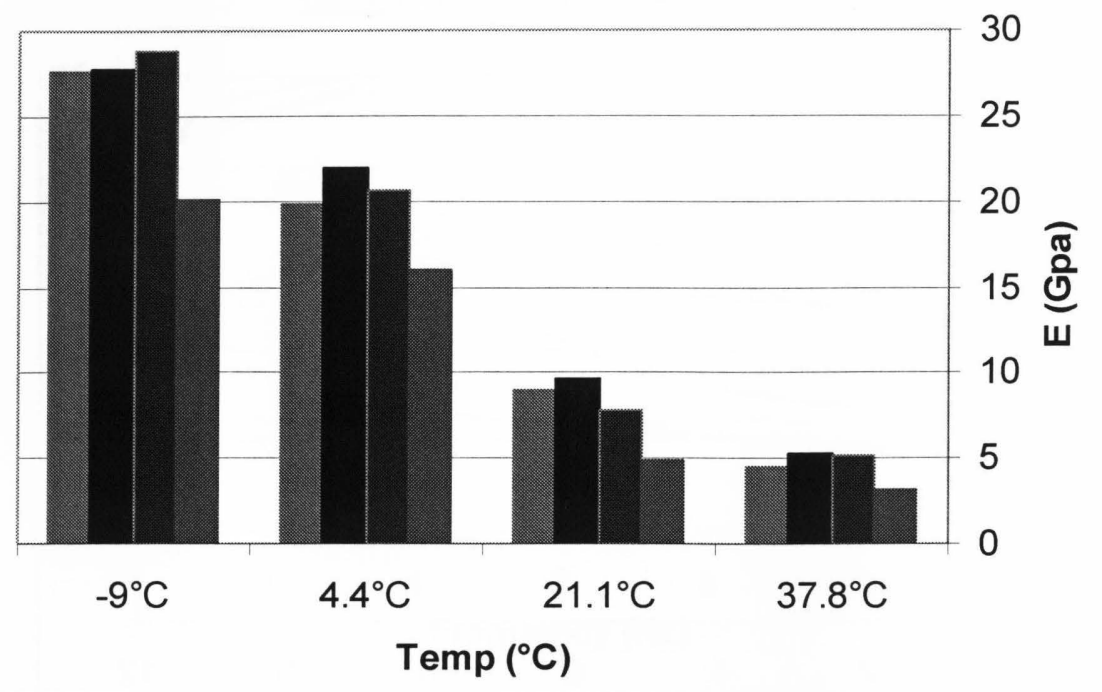

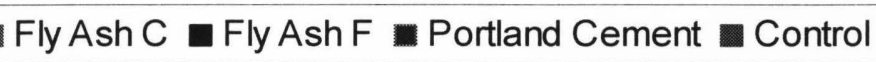

Fig 4.9: Dynamic Modulus vs. Temperature (@10Hz)

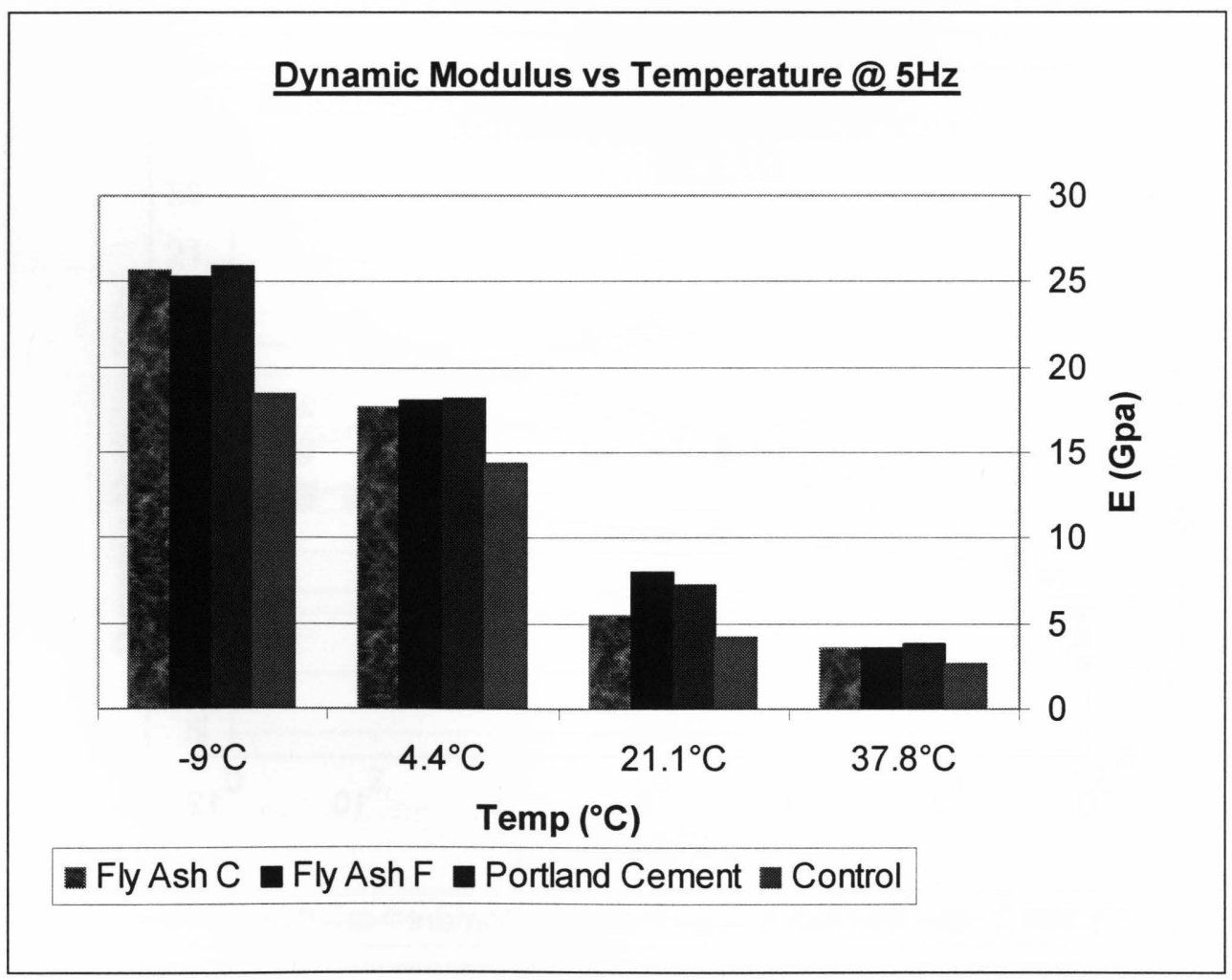

Fig 4.10: Dynamic Modulus vs. Temperature (@5Hz) 


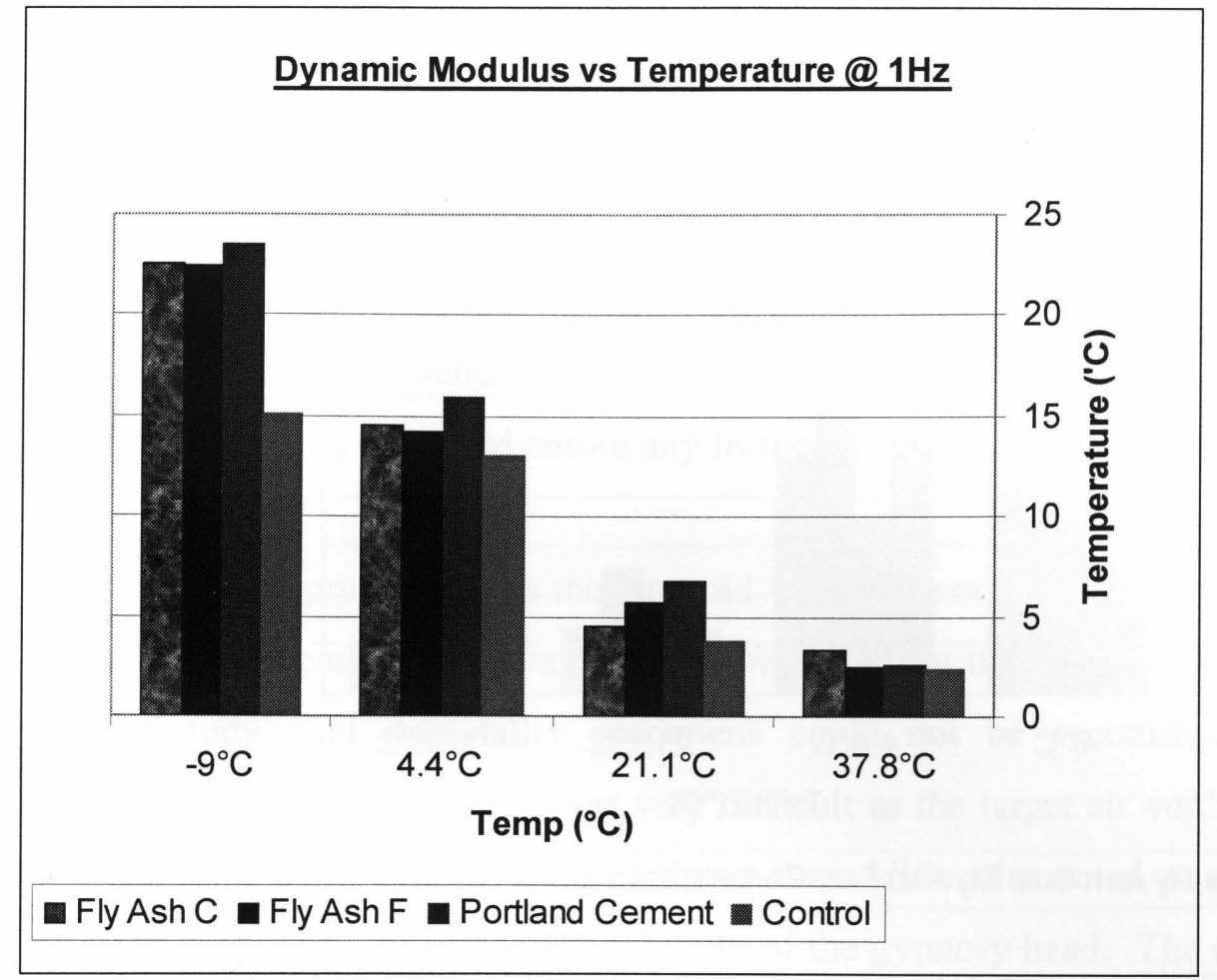

Fig 4.11: Dynamic Modulus vs. Temperature (@1Hz)

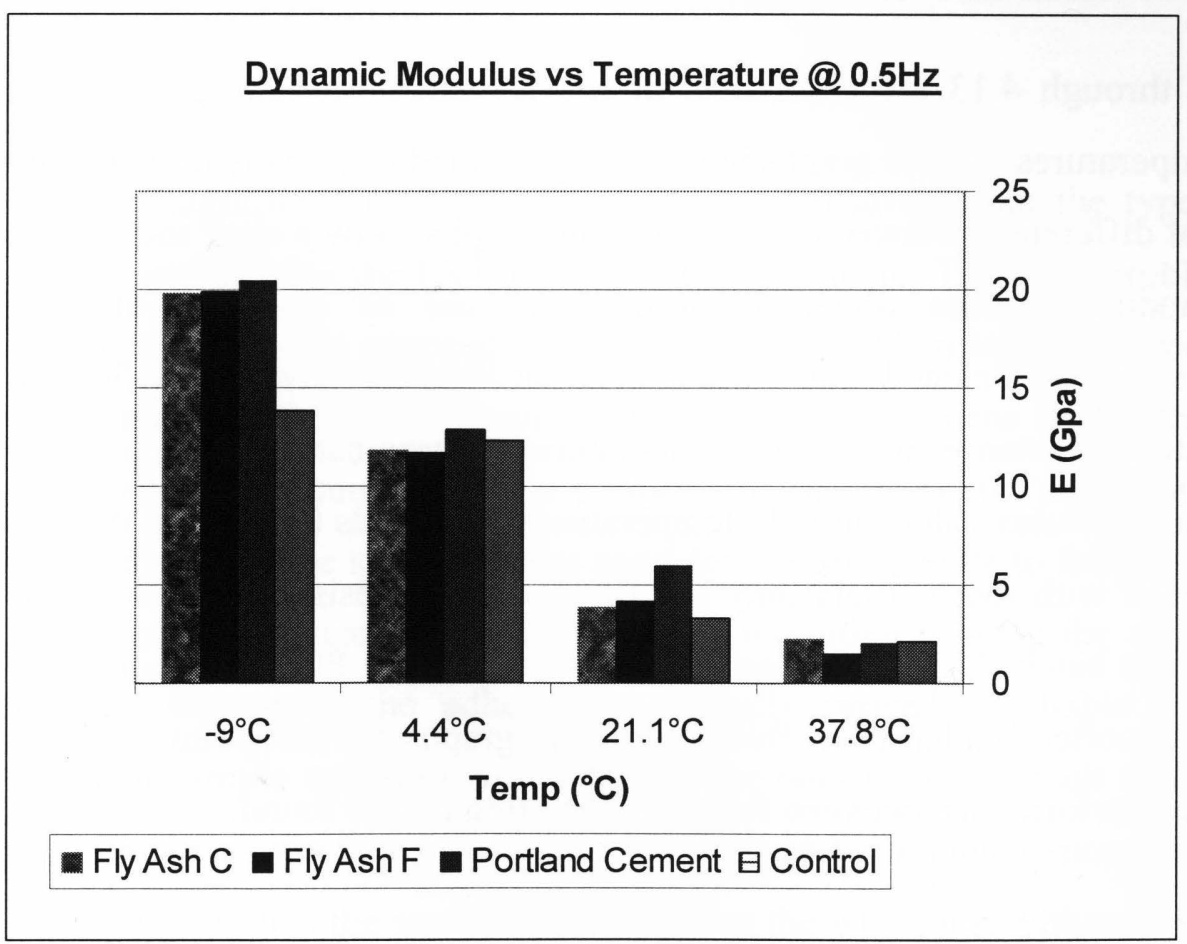

Fig 4.12: Dynamic Modulus vs. Temperature (@0.5Hz) 


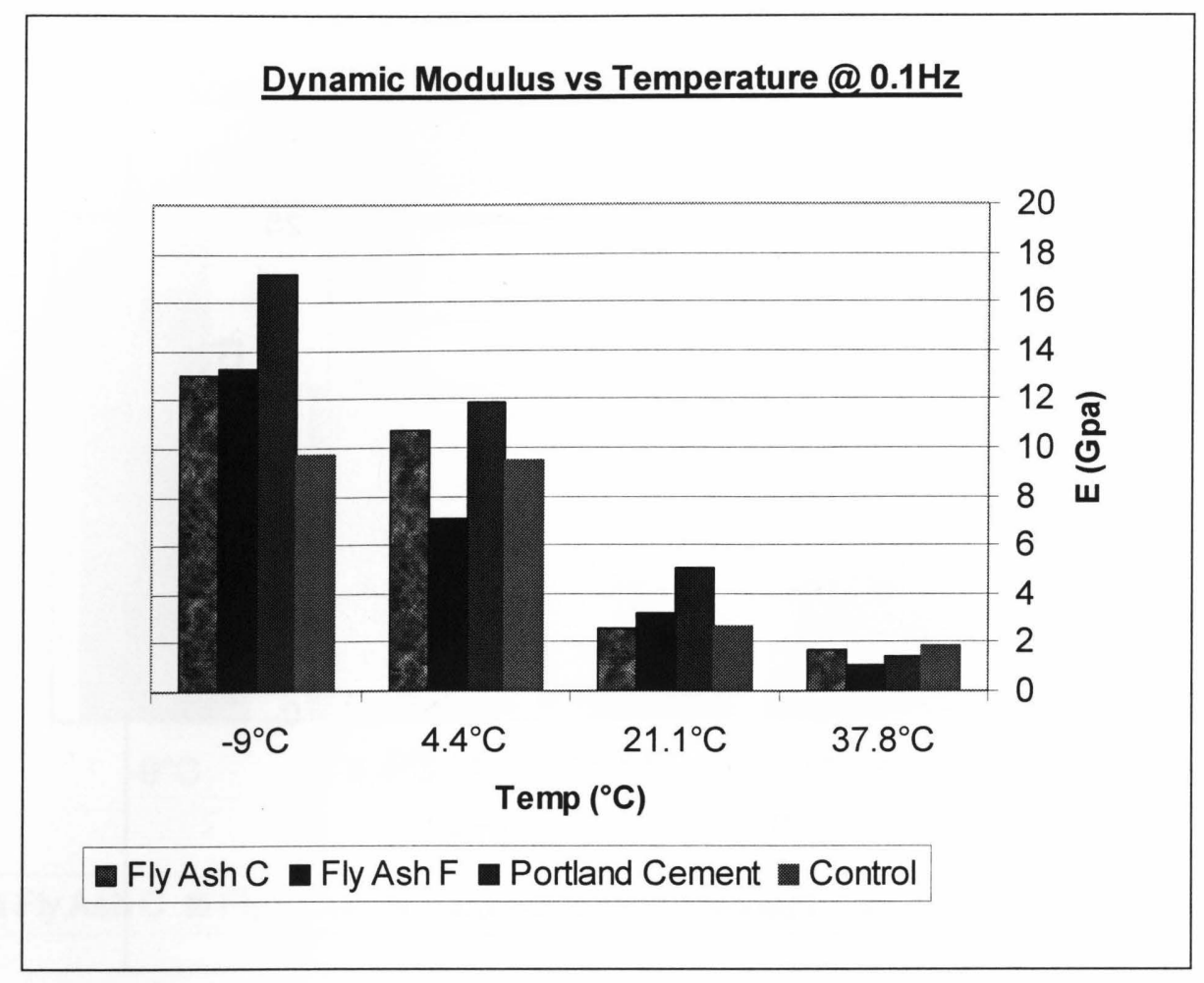

Fig 4.13: Dynamic Modulus vs. Temperature (@0.1Hz)

Figures 4.9 through 4.13 are depictions of the Dynamic Modulus readings at different temperatures. These graphs have been generated to visually demonstrate core material differences between each mix. The graphs show a clear increase in dynamic modulus values obtained through the use of Fly Ash at high temperatures. These elevated values are a sign that Fly Ash may be beneficial in terms of rutting resistance in extreme temperatures. These bar graphs also show high dynamic modulus values in cold temperatures, this lends to the idea that the materials made with these fillers may not be capable of resisting fatigue. The HMA materials batched in this research were all made with PG 58-28 binder, so the use of a softer binder may shift these bar graphs to the point where a compromised performance between fatigue and rutting can be found. 


\subsection{Limitations of Test Set-up}

Dynamic testing is often hindered by many small problems due to the unpredictable nature of the equipment and materials. This testing program and the equipment used for this study have experienced the same material and equipment limitation found by other researchers in the past. In this study many problems had to be corrected before any further research could continue.

The first of the problems was the Brovold Gyratory compaction device used for this testing. Due to limited availability, it was inherent that the system be applied to this study, and thus taller specimens could not be accommodated. The compaction process in general was very difficult as the target air void content of $4 \%$ was hard to achieve without applying the additional manual or mechanical compaction needed to facilitate the closure of the gyratory head. The mechanical compaction was performed by only one researcher which removed some variability; however some natural inconsistencies can never be completely eliminated.

Another significant problem with this program arose from the type of glue or epoxy used to affix the LVDT studs to the specimen. The main problem with the epoxy resin was the materials failure rate. The problem initially became apparent when many of the studs began breaking off the specimens before testing. Even when allowed to cure for longer periods than necessary, the adhesive holding the studs affixed to the specimen was considerably susceptible to failure. In addition, regardless of the care applied during the mounting process for ensuring not to damage the studs, the adhesive continually proved unreliable as the bonds between sample and stud would fail. The only positive result from the use of adhesives was the fact that if the LVDT could be mounted successfully without losing a stud, then the sample would survive the whole test without a stud failure. 
Comparatively speaking, the dynamic values obtained in this paper were deemed acceptable as they were similar to values obtained from related conducted research. According to the publications presented at the annual conference of the transportation association of Canada in 2006 by Ludomir Uzarowski and his group, the dynamic modulus values obtained therein for SP19 were very similar to the values obtained for the control mix used for this study. 


\section{H A P T E R 5}

\section{CONCLUSIONS \& RECOMMENDATIONS}

Based on the investigations conducted in this study, the conclusions are summarized as follows:

1. The test set-up developed to determine dynamic modulus values of HMA materials was successful in attaining dynamic modulus values for the mixtures tested in this program.

2. An inexpensive alternative was found for measuring axial deformations in the HMA specimens through the design and fabrication of specific LVDT holders and mounting hardware.

3. High temperature sag attenuation issues were addressed in this system through the modification of mounting hardware and the LVDT's used.

4. The production of specimens using the available gyratory compaction equipment was successful in attaining the required amount of air voids in each specimen.

5. A suitable method was developed for restraining and coring gyratory compacted HMA pucks to their desired dimension was successful.

6. The development of suitable end cutting process was successfully devised and applied to the specimens tested in this study.

7. The effect mineral fillers on asphalt mixtures was successfully demonstrated through the observed changes in dynamic modulus values obtained herein.

8. There was a noticeable increase in the dynamic modulus values obtained from testing the materials containing fly ash fillers.

9. Similar to the Fly Ash, Portland cement performed well in terms of rutting but it exhibited high dynamic modulus values at low temperature and high frequency which may lead to diminished performance in terms of fatigue. 
The test set-up was developed to determine dynamic modulus values of HMA materials. This set-up was successful in attaining dynamic modulus values for each mix design tested as the values obtained are reasonable when compared to values published by NCHRP report 465. An inexpensive alternative was found for the measurement of axial deformations in the HMA specimens through the in house design and fabrication of specific LVDT holders and mounting hardware. Commercially available displacement transducers specified for this test are available but at a much higher cost.

The modification of the linear variable displacement transducers used in this project made it possible to run all necessary testing at low cost. The modifications to the purchased components included the design of new holders which mounted only few $\mathrm{mm}$ away from the surface of the sample. The LVDT springs and collars were also removed. These changes were made to negate the effect of the spring force during high temperature displacement measurements. The preparation of asphalt specimens using the current compaction equipment was successful in attaining the required amount of air voids in each specimen as shown in this report. The development of a suitable in house method for coring gyratory compacted HMA pucks to their desired dimension was successful through the design and fabrication of a unique puck holding device. Both end cutting and coring were greatly aided through the freezing of the sample prior to machining.

The effect of each mineral fillers attributes was successfully demonstrated through the observed changes in dynamic modulus values obtained herein. From the graphs it is apparent that fly ash performs best in terms of rutting resistance. Howerever, fly ash's performance in terms of fatigue requires further investigations as it resulted in an increase in the dynamic modulus of the mixtures at low temperature. 


\subsection{Recommendations for Future Research}

In the future, certain key areas not covered here should be analyzed. For example this testing program did not include very high frequencies, namely the $25 \mathrm{~Hz}$ band. This frequency band was not used as some researchers have experienced stability problems and error due to micro vibration in their samples. Similarly, very high temperatures were not tested. The highest temperature tested here was below $40^{\circ} \mathrm{C}$ although some believe that the testing should continue up to $54.4^{\circ} \mathrm{C}$. High temperatures were not considered here as they would further complicate the development process by introducing sag attenuation. With the addition of a higher range of temperatures masters curves can be generated to help further distinguish and differentiate each material, as well as allow for temperature superposition to theoretically predict the materials response without having to test

it. By performing more tests and generating maters curves there is a possibility that the pavement thickness can be decreased without compromising strength or structural integrity through the use of mineral fillers. Now that all the essential work has been done in establishing a frame and testing its capability many more materials can be tested as fillers. There are now numerous possibilities for testing different materials now that the ground work has been laid. All that remains is the production of samples and the testing using the newly available test set-up.

The main problem with the asphalt mixtures tested in this research was their low resistance to fatigue due to their high rigidity in cold temperatures. This disadvantage may possibly be overcome through the use of softer binders which would soften up the system so that it may perform better in terms of fatigue. Also, it is apparent from the literature review that the fineness of the mineral filler has a large effect on its performance. It would be beneficial in future research to possibly substitute mineral fillers with different gradations to evaluate the effect of fineness on the material performance. 


\subsection{Possible Program Changes and Improvements}

It would be beneficial for future research in this area to obtain a compaction device capable of producing taller specimens. In this report a shorter sample height was used in accordance with NCHRP test protocol. It should be known that to remain versatile a facility should have the ability to create taller specimens which will allow for conformance with ASTM and AASHTO standards as well.

Data analysis was a significant part of this research. The identification of the last five loading cycles as well as the data collection had to be done manually which was very tedious. Dynamic modulus software is readily available to identify, record, as well as plot the data points and final values for each test. The acquisition of such software would probably shorten the analysis time. 
Appendix - A

Sample Experimental Results 
Dynamic Modulus Determination example for Cement $37.8^{\prime} \mathrm{C} 10 \mathrm{~Hz}$

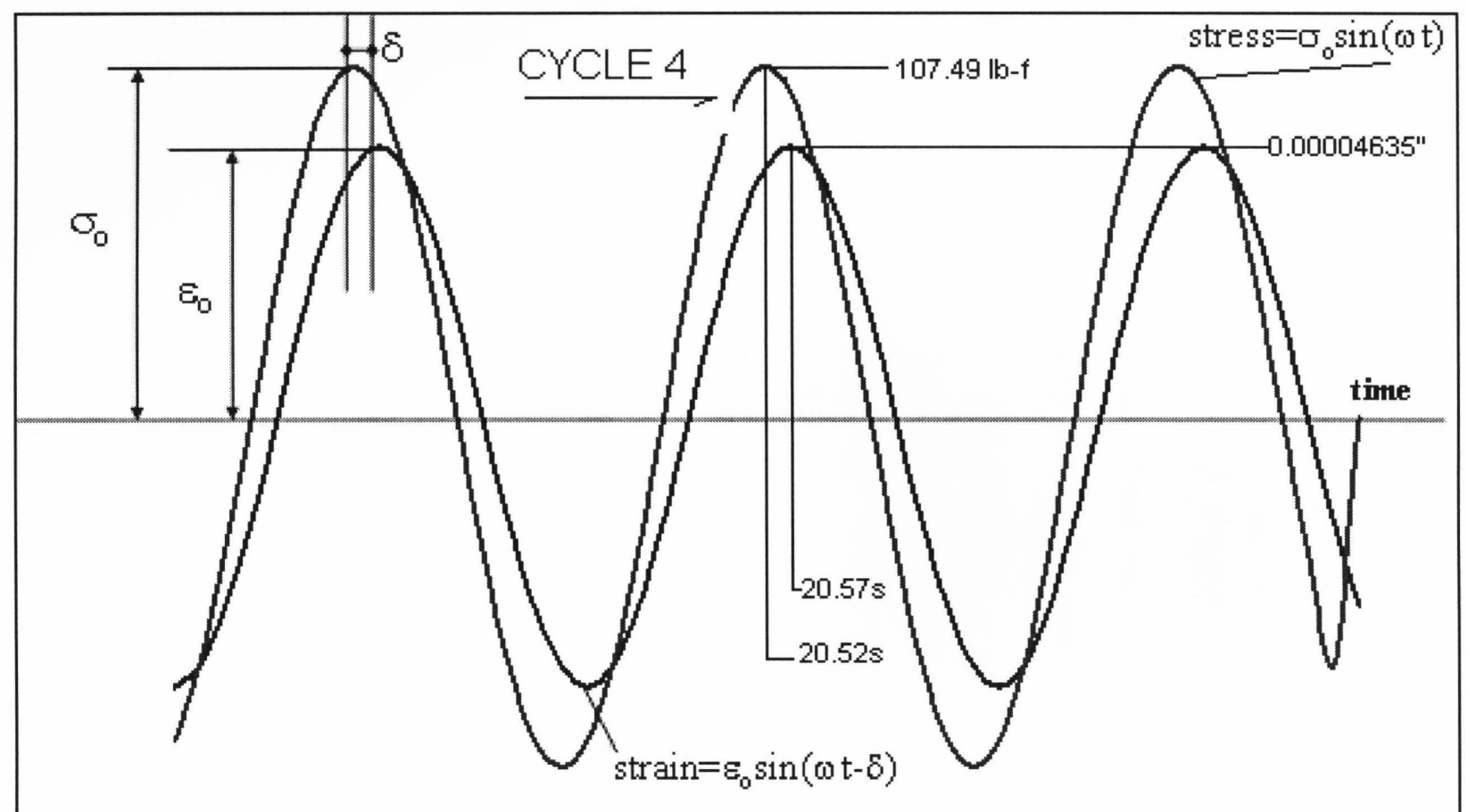

- Load (ft-lbs)

- AVG Displacement (in)
Calculations

gauge length $\mathrm{GL}=3.5^{\prime \prime}$ Area $A=10.75$ in-sq

Dynarnic Modulus [E*] = Stress $/$ Strain = $9.9990 / 0.000013242=755,048.5437 \mathrm{lb} / \mathrm{sq}$.in (psi) $755,048.5437 \mathrm{lb} / \mathrm{sq}$.in $(p s i)=5205876.232015 \mathrm{kPa}=5.20 \mathrm{GPa}$ 
Cement

(-9 degrees)

\section{Freq Peak Displ. Peak Load Peak Displ. Peak Load \\ (Hz) Values (in) Values (lb-f) Time (secs) Time (secs)

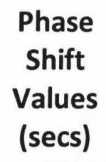

10

$\begin{array}{lll}0.00008183 & 1041.4406 & 26.57536 \\ 0.00008091 & 1038.3851 & 26.67725 \\ 0.00008091 & 1037.9147 & 26.77376 \\ 0.00008091 & 1036.0004 & 26.88298 \\ 0.00008091 & 1038.1372 & 26.97689\end{array}$

50.00009121

0.00009121

0.00009121

0.00009121

0.00009121

10.00010112

0.00010112

0.00010112

0.00010112

0.00010112

$0.5 \quad 0.00011672$

0.00011672

0.00011672

0.00011672

0.00011672

$0.1 \quad 0.00013891$

0.00013891

0.00013891

0.00013891

0.00013891
$1042.218 \quad 46.13705$

$1040.4429 \quad 46.34343$

1041.547

1040.7267

1041.9926

1040.6821

1046.1841

1040.903

1043.6071

1041.3528

1045.7644

1049.4213

1046.3206

1047.1211

1045.585

1050.4585

1046.9055

1051.6189

1050.7767

1051.6792
46.53272

46.73861

46.93278

62.55827

63.5739

64.5739

65.57341

66.57632

88.06543

90.10938

92.12451

94.13574

96.15609

182.4141

192.1908

202.4564

212.4883

222.6141
26.57308

$26.67448 \quad 0.002768$

$\begin{array}{ll}26.774904 & 0.00114\end{array}$

$\begin{array}{lll}26.875978 & 0.006999\end{array}$

$\begin{array}{lll}26.947611 & 0.029278\end{array}$

46.1293950 .007652

46.329590 .013836

$\begin{array}{lll}46.529461 & 0.003254\end{array}$

46.7301450 .008464

$\begin{array}{ll}46.928062 & 0.004719\end{array}$

$62.554203 \quad 0.004067$

$\begin{array}{lll}63.538414 & 0.035481\end{array}$

64.5584340 .015464

$65.549644 \quad 0.023766$

$66.55682-0.0195$

$88.072594 \quad 0.007164$

$90.072594 \quad 0.036781$

$92.070969 \quad 0.053543$

$94.074875 \quad 0.060867$

$96.074875 \quad 0.081215$

$\begin{array}{ll}182.14063 & 0.27343\end{array}$

$192.15186 \quad 0.03891$

$\begin{array}{ll}202.12402 & 0.33237\end{array}$

$212.19678 \quad 0.2915$

$222.18408 \quad 0.43003$
Average Average

Displ. Load (Ib)

8.11E-

$05 \quad 1038.38$

9.12E-

$\begin{array}{ll}05 & 1056.39\end{array}$

1.01E-

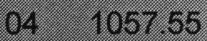

1.17E-

$0 4 \longdiv { 1 0 6 1 . 8 4 }$

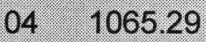

\begin{tabular}{|c|c|c|}
\hline \multicolumn{2}{|c|}{$10 \mathrm{~Hz}$} & \multirow{2}{*}{} \\
\cline { 1 - 2 } Cycle \# & $\mathbf{P}$ (lb-f) & A(in2) \\
\hline 1 & 1041.4406 & 10.75 \\
\hline 2 & 1038.3851 & 10.75 \\
\hline 3 & 1037.9147 & 10.75 \\
\hline 4 & 1036.0004 & 10.75 \\
\hline 5 & 1038.1372 & 10.75 \\
\hline
\end{tabular}

\begin{tabular}{|c|c|}
\hline$\Delta$ & GL \\
\hline 0.00008183 & 3.5 \\
\hline 0.00008091 & 3.5 \\
\hline 0.00008091 & 3.5 \\
\hline 0.00008091 & 3.5 \\
\hline 0.00008091 & 3.5 \\
\hline
\end{tabular}




\begin{tabular}{|c|l|c|c|r|}
\hline Cycle \# & $\sigma=P / A$ & $\varepsilon=\Delta / G L$ & $\begin{array}{l}{\left[E^{*}\right]=\sigma / \varepsilon} \\
\text { (psi) }\end{array}$ & $\begin{array}{l}{\left[\mathrm{E}^{*}\right]=\sigma / \varepsilon} \\
(\mathrm{GPa})\end{array}$ \\
\hline 1 & 96.8781953 & $2.3381 \mathrm{E}-05$ & 4143467 & 28.548485 \\
\hline 2 & 96.5939628 & $2.31168 \mathrm{E}-05$ & 4178527 & 28.79005 \\
3 & 96.5502047 & $2.31168 \mathrm{E}-05$ & 4176634 & 28.777008 \\
\hline 4 & 96.3721302 & $2.31168 \mathrm{E}-05$ & 4168931 & 28.723933 \\
\hline 5 & 96.5709023 & $2.31168 \mathrm{E}-05$ & 4177529 & 28.783177 \\
\hline
\end{tabular}

\begin{tabular}{|l|c|}
\hline $\mathrm{Kpa}$ & $\log \mathrm{KPa}$ \\
\hline $2.9 \mathrm{E}+07$ & 7.45558 \\
\hline $2.9 \mathrm{E}+07$ & 7.45924 \\
\hline $2.9 \mathrm{E}+07$ & 7.45905 \\
\hline $2.9 \mathrm{E}+07$ & 7.45824 \\
\hline $2.9 \mathrm{E}+07$ & 7.45914 \\
\hline
\end{tabular}

\begin{tabular}{|c|r|c|}
\hline \multicolumn{2}{|c|}{$\mathbf{5 H z}$} & \multicolumn{1}{|}{} \\
\hline Cycle \# & \multicolumn{1}{|c|}{$\mathbf{P}(\mathbf{l b}-\mathbf{f})$} & $\mathbf{A}$ (in2) \\
\hline 1 & 1057.218 & 10.75 \\
\hline 2 & 1055.4429 & 10.75 \\
\hline 3 & 1056.547 & 10.75 \\
\hline 4 & 1055.7267 & 10.75 \\
\hline 5 & 1056.9926 & 10.75 \\
\hline
\end{tabular}

\begin{tabular}{|c|c|}
\hline$\Delta$ & GL \\
\hline 0.00009121 & 3.5 \\
\hline 0.00009121 & 3.5 \\
\hline 0.00009121 & 3.5 \\
\hline 0.00009121 & 3.5 \\
\hline 0.00009121 & 3.5 \\
\hline
\end{tabular}

\begin{tabular}{|c|l|c|c|c|}
\hline Cycle \# & $\sigma=P / A$ & $\varepsilon=\Delta / G L$ & $\begin{array}{l}{\left[E^{*}\right]=\sigma / \varepsilon} \\
\text { (psi) }\end{array}$ & $\begin{array}{l}{\left[E^{*}\right]=\sigma / \varepsilon} \\
(\mathrm{GPa})\end{array}$ \\
\hline 1 & 98.3458605 & $2.60598 \mathrm{E}-05$ & 3773852 & 26.00184 \\
\hline 2 & 98.1807349 & $2.60598 \mathrm{E}-05$ & 3767516 & 25.958182 \\
\hline 3 & 98.2834419 & $2.60598 \mathrm{E}-05$ & 3771457 & 25.985337 \\
\hline 4 & 98.2071349 & $2.60598 \mathrm{E}-05$ & 3768529 & 25.965162 \\
\hline 5 & 98.324893 & $2.60598 \mathrm{E}-05$ & 3773047 & 25.996296 \\
\hline
\end{tabular}

\begin{tabular}{|l|r|}
\hline$E(K p a)$ & $\begin{array}{l}\text { logE } \\
\text { (Kpa) }\end{array}$ \\
\hline $2.6 \mathrm{E}+07$ & 7.415 \\
\hline $2.6 \mathrm{E}+07$ & 7.41427 \\
\hline $2.6 \mathrm{E}+07$ & 7.41473 \\
\hline $2.6 \mathrm{E}+07$ & 7.41439 \\
\hline $2.6 \mathrm{E}+07$ & 7.41491 \\
\hline
\end{tabular}

\begin{tabular}{|c|r|r|}
\hline \multicolumn{2}{|c|}{ 1HZ } & \multicolumn{1}{|c}{} \\
\hline Cycle \# & \multicolumn{1}{|c|}{$\mathbf{P}(\mathbf{l b}$-f) } & A(in2) \\
\hline 1 & 1055.6821 & 10.75 \\
\hline 2 & 1061.1841 & 10.75 \\
\hline 3 & 1055.903 & 10.75 \\
\hline 4 & 1058.6071 & 10.75 \\
\hline 5 & 1056.3528 & 10.75 \\
\hline
\end{tabular}

\begin{tabular}{|c|c|}
\hline$\Delta$ & GL \\
\hline 0.00010112 & 3.5 \\
\hline 0.00010112 & 3.5 \\
\hline 0.00010112 & 3.5 \\
\hline 0.00010112 & 3.5 \\
\hline 0.00010112 & 3.5 \\
\hline
\end{tabular}

\begin{tabular}{|c|c|c|c|c|}
\hline Cycle \# & $\sigma=\mathrm{P} / \mathrm{A}$ & $\varepsilon=\Delta / \mathrm{GL}$ & $\begin{array}{l}{\left[\mathrm{E}^{*}\right]=\sigma / \varepsilon} \\
\text { (psi) }\end{array}$ & $\begin{array}{l}{\left[\mathrm{E}^{*}\right]=\sigma / \varepsilon} \\
(\mathrm{GPa})\end{array}$ \\
\hline 1 & 98.202986 & $2.88923 \mathrm{E}-05$ & 3398929 & 23.418618 \\
\hline 2 & 98.7148 & $2.88923 \mathrm{E}-05$ & 3416643 & 23.540671 \\
\hline 3 & 98.2235349 & $2.88923 \mathrm{E}-05$ & 3399640 & 23.423518 \\
\hline 4 & 98.4750791 & $2.88923 \mathrm{E}-05$ & 3408346 & 23.483504 \\
\hline 5 & 98.2653767 & $2.88923 \mathrm{E}-05$ & 3401088 & 23.433496 \\
\hline
\end{tabular}

\begin{tabular}{|l|l|}
\hline$E(K p a)$ & $\begin{array}{l}\text { logE } \\
\text { (Kpa) }\end{array}$ \\
\hline $2.3 E+07$ & 7.36956 \\
\hline $2.4 E+07$ & 7.37182 \\
\hline $2.3 E+07$ & 7.36965 \\
\hline $2.3 E+07$ & 7.37076 \\
\hline $2.3 E+07$ & 7.36984 \\
\hline
\end{tabular}




\begin{tabular}{|c|c|c|c|c|}
\hline \multicolumn{2}{|c|}{$0.5 \mathrm{~Hz}$} & \multirow[b]{2}{*}{$A($ in2) } & \multirow[b]{2}{*}{$\Delta$} & \multirow[b]{2}{*}{ GL } \\
\hline Cycle \# & $P(l b-f)$ & & & \\
\hline 1 & 1060.7644 & 10.75 & 0.00011672 & 3.5 \\
\hline 2 & 1064.4213 & 10.75 & 0.00011672 & 3.5 \\
\hline 3 & 1061.3206 & 10.75 & 0.00011672 & 3.5 \\
\hline 4 & 1062.1211 & 10.75 & 0.00011672 & 3.5 \\
\hline 5 & 1060.585 & 10.75 & 0.00011672 & 3.5 \\
\hline
\end{tabular}

\begin{tabular}{|c|l|c|c|c|}
\hline Cycle \# & $\sigma=P / A$ & $\varepsilon=\Delta / G L$ & $\begin{array}{l}{\left[\mathrm{E}^{*}\right]=\sigma / \varepsilon} \\
\text { (psi) }\end{array}$ & $\begin{array}{l}{\left[\mathrm{E}^{*}\right]=\sigma / \varepsilon} \\
(\mathrm{GPa})\end{array}$ \\
\hline 1 & 98.6757581 & $3.33488 \mathrm{E}-05$ & 2958899 & 20.386815 \\
\hline 2 & 99.0159349 & $3.33488 \mathrm{E}-05$ & 2969100 & 20.457097 \\
\hline 3 & 98.7274977 & $3.33488 \mathrm{E}-05$ & 2960451 & 20.397504 \\
\hline 4 & 98.8019628 & $3.33488 \mathrm{E}-05$ & 2962683 & 20.412889 \\
\hline 5 & 98.6590698 & $3.33488 \mathrm{E}-05$ & 2958399 & 20.383367 \\
\hline
\end{tabular}

\begin{tabular}{|c|r|}
\hline$E(K p a)$ & $\begin{array}{l}\text { logE } \\
(\mathrm{Kpa})\end{array}$ \\
\hline $2 \mathrm{E}+07$ & 7.30935 \\
\hline $2 \mathrm{E}+07$ & 7.31084 \\
\hline $2 \mathrm{E}+07$ & 7.30958 \\
\hline $2 \mathrm{E}+07$ & 7.3099 \\
\hline $2 \mathrm{E}+07$ & 7.30928 \\
\hline
\end{tabular}

\begin{tabular}{|c|c|c|}
\hline \multicolumn{2}{|c|}{$\mathbf{0 . 1 H z}$} & \multicolumn{1}{|c}{} \\
\hline Cycle \# & $\mathbf{P}(\mathbf{l b}$-f) & A(in2) \\
\hline 1 & 1065.4585 & 10.75 \\
\hline 2 & 1061.9055 & 10.75 \\
\hline 3 & 1066.6189 & 10.75 \\
\hline 4 & 1065.7767 & 10.75 \\
\hline 5 & 1066.6792 & 10.75 \\
\hline
\end{tabular}

\begin{tabular}{|c|}
\hline \multicolumn{1}{|c|}{$\Delta$} \\
\hline 0.00013891 \\
\hline 0.00013891 \\
\hline 0.00013891 \\
\hline 0.00013891 \\
\hline 0.00013891 \\
\hline \\
\hline $\begin{array}{l}{[\mathrm{E} * \mathrm{G}=\sigma / \varepsilon} \\
\text { (GPa) }\end{array}$ \\
\hline 17.206119 \\
\hline 17.148741 \\
\hline 17.224858 \\
\hline 17.211258 \\
\hline 17.225832 \\
\hline
\end{tabular}

\begin{tabular}{|c|c|c|c|c|}
\hline Cycle \# & $\sigma=P / A$ & $\varepsilon=\Delta / G L$ & $\begin{array}{l}{\left[E^{*}\right]=\sigma / \varepsilon} \\
(p s i)\end{array}$ & $\begin{array}{l}{\left[E^{*}\right]=\sigma / \varepsilon} \\
(\mathrm{GPa})\end{array}$ \\
\hline 1 & 99.1124186 & $3.96885 \mathrm{E}-05$ & 2497260 & 17.206119 \\
\hline 2 & 98.781907 & $3.96885 \mathrm{E}-05$ & 2488932 & 17.148741 \\
\hline 3 & 99.2203628 & $3.96885 \mathrm{E}-05$ & 2499979 & 17.224858 \\
\hline 4 & 99.1420186 & $3.96885 \mathrm{E}-05$ & 2498005 & 17.211258 \\
\hline 5 & 99.2259721 & $3.96885 \mathrm{E}-05$ & 2500121 & 17.225832 \\
\hline
\end{tabular}

\begin{tabular}{|l|l|}
\hline \multicolumn{2}{|c|}{} \\
\hline $\mathbf{E}(\mathrm{Kpa})$ & $\begin{array}{l}\text { logE } \\
\text { (Kpa) }\end{array}$ \\
\hline $1.7 \mathrm{E}+07$ & 7.23568 \\
\hline $1.7 \mathrm{E}+07$ & 7.23423 \\
\hline $1.7 \mathrm{E}+07$ & 7.23616 \\
\hline $1.7 \mathrm{E}+07$ & 7.23581 \\
\hline $1.7 \mathrm{E}+07$ & 7.23618 \\
\hline
\end{tabular}


Cement

(4.4 degrees)

\begin{tabular}{|c|c|c|c|c|c|c|c|}
\hline Freq (Hz) & $\begin{array}{l}\text { Peak Displ. } \\
\text { Values (in) }\end{array}$ & $\begin{array}{c}\text { Peak } \\
\text { Load } \\
\text { Values } \\
\text { (lb-f) }\end{array}$ & $\begin{array}{l}\text { Peak Displ. } \\
\text { Time (secs) }\end{array}$ & $\begin{array}{l}\text { Peak Load } \\
\text { Time (secs) }\end{array}$ & $\begin{array}{c}\text { Phase } \\
\text { Shift } \\
\text { Values } \\
\text { (secs) }\end{array}$ & $\begin{array}{l}\text { Average } \\
\text { Displ. (in) }\end{array}$ & $\begin{array}{l}\text { Average } \\
\text { Load (lb) }\end{array}$ \\
\hline \multirow[t]{5}{*}{10} & 0.00008566 & 785.79 & 22.31779 & 22.266928 & 0.050862 & 8.6E-05 & 785.136 \\
\hline & 0.00008566 & 785.59 & 22.42057 & 22.367676 & 0.052898 & & \\
\hline & 0.00008566 & 785.97 & 22.52148 & 22.467123 & 0.054361 & & \\
\hline & 0.00008566 & 783.98 & 22.61947 & 22.568523 & 0.050944 & & \\
\hline & 0.00008566 & 784.35 & 22.7194 & 22.667645 & 0.051757 & & \\
\hline \multirow[t]{5}{*}{5} & 0.00009930 & 802.5485 & 41.9266 & 41.921715 & 0.004883 & $9.9 E-05$ & 802.5449 \\
\hline & 0.00009930 & 803.2217 & 42.13135 & 42.122234 & 0.009114 & & \\
\hline & 0.00009930 & 802.0156 & 42.32585 & 42.323406 & 0.002442 & & \\
\hline & 0.00009930 & 802.2455 & 42.53158 & 42.522137 & 0.009441 & & \\
\hline & 0.00009930 & 802.693 & 42.72575 & 42.721844 & 0.003906 & & \\
\hline \multirow[t]{5}{*}{1} & 0.00011322 & 804.7286 & 58.4069 & 58.351074 & 0.055828 & 0.00011 & 804.3579 \\
\hline & 0.00011322 & 803.7513 & 59.41504 & 59.351074 & 0.063965 & & \\
\hline & 0.00011322 & 804.1942 & 60.42611 & 60.347332 & 0.078777 & & \\
\hline & 0.00011322 & 806.0897 & 61.41488 & 61.337078 & 0.077801 & & \\
\hline & 0.00011322 & 803.026 & 62.42416 & 62.353844 & 0.070312 & & \\
\hline \multirow[t]{5}{*}{0.5} & 0.00014096 & 809.1213 & 84.01058 & 83.86377 & 0.146812 & 0.00014 & 808.8949 \\
\hline & 0.00014096 & 809.0932 & 86.00603 & 85.863121 & 0.142906 & & \\
\hline & 0.00014096 & 809.1033 & 88.01937 & 87.861984 & 0.157387 & & \\
\hline & 0.00014096 & 808.1333 & 90.02116 & 89.977121 & 0.044043 & & \\
\hline & 0.00014096 & 809.0234 & 92.04607 & 91.860519 & 0.185547 & & \\
\hline \multirow[t]{5}{*}{0.1} & 0.00015334 & 812.8214 & 178.8163 & 177.99577 & 0.82048 & 0.00015 & 813.2234 \\
\hline & 0.00015334 & 812.6185 & 188.7661 & 188.02719 & 0.73892 & & \\
\hline & 0.00015334 & 813.3356 & 198.9063 & 197.96989 & 0.93636 & & \\
\hline & 0.00015334 & 814.413 & 208.8467 & 207.94238 & 0.9043 & & \\
\hline & 0.00015334 & 812.9284 & 218.9839 & 218.00163 & 0.98226 & & \\
\hline
\end{tabular}

\begin{tabular}{|c|c|c|c|c|c|}
\hline \multicolumn{2}{|c|}{$10 \mathrm{~Hz}$} & \multicolumn{5}{|c|}{} \\
\cline { 1 - 2 } Cycle \# & P(lb-f) & A(in2) & & $\Delta$ & GL \\
\hline 1 & 785.79 & 10.75 & & 0.00008566 & 3.5 \\
\hline 2 & 785.59 & 10.75 & & 0.00008566 & 3.5 \\
\hline 3 & 785.97 & 10.75 & & 0.00008566 & 3.5 \\
\hline 4 & 783.98 & 10.75 & & 0.00008566 & 3.5 \\
\hline 5 & 784.35 & 10.75 & & 0.00008566 & 3.5 \\
\hline
\end{tabular}




\begin{tabular}{|c|c|c|l|l|}
\hline Cycle \# & $\sigma=P / A$ & $\varepsilon=\Delta / G L$ & $\begin{array}{l}{\left[E^{*}\right]=\sigma / \varepsilon} \\
(p s i)\end{array}$ & $\begin{array}{l}{\left[E^{*}\right]=\sigma / \varepsilon} \\
(\mathrm{GPa})\end{array}$ \\
\hline 1 & 73.096744 & $2.45 \mathrm{E}-05$ & 2986597 & 20.577656 \\
\hline 2 & 73.07814 & $2.45 \mathrm{E}-05$ & 2985837 & 20.572418 \\
\hline 3 & 73.113488 & $2.45 \mathrm{E}-05$ & 2987281 & 20.582369 \\
\hline 4 & 72.928372 & $2.45 \mathrm{E}-05$ & 2979718 & 20.530257 \\
\hline 5 & 72.962791 & $2.45 \mathrm{E}-05$ & 2981124 & 20.539946 \\
\hline
\end{tabular}

\begin{tabular}{|l|l|}
\hline $\mathrm{Kpa}$ & $\log \mathrm{KPa}$ \\
\hline $2.1 \mathrm{E}+07$ & 7.313396 \\
\hline $2.1 \mathrm{E}+07$ & 7.313285 \\
\hline $2.1 \mathrm{E}+07$ & 7.313495 \\
\hline $2.1 \mathrm{E}+07$ & 7.312394 \\
\hline $2.1 \mathrm{E}+07$ & 7.312599 \\
\hline
\end{tabular}

\begin{tabular}{|c|c|c|l|c|c|}
\hline \multicolumn{2}{|c|}{$5 \mathrm{~Hz}$} & \multicolumn{5}{l|}{} \\
\hline Cycle \# & P(lb-f) & A(in2) & & $\boldsymbol{\Delta}$ & GL \\
\hline 1 & 802.54846 & 10.75 & & 0.00009930 & 3.5 \\
\hline 2 & 803.22174 & 10.75 & & 0.00009930 & 3.5 \\
\hline 3 & 802.01563 & 10.75 & & 0.00009930 & 3.5 \\
\hline 4 & 802.24554 & 10.75 & & 0.00009930 & 3.5 \\
\hline 5 & 802.69299 & 10.75 & & 0.00009930 & 3.5 \\
\hline
\end{tabular}

\begin{tabular}{|c|l|c|l|r|}
\hline Cycle \# & $\sigma=P / A$ & $\varepsilon=\Delta-G L$ & $\begin{array}{l}{\left[E^{*}\right]=\sigma / \varepsilon} \\
(p s i)\end{array}$ & $\begin{array}{l}{\left[E^{*}\right]=\sigma / \varepsilon} \\
(G P a)\end{array}$ \\
\hline 1 & 74.655671 & $2.84 \mathrm{E}-05$ & 2631416 & 18.130459 \\
\hline 2 & 74.718301 & $2.84 \mathrm{E}-05$ & 2633624 & 18.14567 \\
\hline 3 & 74.606105 & $2.84 \mathrm{E}-05$ & 2629669 & 18.118422 \\
\hline 4 & 74.627492 & $2.84 \mathrm{E}-05$ & 2630423 & 18.123616 \\
\hline 5 & 74.669115 & $2.84 \mathrm{E}-05$ & 2631890 & 18.133724 \\
\hline
\end{tabular}

\begin{tabular}{|c|r|}
\hline$E(K p a)$ & $\begin{array}{l}\text { logE } \\
\text { (Kpa) }\end{array}$ \\
\hline $1.8 \mathrm{E}+07$ & 7.258409 \\
\hline $1.8 \mathrm{E}+07$ & 7.258773 \\
\hline $1.8 \mathrm{E}+07$ & 7.25812 \\
\hline $1.8 \mathrm{E}+07$ & 7.258245 \\
\hline $1.8 \mathrm{E}+07$ & 7.258487 \\
\hline
\end{tabular}

\begin{tabular}{|c|c|c|c|c|c|}
\hline \multicolumn{2}{|c|}{ 1HZ } & \multicolumn{5}{l|}{} \\
\hline Cycle \# & P(lb-f) & A(in2) & & $\Delta$ & GL \\
\hline 1 & 804.72858 & 10.75 & & 0.00011322 & 3.5 \\
\hline 2 & 803.75128 & 10.75 & & 0.00011322 & 3.5 \\
\hline 3 & 804.19421 & 10.75 & & 0.00011322 & 3.5 \\
\hline 4 & 806.08966 & 10.75 & & 0.00011322 & 3.5 \\
\hline 5 & 803.026 & 10.75 & & 0.00011322 & 3.5 \\
\hline
\end{tabular}

\begin{tabular}{|c|l|c|c|c|}
\hline Cycle \# & $\sigma=P / A$ & $\varepsilon=\Delta-G L$ & $\begin{array}{l}{\left[E^{*}\right]=\sigma / \varepsilon} \\
(\mathbf{p s i})\end{array}$ & $\begin{array}{l}{\left[E^{*}\right]=\sigma / \varepsilon} \\
(\mathrm{GPa})\end{array}$ \\
\hline 1 & 74.858473 & $3.23 \mathrm{E}-05$ & 2314217 & 15.944957 \\
\hline 2 & 74.767561 & $3.23 \mathrm{E}-05$ & 2311407 & 15.925593 \\
\hline 3 & 74.808764 & $3.23 \mathrm{E}-05$ & 2312681 & 15.934369 \\
\hline 4 & 74.985085 & $3.23 \mathrm{E}-05$ & 2318131 & 15.971926 \\
\hline 5 & 74.700093 & $3.23 \mathrm{E}-05$ & 2309321 & 15.911222 \\
\hline
\end{tabular}

\begin{tabular}{|c|l|}
\hline$E(K p a)$ & $\begin{array}{l}\text { logE } \\
(\text { Kpa })\end{array}$ \\
\hline $1.6 \mathrm{E}+07$ & 7.202623 \\
\hline $1.6 \mathrm{E}+07$ & 7.202096 \\
\hline $1.6 \mathrm{E}+07$ & 7.202335 \\
\hline $1.6 \mathrm{E}+07$ & 7.203357 \\
\hline $1.6 \mathrm{E}+07$ & 7.201704 \\
\hline
\end{tabular}




\begin{tabular}{|c|r|c|l|c|c|}
\hline \multicolumn{2}{|c|}{$\mathbf{0 . 5 H z}$} & \multicolumn{5}{|l|}{} \\
\cline { 1 - 2 } Cycle \# & \multicolumn{1}{|c|}{$\mathbf{P}(\mathbf{l b}$-f) } & A(in2) & & $\Delta$ & GL \\
\hline 1 & 809.12134 & 10.75 & & 0.00014096 & 3.5 \\
\hline 2 & 809.0932 & 10.75 & & 0.00014096 & 3.5 \\
\hline 3 & 809.10327 & 10.75 & & 0.00014096 & 3.5 \\
\hline 4 & 808.1333 & 10.75 & & 0.00014096 & 3.5 \\
\hline 5 & 809.02338 & 10.75 & & 0.00014096 & 3.5 \\
\hline
\end{tabular}

\begin{tabular}{|c|c|c|c|c|}
\hline Cycle \# & $\sigma=P / A$ & $\varepsilon=\Delta-G L$ & $\begin{array}{l}{\left[E^{*}\right]=\sigma / \varepsilon} \\
(p s i)\end{array}$ & $\begin{array}{l}{\left[E^{*}\right]=\sigma / \varepsilon} \\
(G P a)\end{array}$ \\
\hline 1 & 75.267101 & $4.03 E-05$ & 1868798 & 12.876021 \\
\hline 2 & 75.264484 & $4.03 E-05$ & 1868733 & 12.875573 \\
\hline 3 & 75.26542 & $4.03 E-05$ & 1868757 & 12.875733 \\
\hline 4 & 75.175191 & $4.03 E-05$ & 1866516 & 12.860298 \\
\hline 5 & 75.257989 & $4.03 E-05$ & 1868572 & 12.874462 \\
\hline
\end{tabular}

\begin{tabular}{|c|l|}
\hline $\mathrm{E}(\mathrm{Kpa})$ & $\begin{array}{l}\text { logE } \\
(\mathrm{Kpa})\end{array}$ \\
\hline $1.3 \mathrm{E}+07$ & 7.109782 \\
\hline $1.3 \mathrm{E}+07$ & 7.109767 \\
\hline $1.3 \mathrm{E}+07$ & 7.109772 \\
\hline $1.3 \mathrm{E}+07$ & 7.109251 \\
\hline $1.3 \mathrm{E}+07$ & 7.109729 \\
\hline
\end{tabular}

\begin{tabular}{|c|c|c|c|c|c|}
\hline \multicolumn{2}{|c|}{$\mathbf{0 . 1 H z}$} & \multicolumn{5}{|l|}{} \\
\hline Cycle \# & P(lb-f) & A(in2) & & $\mathbf{\Delta}$ & GL \\
\hline 1 & 812.82135 & 10.75 & & 0.00015334 & 3.5 \\
\hline 2 & 812.61853 & 10.75 & & 0.00015334 & 3.5 \\
\hline 3 & 813.33557 & 10.75 & & 0.00015334 & 3.5 \\
\hline 4 & 814.41296 & 10.75 & & 0.00015334 & 3.5 \\
\hline 5 & 812.92841 & 10.75 & & 0.00015334 & 3.5 \\
\hline
\end{tabular}

\begin{tabular}{|c|l|c|c|r|}
\hline Cycle \# & $\sigma=P / A$ & $\varepsilon=\Delta / G L$ & $\begin{array}{l}{[\mathrm{E} *]=\sigma / \varepsilon} \\
\text { (psi) }\end{array}$ & $\begin{array}{l}{\left[\mathrm{E}^{*}\right]=\sigma / \varepsilon} \\
(\mathrm{GPa})\end{array}$ \\
\hline 1 & 75.611288 & $4.38 \mathrm{E}-05$ & 1725846 & 11.891076 \\
\hline 2 & 75.592421 & $4.38 \mathrm{E}-05$ & 1725415 & 11.888109 \\
\hline 3 & 75.659123 & $4.38 \mathrm{E}-05$ & 1726937 & 11.898598 \\
\hline 4 & 75.759345 & $4.38 \mathrm{E}-05$ & 1729225 & 11.91436 \\
\hline 5 & 75.621247 & $4.38 \mathrm{E}-05$ & 1726073 & 11.892642 \\
\hline & & & & \\
\hline
\end{tabular}

\begin{tabular}{|c|l|}
\hline $\mathrm{E}(\mathrm{Kpa})$ & $\begin{array}{l}\text { logE } \\
(\mathrm{Kpa})\end{array}$ \\
\hline $1.2 \mathrm{E}+07$ & 7.075221 \\
\hline $1.2 \mathrm{E}+07$ & 7.075113 \\
\hline $1.2 \mathrm{E}+07$ & 7.075496 \\
\hline $1.2 \mathrm{E}+07$ & 7.076071 \\
\hline $1.2 \mathrm{E}+07$ & 7.075278 \\
\hline & \\
\hline
\end{tabular}


Cement

(21.1 degrees)

\begin{tabular}{|c|c|c|c|c|c|c|c|}
\hline Freq $(\mathrm{Hz})$ & $\begin{array}{l}\text { Peak Displ. } \\
\text { Values (in) }\end{array}$ & $\begin{array}{l}\text { Peak } \\
\text { Load } \\
\text { Values } \\
\text { (lb-f) }\end{array}$ & $\begin{array}{l}\text { Peak Displ. } \\
\text { Time (secs) }\end{array}$ & $\begin{array}{c}\text { Peak Load } \\
\text { Time (secs) }\end{array}$ & $\begin{array}{l}\text { Phase } \\
\text { Shift } \\
\text { Values } \\
\text { (secs) }\end{array}$ & $\begin{array}{l}\text { Average } \\
\text { Displ. (in) }\end{array}$ & $\begin{array}{l}\text { Average } \\
\text { Load (Ib) }\end{array}$ \\
\hline \multirow[t]{5}{*}{10} & 0.00000676 & 283.2143 & 20.5197 & 20.507324 & 0.012371 & 6.76E-06 & 282.6051 \\
\hline & 0.00000676 & 282.4868 & 20.61816 & 20.608236 & 0.009928 & & \\
\hline & 0.00000676 & 283.4516 & 20.71696 & 20.707684 & 0.009277 & & \\
\hline & 0.00000676 & 282.8185 & 20.81722 & 20.807617 & 0.009604 & & \\
\hline & 0.00000676 & 281.0541 & 20.91732 & 20.909018 & 0.0083 & & \\
\hline \multirow[t]{5}{*}{5} & 0.00000760 & 283.4243 & 40.18278 & 40.164063 & 0.018718 & 7.6E-06 & 293.4526 \\
\hline & 0.00000760 & 282.8526 & 40.38786 & 40.367027 & 0.020832 & & \\
\hline & 0.00000760 & 282.4704 & 40.58561 & 40.562988 & 0.022625 & & \\
\hline & 0.00000760 & 284.094 & 40.785 & 40.761395 & 0.023601 & & \\
\hline & 0.00000760 & 284.4217 & 40.99138 & 40.962078 & 0.029297 & & \\
\hline \multirow[t]{5}{*}{1.} & 0.00000843 & 284.725 & 58.67709 & 58.351074 & 0.326012 & $8.43 E-06$ & 304.8568 \\
\hline & 0.00000843 & 284.848 & 59.66602 & 59.351074 & 0.314942 & & \\
\hline & 0.00000843 & 285.8111 & 60.69011 & 60.347332 & 0.342773 & & \\
\hline & 0.00000843 & 284.8592 & 61.69352 & 61.337078 & 0.356445 & & \\
\hline & 0.00000843 & 284.0409 & 62.67871 & 62.353844 & 0.324867 & & \\
\hline \multirow[t]{5}{*}{0.5} & 0.00000973 & 289.4008 & 82.30322 & 82.120445 & 0.182778 & $9.73 E-06$ & 309.2206 \\
\hline & 0.00000973 & 289.3117 & 84.29134 & 84.115562 & 0.175782 & & \\
\hline & 0.00000973 & 290.8142 & 86.26547 & 86.094078 & 0.171387 & & \\
\hline & 0.00000973 & 289.1966 & 88.33529 & 88.124512 & 0.210777 & & \\
\hline & 0.00000973 & 287.3796 & 90.31999 & 90.148277 & 0.171715 & & \\
\hline \multirow[t]{5}{*}{0.1} & 0.00001158 & 295.5146 & 187.1919 & 186.22754 & 0.96435 & 1.16E-05 & 314.599 \\
\hline & 0.00001158 & 295.346 & 197.1797 & 196.27637 & 0.90332 & & \\
\hline & 0.00001158 & 294.2157 & 207.225 & 206.20215 & 1.02281 & & \\
\hline & 0.00001158 & 294.62 & 217.214 & 216.257 & 0.95704 & & \\
\hline & 0.00001158 & 293.2988 & 227.2551 & 226.36882 & 0.88623 & & \\
\hline
\end{tabular}

\begin{tabular}{|c|c|c|c|c|c|}
\hline \multicolumn{2}{|c|}{$10 \mathrm{~Hz}$} & \multicolumn{5}{l|}{} \\
\cline { 1 - 2 } Cycle \# & P(lb-f) & A(in2) & & $\Delta$ & GL \\
\hline 1 & 283.21426 & 10.75 & & 0.00000676 & 3.5 \\
\hline 2 & 282.48682 & 10.75 & & 0.00000676 & 3.5 \\
\hline 3 & 283.4516 & 10.75 & & 0.00000676 & 3.5 \\
\hline 4 & 282.81848 & 10.75 & & 0.00000676 & 3.5 \\
\hline 5 & 281.05414 & 10.75 & & 0.00000676 & 3.5 \\
\hline
\end{tabular}




\begin{tabular}{|c|l|l|l|l|}
\hline Cycle \# & $\sigma=P / A$ & $\varepsilon=\Delta / G L$ & $\begin{array}{l}{\left[E^{*}\right]=\sigma / \varepsilon} \\
(p s i)\end{array}$ & $\begin{array}{l}{\left[E^{*}\right]=\sigma / \varepsilon} \\
(\mathrm{GPa})\end{array}$ \\
\hline 1 & 26.34551256 & $1.93 \mathrm{E}-06$ & 13644874 & 94.0131836 \\
\hline 2 & 26.27784372 & $1.93 \mathrm{E}-06$ & 13609827 & 93.7717093 \\
\hline 3 & 26.3675907 & $1.93 \mathrm{E}-06$ & 13656309 & 94.0919688 \\
\hline 4 & 26.30869581 & $1.93 \mathrm{E}-06$ & 13625806 & 93.8818041 \\
\hline 5 & 26.14457116 & $1.93 \mathrm{E}-06$ & 13540803 & 93.2961301 \\
\hline
\end{tabular}

\begin{tabular}{|l|l|}
\hline Kpa & log KPa \\
\hline 94013184 & 7.973189 \\
\hline 93771709 & 7.972072 \\
\hline 94091969 & 7.973553 \\
\hline 93881804 & 7.972581 \\
\hline 93296130 & 7.969864 \\
\hline
\end{tabular}

\begin{tabular}{|c|c|c|c|c|c|}
\hline \multicolumn{2}{|c|}{ 5Hz } & \multicolumn{5}{l|}{} \\
\hline Cycle \# & P(lb-f) & A(in2) & & $\Delta$ & GL \\
\hline 1 & 293.42429 & 10.75 & & 0.00000760 & 3.5 \\
\hline 2 & 292.85257 & 10.75 & & 0.00000760 & 3.5 \\
\hline 3 & 292.47037 & 10.75 & & 0.00000760 & 3.5 \\
\hline 4 & 294.09402 & 10.75 & & 0.00000760 & 3.5 \\
\hline 5 & 294.42169 & 10.75 & & 0.00000760 & 3.5 \\
\hline
\end{tabular}

\begin{tabular}{|c|l|l|l|l|}
\hline Cycle \# & $\sigma=P / A$ & $\varepsilon=\Delta / G L$ & $\begin{array}{l}{\left[E^{*}\right]=\sigma / \varepsilon} \\
\text { (psi) }\end{array}$ & $\begin{array}{l}{[\mathrm{E} *]=\sigma / \varepsilon} \\
\text { (GPa) }\end{array}$ \\
\hline 1 & 27.29528279 & $2.17 \mathrm{E}-06$ & 12568910 & 86.5997907 \\
\hline 2 & 27.24209953 & $2.17 \mathrm{E}-06$ & 12544420 & 86.4310561 \\
\hline 3 & 27.20654605 & $2.17 \mathrm{E}-06$ & 12528049 & 86.3182555 \\
\hline 4 & 27.35758326 & $2.17 \mathrm{E}-06$ & 12597598 & 86.7974515 \\
\hline 5 & 27.38806419 & $2.17 \mathrm{E}-06$ & 12611634 & 86.8941584 \\
\hline
\end{tabular}

\begin{tabular}{|l|l|}
\hline$E(K p a)$ & $\begin{array}{l}\text { logE } \\
\text { (Kpa) }\end{array}$ \\
\hline 86599791 & 7.937517 \\
\hline 86431056 & 7.93667 \\
\hline 86318256 & 7.936103 \\
\hline 86797452 & 7.938507 \\
\hline 86894158 & 7.938991 \\
\hline
\end{tabular}

\begin{tabular}{|c|c|c|c|c|c|}
\hline \multicolumn{2}{|c|}{ 1HZ } & \multicolumn{5}{l|}{} \\
\cline { 1 - 2 } Cycle \# & P(lb-f) & A(in2) & & $\Delta$ & GL \\
\hline 1 & 304.72495 & 10.75 & & 0.00000843 & 3.5 \\
\hline 2 & 304.84796 & 10.75 & & 0.00000843 & 3.5 \\
\hline 3 & 305.81113 & 10.75 & & 0.00000843 & 3.5 \\
\hline 4 & 304.85922 & 10.75 & & 0.00000843 & 3.5 \\
\hline 5 & 304.04086 & 10.75 & & 0.00000843 & 3.5 \\
\hline
\end{tabular}

\begin{tabular}{|c|c|c|l|l|}
\hline Cycle \# & $\sigma=P / A$ & $\varepsilon=\Delta / G L$ & $\begin{array}{l}{\left[E^{*}\right]=\sigma / \varepsilon} \\
(p s i)\end{array}$ & $\begin{array}{l}{\left[E^{*}\right]=\sigma / \varepsilon} \\
(\mathrm{GPa})\end{array}$ \\
\hline 1 & 28.34650698 & $2.41 \mathrm{E}-06$ & 11773298 & 81.1180241 \\
\hline 2 & 28.35794977 & $2.41 \mathrm{E}-06$ & 11778051 & 81.1507695 \\
\hline 3 & 28.44754698 & $2.41 \mathrm{E}-06$ & 11815264 & 81.4071661 \\
\hline 4 & 28.35899721 & $2.41 \mathrm{E}-06$ & 11778486 & 81.1537669 \\
\hline 5 & 28.2828707 & $2.41 \mathrm{E}-06$ & 11746868 & 80.9359188 \\
\hline
\end{tabular}

\begin{tabular}{|l|l|}
\hline$E(K p a)$ & $\begin{array}{l}\text { logE } \\
\text { (Kpa) }\end{array}$ \\
\hline 81118024 & 7.909117 \\
\hline 81150769 & 7.909293 \\
\hline 81407166 & 7.910663 \\
\hline 81153767 & 7.909309 \\
\hline 80935919 & 7.908141 \\
\hline
\end{tabular}




\begin{tabular}{|c|c|c|c|c|c|}
\hline \multicolumn{2}{|c|}{$\mathbf{0 . 5 H z}$} & \multicolumn{5}{l|}{} \\
\hline Cycle \# & P(lb-f) & A(in2) & & $\Delta$ & GL \\
\hline 1 & 309.40076 & 10.75 & & 0.00000973 & 3.5 \\
\hline 2 & 309.31165 & 10.75 & & 0.00000973 & 3.5 \\
\hline 3 & 310.81415 & 10.75 & & 0.00000973 & 3.5 \\
\hline 4 & 309.19662 & 10.75 & & 0.00000973 & 3.5 \\
\hline 5 & 307.37964 & 10.75 & & 0.00000973 & 3.5 \\
\hline
\end{tabular}

\begin{tabular}{|c|l|c|l|l|}
\hline Cycle \# & $\sigma=P / A$ & $\varepsilon=\Delta / G L$ & $\begin{array}{l}{\left[E^{*}\right]=\sigma / \varepsilon} \\
\text { (psi) }\end{array}$ & $\begin{array}{l}{\left[E^{*}\right]=\sigma / \varepsilon} \\
\text { (GPa) }\end{array}$ \\
\hline 1 & 28.78146605 & $2.78 \mathrm{E}-06$ & 10356520 & 71.3564219 \\
\hline 2 & 28.77317674 & $2.78 \mathrm{E}-06$ & 10353537 & 71.3358706 \\
\hline 3 & 28.91294419 & $2.78 \mathrm{E}-06$ & 10403830 & 71.6823889 \\
\hline 4 & 28.76247628 & $2.78 \mathrm{E}-06$ & 10349687 & 71.3093415 \\
\hline 5 & 28.59345488 & $2.78 \mathrm{E}-06$ & 10288867 & 70.8902954 \\
\hline
\end{tabular}

\begin{tabular}{|l|l|}
\hline$E$ (Kpa) & $\begin{array}{l}\text { logE } \\
\text { (Kpa) }\end{array}$ \\
\hline 71356422 & 7.853433 \\
\hline 71335871 & 7.853308 \\
\hline 71682389 & 7.855412 \\
\hline 71309341 & 7.853146 \\
\hline 70890295 & 7.850587 \\
\hline
\end{tabular}

\begin{tabular}{|c|c|c|c|c|c|}
\hline \multicolumn{2}{|c|}{$\mathbf{0 . 1 H z}$} & \multicolumn{5}{|l|}{} \\
\hline Cycle \# & P(lb-f) & A(in2) & & $\boldsymbol{\Delta}$ & GL \\
\hline 1 & 315.51459 & 10.75 & & 0.00001158 & 3.5 \\
\hline 2 & 315.34598 & 10.75 & & 0.00001158 & 3.5 \\
\hline 3 & 314.21573 & 10.75 & & 0.00001158 & 3.5 \\
\hline 4 & 314.62003 & 10.75 & & 0.00001158 & 3.5 \\
\hline 5 & 313.29883 & 10.75 & & 0.00001158 & 3.5 \\
\hline
\end{tabular}

\begin{tabular}{|c|c|c|c|l|}
\hline Cycle \# & $\sigma=P / A$ & $\varepsilon=\Delta / G L$ & $\begin{array}{l}{\left[E^{*}\right]=\sigma / \varepsilon} \\
\text { (psi) }\end{array}$ & $\begin{array}{l}{\left[E^{*}\right]=\sigma / \varepsilon} \\
\text { (GPa) }\end{array}$ \\
\hline 1 & 29.35019442 & $3.31 \mathrm{E}-06$ & 8874172 & 61.1430467 \\
\hline 2 & 29.33450977 & $3.31 \mathrm{E}-06$ & 8869430 & 61.1103721 \\
\hline 3 & 29.22937023 & $3.31 \mathrm{E}-06$ & 8837640 & 60.8913428 \\
\hline 4 & 29.26697953 & $3.31 \mathrm{E}-06$ & 8849012 & 60.9696914 \\
\hline 5 & 29.14407721 & $3.31 \mathrm{E}-06$ & 8811852 & 60.7136583 \\
\hline
\end{tabular}

\begin{tabular}{|l|l|}
\hline$E(K p a)$ & $\begin{array}{l}\text { logE } \\
\text { (Kpa) }\end{array}$ \\
\hline 61143047 & 7.786347 \\
\hline 61110372 & 7.786115 \\
\hline 60891343 & 7.784556 \\
\hline 60969691 & 7.785114 \\
\hline 60713658 & 7.783286 \\
\hline
\end{tabular}


Cement

(37.8 degrees)

\begin{tabular}{|c|c|c|c|c|c|c|c|}
\hline $\begin{array}{l}\text { Freq } \\
(\mathrm{Hz})\end{array}$ & $\begin{array}{l}\text { Peak Displ. } \\
\text { Values (in) }\end{array}$ & $\begin{array}{l}\text { Peak } \\
\text { Load } \\
\text { Values } \\
\text { (lb-f) }\end{array}$ & $\begin{array}{l}\text { Peak Displ. } \\
\text { Time (secs) }\end{array}$ & $\begin{array}{l}\text { Peak Load } \\
\text { Time (secs) }\end{array}$ & $\begin{array}{l}\text { Phase } \\
\text { Shift } \\
\text { Values } \\
\text { (secs) }\end{array}$ & $\begin{array}{l}\text { Average } \\
\text { Displ. } \\
\text { (in) }\end{array}$ & $\begin{array}{l}\text { Average } \\
\text { Load (Ib) }\end{array}$ \\
\hline \multirow[t]{5}{*}{10} & 0.00004635 & 107.49 & 20.5319 & 20.521973 & 0.009929 & 4.6E-05 & 107.1218 \\
\hline & 0.00004635 & 107.289 & 20.63558 & 20.62435 & 0.01123 & & \\
\hline & 0.00004635 & 106.988 & 20.73438 & 20.724936 & 0.009439 & & \\
\hline & 0.00004635 & 107.412 & 20.83398 & 20.824545 & 0.009439 & & \\
\hline & 0.00004635 & 106.43 & 20.93311 & 20.92627 & 0.006835 & & \\
\hline \multirow[t]{5}{*}{5} & 0.00006631 & 103.985 & 40.20052 & 40.178875 & 0.021648 & 6.6E-05 & 114.2454 \\
\hline & 0.00006631 & 104.729 & 40.39974 & 40.380371 & 0.019371 & & \\
\hline & 0.00006631 & 104.633 & 40.59522 & 40.582848 & 0.012367 & & \\
\hline & 0.00006631 & 104.277 & 40.80534 & 40.786133 & 0.019207 & & \\
\hline & 0.00006631 & 103.604 & 40.99235 & 40.983398 & 0.008954 & & \\
\hline \multirow[t]{5}{*}{1} & 0.00010777 & 103.272 & 56.68604 & 56.626141 & 0.059894 & 0.00011 & 123.1953 \\
\hline & 0.00010777 & 102.99 & 57.69125 & 57.63916 & 0.052086 & & \\
\hline & 0.00010777 & 102.883 & 58.68181 & 58.616051 & 0.065754 & & \\
\hline & 0.00010777 & 103.102 & 59.71754 & 59.631348 & 0.086192 & & \\
\hline & 0.00010777 & 103.73 & 60.71501 & 60.61491 & 0.100098 & & \\
\hline \multirow[t]{5}{*}{0.5} & 0.00014151 & 106.517 & 82.17773 & 82.288574 & 0.11084 & 0.00014 & 127.7933 \\
\hline & 0.00014151 & 105.23 & 84.1823 & 84.255859 & 0.073562 & & \\
\hline & 0.00014151 & 105.985 & 86.16863 & 86.306808 & 0.138183 & & \\
\hline & 0.00014151 & 105.31 & 88.18523 & 88.290527 & 0.105301 & & \\
\hline & 0.00014151 & 105.924 & 90.11556 & 90.274094 & 0.158532 & & \\
\hline \multirow[t]{5}{*}{0.1} & 0.00019949 & 104.848 & 106.9883 & 106.3833 & 0.60498 & 0.0002 & 129.7586 \\
\hline & 0.00019949 & 104.018 & 117.2069 & 116.54167 & 0.6652 & & \\
\hline & 0.00019949 & 105.494 & 127.0112 & 126.65446 & 0.35677 & & \\
\hline & 0.00019949 & 105.721 & 136.8094 & 136.48618 & 0.32324 & & \\
\hline & 0.00019949 & 103.712 & 147.2655 & 146.60075 & 0.66472 & & \\
\hline
\end{tabular}

\begin{tabular}{|c|c|c|c|c|c|}
\hline \multicolumn{2}{|c|}{$\mathbf{1 0 H z}$} & \multicolumn{5}{l|}{} \\
\hline Cycle \# & P(lb-f) & A(in2) & & $\Delta$ & GL \\
\hline 1 & 107.48969 & 10.75 & & 0.00004635 & 3.5 \\
\hline 2 & 107.28922 & 10.75 & & 0.00004635 & 3.5 \\
\hline 3 & 106.98802 & 10.75 & & 0.00004635 & 3.5 \\
\hline 4 & 107.41166 & 10.75 & & 0.00004635 & 3.5 \\
\hline 5 & 106.43047 & 10.75 & & 0.00004635 & 3.5 \\
\hline
\end{tabular}

\begin{tabular}{|c|l|c|c|c|}
\hline Cycle \# & $\sigma=P / A$ & $\varepsilon=\Delta / G L$ & $\begin{array}{l}{\left[E^{*}\right]=\sigma / \varepsilon} \\
\text { (psi) }\end{array}$ & $\begin{array}{l}{\left[E^{*}\right]=\sigma / \varepsilon} \\
(\mathrm{GPa})\end{array}$ \\
\hline 1 & 9.99904093 & $1.3 \mathrm{E}-05$ & 754994 & 5.2019085 \\
\hline 2 & 9.98039256 & $1.3 \mathrm{E}-05$ & 753585.9 & 5.1922068 \\
\hline 3 & 9.95237395 & $1.3 \mathrm{E}-05$ & 751470.3 & 5.1776304 \\
\hline 4 & 9.99178233 & $1.3 \mathrm{E}-05$ & 754445.9 & 5.1981322 \\
\hline 5 & 9.90050884 & $1.3 \mathrm{E}-05$ & 747554.1 & 5.1506481 \\
\hline
\end{tabular}

\begin{tabular}{|l|l|}
\hline Kpa & log KPa \\
\hline 5201908 & 6.716163 \\
\hline 5192207 & 6.715352 \\
\hline 5177630 & 6.714131 \\
\hline 5198132 & 6.715847 \\
\hline 5150648 & 6.711862 \\
\hline
\end{tabular}




\begin{tabular}{|c|c|c|c|c|c|}
\hline \multicolumn{2}{|c|}{$5 \mathrm{~Hz}$} & \multicolumn{5}{l|}{} \\
\hline Cycle \# & P(lb-f) & A(in2) & & $\boldsymbol{\Delta}$ & GL \\
\hline 1 & 113.98477 & 10.75 & & 0.00006631 & 3.5 \\
\hline 2 & 114.72874 & 10.75 & & 0.00006631 & 3.5 \\
\hline 3 & 114.63306 & 10.75 & & 0.00006631 & 3.5 \\
\hline 4 & 114.27662 & 10.75 & & 0.00006631 & 3.5 \\
\hline 5 & 113.60381 & 10.75 & & 0.00006631 & 3.5 \\
\hline
\end{tabular}

\begin{tabular}{|c|l|c|c|c|}
\hline Cycle \# & $\sigma=P / A$ & $\varepsilon=\Delta / G L$ & $\begin{array}{l}{\left[E^{*}\right]=\sigma / \varepsilon} \\
\text { (psi) }\end{array}$ & $\begin{array}{l}{\left[E^{*}\right]=\sigma / \varepsilon} \\
(G P a)\end{array}$ \\
\hline 1 & 10.6032344 & $1.9 \mathrm{E}-05$ & 559657 & 3.8560366 \\
\hline 2 & 10.6724409 & $1.9 \mathrm{E}-05$ & 563309.8 & 3.8812046 \\
\hline 3 & 10.6635405 & $1.9 \mathrm{E}-05$ & 562840 & 3.8779678 \\
\hline 4 & 10.6303833 & $1.9 \mathrm{E}-05$ & 561089.9 & 3.8659097 \\
\hline 5 & 10.5677963 & $1.9 \mathrm{E}-05$ & 557786.5 & 3.8431489 \\
\hline
\end{tabular}

\begin{tabular}{|l|l|}
\hline$E$ (Kpa) & $\begin{array}{l}\text { logE } \\
\text { (Kpa) }\end{array}$ \\
\hline 3856037 & 6.586141 \\
\hline 3881205 & 6.588967 \\
\hline 3877968 & 6.588604 \\
\hline 3865910 & 6.587252 \\
\hline 3843149 & 6.584687 \\
\hline
\end{tabular}

\begin{tabular}{|c|c|c|c|c|c|}
\hline \multicolumn{2}{|c|}{ 1Hz } & \multicolumn{5}{l|}{} \\
\cline { 1 - 2 } Cycle \# & P(lb-f) & A(in2) & & $\Delta$ & GL \\
\hline 1 & 123.27248 & 10.75 & & 0.00010777 & 3.5 \\
\hline 2 & 122.98989 & 10.75 & & 0.00010777 & 3.5 \\
\hline 3 & 122.88288 & 10.75 & & 0.00010777 & 3.5 \\
\hline 4 & 123.10165 & 10.75 & & 0.00010777 & 3.5 \\
\hline 5 & 123.72961 & 10.75 & & 0.00010777 & 3.5 \\
\hline
\end{tabular}

\begin{tabular}{|c|c|c|l|l|}
\hline Cycle \# & $\sigma=P / A$ & $\varepsilon=\Delta-G L$ & $\begin{array}{l}{\left[E^{*}\right]=\sigma / \varepsilon} \\
(\mathbf{p s i})\end{array}$ & $\begin{array}{l}{\left[\mathrm{E}^{*}\right]=\sigma / \varepsilon} \\
(\mathrm{GPa})\end{array}$ \\
\hline 1 & 11.4672074 & $3.1 \mathrm{E}-05$ & 372403.8 & 2.5658621 \\
\hline 2 & 11.44092 & $3.1 \mathrm{E}-05$ & 371550.1 & 2.5599801 \\
\hline 3 & 11.4309656 & $3.1 \mathrm{E}-05$ & 371226.8 & 2.5577527 \\
\hline 4 & 11.4513163 & $3.1 \mathrm{E}-05$ & 371887.7 & 2.5623063 \\
\hline 5 & 11.5097312 & $3.1 \mathrm{E}-05$ & 373784.8 & 2.5753771 \\
\hline
\end{tabular}

\begin{tabular}{|l|l|}
\hline$E$ (Kpa) & $\begin{array}{l}\text { logE } \\
\text { (Kpa) }\end{array}$ \\
\hline 2565862 & 6.409233 \\
\hline 2559980 & 6.408237 \\
\hline 2557753 & 6.407859 \\
\hline 2562306 & 6.408631 \\
\hline 2575377 & 6.410841 \\
\hline
\end{tabular}

\begin{tabular}{|c|c|c|c|c|c|}
\hline \multicolumn{2}{|c|}{$\mathbf{0 . 5 H z}$} & \multicolumn{5}{l|}{} \\
\hline Cycle \# & P(lb-f) & A(in2) & & $\Delta$ & GL \\
\hline 1 & 128.51718 & 10.75 & & 0.00014151 & 3.5 \\
\hline 2 & 127.22974 & 10.75 & & 0.00014151 & 3.5 \\
\hline 3 & 127.98494 & 10.75 & & 0.00014151 & 3.5 \\
\hline 4 & 127.31049 & 10.75 & & 0.00014151 & 3.5 \\
\hline 5 & 127.92416 & 10.75 & & 0.00014151 & 3.5 \\
\cline { 5 - 6 } & & & & &
\end{tabular}




\begin{tabular}{|c|l|c|c|c|}
\hline Cycle \# & $\sigma=P / A$ & $\varepsilon=\Delta-G L$ & $\begin{array}{l}{\left[\mathrm{E}^{*}\right]=\sigma / \varepsilon} \\
\text { (psi) }\end{array}$ & $\begin{array}{l}{\left[\mathrm{E}^{*}\right]=\sigma / \varepsilon} \\
(\mathrm{GPa})\end{array}$ \\
\hline 1 & 11.9550865 & 4E-05 & 295694.8 & 2.0373375 \\
\hline 2 & 11.8353247 & $4 \mathrm{E}-05$ & 292732.7 & 2.0169282 \\
\hline 3 & 11.9055758 & $4 \mathrm{E}-05$ & 294470.3 & 2.0289001 \\
\hline 4 & 11.8428363 & $4 \mathrm{E}-05$ & 292918.5 & 2.0182083 \\
\hline 5 & 11.8999219 & 4E-05 & 294330.4 & 2.0279365 \\
\hline
\end{tabular}

\begin{tabular}{|l|r|}
\hline$E$ (Kpa) & $\begin{array}{l}\text { logE } \\
\text { (Kpa) }\end{array}$ \\
\hline 2037337 & 6.309063 \\
\hline 2016928 & 6.30469 \\
\hline 2028900 & 6.307261 \\
\hline 2018208 & 6.304966 \\
\hline 2027937 & 6.307054 \\
\hline
\end{tabular}

\begin{tabular}{|c|r|c|l|c|c|}
\hline \multicolumn{2}{|c|}{$\mathbf{0 . 1 H z}$} & \multicolumn{5}{l|}{} \\
\cline { 1 - 2 } Cycle \# & \multicolumn{1}{|c|}{$\mathbf{P}(\mathbf{l b}$-f) } & A(in2) & & $\boldsymbol{\Delta}$ & GL \\
\hline 1 & 129.84775 & 10.75 & & 0.00019949 & 3.5 \\
\hline 2 & 129.0177 & 10.75 & & 0.00019949 & 3.5 \\
\hline 3 & 130.49399 & 10.75 & & 0.00019949 & 3.5 \\
\hline 4 & 130.72139 & 10.75 & & 0.00019949 & 3.5 \\
\hline 5 & 128.71228 & 10.75 & & 0.00019949 & 3.5 \\
\hline
\end{tabular}

\begin{tabular}{|c|l|c|c|c|}
\hline Cycle \# & $\sigma=P / A$ & $\varepsilon=\Delta$-GL & $\begin{array}{l}{\left[E^{*}\right]=\sigma / \varepsilon} \\
(\mathbf{p s i})\end{array}$ & $\begin{array}{l}{\left[E^{*}\right]=\sigma / \varepsilon} \\
(\mathrm{GPa})\end{array}$ \\
\hline 1 & 12.0788605 & $5.7 \mathrm{E}-05$ & 211923.5 & 1.4601532 \\
\hline 2 & 12.0016465 & $5.7 \mathrm{E}-05$ & 210568.8 & 1.4508192 \\
\hline 3 & 12.1389758 & $5.7 \mathrm{E}-05$ & 212978.3 & 1.4674202 \\
\hline 4 & 12.1601293 & $5.7 \mathrm{E}-05$ & 213349.4 & 1.4699773 \\
\hline 5 & 11.9732353 & $5.7 \mathrm{E}-05$ & 210070.3 & 1.4473847 \\
\hline
\end{tabular}

\begin{tabular}{|l|l|}
\hline$E(K p a)$ & $\begin{array}{l}\text { logE } \\
\text { (Kpa) }\end{array}$ \\
\hline 1460153 & 6.164398 \\
\hline 1450819 & 6.161613 \\
\hline 1467420 & 6.166554 \\
\hline 1469977 & 6.167311 \\
\hline 1447385 & 6.160584 \\
\hline
\end{tabular}


$\mathrm{Fa} \odot$

(-9 degrees)

\begin{tabular}{|c|c|c|c|c|c|c|c|}
\hline $\begin{array}{l}\text { Freq } \\
(\mathrm{Hz})\end{array}$ & $\begin{array}{l}\text { Peak } \\
\text { Displ. } \\
\text { Values } \\
\text { (in) }\end{array}$ & $\begin{array}{l}\text { Peak } \\
\text { Load } \\
\text { Values } \\
\text { (lb-ft) }\end{array}$ & $\begin{array}{l}\text { Peak Displ. } \\
\text { Time (secs) }\end{array}$ & $\begin{array}{l}\text { Peak Load } \\
\text { Time (secs) }\end{array}$ & $\begin{array}{l}\text { Phase } \\
\text { Shift } \\
\text { Values } \\
\text { (secs) }\end{array}$ & $\begin{array}{l}\text { Average } \\
\text { Displ. } \\
\text { (in) }\end{array}$ & $\begin{array}{l}\text { Average } \\
\text { Load (Ib) }\end{array}$ \\
\hline \multirow[t]{5}{*}{10} & 8.32E-05 & 1020.9 & 20.5928 & 20.599121 & 0.00635 & 8.3E-05 & 1025.21 \\
\hline & 8.32E-05 & 1027.28 & 20.6982 & 20.697592 & 0.00065 & & \\
\hline & 8.32E-05 & 1027.28 & 20.7988 & 20.797527 & 0.0013 & & \\
\hline & 8.32E-05 & 1021.88 & 20.8983 & 20.898926 & 0.00065 & & \\
\hline & 8.32E-05 & 1028.7 & 20.9935 & 20.99707 & 0.00358 & & \\
\hline \multirow[t]{5}{*}{5} & 8.97E-05 & 1024.62 & 40.2668 & 40.262695 & 0.00407 & 9E-05 & 1027.47 \\
\hline & 8.97E-05 & 1030.22 & 40.4614 & 40.460289 & 0.00114 & & \\
\hline & 8.97E-05 & 1027.04 & 40.6668 & 40.661785 & 0.00505 & & \\
\hline & 8.97E-05 & 1031.18 & 40.8669 & 40.859539 & 0.00732 & & \\
\hline & $8.97 E-05$ & 1024.28 & 41.0674 & 41.062828 & 0.00455 & & \\
\hline \multirow[t]{5}{*}{1} & 0.000102 & 1026.1 & 56.6636 & 56.664391 & 0.00082 & 0.0001 & 1023.79 \\
\hline & 0.000102 & 1026.14 & 57.6964 & 57.667809 & 0.0286 & & \\
\hline & 0.000102 & 1020.17 & 58.7085 & 58.688805 & 0.01969 & & \\
\hline & 0.000102 & 1020.3 & 59.7246 & 59.688805 & 0.0358 & & \\
\hline & 0.000102 & 1026.26 & 60.7646 & 60.66618 & 0.09847 & & \\
\hline \multirow[t]{5}{*}{0.5} & 0.000116 & 1021.2 & 82.2616 & 82.216309 & 0.04525 & 0.00012 & 1022.38 \\
\hline & 0.000116 & 1021.32 & 84.2842 & 84.216965 & 0.06722 & & \\
\hline & 0.000116 & 1027.04 & 86.279 & 86.172363 & 0.10661 & & \\
\hline & 0.000116 & 1015.33 & 88.3063 & 88.236328 & 0.06999 & & \\
\hline & 0.000116 & 1027 & 90.3351 & 90.171715 & 0.16341 & & \\
\hline \multirow[t]{5}{*}{0.1} & 0.000176 & 1027 & 196.974 & 196.34392 & 0.6302 & 0.00018 & 1025.46 \\
\hline & 0.000176 & 1021.17 & 207.779 & 206.48503 & 1.29363 & & \\
\hline & 0.000176 & 1027 & 216.627 & 216.31967 & 0.30713 & & \\
\hline & 0.000176 & 1026.88 & 218.757 & 218.2693 & 0.4875 & & \\
\hline & 0.000176 & 1025.24 & 221.563 & 220.985 & 0.578 & & \\
\hline \multicolumn{6}{|c|}{$10 \mathrm{~Hz}$} & & \\
\hline Cycle \# & $P(l b-f)$ & $A($ in2) & & $\Delta$ & GL & & \\
\hline 1 & 1020.905 & 10.75 & & 0.00008325 & 3.5 & & \\
\hline 2 & 1027.278 & 10.75 & & 0.00008325 & 3.5 & & \\
\hline 3 & 1027.284 & 10.75 & & 0.00008325 & 3.5 & & \\
\hline 4 & 1021.879 & 10.75 & & 0.00008325 & 3.5 & & \\
\hline 5 & 1028.698 & 10.75 & & 0.00008325 & 3.5 & & \\
\hline
\end{tabular}

\begin{tabular}{|c|c|c|c|c|}
\hline Cycle \# & $\sigma=P / A$ & $\varepsilon=\Delta-G L$ & $\begin{array}{l}{\left[\mathrm{E}^{*}\right]=\sigma / \varepsilon} \\
\text { (psi) }\end{array}$ & $\begin{array}{l}{\left[\mathrm{E}^{*}\right]=\sigma / \varepsilon} \\
(\mathrm{GPa})\end{array}$ \\
\hline 1 & 94.96788 & 2.4E-05 & 3992741 & 27.509986 \\
\hline 2 & 95.56078 & 2.4E-05 & 4017669 & 27.681736 \\
\hline 3 & 95.56134 & $2.4 \mathrm{E}-05$ & 4017692 & 27.681898 \\
\hline 4 & 95.05853 & 2.4E-05 & 3996552 & 27.536246 \\
\hline 5 & 95.69279 & 2.4E-05 & 4023219 & 27.719976 \\
\hline
\end{tabular}

\begin{tabular}{|l|r|}
\hline Kpa & \multicolumn{1}{|c|}{$\log \mathrm{KPa}$} \\
\hline $2.8 \mathrm{E}+07$ & 7.43949 \\
\hline $2.8 \mathrm{E}+07$ & 7.44219 \\
\hline $2.8 \mathrm{E}+07$ & 7.4422 \\
\hline $2.8 \mathrm{E}+07$ & 7.4399 \\
\hline $2.8 \mathrm{E}+07$ & 7.44279 \\
\hline
\end{tabular}




\begin{tabular}{|c|r|c|l|c|c|}
\hline \multicolumn{2}{|c|}{$\mathbf{5 H z}$} & \multicolumn{5}{|l|}{} \\
\cline { 1 - 2 } Cycle \# & P(lb-f) & A(in2) & & $\Delta$ & GL \\
\hline 1 & 1024.617 & 10.75 & & 0.00008965 & 3.5 \\
\hline 2 & 1030.222 & 10.75 & & 0.00008965 & 3.5 \\
\hline 3 & 1027.044 & 10.75 & & 0.00008965 & 3.5 \\
\hline 4 & 1031.18 & 10.75 & & 0.00008965 & 3.5 \\
\hline 5 & 1024.285 & 10.75 & & 0.00008965 & 3.5 \\
\hline
\end{tabular}

\begin{tabular}{|c|l|c|c|c|}
\hline Cycle \# & $\sigma=P / A$ & $\varepsilon=\Delta-G L$ & $\begin{array}{l}{\left[E^{*}\right]=\sigma / \varepsilon} \\
\text { (psi) }\end{array}$ & $\begin{array}{l}{\left[E^{*}\right]=\sigma / \varepsilon} \\
\text { (GPa) }\end{array}$ \\
\hline 1 & 95.31323 & $2.6 \mathrm{E}-05$ & 3721077 & 25.638221 \\
\hline 2 & 95.83464 & $2.6 \mathrm{E}-05$ & 3741433 & 25.778475 \\
\hline 3 & 95.53901 & $2.6 \mathrm{E}-05$ & 3729892 & 25.698955 \\
\hline 4 & 95.92371 & $2.6 \mathrm{E}-05$ & 3744911 & 25.802434 \\
\hline 5 & 95.28228 & $2.6 \mathrm{E}-05$ & 3719869 & 25.629896 \\
\hline
\end{tabular}

\begin{tabular}{|l|l|}
\hline$E(K p a)$ & $\begin{array}{l}\text { logE } \\
\text { (Kpa) }\end{array}$ \\
\hline $2.6 \mathrm{E}+07$ & 7.40889 \\
\hline $2.6 \mathrm{E}+07$ & 7.41126 \\
\hline $2.6 \mathrm{E}+07$ & 7.40992 \\
\hline $2.6 \mathrm{E}+07$ & 7.41166 \\
\hline $2.6 \mathrm{E}+07$ & 7.40875 \\
\hline
\end{tabular}

\begin{tabular}{|c|c|c|c|c|c|}
\hline \multicolumn{2}{|c|}{$\mathbf{H Z}$} & \multicolumn{5}{|l|}{} \\
\cline { 1 - 2 } Cycle \# & P(lb-f) & A(in2) & & $\boldsymbol{\Delta}$ & GL \\
\hline 1 & 1026.096 & 10.75 & & 0.00010192 & 3.5 \\
\hline 2 & 1026.137 & 10.75 & & 0.00010192 & 3.5 \\
\hline 3 & 1020.174 & 10.75 & & 0.00010192 & 3.5 \\
\hline 4 & 1020.295 & 10.75 & & 0.00010192 & 3.5 \\
\hline 5 & 1026.264 & 10.75 & & 0.00010192 & 3.5 \\
\hline
\end{tabular}

\begin{tabular}{|c|l|c|l|l|}
\hline Cycle \# & $\sigma=P / A$ & $\varepsilon=\Delta-G L$ & $\begin{array}{l}{\left[E^{*}\right]=\sigma / \varepsilon} \\
(p s i)\end{array}$ & $\begin{array}{l}{\left[E^{*}\right]=\sigma / \varepsilon} \\
(G P a)\end{array}$ \\
\hline 1 & 95.45078 & $2.9 E-05$ & 3277927 & 22.584918 \\
\hline 2 & 95.45457 & $2.9 E-05$ & 3278057 & 22.585814 \\
\hline 3 & 94.89994 & $2.9 E-05$ & 3259011 & 22.454583 \\
\hline 4 & 94.91116 & $2.9 E-05$ & 3259396 & 22.457237 \\
\hline 5 & 95.46644 & $2.9 E-05$ & 3278465 & 22.588623 \\
\hline
\end{tabular}

\begin{tabular}{|l|r|}
\hline $\mathrm{E}(\mathrm{Kpa})$ & $\begin{array}{l}\text { logE } \\
\text { (Kpa) }\end{array}$ \\
\hline $2.3 \mathrm{E}+07$ & 7.35382 \\
\hline $2.3 \mathrm{E}+07$ & 7.35384 \\
\hline $2.2 \mathrm{E}+07$ & 7.3513 \\
\hline $2.2 \mathrm{E}+07$ & 7.35136 \\
\hline $2.3 \mathrm{E}+07$ & 7.35389 \\
\hline
\end{tabular}

\begin{tabular}{|c|c|c|c|c|c|}
\hline \multicolumn{2}{|c|}{$\mathbf{0 . 5 H z}$} & \multicolumn{5}{l|}{} \\
\hline Cycle \# & P(lb-f) & A(in2) & & $\Delta$ & GL \\
\hline 1 & 1021.2 & 10.75 & & 0.00011562 & 3.5 \\
\hline 2 & 1021.319 & 10.75 & & 0.00011562 & 3.5 \\
\hline 3 & 1027.037 & 10.75 & & 0.00011562 & 3.5 \\
\hline 4 & 1015.326 & 10.75 & & 0.00011562 & 3.5 \\
\hline 5 & 1027.003 & 10.75 & & 0.00011562 & 3.5 \\
\end{tabular}




\begin{tabular}{|c|c|c|c|c|}
\hline Cycle \# & $\sigma=P / A$ & $\varepsilon=\Delta-G L$ & $\begin{array}{l}{\left[\mathrm{E}^{*}\right]=\sigma / \varepsilon} \\
\text { (psi) }\end{array}$ & $\begin{array}{l}{\left[E^{*}\right]=\sigma / \varepsilon} \\
(\mathrm{GPa})\end{array}$ \\
\hline 1 & 94.99535 & 3.3E-05 & 2875678 & 19.813421 \\
\hline 2 & 95.00638 & 3.3E-05 & 2876012 & 19.815722 \\
\hline 3 & 95.53836 & 3.3E-05 & 2892116 & 19.926678 \\
\hline 4 & 94.44889 & 3.3E-05 & 2859136 & 19.699445 \\
\hline 5 & 95.53518 & 3.3E-05 & 2892020 & 19.926015 \\
\hline
\end{tabular}

\begin{tabular}{|c|l|}
\hline$E(K p a)$ & $\begin{array}{l}\text { logE } \\
\text { (Kpa) }\end{array}$ \\
\hline $2 \mathrm{E}+07$ & 7.29696 \\
\hline $2 \mathrm{E}+07$ & 7.29701 \\
\hline $2 \mathrm{E}+07$ & 7.29943 \\
\hline $2 \mathrm{E}+07$ & 7.29445 \\
\hline $2 \mathrm{E}+07$ & 7.29942 \\
\hline
\end{tabular}

\begin{tabular}{|c|c|c|l|c|c|}
\hline \multicolumn{2}{|c|}{$\mathbf{0 . 1 H z}$} & \multicolumn{5}{|l|}{} \\
\hline Cycle \# & P(lb-f) & A(in2) & & $\boldsymbol{\Delta}$ & GL \\
\hline 1 & 1026.998 & 10.75 & & 0.00017641 & 3.5 \\
\hline 2 & 1021.169 & 10.75 & & 0.00017641 & 3.5 \\
\hline 3 & 1026.997 & 10.75 & & 0.00017641 & 3.5 \\
\hline 4 & 1026.875 & 10.75 & & 0.00017641 & 3.5 \\
\hline 5 & 1025.235 & 10.75 & & 0.00017641 & 3.5 \\
\hline
\end{tabular}

\begin{tabular}{|c|l|c|c|r|}
\hline Cycle \# & $\boldsymbol{\sigma = P / A}$ & $\boldsymbol{\varepsilon}=\Delta-\mathrm{GL}$ & $\begin{array}{l}{\left[\mathrm{E}^{*}\right]=\sigma / \varepsilon} \\
\text { (psi) }\end{array}$ & $\begin{array}{l}{\left[\mathrm{E}^{*}\right]=\sigma / \varepsilon} \\
(\mathrm{GPa})\end{array}$ \\
\hline 1 & 95.53473 & $5 \mathrm{E}-05$ & 1895425 & 13.059477 \\
\hline 2 & 94.99248 & $5 \mathrm{E}-05$ & 1884666 & 12.985352 \\
\hline 3 & 95.53461 & $5 \mathrm{E}-05$ & 1895422 & 13.05946 \\
\hline 4 & 95.52329 & $5 \mathrm{E}-05$ & 1895198 & 13.057913 \\
\hline 5 & 95.3707 & $5 \mathrm{E}-05$ & 1892170 & 13.037053 \\
\hline
\end{tabular}

\begin{tabular}{|l|l|}
\hline$E(K p a)$ & $\begin{array}{l}\text { logE } \\
\text { (Kpa) }\end{array}$ \\
\hline $1.3 \mathrm{E}+07$ & 7.11593 \\
\hline $1.3 \mathrm{E}+07$ & 7.11345 \\
\hline $1.3 \mathrm{E}+07$ & 7.11593 \\
\hline $1.3 \mathrm{E}+07$ & 7.11587 \\
\hline $1.3 \mathrm{E}+07$ & 7.11518 \\
\hline
\end{tabular}


(4.4 degrees)

\begin{tabular}{|c|c|c|c|c|c|c|c|}
\hline Freq (Hz) & $\begin{array}{l}\text { Peak Displ. } \\
\text { Values (in) }\end{array}$ & $\begin{array}{c}\text { Peak } \\
\text { Load } \\
\text { Values } \\
\text { (lb-f) }\end{array}$ & $\begin{array}{l}\text { Peak Displ. } \\
\text { Time (secs) }\end{array}$ & $\begin{array}{c}\text { Peak Load } \\
\text { Time (secs) }\end{array}$ & $\begin{array}{l}\text { Phase } \\
\text { Shift } \\
\text { Values } \\
\text { (secs) }\end{array}$ & $\begin{array}{l}\text { Average } \\
\text { Displ. (in) }\end{array}$ & $\begin{array}{l}\text { Average } \\
\text { Load (Ib) }\end{array}$ \\
\hline \multirow[t]{5}{*}{10} & 8.843E-05 & 782.979 & 20.63607 & 20.628256 & 0.007812 & 8.84E-05 & 780.3022 \\
\hline & 8.843E-05 & 781.082 & 20.73535 & 20.72933 & 0.006022 & & \\
\hline & 8.843E-05 & 775.438 & 20.83513 & 20.831543 & 0.003582 & & \\
\hline & 8.843E-05 & 782.979 & 20.9349 & 20.928061 & 0.006835 & & \\
\hline & 8.843E-05 & 779.033 & 21.03499 & 21.030437 & 0.004557 & & \\
\hline \multirow[t]{5}{*}{5} & $9.964 \mathrm{E}-05$ & 785.308 & 40.19157 & 40.187176 & 0.004394 & 9.96E-05 & 783.2961 \\
\hline & 9.964 E-05 & 785.717 & 40.38623 & 40.387047 & 0.000817 & & \\
\hline & $9.964 \mathrm{E}-05$ & 786.027 & 40.5918 & 40.585289 & 0.006508 & & \\
\hline & 9.964 E-05 & 777.924 & 40.79248 & 40.790691 & 0.001789 & & \\
\hline & 9.964E-05 & 781.505 & 40.9917 & 40.988531 & 0.003168 & & \\
\hline \multirow[t]{5}{*}{1} & 0.0001211 & 779.828 & 56.6958 & 56.616051 & 0.07975 & 0.000117 & 782.6533 \\
\hline & 0.0001211 & 781.049 & 57.68197 & 57.611328 & 0.070641 & & \\
\hline & 0.0001211 & 783.578 & 58.66553 & 58.065145 & 0.600382 & & \\
\hline & 0.0001211 & 785.068 & 59.68295 & 59.596355 & 0.08659 & & \\
\hline & 0.0001211 & 783.744 & 60.69385 & 60.605309 & 0.088539 & & \\
\hline \multirow[t]{5}{*}{0.5} & 0.0001473 & 779.321 & 82.37207 & 82.139 & 0.23307 & 0.000142 & 776.6186 \\
\hline & 0.0001473 & 779.116 & 84.34197 & 84.140625 & 0.20134 & & \\
\hline & 0.0001473 & 774.825 & 86.3532 & 86.159348 & 0.193847 & & \\
\hline & 0.0001473 & 774.791 & 88.36572 & 88.158531 & 0.207192 & & \\
\hline & 0.0001473 & 775.04 & 90.37614 & 90.158691 & 0.217453 & & \\
\hline \multirow[t]{5}{*}{0.1} & 0.0001647 & 784.694 & 177.3254 & 176.24707 & 1.07829 & 0.000161 & 784.2826 \\
\hline & 0.0001647 & 784.957 & 187.2585 & 186.2518 & 1.00667 & & \\
\hline & 0.0001647 & 783.865 & 197.245 & 196.27946 & 0.9655 & & \\
\hline & 0.0001647 & 784.551 & 207.1693 & 206.1945 & 0.97478 & & \\
\hline & 0.0001647 & 783.347 & 217.1458 & 216.29004 & 0.8558 & & \\
\hline
\end{tabular}

\begin{tabular}{|c|c|c|c|c|c|}
\hline \multicolumn{2}{|c|}{$10 \mathrm{~Hz}$} & \multicolumn{5}{l|}{} \\
\cline { 1 - 2 } Cycle \# & P(lb-f) & A(in2) & & $\Delta$ & GL \\
\hline 1 & 782.97931 & 10.75 & & 0.00008843 & 3.5 \\
\hline 2 & 781.08203 & 10.75 & & 0.00008843 & 3.5 \\
\hline 3 & 775.43768 & 10.75 & & 0.00008843 & 3.5 \\
\hline 4 & 782.97925 & 10.75 & & 0.00008843 & 3.5 \\
\hline 5 & 779.03259 & 10.75 & & 0.00008843 & 3.5 \\
\hline
\end{tabular}

\begin{tabular}{|c|l|c|c|c|}
\hline Cycle \# & $\sigma=P / A$ & $\varepsilon=\Delta-G L$ & $\begin{array}{l}{\left[E^{*}\right]=\sigma / \varepsilon} \\
\text { (psi) }\end{array}$ & $\begin{array}{l}{\left[E^{*}\right]=\sigma / \varepsilon} \\
\text { (GPa) }\end{array}$ \\
\hline 1 & 72.835285 & $2.5 E-05$ & 2882651 & 19.861466 \\
\hline 2 & 72.658793 & $2.5 E-05$ & 2875666 & 19.813338 \\
\hline 3 & 72.133738 & $2.5 E-05$ & 2854885 & 19.670161 \\
\hline 4 & 72.835279 & $2.5 E-05$ & 2882651 & 19.861464 \\
\hline 5 & 72.468148 & $2.5 E-05$ & 2868121 & 19.761351 \\
\hline
\end{tabular}

\begin{tabular}{|l|l|}
\hline Kpa & log KPa \\
\hline 19861466 & 7.298011 \\
\hline 19813338 & 7.296958 \\
\hline 19670161 & 7.293808 \\
\hline 19861464 & 7.298011 \\
\hline 19761351 & 7.295817 \\
\hline
\end{tabular}




\begin{tabular}{|c|c|c|c|c|c|}
\cline { 1 - 2 } \multicolumn{2}{|c|}{$5 \mathrm{~Hz}$} & \multicolumn{5}{l|}{} \\
\hline Cycle \# & P(lb-f) & A(in2) & & $\Delta$ & GL \\
\hline 1 & 785.30774 & 10.75 & & 0.00009964 & 3.5 \\
\hline 2 & 785.71698 & 10.75 & & 0.00009964 & 3.5 \\
\hline 3 & 786.02667 & 10.75 & & 0.00009964 & 3.5 \\
\hline 4 & 777.92383 & 10.75 & & 0.00009964 & 3.5 \\
\hline 5 & 781.50531 & 10.75 & & 0.00009964 & 3.5 \\
\hline
\end{tabular}

\begin{tabular}{|c|c|c|c|c|}
\hline Cycle \# & $\sigma=P / A$ & $\varepsilon=\Delta-G L$ & $\begin{array}{l}{\left[E^{*}\right]=\sigma / \varepsilon} \\
(p s i)\end{array}$ & $\begin{array}{l}{\left[E^{*}\right]=\sigma / \varepsilon} \\
(\mathrm{GPa})\end{array}$ \\
\hline 1 & 73.051883 & $2.8 \mathrm{E}-05$ & 2565974 & 17.67956 \\
\hline 2 & 73.089952 & $2.8 \mathrm{E}-05$ & 2567311 & 17.688773 \\
\hline 3 & 73.11876 & $2.8 \mathrm{E}-05$ & 2568323 & 17.695745 \\
\hline 4 & 72.365007 & $2.8 \mathrm{E}-05$ & 2541847 & 17.513327 \\
\hline 5 & 72.698168 & $2.8 \mathrm{E}-05$ & 2553550 & 17.593956 \\
\hline
\end{tabular}

\begin{tabular}{|l|l|}
\hline$E(K p a)$ & $\begin{array}{l}\text { logE } \\
\text { (Kpa) }\end{array}$ \\
\hline 17679560 & 7.247471 \\
\hline 17688773 & 7.247698 \\
\hline 17695745 & 7.247869 \\
\hline 17513327 & 7.243369 \\
\hline 17593956 & 7.245364 \\
\hline
\end{tabular}

\begin{tabular}{|c|c|c|c|c|c|}
\hline \multicolumn{2}{|c|}{ 1HZ } & \multicolumn{5}{l|}{} \\
\cline { 1 - 2 } Cycle \# & P(lb-f) & A(in2) & & $\Delta$ & GL \\
\hline 1 & 779.828 & 10.75 & & 0.00012110 & 3.5 \\
\hline 2 & 781.04883 & 10.75 & & 0.00012110 & 3.5 \\
\hline 3 & 783.57776 & 10.75 & & 0.00012110 & 3.5 \\
\hline 4 & 785.06812 & 10.75 & & 0.00012110 & 3.5 \\
\hline 5 & 783.7439 & 10.75 & & 0.00012110 & 3.5 \\
\hline
\end{tabular}

\begin{tabular}{|c|c|c|c|c|}
\hline Cycle \# & $\sigma=P / A$ & $\varepsilon=\Delta-G L$ & $\begin{array}{l}{\left[E^{*}\right]=\sigma / \varepsilon} \\
\text { (psi) }\end{array}$ & $\begin{array}{l}{\left[E^{*}\right]=\sigma / \varepsilon} \\
(\mathrm{GPa})\end{array}$ \\
\hline 1 & 72.54214 & $3.5 \mathrm{E}-05$ & 2096667 & 14.446036 \\
\hline 2 & 72.655705 & $3.5 \mathrm{E}-05$ & 2099949 & 14.468651 \\
\hline 3 & 72.890954 & $3.5 \mathrm{E}-05$ & 2106749 & 14.515499 \\
\hline 4 & 73.029593 & $3.5 \mathrm{E}-05$ & 2110756 & 14.543107 \\
\hline 5 & 72.906409 & $3.5 \mathrm{E}-05$ & 2107195 & 14.518577 \\
\hline
\end{tabular}

\begin{tabular}{|l|l|}
\hline$E(K p a)$ & $\begin{array}{l}\text { logE } \\
\text { (Kpa) }\end{array}$ \\
\hline 14446036 & 7.159749 \\
\hline 14468651 & 7.160428 \\
\hline 14515499 & 7.161832 \\
\hline 14543107 & 7.162657 \\
\hline 14518577 & 7.161924 \\
\hline
\end{tabular}

\begin{tabular}{|c|c|c|c|c|c|}
\hline \multicolumn{2}{|c|}{$\mathbf{0 . 5 H z}$} & \multicolumn{1}{l|}{} \\
\hline Cycle \# & P(lb-f) & A(in2) & & $\boldsymbol{\Delta}$ & GL \\
\hline 1 & 779.32068 & 10.75 & & 0.00014734 & 3.5 \\
\hline 2 & 779.11646 & 10.75 & & 0.00014734 & 3.5 \\
\hline 3 & 774.82477 & 10.75 & & 0.00014734 & 3.5 \\
\hline 4 & 774.79114 & 10.75 & & 0.00014734 & 3.5 \\
\hline 5 & 775.0401 & 10.75 & & 0.00014734 & 3.5 \\
\hline
\end{tabular}




\begin{tabular}{|c|c|c|c|c|}
\hline Cycle \# & $\sigma=P / A$ & $\varepsilon=\Delta-G L$ & $\begin{array}{l}{\left[\mathrm{E}^{*}\right]=\sigma / \varepsilon} \\
\text { (psi) }\end{array}$ & $\begin{array}{l}{\left[\mathrm{E}^{*}\right]=\sigma / \varepsilon} \\
(\mathrm{GPa})\end{array}$ \\
\hline 1 & 72.494947 & 4.2E-05 & 1722039 & 11.86485 \\
\hline 2 & 72.47595 & 4.2E-05 & 1721588 & 11.861741 \\
\hline 3 & 72.076723 & 4.2E-05 & 1712105 & 11.796402 \\
\hline 4 & 72.073594 & 4.2E-05 & 1712030 & 11.79589 \\
\hline 5 & 72.096753 & 4.2E-05 & 1712581 & 11.79968 \\
\hline
\end{tabular}

\begin{tabular}{|l|r|}
\hline$E(K p a)$ & $\begin{array}{l}\text { logE } \\
\text { (Kpa) }\end{array}$ \\
\hline 11864850 & 7.074262 \\
\hline 11861741 & 7.074148 \\
\hline 11796402 & 7.07175 \\
\hline 11795890 & 7.071731 \\
\hline 11799680 & 7.07187 \\
\hline
\end{tabular}

\begin{tabular}{|c|c|c|l|c|c|}
\hline \multicolumn{2}{|c|}{$\mathbf{0 . 1 H z}$} & \multicolumn{5}{l|}{} \\
\cline { 1 - 2 } Cycle \# & P(lb-f) & A(in2) & & $\Delta$ & GL \\
\hline 1 & 784.69366 & 10.75 & & 0.00016473 & 3.5 \\
\hline 2 & 784.95685 & 10.75 & & 0.00016473 & 3.5 \\
\hline 3 & 783.86487 & 10.75 & & 0.00016473 & 3.5 \\
\hline 4 & 784.55066 & 10.75 & & 0.00016473 & 3.5 \\
\hline 5 & 783.34705 & 10.75 & & 0.00016473 & 3.5 \\
\hline
\end{tabular}

\begin{tabular}{|c|l|c|c|c|}
\hline Cycle \# & $\sigma=P / A$ & $\varepsilon=\Delta-G L$ & $\begin{array}{l}{\left[E^{*}\right]=\sigma / \varepsilon} \\
(p s i)\end{array}$ & $\begin{array}{l}{\left[E^{*}\right]=\sigma / \varepsilon} \\
(\mathrm{GPa})\end{array}$ \\
\hline 1 & 72.994759 & $4.7 \mathrm{E}-05$ & 1550867 & 10.685475 \\
\hline 2 & 73.019242 & $4.7 \mathrm{E}-05$ & 1551387 & 10.689059 \\
\hline 3 & 72.917662 & $4.7 \mathrm{E}-05$ & 1549229 & 10.674189 \\
\hline 4 & 72.981457 & $4.7 \mathrm{E}-05$ & 1550585 & 10.683528 \\
\hline 5 & 72.869493 & $4.7 \mathrm{E}-05$ & 1548206 & 10.667138 \\
\hline
\end{tabular}

\begin{tabular}{|l|l|}
\hline$E(K p a)$ & $\begin{array}{l}\text { logE } \\
\text { (Kpa) }\end{array}$ \\
\hline 10685475 & 7.028794 \\
\hline 10689059 & 7.028939 \\
\hline 10674189 & 7.028335 \\
\hline 10683528 & 7.028715 \\
\hline 10667138 & 7.028048 \\
\hline
\end{tabular}


(21.1 degrees)

\begin{tabular}{|c|c|c|c|c|c|c|c|}
\hline Freq (Hz) & $\begin{array}{l}\text { Peak Displ. } \\
\text { Values (in) }\end{array}$ & $\begin{array}{l}\text { Peak } \\
\text { Load } \\
\text { Values } \\
\text { (lb-ft) }\end{array}$ & $\begin{array}{l}\text { Peak Displ. } \\
\text { Time (secs) }\end{array}$ & $\begin{array}{l}\text { Peak Load } \\
\text { Time (secs) }\end{array}$ & $\begin{array}{l}\text { Phase } \\
\text { Shift } \\
\text { Values } \\
\text { (secs) }\end{array}$ & $\begin{array}{l}\text { Average } \\
\text { Displ. (in) }\end{array}$ & $\begin{array}{l}\text { Average } \\
\text { Load (Ib) }\end{array}$ \\
\hline \multirow[t]{5}{*}{10} & 6.972E-05 & 280.586 & 29.34245 & 29.38916 & -0.04671 & 6.97E-05 & 280.1274 \\
\hline & 6.972E-05 & 280.551 & 29.49658 & 29.489258 & 0.007324 & & \\
\hline & $6.972 \mathrm{E}-05$ & 280.016 & 29.59912 & 29.590008 & 0.009113 & & \\
\hline & 6.972E-05 & 279.075 & 29.69434 & 29.690918 & 0.003418 & & \\
\hline & $6.972 E-05$ & 280.409 & 29.80013 & 29.789551 & 0.01058 & & \\
\hline \multirow[t]{5}{*}{5} & 0.0001152 & 280.55 & 48.76318 & 48.744629 & 0.018555 & 0.000115 & 280.458 \\
\hline & 0.0001152 & 281.34 & 48.96484 & 48.41246 & -0.55238 & & \\
\hline & 0.0001152 & 280.526 & 49.16309 & 49.144859 & 0.018227 & & \\
\hline & 0.0001152 & 280.324 & 49.36165 & 49.345379 & 0.016274 & & \\
\hline & 0.0001152 & 279.55 & 49.56201 & 49.546875 & 0.015137 & & \\
\hline \multirow[t]{5}{*}{1.} & 0.0001413 & 287.594 & 65.45671 & 65.37175 & 0.084961 & 0.000136 & 287.7216 \\
\hline & 0.0001413 & 287.539 & 66.45036 & 66.370605 & 0.079758 & & \\
\hline & 0.0001413 & 287.56 & 67.44743 & 67.370934 & 0.076499 & & \\
\hline & 0.0001413 & 288.35 & 68.47168 & 68.361008 & 0.110672 & & \\
\hline & 0.0001413 & 287.565 & 69.47624 & 69.366539 & 0.109703 & & \\
\hline \multirow[t]{5}{*}{0.5} & 0.0001699 & 287.788 & 91.10352 & 90.889816 & 0.2137 & 0.000164 & 287.7919 \\
\hline & 0.0001699 & 286.907 & 93.0892 & 92.906578 & 0.182617 & & \\
\hline & 0.0001699 & 288.718 & 95.10629 & 94.854172 & 0.252113 & & \\
\hline & 0.0001699 & 287.789 & 97.09489 & 96.888184 & 0.20671 & & \\
\hline & 0.0001699 & 287.758 & 99.04232 & 98.86882 & 0.1735 & & \\
\hline \multirow[t]{5}{*}{0.1} & 0.0002543 & 287.152 & 205.9115 & 205.04851 & 0.86296 & 0.000237 & 286.7488 \\
\hline & 0.0002543 & 286.664 & 215.8386 & 215.0498 & 0.78875 & & \\
\hline & 0.0002543 & 287.026 & 225.8423 & 224.93864 & 0.90365 & & \\
\hline & 0.0002543 & 285.357 & 235.8387 & 235.07114 & 0.76757 & & \\
\hline & 0.0002543 & 287.545 & 245.6803 & 245.02866 & 0.65168 & & \\
\hline
\end{tabular}

\begin{tabular}{|c|c|c|c|c|c|}
\hline \multicolumn{2}{|c|}{$10 \mathrm{~Hz}$} & \multicolumn{5}{l|}{} \\
\cline { 1 - 2 } Cycle \# & P(lb-f) & A(in2) & & $\Delta$ & GL \\
\hline 1 & 280.58624 & 10.75 & & 0.00006972 & 3.5 \\
\hline 2 & 280.55148 & 10.75 & & 0.00006972 & 3.5 \\
\hline 3 & 280.01596 & 10.75 & & 0.00006972 & 3.5 \\
\hline 4 & 279.07468 & 10.75 & & 0.00006972 & 3.5 \\
\hline 5 & 280.40851 & 10.75 & & 0.00006972 & 3.5 \\
\hline
\end{tabular}

\begin{tabular}{|c|l|c|l|l|}
\hline Cycle \# & $\sigma=P / A$ & $\varepsilon=\Delta-G L$ & $\begin{array}{l}{\left[E^{*}\right]=\sigma / \varepsilon} \\
(p s i)\end{array}$ & $\begin{array}{l}{\left[E^{*}\right]=\sigma / \varepsilon} \\
(\mathrm{GPa})\end{array}$ \\
\hline 1 & 26.101046 & $2 \mathrm{E}-05$ & 1310356 & 9.02835354 \\
\hline 2 & 26.097812 & $2 \mathrm{E}-05$ & 1310194 & 9.02723507 \\
\hline 3 & 26.047996 & $2 \mathrm{E}-05$ & 1307693 & 9.01000378 \\
\hline 4 & 25.960435 & $2 \mathrm{E}-05$ & 1303297 & 8.97971645 \\
\hline 5 & 26.084513 & $2 \mathrm{E}-05$ & 1309526 & 9.02263476 \\
\hline
\end{tabular}

\begin{tabular}{|l|l|}
\hline $\mathrm{Kpa}$ & $\log \mathrm{KPa}$ \\
\hline 9028354 & 6.955609 \\
\hline 9027235 & 6.955555 \\
\hline 9010004 & 6.954725 \\
\hline 8979716 & 6.953263 \\
\hline 9022635 & 6.955333 \\
\hline
\end{tabular}




\begin{tabular}{|c|c|c|c|c|c|}
\hline \multicolumn{2}{|c|}{$5 \mathrm{~Hz}$} & \multicolumn{5}{l|}{} \\
\hline Cycle \# & P(lb-f) & A(in2) & & $\Delta$ & GL \\
\hline 1 & 280.55035 & 10.75 & & 0.00011518 & 3.5 \\
\hline 2 & 281.34003 & 10.75 & & 0.00011518 & 3.5 \\
\hline 3 & 280.52609 & 10.75 & & 0.00011518 & 3.5 \\
\hline 4 & 280.32376 & 10.75 & & 0.00011518 & 3.5 \\
\hline 5 & 279.54974 & 10.75 & & 0.00011518 & 3.5 \\
\hline
\end{tabular}

\begin{tabular}{|c|l|l|l|l|}
\hline Cycle \# & $\sigma=P / A$ & $\varepsilon=\Delta-G L$ & $\begin{array}{l}{\left[E^{*}\right]=\sigma / \varepsilon} \\
\text { (psi) }\end{array}$ & $\begin{array}{l}{\left[E^{*}\right]=\sigma / \varepsilon} \\
(\mathrm{GPa})\end{array}$ \\
\hline 1 & 26.097707 & $3.3 \mathrm{E}-05$ & 793057.8 & 5.46416859 \\
\hline 2 & 26.171166 & $3.3 \mathrm{E}-05$ & 795290.1 & 5.47954887 \\
\hline 3 & 26.09545 & $3.3 \mathrm{E}-05$ & 792989.3 & 5.46369608 \\
\hline 4 & 26.076629 & $3.3 \mathrm{E}-05$ & 792417.3 & 5.45975538 \\
\hline 5 & 26.004627 & $3.3 \mathrm{E}-05$ & 790229.3 & 5.4446801 \\
\hline
\end{tabular}

\begin{tabular}{|l|l|}
\hline$E(K p a)$ & $\begin{array}{l}\text { logE } \\
\text { (Kpa) }\end{array}$ \\
\hline 5464169 & 6.737524 \\
\hline 5479549 & 6.738745 \\
\hline 5463696 & 6.737487 \\
\hline 5459755 & 6.737173 \\
\hline 5444680 & 6.735972 \\
\hline
\end{tabular}

\begin{tabular}{|c|r|c|l|c|c|}
\cline { 1 - 2 } Cycle \# & P(lb-f) & A(in2) & & $\Delta$ & GL \\
\hline 1 & 287.59357 & 10.75 & & 0.00014133 & 3.5 \\
\hline 2 & 287.53928 & 10.75 & & 0.00014133 & 3.5 \\
\hline 3 & 287.55963 & 10.75 & & 0.00014133 & 3.5 \\
\hline 4 & 288.3501 & 10.75 & & 0.00014133 & 3.5 \\
\hline 5 & 287.5654 & 10.75 & & 0.00014133 & 3.5 \\
\hline
\end{tabular}

\begin{tabular}{|c|c|c|l|l|}
\hline Cycle \# & $\sigma=P / A$ & $\varepsilon=\Delta-G L$ & $\begin{array}{l}{\left[E^{*}\right]=\sigma / \varepsilon} \\
\text { (psi) }\end{array}$ & $\begin{array}{l}{\left[E^{*}\right]=\sigma / \varepsilon} \\
(\mathrm{GPa})\end{array}$ \\
\hline 1 & 26.75289 & $4 \mathrm{E}-05$ & 662517.4 & 4.56474457 \\
\hline 2 & 26.74784 & $4 \mathrm{E}-05$ & 662392.3 & 4.56388287 \\
\hline 3 & 26.749733 & $4 \mathrm{E}-05$ & 662439.2 & 4.56420587 \\
\hline 4 & 26.823265 & $4 \mathrm{E}-05$ & 664260.1 & 4.57675237 \\
\hline 5 & 26.75027 & $4 \mathrm{E}-05$ & 662452.5 & 4.56429745 \\
\hline
\end{tabular}

\begin{tabular}{|l|l|}
\hline$E(K p a)$ & $\begin{array}{l}\text { logE } \\
\text { (Kpa) }\end{array}$ \\
\hline 4564745 & 6.659416 \\
\hline 4563883 & 6.659334 \\
\hline 4564206 & 6.659365 \\
\hline 4576752 & 6.660557 \\
\hline 4564297 & 6.659374 \\
\hline
\end{tabular}

\begin{tabular}{|c|r|c|c|c|c|}
\hline \multicolumn{2}{|c|}{$\mathbf{0 . 5 H z}$} & \multicolumn{1}{l|}{} \\
\cline { 1 - 3 } Cycle \# & \multicolumn{1}{|c|}{ P(lb-f) } & A(in2) & & $\boldsymbol{\Delta}$ & GL \\
\hline 1 & 287.7876 & 10.75 & & 0.00016990 & 3.5 \\
\hline 2 & 286.90668 & 10.75 & & 0.00016990 & 3.5 \\
\hline 3 & 288.71835 & 10.75 & & 0.00016990 & 3.5 \\
\hline 4 & 287.789 & 10.75 & & 0.00016990 & 3.5 \\
\hline 5 & 287.75769 & 10.75 & & 0.00016990 & 3.5 \\
\hline
\end{tabular}




\begin{tabular}{|c|c|c|l|l|}
\hline Cycle \# & $\sigma=P / A$ & $\varepsilon=\Delta-G L$ & $\begin{array}{l}{\left[\mathrm{E}^{*}\right]=\sigma / \varepsilon} \\
\text { (psi) }\end{array}$ & $\begin{array}{l}{\left[\mathrm{E}^{*}\right]=\sigma / \varepsilon} \\
(\mathrm{GPa})\end{array}$ \\
\hline 1 & 26.77094 & $4.9 \mathrm{E}-05$ & 551497.2 & 3.79981603 \\
\hline 2 & 26.688993 & $4.9 \mathrm{E}-05$ & 549809.1 & 3.78818476 \\
\hline 3 & 26.857521 & $4.9 \mathrm{E}-05$ & 553280.9 & 3.81210523 \\
\hline 4 & 26.77107 & $4.9 \mathrm{E}-05$ & 551499.9 & 3.79983451 \\
\hline 5 & 26.768157 & $4.9 \mathrm{E}-05$ & 551439.9 & 3.79942111 \\
\hline
\end{tabular}

\begin{tabular}{|l|l|}
\hline$E(K p a)$ & $\begin{array}{l}\text { logE } \\
\text { (Kpa) }\end{array}$ \\
\hline 3799816 & 6.579763 \\
\hline 3788185 & 6.578431 \\
\hline 3812105 & 6.581165 \\
\hline 3799835 & 6.579765 \\
\hline 3799421 & 6.579717 \\
\hline
\end{tabular}

\begin{tabular}{|c|c|c|c|c|c|}
\hline \multicolumn{2}{|c|}{$\mathbf{0 . 1 H z}$} & \multicolumn{5}{|l|}{} \\
\hline Cycle \# & P(lb-f) & A(in2) & & $\boldsymbol{\Delta}$ & GL \\
\hline 1 & 287.15192 & 10.75 & & 0.00025428 & 3.5 \\
\hline 2 & 286.66422 & 10.75 & & 0.00025428 & 3.5 \\
\hline 3 & 287.02618 & 10.75 & & 0.00025428 & 3.5 \\
\hline 4 & 285.35727 & 10.75 & & 0.00025428 & 3.5 \\
\hline 5 & 287.54453 & 10.75 & & 0.00025428 & 3.5 \\
\hline
\end{tabular}

\begin{tabular}{|c|c|c|c|c|}
\hline Cycle \# & $\sigma=P / A$ & $\varepsilon=\Delta-G L$ & $\begin{array}{l}{\left[\mathrm{E}^{*}\right]=\sigma / \varepsilon} \\
\text { (psi) }\end{array}$ & $\begin{array}{l}{\left[\mathrm{E}^{*}\right]=\sigma / \varepsilon} \\
(\mathrm{GPa})\end{array}$ \\
\hline 1 & 26.711807 & 7.3E-05 & 367668.2 & 2.53323415 \\
\hline 2 & 26.666439 & 7.3E-05 & 367043.8 & 2.5289317 \\
\hline 3 & 26.70011 & 7.3E-05 & 367507.2 & 2.53212489 \\
\hline 4 & 26.544862 & 7.3E-05 & 365370.4 & 2.51740188 \\
\hline 5 & 26.748328 & 7.3E-05 & 368170.9 & 2.53669773 \\
\hline
\end{tabular}

\begin{tabular}{|l|l|}
\hline$E(K p a)$ & $\begin{array}{l}\text { logE } \\
(\mathrm{Kpa})\end{array}$ \\
\hline 2533234 & 6.403675 \\
\hline 2528932 & 6.402937 \\
\hline 2532125 & 6.403485 \\
\hline 2517402 & 6.400953 \\
\hline 2536698 & 6.404269 \\
\hline
\end{tabular}


(37.8 degrees)

\begin{tabular}{|c|c|c|c|c|c|c|c|}
\hline Freq (Hz) & $\begin{array}{l}\text { Peak Displ. } \\
\text { Values (in) }\end{array}$ & $\begin{array}{l}\text { Peak } \\
\text { Load } \\
\text { Values } \\
\text { (lb-ft) }\end{array}$ & $\begin{array}{l}\text { Peak Displ. } \\
\text { Time (secs) }\end{array}$ & $\begin{array}{l}\text { Peak Load } \\
\text { Time (secs) }\end{array}$ & $\begin{array}{l}\text { Phase } \\
\text { Shift } \\
\text { Values } \\
\text { (secs) }\end{array}$ & $\begin{array}{l}\text { Average } \\
\text { Displ. (in) }\end{array}$ & $\begin{array}{l}\text { Average } \\
\text { Load (Ib) }\end{array}$ \\
\hline \multirow[t]{5}{*}{10} & 5.367E-05 & 108.025 & 28.84131 & 28.82601 & 0.015299 & 5.37E-05 & 107.9819 \\
\hline & 5.367E-05 & 108.561 & 28.93148 & 28.926434 & 0.005045 & & \\
\hline & 5.367E-05 & 107.893 & 29.03728 & 29.026367 & 0.010912 & & \\
\hline & 5.367E-05 & 107.713 & 29.13962 & 29.127441 & 0.012182 & & \\
\hline & 5.367E-05 & 107.717 & 29.23161 & 29.227051 & 0.004558 & & \\
\hline \multirow[t]{5}{*}{5} & $7.178 \mathrm{E}-05$ & 115.827 & 48.19369 & 48.18441 & 0.009277 & 7.18E-05 & 115.5454 \\
\hline & $7.178 \mathrm{E}-05$ & 115.568 & 48.39909 & 48.368883 & -0.03021 & & \\
\hline & $7.178 \mathrm{E}-05$ & 115.471 & 48.60433 & 48.584801 & 0.019531 & & \\
\hline & 7.178E-05 & 115.448 & 48.8099 & 48.785156 & 0.024742 & & \\
\hline & $7.178 \mathrm{E}-05$ & 115.413 & 48.99886 & 48.984539 & 0.014324 & & \\
\hline \multirow[t]{5}{*}{1} & $8.247 \mathrm{E}-05$ & 124.17 & 64.90837 & 64.820641 & 0.08773 & $8.03 E-05$ & 124.0835 \\
\hline & 8.247E-05 & 124.034 & 65.88461 & 65.829269 & 0.055336 & & \\
\hline & $8.247 E-05$ & 124.349 & 66.89372 & 66.818039 & 0.075684 & & \\
\hline & $8.247 \mathrm{E}-05$ & 123.762 & 67.90804 & 67.842125 & 0.065918 & & \\
\hline & 8.247 E-05 & 124.102 & 68.9082 & 68.818848 & 0.089355 & & \\
\hline \multirow[t]{5}{*}{0.5} & 0.0001288 & 128.794 & 90.49512 & 90.32959 & 0.165527 & 0.00012 & 128.159 \\
\hline & 0.0001288 & 128.247 & 92.50033 & 92.323242 & 0.177086 & & \\
\hline & 0.0001288 & 127.755 & 94.52279 & 94.345055 & 0.177734 & & \\
\hline & 0.0001288 & 127.729 & 96.46322 & 96.394371 & 0.068848 & & \\
\hline & 0.0001288 & 128.269 & 98.49577 & 98.335617 & 0.160156 & & \\
\hline \multirow[t]{5}{*}{0.1} & 0.0001764 & 129.732 & 195.2235 & 194.57275 & 0.65073 & 0.000167 & 129.6283 \\
\hline & 0.0001764 & 130.732 & 205.2121 & 204.62549 & 0.58659 & & \\
\hline & 0.0001764 & 129.724 & 215.035 & 214.72412 & 0.31088 & & \\
\hline & 0.0001764 & 128.801 & 225.2738 & 224.57358 & 0.70019 & & \\
\hline & 0.0001764 & 129.152 & 235.2333 & 234.7507 & 0.48255 & & \\
\hline
\end{tabular}

\begin{tabular}{|c|c|c|c|c|c|}
\hline \multicolumn{2}{|c|}{$10 \mathrm{~Hz}$} & \multicolumn{5}{l|}{} \\
\cline { 1 - 2 } Cycle \# & P(lb-f) & A(in2) & & $\Delta$ & GL \\
\hline 1 & 108.02493 & 10.75 & & 0.00005367 & 3.5 \\
\hline 2 & 108.56139 & 10.75 & & 0.00005367 & 3.5 \\
\hline 3 & 107.89334 & 10.75 & & 0.00005367 & 3.5 \\
\hline 4 & 107.71287 & 10.75 & & 0.00005367 & 3.5 \\
\hline 5 & 107.71674 & 10.75 & & 0.00005367 & 3.5 \\
\hline
\end{tabular}

\begin{tabular}{|c|c|c|l|l|}
\hline Cycle \# & $\sigma=P / A$ & $\varepsilon=\Delta-G L$ & $\begin{array}{l}{\left[E^{*}\right]=\sigma / \varepsilon} \\
(p s i)\end{array}$ & $\begin{array}{l}{\left[E^{*}\right]=\sigma / \varepsilon} \\
(\mathrm{GPa})\end{array}$ \\
\hline 1 & 10.048831 & $1.5 \mathrm{E}-05$ & 655307.8 & 4.51507108 \\
\hline 2 & 10.098734 & $1.5 \mathrm{E}-05$ & 658562.2 & 4.53749327 \\
\hline 3 & 10.03659 & $1.5 \mathrm{E}-05$ & 654509.6 & 4.50957107 \\
\hline 4 & 10.019802 & $1.5 \mathrm{E}-05$ & 653414.8 & 4.50202805 \\
\hline 5 & 10.020162 & $1.5 \mathrm{E}-05$ & 653438.3 & 4.5021898 \\
\hline
\end{tabular}

\begin{tabular}{|l|l|}
\hline $\mathrm{Kpa}$ & $\log \mathrm{KPa}$ \\
\hline 4515071 & 6.654665 \\
\hline 4537493 & 6.656816 \\
\hline 4509571 & 6.654135 \\
\hline 4502028 & 6.653408 \\
\hline 4502190 & 6.653424 \\
\hline
\end{tabular}




\begin{tabular}{|c|r|c|c|c|c|}
\hline \multicolumn{2}{|c|}{$5 \mathrm{~Hz}$} & \multicolumn{5}{l|}{} \\
\hline Cycle \# & P(lb-f) & A(in2) & & $\Delta$ & GL \\
\hline 1 & 115.82689 & 10.75 & & 0.00007178 & 3.5 \\
\hline 2 & 115.56783 & 10.75 & & 0.00007178 & 3.5 \\
\hline 3 & 115.47129 & 10.75 & & 0.00007178 & 3.5 \\
\hline 4 & 115.44812 & 10.75 & & 0.00007178 & 3.5 \\
\hline 5 & 115.4127 & 10.75 & & 0.00007178 & 3.5 \\
\hline
\end{tabular}

\begin{tabular}{|c|l|l|l|l|}
\hline Cycle \# & $\sigma=P / A$ & $\varepsilon=\Delta-G L$ & $\begin{array}{l}{\left[\mathrm{E}^{*}\right]=\sigma / \varepsilon} \\
(\mathbf{p s i})\end{array}$ & $\begin{array}{l}{[\mathrm{E} *]=\sigma / \varepsilon} \\
(\mathrm{GPa})\end{array}$ \\
\hline 1 & 10.774594 & $2.1 \mathrm{E}-05$ & 525353.5 & 3.61968531 \\
\hline 2 & 10.750496 & $2.1 \mathrm{E}-05$ & 524178.4 & 3.61158947 \\
\hline 3 & 10.741515 & $2.1 \mathrm{E}-05$ & 523740.6 & 3.60857252 \\
\hline 4 & 10.73936 & $2.1 \mathrm{E}-05$ & 523635.5 & 3.60784844 \\
\hline 5 & 10.736065 & $2.1 \mathrm{E}-05$ & 523474.8 & 3.60674153 \\
\hline
\end{tabular}

\begin{tabular}{|l|l|}
\hline$E(K p a)$ & $\begin{array}{l}\text { logE } \\
\text { (Kpa) }\end{array}$ \\
\hline 3619685 & 6.558671 \\
\hline 3611589 & 6.557698 \\
\hline 3608573 & 6.557335 \\
\hline 3607848 & 6.557248 \\
\hline 3606742 & 6.557115 \\
\hline
\end{tabular}

\begin{tabular}{|c|c|c|c|c|c|}
\hline \multicolumn{2}{|c|}{ 1HZ } & \multicolumn{5}{|l|}{} \\
\cline { 1 - 2 } Cycle \# & P(lb-f) & A(in2) & & $\boldsymbol{\Delta}$ & GL \\
\hline 1 & 124.17049 & 10.75 & & 0.00008247 & 3.5 \\
\hline 2 & 124.03366 & 10.75 & & 0.00008247 & 3.5 \\
\hline 3 & 124.34949 & 10.75 & & 0.00008247 & 3.5 \\
\hline 4 & 123.76157 & 10.75 & & 0.00008247 & 3.5 \\
\hline 5 & 124.10216 & 10.75 & & 0.00008247 & 3.5 \\
\hline
\end{tabular}

\begin{tabular}{|c|l|l|l|l|}
\hline Cycle \# & $\sigma=P / A$ & $\varepsilon=\Delta-G L$ & $\begin{array}{l}{\left[E^{*}\right]=\sigma / \varepsilon} \\
\text { (psi) }\end{array}$ & $\begin{array}{l}{\left[E^{*}\right]=\sigma / \varepsilon} \\
(\mathrm{GPa})\end{array}$ \\
\hline 1 & 11.550743 & $2.4 \mathrm{E}-05$ & 490209.5 & 3.37754361 \\
\hline 2 & 11.538015 & $2.4 \mathrm{E}-05$ & 489669.3 & 3.37382172 \\
\hline 3 & 11.567394 & $2.4 \mathrm{E}-05$ & 490916.2 & 3.38241256 \\
\hline 4 & 11.512704 & $2.4 \mathrm{E}-05$ & 488595.2 & 3.36642064 \\
\hline 5 & 11.544387 & $2.4 \mathrm{E}-05$ & 489939.8 & 3.37568497 \\
\hline
\end{tabular}

\begin{tabular}{|l|l|}
\hline$E$ (Kpa) & $\begin{array}{l}\text { logE } \\
\text { (Kpa) }\end{array}$ \\
\hline 3377544 & 6.528601 \\
\hline 3373822 & 6.528122 \\
\hline 3382413 & 6.529227 \\
\hline 3366421 & 6.527168 \\
\hline 3375685 & 6.528362 \\
\hline
\end{tabular}

\begin{tabular}{|c|c|c|c|c|c|}
\cline { 1 - 2 } & \multicolumn{1}{|c|}{$\mathbf{0 . 5 H z}$} & \multicolumn{1}{l|}{} \\
\cline { 1 - 2 } Cycle \# & P(lb-f) & A(in2) & & $\Delta$ & GL \\
\hline 1 & 128.7943 & 10.75 & & 0.00012878 & 3.5 \\
\hline 2 & 128.24724 & 10.75 & & 0.00012878 & 3.5 \\
\hline 3 & 127.75493 & 10.75 & & 0.00012878 & 3.5 \\
\hline 4 & 127.72888 & 10.75 & & 0.00012878 & 3.5 \\
\hline 5 & 128.26949 & 10.75 & & 0.00012878 & 3.5
\end{tabular}




\begin{tabular}{|c|c|c|c|c|}
\hline Cycle \# & $\sigma=P / A$ & $\varepsilon=\Delta-G L$ & $\begin{array}{l}{\left[E^{*}\right]=\sigma / \varepsilon} \\
\text { (psi) }\end{array}$ & $\begin{array}{l}{\left[E^{*}\right]=\sigma / \varepsilon} \\
(\mathrm{GPa})\end{array}$ \\
\hline 1 & 11.980865 & 3.7E-05 & 325616.4 & 2.24349666 \\
\hline 2 & 11.929976 & 3.7E-05 & 324233.3 & 2.2339673 \\
\hline 3 & 11.88418 & 3.7E-05 & 322988.6 & 2.22539165 \\
\hline 4 & 11.881756 & 3.7E-05 & 322922.8 & 2.22493787 \\
\hline 5 & 11.932046 & 3.7E-05 & 324289.5 & 2.23435488 \\
\hline
\end{tabular}

\begin{tabular}{|l|l|}
\hline$E(K p a)$ & $\begin{array}{l}\text { logE } \\
\text { (Kpa) }\end{array}$ \\
\hline 2243497 & 6.350925 \\
\hline 2233967 & 6.349077 \\
\hline 2225392 & 6.347406 \\
\hline 2224938 & 6.347318 \\
\hline 2234355 & 6.349152 \\
\hline
\end{tabular}

\begin{tabular}{|c|c|c|c|c|c|}
\hline \multicolumn{2}{|c|}{$\mathbf{0 . 1 H z}$} & \multicolumn{5}{l|}{} \\
\hline Cycle \# & P(lb-f) & A(in2) & & $\Delta$ & GL \\
\hline 1 & 129.73183 & 10.75 & & 0.00017639 & 3.5 \\
\hline 2 & 130.73183 & 10.75 & & 0.00017639 & 3.5 \\
\hline 3 & 129.72412 & 10.75 & & 0.00017639 & 3.5 \\
\hline 4 & 128.80125 & 10.75 & & 0.00017639 & 3.5 \\
\hline 5 & 129.15231 & 10.75 & & 0.00017639 & 3.5 \\
\hline
\end{tabular}

\begin{tabular}{|c|c|c|c|l|}
\hline Cycle \# & $\sigma=\mathrm{P} / \mathrm{A}$ & $\varepsilon=\Delta-\mathrm{GL}$ & $\begin{array}{l}{\left[\mathrm{E}^{*}\right]=\sigma / \varepsilon} \\
(\mathrm{psi})\end{array}$ & $\begin{array}{l}{[\mathrm{E} *]=\sigma / \varepsilon} \\
(\mathrm{GPa})\end{array}$ \\
\hline 1 & 12.068077 & $5 \mathrm{E}-05$ & 239454.8 & 1.64984326 \\
\hline 2 & 12.1611 & $5 \mathrm{E}-05$ & 241300.5 & 1.66256059 \\
\hline 3 & 12.06736 & $5 \mathrm{E}-05$ & 239440.5 & 1.64974521 \\
\hline 4 & 11.981512 & $5 \mathrm{E}-05$ & 237737.1 & 1.63800876 \\
\hline 5 & 12.014168 & $5 \mathrm{E}-05$ & 238385.1 & 1.64247331 \\
\hline
\end{tabular}

\begin{tabular}{|l|l|}
\hline$E$ (Kpa) & $\begin{array}{l}\text { logE } \\
\text { (Kpa) }\end{array}$ \\
\hline 1649843 & 6.217443 \\
\hline 1662561 & 6.220777 \\
\hline 1649745 & 6.217417 \\
\hline 1638009 & 6.214316 \\
\hline 1642473 & 6.215498 \\
\hline
\end{tabular}


LC

(-9 degrees)

\begin{tabular}{|c|c|c|c|c|c|c|c|}
\hline Freq $(\mathrm{Hz})$ & $\begin{array}{l}\text { Peak Displ. } \\
\text { Values (in) }\end{array}$ & $\begin{array}{c}\text { Peak } \\
\text { Load } \\
\text { Values } \\
\text { (lb-f) }\end{array}$ & $\begin{array}{l}\text { Peak Displ. } \\
\text { Time (secs) }\end{array}$ & $\begin{array}{l}\text { Peak Load } \\
\text { Time (secs) }\end{array}$ & $\begin{array}{l}\text { Phase } \\
\text { Shift } \\
\text { Values } \\
\text { (secs) }\end{array}$ & $\begin{array}{l}\text { Average } \\
\text { Displ. (in) }\end{array}$ & $\begin{array}{l}\text { Average } \\
\text { Load (lb) }\end{array}$ \\
\hline \multirow[t]{5}{*}{10} & 0.00008393 & 1041.97 & 224.3924 & 224.33627 & 0.05616 & 8.39E-05 & 1039.506 \\
\hline & 0.00008393 & 1038.64 & 224.4924 & 224.43491 & 0.05745 & & \\
\hline & 0.00008393 & 1041.57 & 224.5869 & 224.53598 & 0.05093 & & \\
\hline & 0.00008393 & 1035.75 & 224.6917 & 224.63412 & 0.05762 & & \\
\hline & 0.00008393 & 1039.61 & 224.793 & 224.7352 & 0.05777 & & \\
\hline \multirow[t]{5}{*}{5} & 0.00009267 & 1045.86 & 243.9875 & 243.79053 & 0.19694 & $9.27 E-05$ & 1043.59 \\
\hline & 0.00009267 & 1043.89 & 244.2041 & 243.98828 & 0.21582 & & \\
\hline & 0.00009267 & 1041.34 & 244.3928 & 244.18718 & 0.20557 & & \\
\hline & 0.00009267 & 1043.1 & 244.6047 & 244.38818 & 0.21648 & & \\
\hline & 0.00009267 & 1043.76 & 244.7808 & 244.58855 & 0.19221 & & \\
\hline \multirow[t]{5}{*}{1} & 0.000104763 & 1052.38 & 260.4152 & 259.38446 & 1.03076 & 0.000105 & 1046.148 \\
\hline & 0.000104763 & 1046.04 & 261.3921 & 260.36899 & 1.0231 & & \\
\hline & 0.000104763 & 1046.23 & 262.4251 & 261.36835 & 1.05679 & & \\
\hline & 0.000104763 & 1042.74 & 263.3636 & 262.36298 & 1.00064 & & \\
\hline & 0.000104763 & 1043.35 & 264.3861 & 263.36362 & 1.02246 & & \\
\hline \multirow[t]{5}{*}{0.5} & 0.000118223 & 1046.05 & 285.9455 & 285.84277 & 0.10273 & 0.000118 & 1047.346 \\
\hline & 0.000118223 & 1045.97 & 287.8615 & 287.8436 & 0.01791 & & \\
\hline & 0.000118223 & 1049.33 & 289.9378 & 289.85712 & 0.08072 & & \\
\hline & 0.000118223 & 1049.48 & 291.9549 & 291.8576 & 0.09733 & & \\
\hline & 0.000118223 & 1045.91 & 293.8758 & 293.84262 & 0.0332 & & \\
\hline \multirow[t]{5}{*}{0.1} & 0.00017641 & 1047 & 196.9741 & 196.34392 & 0.6302 & 0.000176 & 1045.455 \\
\hline & 0.00017641 & 1041.17 & 207.7787 & 206.48503 & 1.29363 & & \\
\hline & 0.00017641 & 1047 & 216.6268 & 216.31967 & 0.30713 & & \\
\hline & 0.00017641 & 1046.88 & 218.7568 & 218.2693 & 0.4875 & & \\
\hline & 0.00017641 & 1045.24 & 221.563 & 220.985 & 0.578 & & \\
\hline
\end{tabular}

\begin{tabular}{|c|c|c|c|c|c|}
\hline \multicolumn{2}{|c|}{$10 \mathrm{~Hz}$} & \multicolumn{5}{l|}{} \\
\cline { 1 - 2 } Cycle \# & P(lb-f) & A(in2) & & $\boldsymbol{\Delta}$ & GL \\
\hline 1 & 1041.967 & 10.75 & & 0.00008393 & 3.5 \\
\hline 2 & 1038.6353 & 10.75 & & 0.00008393 & 3.5 \\
\hline 3 & 1041.5702 & 10.75 & & 0.00008393 & 3.5 \\
\hline 4 & 1035.7476 & 10.75 & & 0.00008393 & 3.5 \\
\hline 5 & 1039.6091 & 10.75 & & 0.00008393 & 3.5 \\
\hline
\end{tabular}

\begin{tabular}{|c|l|l|l|r|}
\hline Cycle \# & $\sigma=P / A$ & $\varepsilon=\Delta-G L$ & $\begin{array}{l}{\left[E^{*}\right]=\sigma / \varepsilon} \\
(p s i)\end{array}$ & $\begin{array}{l}{\left[E^{*}\right]=\sigma / \varepsilon} \\
(\mathrm{GPa})\end{array}$ \\
\hline 1 & 96.92716279 & $2.4 \mathrm{E}-05$ & 4042007 & 27.849431 \\
\hline 2 & 96.61723721 & $2.4 \mathrm{E}-05$ & 4029083 & 27.760382 \\
\hline 3 & 96.89025116 & $2.4 \mathrm{E}-05$ & 4040468 & 27.838825 \\
\hline 4 & 96.34861395 & $2.4 \mathrm{E}-05$ & 4017881 & 27.6832 \\
\hline 5 & 96.70782326 & $2.4 \mathrm{E}-05$ & 4032861 & 27.786409 \\
\hline
\end{tabular}

\begin{tabular}{|l|l|}
\hline Kpa & log KPa \\
\hline 27849431 & 7.444816 \\
\hline 27760382 & 7.443425 \\
\hline 27838825 & 7.444651 \\
\hline 27683200 & 7.442216 \\
\hline 27786409 & 7.443832 \\
\hline
\end{tabular}




\begin{tabular}{|c|c|c|c|c|c|}
\hline \multicolumn{2}{|c|}{$5 \mathrm{~Hz}$} & \multicolumn{5}{l|}{} \\
\cline { 1 - 2 } Cycle \# & P(lb-f) & A(in2) & & $\boldsymbol{\Delta}$ & GL \\
\hline 1 & 1045.8628 & 10.75 & & 0.00009267 & 3.5 \\
\hline 2 & 1043.8903 & 10.75 & & 0.00009267 & 3.5 \\
\hline 3 & 1041.3416 & 10.75 & & 0.00009267 & 3.5 \\
\hline 4 & 1043.0994 & 10.75 & & 0.00009267 & 3.5 \\
\hline 5 & 1043.7556 & 10.75 & & 0.00009267 & 3.5 \\
\hline
\end{tabular}

\begin{tabular}{|c|c|c|c|c|}
\hline Cycle \# & $\sigma=P / A$ & $\varepsilon=\Delta-\mathbf{G L}$ & $\begin{array}{l}{\left[\mathrm{E}^{*}\right]=\sigma / \varepsilon} \\
\text { (psi) }\end{array}$ & $\begin{array}{l}{\left[\mathrm{E}^{*}\right]=\sigma / \varepsilon} \\
(\mathrm{GPa})\end{array}$ \\
\hline 1 & 97.28956279 & 2.6E-05 & 3674661 & 25.318417 \\
\hline 2 & 97.10607442 & 2.6E-05 & 3667731 & 25.270666 \\
\hline 3 & 96.86898605 & 2.6E-05 & 3658776 & 25.208967 \\
\hline 4 & 97.03250233 & 2.6E-05 & 3664952 & 25.25152 \\
\hline 5 & 97.09354419 & 2.6E-05 & 3667258 & 25.267406 \\
\hline
\end{tabular}

\begin{tabular}{|l|l|}
\hline$E(K p a)$ & $\begin{array}{l}\text { logE } \\
\text { (Kpa) }\end{array}$ \\
\hline 25318417 & 7.403437 \\
\hline 25270666 & 7.402617 \\
\hline 25208967 & 7.401555 \\
\hline 25251520 & 7.402288 \\
\hline 25267406 & 7.402561 \\
\hline
\end{tabular}

\begin{tabular}{|c|r|r|l|c|c|}
\hline \multicolumn{2}{|c|}{ 1HZ } & \multicolumn{1}{l|}{} \\
\hline Cycle \# & P(lb-f) & A(in2) & & $\boldsymbol{\Delta}$ & GL \\
\hline 1 & 1052.38446 & 10.75 & & 0.00010476 & 3.5 \\
\hline 2 & 1046.0364 & 10.75 & & 0.00010476 & 3.5 \\
\hline 3 & 1046.2294 & 10.75 & & 0.00010476 & 3.5 \\
\hline 4 & 1042.7382 & 10.75 & & 0.00010476 & 3.5 \\
\hline 5 & 1043.353 & 10.75 & & 0.00010476 & 3.5 \\
\hline
\end{tabular}

\begin{tabular}{|c|l|c|l|r|}
\hline Cycle \# & $\sigma=P / A$ & $\varepsilon=\Delta-G L$ & $\begin{array}{l}{\left[E^{*}\right]=\sigma / \varepsilon} \\
\text { (psi) }\end{array}$ & $\begin{array}{l}{\left[E^{*}\right]=\sigma / \varepsilon} \\
(\mathrm{GPa})\end{array}$ \\
\hline 1 & 97.89622884 & $3 \mathrm{E}-05$ & 3270600 & 22.534433 \\
\hline 2 & 97.30571163 & $3 \mathrm{E}-05$ & 3250871 & 22.398503 \\
\hline 3 & 97.32366512 & $3 \mathrm{E}-05$ & 3251471 & 22.402636 \\
\hline 4 & 96.99890233 & $3 \mathrm{E}-05$ & 3240621 & 22.32788 \\
\hline 5 & 97.05609302 & $3 \mathrm{E}-05$ & 3242532 & 22.341044 \\
\hline
\end{tabular}

\begin{tabular}{|l|l|}
\hline$E(K p a)$ & $\begin{array}{l}\text { logE } \\
\text { (Kpa) }\end{array}$ \\
\hline 22534433 & 7.352847 \\
\hline 22398503 & 7.350219 \\
\hline 22402636 & 7.350299 \\
\hline 22327880 & 7.348847 \\
\hline 22341044 & 7.349103 \\
\hline
\end{tabular}

\begin{tabular}{|c|c|c|c|c|c|}
\hline \multicolumn{2}{|c|}{$\mathbf{0 . 5 H z}$} & \multicolumn{1}{|l|}{} \\
\cline { 1 - 2 } Cycle \# & P(lb-f) & A(in2) & & $\boldsymbol{\Delta}$ & GL \\
\hline 1 & 1046.046 & 10.75 & & 0.00011822 & 3.5 \\
\hline 2 & 1045.968 & 10.75 & & 0.00011822 & 3.5 \\
\hline 3 & 1049.3273 & 10.75 & & 0.00011822 & 3.5 \\
\hline 4 & 1049.4825 & 10.75 & & 0.00011822 & 3.5 \\
\hline 5 & 1045.9067 & 10.75 & & 0.00011822 & 3.5
\end{tabular}




\begin{tabular}{|c|c|c|c|c|}
\hline Cycle \# & $\sigma=P / A$ & $\varepsilon=\Delta-G L$ & $\begin{array}{l}{\left[\mathrm{E}^{*}\right]=\sigma / \varepsilon} \\
\text { (psi) }\end{array}$ & $\begin{array}{l}{\left[\mathrm{E}^{*}\right]=\sigma / \varepsilon} \\
(\mathrm{GPa})\end{array}$ \\
\hline 1 & 97.30660465 & $3.4 \mathrm{E}-05$ & 2880770 & 19.848506 \\
\hline 2 & 97.29934884 & 3.4E-05 & 2880555 & 19.847026 \\
\hline 3 & 97.61184186 & 3.4E-05 & 2889807 & 19.910768 \\
\hline 4 & 97.62627907 & $3.4 \mathrm{E}-05$ & 2890234 & 19.913713 \\
\hline 5 & 97.29364651 & 3.4E-05 & 2880386 & 19.845863 \\
\hline
\end{tabular}

\begin{tabular}{|l|l|}
\hline $\mathbf{E}(\mathrm{Kpa})$ & $\begin{array}{l}\text { logE } \\
\text { (Kpa) }\end{array}$ \\
\hline 19848506 & 7.297728 \\
\hline 19847026 & 7.297695 \\
\hline 19910768 & 7.299088 \\
\hline 19913713 & 7.299152 \\
\hline 19845863 & 7.29767 \\
\hline
\end{tabular}

\begin{tabular}{|c|c|c|c|c|c|}
\hline \multicolumn{2}{|c|}{$\mathbf{0 . 1 H z}$} & \multicolumn{5}{|l|}{} \\
\cline { 1 - 2 } Cycle \# & P(lb-f) & A(in2) & & $\boldsymbol{\Delta}$ & GL \\
\hline 1 & 1046.9984 & 10.75 & & 0.00017641 & 3.5 \\
\hline 2 & 1041.1692 & 10.75 & & 0.00017641 & 3.5 \\
\hline 3 & 1046.9971 & 10.75 & & 0.00017641 & 3.5 \\
\hline 4 & 1046.8754 & 10.75 & & 0.00017641 & 3.5 \\
\hline 5 & 1045.235 & 10.75 & & 0.00017641 & 3.5 \\
\hline
\end{tabular}

\begin{tabular}{|c|c|c|c|c|}
\hline Cycle \# & G=P/A & $\varepsilon=\Delta-G L$ & $\begin{array}{l}{\left[E^{*}\right]=\sigma / \varepsilon} \\
\text { (psi) }\end{array}$ & $\begin{array}{l}{\left[E^{*}\right]=\sigma / \varepsilon} \\
\text { (GPa) }\end{array}$ \\
\hline 1 & 97.3952 & $5 E-05$ & 1932337 & 13.3138 \\
\hline 2 & 96.85294884 & $5 \mathrm{E}-05$ & 1921578 & 13.239675 \\
\hline 3 & 97.39507907 & $5 \mathrm{E}-05$ & 1932334 & 13.313784 \\
\hline 4 & 97.38375814 & $5 \mathrm{E}-05$ & 1932110 & 13.312236 \\
\hline 5 & 97.23116279 & $5 \mathrm{E}-05$ & 1929082 & 13.291376 \\
\hline
\end{tabular}

\begin{tabular}{|l|l|}
\hline \multicolumn{2}{|l|}{} \\
\hline$E(K p a)$ & $\begin{array}{l}\text { logE } \\
\text { (Kpa) }\end{array}$ \\
\hline 13313800 & 7.124302 \\
\hline 13239675 & 7.121877 \\
\hline 13313784 & 7.124301 \\
\hline 13312236 & 7.124251 \\
\hline 13291376 & 7.12357 \\
\hline
\end{tabular}


LC

(4.4 degrees)

\begin{tabular}{|c|c|c|c|c|c|c|c|}
\hline Freq (Hz) & $\begin{array}{l}\text { Peak Displ. } \\
\text { Values (in) }\end{array}$ & $\begin{array}{l}\text { Peak } \\
\text { Load } \\
\text { Values } \\
\text { (lb-f) }\end{array}$ & $\begin{array}{l}\text { Peak Displ. } \\
\text { Time (secs) }\end{array}$ & $\begin{array}{l}\text { Peak Load } \\
\text { Time (secs) }\end{array}$ & $\begin{array}{l}\text { Phase } \\
\text { Shift } \\
\text { Values } \\
\text { (secs) }\end{array}$ & $\begin{array}{l}\text { Average } \\
\text { Displ. (in) }\end{array}$ & $\begin{array}{l}\text { Average } \\
\text { Load (Ib) }\end{array}$ \\
\hline \multirow[t]{5}{*}{10} & 0.00007994 & 778.28 & 20.62549 & 20.62435 & 0.001138 & 7.99E-05 & 780.8427 \\
\hline & 0.00007994 & 780.27 & 20.73519 & 20.724773 & 0.010416 & & \\
\hline & 0.00007994 & 784.66 & 20.82699 & 20.82601 & 0.000976 & & \\
\hline & 0.00007994 & 775.01 & 20.92464 & 20.923666 & 0.000977 & & \\
\hline & 0.00007994 & 785.99 & 21.0319 & 21.026855 & 0.005047 & & \\
\hline \multirow[t]{5}{*}{5} & 0.00009706 & 780.52 & 40.17855 & 40.179039 & 0.000488 & $9.71 E-05$ & 779.2075 \\
\hline & 0.00009706 & 777.88 & 40.38965 & 40.376793 & 0.012855 & & \\
\hline & 0.00009706 & 778.8 & 40.58952 & 40.577637 & 0.011883 & & \\
\hline & 0.00009706 & 779.5 & 40.79525 & 40.77816 & 0.01709 & & \\
\hline & 0.00009706 & 779.33 & 40.98975 & 40.977867 & 0.011879 & & \\
\hline \multirow[t]{5}{*}{1.} & 0.00012201 & 773.91 & 56.6084 & 56.785809 & 0.177411 & 0.000122 & 775.6498 \\
\hline & 0.00012201 & 775.38 & 57.59782 & 57.788574 & 0.190754 & & \\
\hline & 0.00012201 & 776.8 & 58.63151 & 58.794598 & 0.163086 & & \\
\hline & 0.00012201 & 775.38 & 59.61426 & 59.778648 & 0.16439 & & \\
\hline & 0.00012201 & 776.79 & 60.61491 & 60.784996 & 0.170086 & & \\
\hline \multirow[t]{5}{*}{0.5} & 0.00015246 & 782.05 & 82.16162 & 82.04541 & 0.116211 & 0.000152 & 794.0515 \\
\hline & 0.00015246 & 784.06 & 84.25586 & 84.061363 & 0.194496 & & \\
\hline & 0.00015246 & 796.06 & 86.2124 & 86.05504 & 0.157362 & & \\
\hline & 0.00015246 & 788.05 & 88.23406 & 88.046387 & 0.187668 & & \\
\hline & 0.00015246 & 820.05 & 90.15039 & 90.048668 & 0.101723 & & \\
\hline \multirow[t]{5}{*}{0.1} & 0.00025027 & 802.05 & 201.2606 & 200.98721 & 0.27338 & 0.00025 & 792.573 \\
\hline & 0.00025027 & 799.23 & 207.0625 & 206.37109 & 0.69141 & & \\
\hline & 0.00025027 & 800.5 & 216.57 & 216.32858 & 0.24141 & & \\
\hline & 0.00025027 & 801.32 & 225.9873 & 225.76549 & 0.22183 & & \\
\hline & 0.00025027 & 759.77 & 231.9876 & 230.98761 & 1.00001 & & \\
\hline
\end{tabular}

\begin{tabular}{|c|c|c|c|c|c|}
\hline \multicolumn{2}{|c|}{$10 \mathrm{~Hz}$} & \multicolumn{5}{l|}{} \\
\cline { 1 - 2 } Cycle \# & P(lb-f) & A(in2) & & $\Delta$ & GL \\
\hline 1 & 778.28052 & 10.75 & & 0.00007994 & 3.5 \\
\hline 2 & 780.27496 & 10.75 & & 0.00007994 & 3.5 \\
\hline 3 & 784.65747 & 10.75 & & 0.00007994 & 3.5 \\
\hline 4 & 775.00946 & 10.75 & & 0.00007994 & 3.5 \\
\hline 5 & 785.99133 & 10.75 & & 0.00007994 & 3.5 \\
\hline
\end{tabular}

\begin{tabular}{|c|l|c|c|c|}
\hline Cycle \# & $\sigma=P / A$ & $\begin{array}{c}\varepsilon=\Delta- \\
\text { GL }\end{array}$ & $\begin{array}{l}{\left[E^{*}\right]=\sigma / \varepsilon} \\
\text { (psi) }\end{array}$ & $\begin{array}{l}{\left[\mathrm{E}^{*}\right]=\sigma / \varepsilon} \\
(\mathrm{GPa})\end{array}$ \\
\hline 1 & 72.398188 & $2 \mathrm{E}-05$ & 3169922 & 21.8407648 \\
\hline 2 & 72.583717 & $2 \mathrm{E}-05$ & 3178046 & 21.8967344 \\
\hline 3 & 72.991393 & $2 \mathrm{E}-05$ & 3195896 & 22.0197201 \\
\hline 4 & 72.093903 & $2 \mathrm{E}-05$ & 3156599 & 21.7489695 \\
\hline 5 & 73.115473 & $2 \mathrm{E}-05$ & 3201328 & 22.057152 \\
\hline
\end{tabular}

\begin{tabular}{|l|l|}
\hline Kpa & log KPa \\
\hline 21840765 & 7.339268 \\
\hline 21896734 & 7.340379 \\
\hline 22019720 & 7.342812 \\
\hline 21748970 & 7.337439 \\
\hline 22057152 & 7.343549 \\
\hline
\end{tabular}




\begin{tabular}{|c|c|c|c|c|c|}
\hline \multicolumn{2}{|c|}{$5 \mathrm{~Hz}$} & \multicolumn{5}{l|}{} \\
\hline Cycle \# & P(lb-f) & A(in2) & & $\boldsymbol{\Delta}$ & GL \\
\hline 1 & 780.52203 & 10.75 & & 0.00009706 & 3.5 \\
\hline 2 & 777.88422 & 10.75 & & 0.00009706 & 3.5 \\
\hline 3 & 778.79706 & 10.75 & & 0.00009706 & 3.5 \\
\hline 4 & 779.50446 & 10.75 & & 0.00009706 & 3.5 \\
\hline 5 & 779.3299 & 10.75 & & 0.00009706 & 3.5 \\
\hline
\end{tabular}

\begin{tabular}{|c|c|c|c|c|}
\hline Cycle \# & $\sigma=P / A$ & $\begin{array}{c}\varepsilon=\Delta- \\
G L\end{array}$ & $\begin{array}{l}{\left[\mathrm{E}^{*}\right]=\sigma / \varepsilon} \\
\text { (psi) }\end{array}$ & $\begin{array}{l}{\left[\mathrm{E}^{*}\right]=\sigma / \varepsilon} \\
(\mathrm{GPa})\end{array}$ \\
\hline 1 & 72.6067 & $3 E-05$ & 2618223 & 18.0395598 \\
\hline 2 & 72.361323 & $3 E-05$ & 2609375 & 17.9785943 \\
\hline 3 & 72.446238 & $3 E-05$ & 2612437 & 17.999692 \\
\hline 4 & 72.512043 & $3 E-05$ & 2614810 & 18.0160416 \\
\hline 5 & 72.495805 & $3 E-05$ & 2614225 & 18.0120071 \\
\hline
\end{tabular}

\begin{tabular}{|l|l|}
\hline$E(K p a)$ & $\begin{array}{l}\text { logE } \\
\text { (Kpa) }\end{array}$ \\
\hline 18039560 & 7.256226 \\
\hline 17978594 & 7.254756 \\
\hline 17999692 & 7.255265 \\
\hline 18016042 & 7.255659 \\
\hline 18012007 & 7.255562 \\
\hline
\end{tabular}

\begin{tabular}{|c|r|c|l|c|c|}
\hline \multicolumn{2}{|c|}{ 1Hz } & \multicolumn{5}{l|}{} \\
\cline { 1 - 2 } Cycle \# & \multicolumn{1}{|c|}{ P(lb-f) } & A(in2) & & $\Delta$ & GL \\
\hline 1 & 773.90918 & 10.75 & & 0.00012201 & 3.5 \\
\hline 2 & 775.3764 & 10.75 & & 0.00012201 & 3.5 \\
\hline 3 & 776.79767 & 10.75 & & 0.00012201 & 3.5 \\
\hline 4 & 775.37524 & 10.75 & & 0.00012201 & 3.5 \\
\hline 5 & 776.79059 & 10.75 & & 0.00012201 & 3.5 \\
\hline
\end{tabular}

\begin{tabular}{|c|c|c|c|c|}
\hline Cycle \# & $\sigma=P / A$ & $\begin{array}{c}\varepsilon=\Delta- \\
\text { GL }\end{array}$ & $\begin{array}{l}{\left[\mathrm{E}^{*}\right]=\sigma / \varepsilon} \\
\text { (psi) }\end{array}$ & $\begin{array}{l}{\left[\mathrm{E}^{*}\right]=\sigma / \varepsilon} \\
(\mathrm{GPa})\end{array}$ \\
\hline 1 & 71.991552 & $3 \mathrm{E}-05$ & 2065137 & 14.2287913 \\
\hline 2 & 72.128037 & $3 \mathrm{E}-05$ & 2069052 & 14.2557671 \\
\hline 3 & 72.260248 & $3 \mathrm{E}-05$ & 2072844 & 14.281898 \\
\hline 4 & 72.127929 & 3E-05 & 2069049 & 14.2557457 \\
\hline 5 & 72.25959 & $3 \mathrm{E}-05$ & 2072826 & 14.2817678 \\
\hline
\end{tabular}

\begin{tabular}{|l|l|}
\hline$E(K p a)$ & $\begin{array}{l}\text { logE } \\
\text { (Kpa) }\end{array}$ \\
\hline 14228791 & 7.153168 \\
\hline 14255767 & 7.153991 \\
\hline 14281898 & 7.154786 \\
\hline 14255746 & 7.15399 \\
\hline 14281768 & 7.154782 \\
\hline
\end{tabular}

\begin{tabular}{|c|r|c|l|c|c|}
\hline \multicolumn{2}{|c|}{$\mathbf{0 . 5 H z}$} & \multicolumn{5}{l|}{} \\
\cline { 1 - 2 } Cycle \# & P(lb-f) & A(in2) & & $\Delta$ & GL \\
\hline 1 & 782.04541 & 10.75 & & 0.00015246 & 3.5 \\
\hline 2 & 784.06136 & 10.75 & & 0.00015246 & 3.5 \\
\hline 3 & 796.0555 & 10.75 & & 0.00015246 & 3.5 \\
\hline 4 & 788.04639 & 10.75 & & 0.00015246 & 3.5 \\
\hline 5 & 820.04867 & 10.75 & & 0.00015246 & 3.5 \\
\hline
\end{tabular}




\begin{tabular}{|c|c|c|c|l|}
\hline Cycle \# & $\sigma=P / A$ & $\begin{array}{c}\varepsilon=\Delta- \\
\text { GL }\end{array}$ & $\begin{array}{l}{\left[E^{*}\right]=\sigma / \varepsilon} \\
\text { (psi) }\end{array}$ & $\begin{array}{l}{\left[E^{*}\right]=\sigma / \varepsilon} \\
\text { (GPa) }\end{array}$ \\
\hline 1 & 72.74841 & 4E-05 & 1670019 & 11.5064314 \\
\hline 2 & 72.935941 & 4E-05 & 1674324 & 11.5360926 \\
\hline 3 & 74.051675 & 4E-05 & 1699937 & 11.7125655 \\
\hline 4 & 73.306641 & 4E-05 & 1682834 & 11.5947253 \\
\hline 5 & 76.283597 & 4E-05 & 1751173 & 12.0655829 \\
\hline
\end{tabular}

\begin{tabular}{|l|l|}
\hline $\mathbf{E}(\mathrm{Kpa})$ & $\begin{array}{l}\text { logE } \\
\text { (Kpa) }\end{array}$ \\
\hline 11506431 & 7.060941 \\
\hline 11536093 & 7.062059 \\
\hline 11712565 & 7.068652 \\
\hline 11594725 & 7.06426 \\
\hline 12065583 & 7.081548 \\
\hline
\end{tabular}

\begin{tabular}{|c|c|c|l|c|c|}
\cline { 1 - 2 } Cycle \# & P(lb-f) & A(in2) & & $\Delta$ & GL \\
\hline 1 & 802.04657 & 10.75 & & 0.00025027 & 3.5 \\
\hline 2 & 799.22986 & 10.75 & & 0.00025027 & 3.5 \\
\hline 3 & 800.50153 & 10.75 & & 0.00025027 & 3.5 \\
\hline 4 & 801.32189 & 10.75 & & 0.00025027 & 3.5 \\
\hline 5 & 759.76532 & 10.75 & & 0.00025027 & 3.5 \\
\hline
\end{tabular}

\begin{tabular}{|c|c|c|c|c|}
\hline Cycle \# & $\sigma=P / A$ & $\begin{array}{c}\varepsilon=\Delta- \\
\text { GL }\end{array}$ & $\begin{array}{l}{\left[E^{*}\right]=\sigma / \varepsilon} \\
\text { (psi) }\end{array}$ & $\begin{array}{l}{\left[E^{*}\right]=\sigma / \varepsilon} \\
\text { (GPa) }\end{array}$ \\
\hline 1 & 74.608983 & $7 \mathrm{E}-05$ & 1043405 & 7.18906281 \\
\hline 2 & 74.346964 & $7 \mathrm{E}-05$ & 1039741 & 7.16381552 \\
\hline 3 & 74.465259 & $7 \mathrm{E}-05$ & 1041395 & 7.175214 \\
\hline 4 & 74.541571 & $7 \mathrm{E}-05$ & 1042463 & 7.18256722 \\
\hline 5 & 70.675844 & $7 \mathrm{E}-05$ & 988400.5 & 6.81007913 \\
\hline
\end{tabular}

\begin{tabular}{|l|l|}
\hline$E$ (Kpa) & $\begin{array}{l}\text { logE } \\
\text { (Kpa) }\end{array}$ \\
\hline 7189063 & 6.856672 \\
\hline 7163816 & 6.855144 \\
\hline 7175214 & 6.855835 \\
\hline 7182567 & 6.85628 \\
\hline 6810079 & 6.833152 \\
\hline
\end{tabular}


(21.1 degrees)

\begin{tabular}{|c|c|c|c|c|c|c|c|}
\hline Freq (Hz) & $\begin{array}{l}\text { Peak Displ. } \\
\text { Values (in) }\end{array}$ & $\begin{array}{c}\text { Peak } \\
\text { Load } \\
\text { Values } \\
\text { (lb-f) }\end{array}$ & $\begin{array}{l}\text { Peak Displ. } \\
\text { Time (secs) }\end{array}$ & $\begin{array}{l}\text { Peak Load } \\
\text { Time (secs) }\end{array}$ & $\begin{array}{c}\text { Phase } \\
\text { Shift } \\
\text { Values } \\
\text { (secs) }\end{array}$ & $\begin{array}{l}\text { Average } \\
\text { Displ. (in) }\end{array}$ & $\begin{array}{l}\text { Average } \\
\text { Load (lb) }\end{array}$ \\
\hline \multirow[t]{5}{*}{10} & 0.00006479 & 277.77 & 158.506 & 158.49629 & 0.00974 & $6.48 \mathrm{E}-05$ & 277.8493 \\
\hline & 0.00006479 & 277.89 & 158.6012 & 158.59653 & 0.00471 & & \\
\hline & 0.00006479 & 277.4 & 158.7012 & 158.69548 & 0.00569 & & \\
\hline & 0.00006479 & 278.34 & 158.8013 & 158.79688 & 0.00439 & & \\
\hline & 0.00006479 & 277.84 & 158.9022 & 158.89648 & 0.00571 & & \\
\hline \multirow[t]{5}{*}{5} & 0.0009239 & 274.67 & 178.0711 & 178.04883 & 0.02231 & 7.7E-05 & 274.0589 \\
\hline & 0.00007699 & 275.13 & 178.2822 & 178.25 & 0.03223 & & \\
\hline & 0.00007699 & 274.05 & 178.472 & 178.44824 & 0.02378 & & \\
\hline & 0.00007699 & 274.04 & 178.6712 & 178.64941 & 0.02182 & & \\
\hline & 0.00007699 & 272.4 & 178.8698 & 178.84538 & 0.02442 & & \\
\hline \multirow[t]{5}{*}{1} & 0.0012934 & 276.5 & 194.5609 & 194.48698 & 0.0739 & 0.000345 & 276.2922 \\
\hline & 0.00010778 & 276.74 & 195.5607 & 195.43295 & 0.12776 & & \\
\hline & 0.00010778 & 276.57 & 196.5228 & 196.43962 & 0.08318 & & \\
\hline & 0.00010778 & 278.06 & 197.5228 & 197.44434 & 0.07846 & & \\
\hline & 0.00010778 & 273.58 & 198.5111 & 198.41391 & 0.09717 & & \\
\hline \multirow[t]{5}{*}{0.5} & 0.00177792 & 276.65 & 220.1296 & 219.93034 & 0.19922 & 0.000474 & 276.8723 \\
\hline & 0.00014816 & 276.69 & 222.1354 & 221.93864 & 0.19678 & & \\
\hline & 0.00014816 & 277.2 & 224.1183 & 223.94321 & 0.17512 & & \\
\hline & 0.00014816 & 277.2 & 226.141 & 225.94321 & 0.19775 & & \\
\hline & 0.00014816 & 276.62 & 228.1577 & 227.93945 & 0.21826 & & \\
\hline \multirow[t]{5}{*}{0.1} & 0.00296576 & 276.92 & 335.1252 & 334.19385 & 0.93133 & 0.000791 & 276.0462 \\
\hline & 0.00024715 & 275.21 & 344.9676 & 344.33774 & 0.62988 & & \\
\hline & 0.00024715 & 275.6 & 355.1631 & 354.29492 & 0.86817 & & \\
\hline & 0.00024715 & 275.92 & 365.1882 & 364.30731 & 0.88086 & & \\
\hline & 0.00024715 & 276.58 & 375.0314 & 374.26123 & 0.7702 & & \\
\hline
\end{tabular}

\begin{tabular}{|c|c|c|c|c|c|}
\hline \multicolumn{2}{|c|}{$10 \mathrm{~Hz}$} & \multicolumn{5}{l|}{} \\
\cline { 1 - 2 } Cycle \# & P(lb-f) & A(in2) & P(inch) & $\boldsymbol{\Delta}$ & GL \\
\hline 1 & 277.76794 & 10.75 & & 0.00006479 & 3.5 \\
\hline 2 & 277.89304 & 10.75 & & 0.00006479 & 3.5 \\
\hline 3 & 277.40433 & 10.75 & & 0.00006479 & 3.5 \\
\hline 4 & 278.34048 & 10.75 & & 0.00006479 & 3.5 \\
\hline 5 & 277.84094 & 10.75 & & 0.00006479 & 3.5 \\
\hline
\end{tabular}

\begin{tabular}{|c|l|c|c|r|}
\hline Cycle \# & $\sigma=P / A$ & $\begin{array}{c}\varepsilon=\Delta- \\
\text { GL }\end{array}$ & $\begin{array}{l}{\left[\mathrm{E}^{*}\right]=\sigma / \varepsilon} \\
\text { (psi) }\end{array}$ & $\begin{array}{l}{\left[\mathrm{E}^{*}\right]=\sigma / \varepsilon} \\
(\mathrm{GPa})\end{array}$ \\
\hline 1 & 25.8388781 & $2 \mathrm{E}-05$ & 1395796 & 9.61703381 \\
\hline 2 & 25.8505153 & $2 \mathrm{E}-05$ & 1396425 & 9.62136509 \\
\hline 3 & 25.805054 & $2 \mathrm{E}-05$ & 1393969 & 9.6044447 \\
\hline 4 & 25.8921377 & $2 \mathrm{E}-05$ & 1398673 & 9.6368566 \\
\hline 5 & 25.8456688 & $2 \mathrm{E}-05$ & 1396163 & 9.61956125 \\
\hline
\end{tabular}

\begin{tabular}{|l|l|}
\hline Kpa & log KPa \\
\hline 9617034 & 6.983041 \\
\hline 9621365 & 6.983237 \\
\hline 9604445 & 6.982472 \\
\hline 9636857 & 6.983935 \\
\hline 9619561 & 6.983155 \\
\hline
\end{tabular}




\begin{tabular}{|c|c|c|c|c|c|}
\hline \multicolumn{2}{|c|}{$5 \mathrm{~Hz}$} & \multicolumn{5}{l|}{} \\
\hline Cycle \# & P(lb-f) & A(in2) & P(inch) & $\boldsymbol{\Delta}$ & GL \\
\hline 1 & 274.67377 & 10.75 & & $7.6992 \mathrm{E}-05$ & 3.5 \\
\hline 2 & 275.13055 & 10.75 & & 0.00007699 & 3.5 \\
\hline 3 & 274.04565 & 10.75 & & 0.00007699 & 3.5 \\
\hline 4 & 274.04117 & 10.75 & & 0.00007699 & 3.5 \\
\hline 5 & 272.40326 & 10.75 & & 0.00007699 & 3.5 \\
\hline
\end{tabular}

\begin{tabular}{|c|c|c|c|c|}
\hline Cycle \# & $\sigma=P / A$ & $\begin{array}{c}\varepsilon=\Delta- \\
G L\end{array}$ & $\begin{array}{l}{\left[\mathrm{E}^{*}\right]=\sigma / \varepsilon} \\
\text { (psi) }\end{array}$ & $\begin{array}{l}{\left[\mathrm{E}^{*}\right]=\sigma / \varepsilon} \\
(\mathrm{GPa})\end{array}$ \\
\hline 1 & 25.5510484 & $2 \mathrm{E}-05$ & 1161538 & 8.00299684 \\
\hline 2 & 25.5935395 & $2 \mathrm{E}-05$ & 1163470 & 8.01630575 \\
\hline 3 & 25.4926186 & $2 \mathrm{E}-05$ & 1158882 & 7.9846957 \\
\hline 4 & 25.4922019 & $2 \mathrm{E}-05$ & 1158863 & 7.98456517 \\
\hline 5 & 25.3398381 & $2 \mathrm{E}-05$ & 1151936 & 7.93684242 \\
\hline
\end{tabular}

\begin{tabular}{|l|l|}
\hline$E$ (Kpa) & $\begin{array}{l}\text { logE } \\
\text { (Kpa) }\end{array}$ \\
\hline 8002997 & 6.903253 \\
\hline 8016306 & 6.903974 \\
\hline 7984696 & 6.902258 \\
\hline 7984565 & 6.902251 \\
\hline 7936842 & 6.899648 \\
\hline
\end{tabular}

\begin{tabular}{|c|r|c|c|c|c|}
\hline \multicolumn{2}{|c|}{ 1HZ } & \multicolumn{5}{l|}{} \\
\cline { 1 - 2 } Cycle \# & \multicolumn{1}{c|}{ P(lb-f) } & A(in2) & P(inch) & $\Delta$ & GL \\
\hline 1 & 276.50229 & 10.75 & & 0.00034491 & 3.5 \\
\hline 2 & 276.74387 & 10.75 & & 0.00010778 & 3.5 \\
\hline 3 & 276.57056 & 10.75 & & 0.00010778 & 3.5 \\
\hline 4 & 278.0592 & 10.75 & & 0.00010778 & 3.5 \\
\hline 5 & 273.58487 & 10.75 & & 0.00010778 & 3.5 \\
\hline
\end{tabular}

\begin{tabular}{|c|l|c|c|c|}
\hline Cycle \# & $\sigma=P / A$ & $\begin{array}{c}\varepsilon=\Delta- \\
\text { GL }\end{array}$ & $\begin{array}{l}{\left[E^{*}\right]=\sigma / \varepsilon} \\
\text { (psi) }\end{array}$ & $\begin{array}{l}{\left[E^{*}\right]=\sigma / \varepsilon} \\
\text { (GPa) }\end{array}$ \\
\hline 1 & 25.7211433 & $1 \mathrm{E}-04$ & 261010.7 & 1.79836366 \\
\hline 2 & 25.7436158 & $3 \mathrm{E}-05$ & 835964 & 5.75979163 \\
\hline 3 & 25.727494 & $3 \mathrm{E}-05$ & 835440.4 & 5.75618458 \\
\hline 4 & 25.8659721 & $3 \mathrm{E}-05$ & 839937.2 & 5.78716722 \\
\hline 5 & 25.4497553 & $3 \mathrm{E}-05$ & 826421.5 & 5.69404426 \\
\hline
\end{tabular}

\begin{tabular}{|l|l|}
\hline$E(K p a)$ & $\begin{array}{l}\text { logE } \\
\text { (Kpa) }\end{array}$ \\
\hline 1798364 & 6.254878 \\
\hline 5759792 & 6.760407 \\
\hline 5756185 & 6.760135 \\
\hline 5787167 & 6.762466 \\
\hline 5694044 & 6.755421 \\
\hline
\end{tabular}

\begin{tabular}{|c|c|c|c|c|c|}
\hline \multicolumn{2}{|c|}{$\mathbf{0 . 5 H z}$} & \multicolumn{5}{|c|}{} \\
\cline { 1 - 2 } Cycle \# & P(lb-f) & A(in2) & P(inch) & $\Delta$ & GL \\
\hline 1 & 276.64624 & 10.75 & & 0.00047411 & 3.5 \\
\hline 2 & 276.68979 & 10.75 & & 0.00014816 & 3.5 \\
\hline 3 & 277.20328 & 10.75 & & 0.00014816 & 3.5 \\
\hline 4 & 277.19769 & 10.75 & & 0.00014816 & 3.5 \\
\hline 5 & 276.62436 & 10.75 & & 0.00014816 & 3.5 \\
\hline
\end{tabular}




\begin{tabular}{|c|c|c|c|l|}
\hline Cycle \# & $\sigma=P / A$ & $\begin{array}{c}\varepsilon=\Delta- \\
\text { GL }\end{array}$ & $\begin{array}{l}{\left[E^{*}\right]=\sigma / \varepsilon} \\
(p s i)\end{array}$ & $\begin{array}{l}{\left[E^{*}\right]=\sigma / \varepsilon} \\
(\mathrm{GPa})\end{array}$ \\
\hline 1 & 25.734534 & 0.0001 & 189977.6 & 1.30894539 \\
\hline 2 & 25.7385851 & $4 \mathrm{E}-05$ & 608023.9 & 4.18928462 \\
\hline 3 & 25.7863516 & $4 \mathrm{E}-05$ & 609152.3 & 4.19705923 \\
\hline 4 & 25.7858316 & $4 \mathrm{E}-05$ & 609140 & 4.19697459 \\
\hline 5 & 25.7324986 & $4 \mathrm{E}-05$ & 607880.1 & 4.18829396 \\
\hline
\end{tabular}

\begin{tabular}{|l|l|}
\hline$E(K p a)$ & $\begin{array}{l}\text { logE } \\
\text { (Kpa) }\end{array}$ \\
\hline 1308945 & 6.116922 \\
\hline 4189285 & 6.62214 \\
\hline 4197059 & 6.622945 \\
\hline 4196975 & 6.622936 \\
\hline 4188294 & 6.622037 \\
\hline
\end{tabular}

\begin{tabular}{|c|c|c|c|c|c|}
\hline \multicolumn{2}{|c|}{$\mathbf{0 . 1 H z}$} & \multicolumn{5}{l|}{} \\
\hline Cycle \# & P(lb-f) & A(in2) & P(inch) & $\Delta$ & GL \\
\hline 1 & 334.19385 & 10.75 & & 0.00079087 & 3.5 \\
\hline 2 & 344.33774 & 10.75 & & 0.00024715 & 3.5 \\
\hline 3 & 354.29492 & 10.75 & & 0.00024715 & 3.5 \\
\hline 4 & 364.30731 & 10.75 & & 0.00024715 & 3.5 \\
\hline 5 & 374.26123 & 10.75 & & 0.00024715 & 3.5 \\
\hline
\end{tabular}

\begin{tabular}{|c|c|c|c|c|}
\hline Cycle \# & $\sigma=P / A$ & $\begin{array}{c}\varepsilon=\Delta- \\
G L\end{array}$ & $\begin{array}{l}{\left[E^{*}\right]=\sigma / \varepsilon} \\
\text { (psi) }\end{array}$ & $\begin{array}{l}{\left[\mathrm{E}^{*}\right]=\sigma / \varepsilon} \\
\text { (GPa) }\end{array}$ \\
\hline 1 & 31.0878 & 0.0002 & 137579.3 & 0.94792155 \\
\hline 2 & 32.0314177 & 7E-05 & 453617 & 3.12542115 \\
\hline 3 & 32.957667 & 7E-05 & 466734.2 & 3.21579864 \\
\hline 4 & 33.8890521 & 7E-05 & 479924.1 & 3.30667725 \\
\hline 5 & 34.8149981 & 7E-05 & 493037 & 3.39702515 \\
\hline
\end{tabular}

\begin{tabular}{|l|l|}
\hline$E(K p a)$ & $\begin{array}{l}\text { logE } \\
(\mathrm{Kpa})\end{array}$ \\
\hline 947921.6 & 5.976772 \\
\hline 3125421 & 6.494909 \\
\hline 3215799 & 6.507289 \\
\hline 3306677 & 6.519392 \\
\hline 3397025 & 6.531099 \\
\hline
\end{tabular}


(37.8 degrees)

\begin{tabular}{|c|c|c|c|c|c|c|c|}
\hline Freq (Hz) & $\begin{array}{l}\text { Peak Displ. } \\
\text { Values (in) }\end{array}$ & $\begin{array}{l}\text { Peak } \\
\text { Load } \\
\text { Values } \\
\text { (lb-f) }\end{array}$ & $\begin{array}{l}\text { Peak Displ. } \\
\text { Time (secs) }\end{array}$ & $\begin{array}{c}\text { Peak Load } \\
\text { Time (secs) }\end{array}$ & $\begin{array}{l}\text { Phase } \\
\text { Shift } \\
\text { Values } \\
\text { (secs) }\end{array}$ & $\begin{array}{l}\text { Average } \\
\text { Displ. (in) }\end{array}$ & $\begin{array}{l}\text { Average } \\
\text { Load (Ib) }\end{array}$ \\
\hline \multirow[t]{5}{*}{10} & 0.00004295 & 101.833 & 30.60433 & 30.597494 & 0.00684 & 4.3E-05 & 101.5088 \\
\hline & 0.00004295 & 101.289 & 30.69841 & 30.700521 & 0.00211 & & \\
\hline & 0.00004295 & 101.619 & 30.80984 & 30.799807 & 0.01003 & & \\
\hline & 0.00004295 & 101.377 & 30.09993 & 30.0898928 & 0.01004 & & \\
\hline & 0.00004295 & 101.426 & 30.09935 & 30.087561 & 0.01179 & & \\
\hline \multirow[t]{5}{*}{5} & 0.0007746 & 103.979 & 50.16765 & 50.149578 & 0.01807 & 6.46E-05 & 103.4975 \\
\hline & 0.00006455 & 103.562 & 50.36768 & 50.348797 & 0.01888 & & \\
\hline & 0.00006455 & 103.996 & 50.56852 & 50.548668 & 0.01985 & & \\
\hline & 0.00006455 & 102.495 & 50.76791 & 50.747398 & 0.02051 & & \\
\hline & 0.00006455 & 103.456 & 50.96761 & 50.946129 & 0.02148 & & \\
\hline \multirow[t]{5}{*}{1} & 0.0011748 & 107.758 & 66.65414 & 66.592285 & 0.06185 & 0.000313 & 106.7013 \\
\hline & 0.00009790 & 107.157 & 67.63754 & 67.592125 & 0.04541 & & \\
\hline & 0.00009790 & 107.035 & 68.62045 & 68.594079 & 0.02637 & & \\
\hline & 0.00009790 & 106.122 & 69.65463 & 69.612793 & 0.04183 & & \\
\hline & 0.00009790 & 105.434 & 70.65398 & 70.610519 & 0.04346 & & \\
\hline \multirow[t]{5}{*}{0.5} & 0.0019752 & 107.976 & 92.27409 & 92.131676 & 0.14242 & 0.000527 & 106.6774 \\
\hline & 0.00016460 & 106.892 & 94.24007 & 94.182785 & 0.05729 & & \\
\hline & 0.00016460 & 106.138 & 96.32471 & 96.191574 & 0.13313 & & \\
\hline & 0.00016460 & 105.452 & 98.25798 & 98.193527 & 0.06445 & & \\
\hline & 0.00016460 & 106.929 & 100.2747 & 100.18083 & 0.09391 & & \\
\hline \multirow[t]{5}{*}{0.1} & 0.0024766 & 96.9263 & 187.4185 & 187.00017 & 0.41829 & 0.00066 & 100.4018 \\
\hline & 0.00020638 & 102.908 & 197.1528 & 196.68034 & 0.47249 & & \\
\hline & 0.00020638 & 103.272 & 207.0355 & 206.75684 & 0.27865 & & \\
\hline & 0.00020638 & 96.678 & 227.5015 & 226.9904 & 0.51106 & & \\
\hline & 0.00020638 & 102.225 & 237.2862 & 237.04623 & 0.23992 & & \\
\hline
\end{tabular}

\begin{tabular}{|c|c|c|c|c|c|}
\cline { 1 - 2 } \multicolumn{2}{|c|}{$\mathbf{1 0 H z}$} & \multicolumn{5}{l}{} \\
\cline { 1 - 2 } Cycle \# & P(lb-f) & A(in2) & P(inch) & $\Delta$ & GL \\
\hline 1 & 101.83311 & 10.75 & & 0.00004295 & 3.5 \\
\hline 2 & 101.28863 & 10.75 & & 0.00004295 & 3.5 \\
\hline 3 & 101.61946 & 10.75 & & 0.00004295 & 3.5 \\
\hline 4 & 101.37658 & 10.75 & & 0.00004295 & 3.5 \\
\hline 5 & 101.42605 & 10.75 & & 0.00004295 & 3.5 \\
\hline
\end{tabular}

\begin{tabular}{|c|c|c|c|c|}
\hline Cycle \# & $\sigma=P / A$ & $\varepsilon=\Delta-G L$ & $\begin{array}{l}{\left[E^{*}\right]=\sigma / \varepsilon} \\
\text { (psi) }\end{array}$ & $\begin{array}{l}{\left[\mathrm{E}^{*}\right]=\sigma / \varepsilon} \\
(\mathrm{GPa})\end{array}$ \\
\hline 1 & 9.4728474 & 1.2E-05 & 771941.1 & 5.31867407 \\
\hline 2 & 9.4221981 & 1.2E-05 & 767813.7 & 5.29023625 \\
\hline 3 & 9.452973 & $1.2 \mathrm{E}-05$ & 770321.5 & 5.30751527 \\
\hline 4 & 9.4303795 & $1.2 \mathrm{E}-05$ & 768480.4 & 5.29482982 \\
\hline 5 & 9.4349814 & $1.2 \mathrm{E}-05$ & 768855.4 & 5.2974136 \\
\hline
\end{tabular}

\begin{tabular}{|l|l|}
\hline $\mathrm{Kpa}$ & $\log \mathrm{KPa}$ \\
\hline 5318674 & 6.725803 \\
\hline 5290236 & 6.723475 \\
\hline 5307515 & 6.724891 \\
\hline 5294830 & 6.723852 \\
\hline 5297414 & 6.724064 \\
\hline
\end{tabular}




\begin{tabular}{|c|r|c|c|c|c|}
\hline \multicolumn{2}{|c|}{$5 \mathrm{~Hz}$} & \multicolumn{5}{l|}{} \\
\hline Cycle \# & P(lb-f) & A(in2) & P(inch) & $\boldsymbol{\Delta}$ & GL \\
\hline 1 & 103.97933 & 10.75 & & $6.4553 \mathrm{E}-05$ & 3.5 \\
\hline 2 & 103.5618 & 10.75 & & 0.00006455 & 3.5 \\
\hline 3 & 103.99595 & 10.75 & & 0.00006455 & 3.5 \\
\hline 4 & 102.49497 & 10.75 & & 0.00006455 & 3.5 \\
\hline 5 & 103.45555 & 10.75 & & 0.00006455 & 3.5 \\
\hline
\end{tabular}

\begin{tabular}{|c|l|l|l|l|}
\hline Cycle \# & $\sigma=P / A$ & $\varepsilon=\Delta-G L$ & $\begin{array}{l}{\left[E^{*}\right]=\sigma / \varepsilon} \\
(p s i)\end{array}$ & $\begin{array}{l}{\left[E^{*}\right]=\sigma / \varepsilon} \\
(\mathrm{GPa})\end{array}$ \\
\hline 1 & 9.6724958 & $1.8 \mathrm{E}-05$ & 524432.3 & 3.61333858 \\
\hline 2 & 9.6336558 & $1.8 \mathrm{E}-05$ & 522326.4 & 3.59882918 \\
\hline 3 & 9.6740419 & $1.8 \mathrm{E}-05$ & 524516.1 & 3.61391613 \\
\hline 4 & 9.5344158 & $1.8 \mathrm{E}-05$ & 516945.8 & 3.56175625 \\
\hline 5 & 9.6237721 & $1.8 \mathrm{E}-05$ & 521790.6 & 3.59513693 \\
\hline
\end{tabular}

\begin{tabular}{|l|l|}
\hline$E$ (Kpa) & $\begin{array}{l}\text { logE } \\
\text { (Kpa) }\end{array}$ \\
\hline 3613339 & 6.557909 \\
\hline 3598829 & 6.556161 \\
\hline 3613916 & 6.557978 \\
\hline 3561756 & 6.551664 \\
\hline 3595137 & 6.555715 \\
\hline
\end{tabular}

\begin{tabular}{|c|c|c|c|c|c|}
\hline \multicolumn{2}{|c|}{ 1HZ } & \multicolumn{5}{|l|}{} \\
\cline { 1 - 2 } Cycle \# & P(lb-f) & A(in2) & P(inch) & $\Delta$ & GL \\
\hline 1 & 107.7582 & 10.75 & & 0.00031328 & 3.5 \\
\hline 2 & 107.15746 & 10.75 & & 0.00009790 & 3.5 \\
\hline 3 & 107.03481 & 10.75 & & 0.00009790 & 3.5 \\
\hline 4 & 106.12226 & 10.75 & & 0.00009790 & 3.5 \\
\hline 5 & 105.43392 & 10.75 & & 0.00009790 & 3.5 \\
\hline
\end{tabular}

\begin{tabular}{|c|c|c|c|l|}
\hline Cycle \# & $\sigma=P / A$ & $\varepsilon=\Delta-G L$ & $\begin{array}{l}{\left[E^{*}\right]=\sigma / \varepsilon} \\
(\mathbf{p s i})\end{array}$ & $\begin{array}{l}{\left[E^{*}\right]=\sigma / \varepsilon} \\
(\mathrm{GPa})\end{array}$ \\
\hline 1 & 10.024019 & $9 \mathrm{E}-05$ & 111988.3 & 0.77159965 \\
\hline 2 & 9.9681358 & $2.8 \mathrm{E}-05$ & 356364.9 & 2.45535383 \\
\hline 3 & 9.9567265 & $2.8 \mathrm{E}-05$ & 355957 & 2.45254349 \\
\hline 4 & 9.8718381 & $2.8 \mathrm{E}-05$ & 352922.2 & 2.43163376 \\
\hline 5 & 9.8078065 & $2.8 \mathrm{E}-05$ & 350633 & 2.41586147 \\
\hline
\end{tabular}

\begin{tabular}{|l|l|}
\hline$E$ (Kpa) & $\begin{array}{l}\text { logE } \\
\text { (Kpa) }\end{array}$ \\
\hline 771599.7 & 5.887392 \\
\hline 2455354 & 6.390114 \\
\hline 2452543 & 6.389617 \\
\hline 2431634 & 6.385898 \\
\hline 2415861 & 6.383072 \\
\hline
\end{tabular}

\begin{tabular}{|c|c|c|c|c|c|}
\hline \multicolumn{2}{|c|}{$\mathbf{0 . 5 H z}$} & \multicolumn{5}{l|}{} \\
\hline Cycle \# & P(lb-f) & A(in2) & P(inch) & $\boldsymbol{\Delta}$ & GL \\
\hline 1 & 107.97568 & 10.75 & & 0.00052672 & 3.5 \\
\hline 2 & 106.89169 & 10.75 & & 0.00016460 & 3.5 \\
\hline 3 & 106.13837 & 10.75 & & 0.00016460 & 3.5 \\
\hline 4 & 105.45222 & 10.75 & & 0.00016460 & 3.5 \\
\hline 5 & 106.92915 & 10.75 & & 0.00016460 & 3.5 \\
\hline
\end{tabular}




\begin{tabular}{|c|c|c|c|c|}
\hline Cycle \# & $\sigma=P / A$ & $\varepsilon=\Delta-G L$ & $\begin{array}{l}{\left[E^{*}\right]=\sigma / \varepsilon} \\
(\mathbf{p s i})\end{array}$ & $\begin{array}{l}{\left[E^{*}\right]=\sigma / \varepsilon} \\
(\mathrm{GPa})\end{array}$ \\
\hline 1 & 10.044249 & 0.00015 & 66742.46 & 0.45985552 \\
\hline 2 & 9.943413 & $4.7 \mathrm{E}-05$ & 211431.7 & 1.45676458 \\
\hline 3 & 9.8733367 & $4.7 \mathrm{E}-05$ & 209941.7 & 1.44649802 \\
\hline 4 & 9.8095088 & $4.7 \mathrm{E}-05$ & 208584.5 & 1.43714689 \\
\hline 5 & 9.9468977 & $4.7 \mathrm{E}-05$ & 211505.8 & 1.4572751 \\
\hline
\end{tabular}

\begin{tabular}{|l|l|}
\hline$E(K p a)$ & $\begin{array}{l}\text { logE } \\
\text { (Kpa) }\end{array}$ \\
\hline 459855.5 & 5.662621 \\
\hline 1456765 & 6.163389 \\
\hline 1446498 & 6.160318 \\
\hline 1437147 & 6.157501 \\
\hline 1457275 & 6.163542 \\
\hline
\end{tabular}

\begin{tabular}{|c|r|c|c|c|c|}
\hline \multicolumn{2}{|c|}{$\mathbf{0 . 1 H z}$} & \multicolumn{5}{l|}{} \\
\cline { 1 - 2 } Cycle \# & \multicolumn{1}{|c|}{$\mathbf{P}(\mathbf{l b}$-f) } & A(in2) & P(inch) & $\boldsymbol{\Delta}$ & GL \\
\hline 1 & 96.92628 & 10.75 & & 0.00066042 & 3.5 \\
\hline 2 & 102.90831 & 10.75 & & 0.00020638 & 3.5 \\
\hline 3 & 103.27161 & 10.75 & & 0.00020638 & 3.5 \\
\hline 4 & 96.67797 & 10.75 & & 0.00020638 & 3.5 \\
\hline 5 & 102.22502 & 10.75 & & 0.00020638 & 3.5 \\
\hline
\end{tabular}

\begin{tabular}{|c|c|c|c|l|}
\hline Cycle \# & $\sigma=P / A$ & $\varepsilon=\Delta-G L$ & $\begin{array}{l}{[\mathrm{E} *]=\sigma / \varepsilon} \\
\text { (psi) }\end{array}$ & $\begin{array}{l}{\left[\mathrm{E}^{*}\right]=\sigma / \varepsilon} \\
\text { (GPa) }\end{array}$ \\
\hline 1 & 9.0163981 & 0.00019 & 47783.6 & 0.32922897 \\
\hline 2 & 9.572866 & $5.9 \mathrm{E}-05$ & 162344.5 & 1.11855392 \\
\hline 3 & 9.6066614 & $5.9 \mathrm{E}-05$ & 162917.7 & 1.12250278 \\
\hline 4 & 8.9932995 & $5.9 \mathrm{E}-05$ & 152515.8 & 1.05083372 \\
\hline 5 & 9.5093042 & $5.9 \mathrm{E}-05$ & 161266.6 & 1.11112695 \\
\hline
\end{tabular}

\begin{tabular}{|c|l|}
\hline$E$ (Kpa) & $\begin{array}{l}\text { logE } \\
\text { (Kpa) }\end{array}$ \\
\hline 329229 & 5.517498 \\
\hline 1118554 & 6.048657 \\
\hline 1122503 & 6.050187 \\
\hline 1050834 & 6.021534 \\
\hline 1111127 & 6.045764 \\
\hline
\end{tabular}


Control

(-9 degrees)

\begin{tabular}{|c|c|c|c|c|c|c|c|}
\hline Freq $(\mathrm{Hz})$ & $\begin{array}{l}\text { Peak Displ. } \\
\text { Values (in) }\end{array}$ & $\begin{array}{l}\text { Peak } \\
\text { Load } \\
\text { Values } \\
\text { (lb-ft) }\end{array}$ & $\begin{array}{l}\text { Peak Displ. } \\
\text { Time (secs) }\end{array}$ & $\begin{array}{l}\text { Peak Load } \\
\text { Time (secs) }\end{array}$ & $\begin{array}{l}\text { Phase } \\
\text { Shift } \\
\text { Values } \\
\text { (secs) }\end{array}$ & $\begin{array}{l}\text { Average } \\
\text { Displ. (in) }\end{array}$ & $\begin{array}{l}\text { Average } \\
\text { Load (Ib) }\end{array}$ \\
\hline \multirow[t]{5}{*}{10} & 0.00011788 & 1052.76 & 39.98145 & 39.97396 & 0.00749 & 0.000118 & 1052.464 \\
\hline & 0.00011788 & 1052.9 & 40.17253 & 40.17153 & 0.001 & & \\
\hline & 0.00011788 & 1052.64 & 40.38298 & 40.37484 & 0.00814 & & \\
\hline & 0.00011788 & 1053.44 & 40.57813 & 40.57438 & 0.00375 & & \\
\hline & 0.00011788 & 1050.58 & 40.77767 & 40.77474 & 0.00293 & & \\
\hline \multirow[t]{5}{*}{5} & 0.00012826 & 1055.863 & 39.5822 & 39.5765 & 0.0057 & 0.000128 & 1053.59 \\
\hline & 0.00012826 & 1053.89 & 39.7806 & 39.77767 & 0.00293 & & \\
\hline & 0.00012826 & 1051.342 & 39.97966 & 39.97461 & 0.00505 & & \\
\hline & 0.00012826 & 1053.099 & 40.1792 & 40.17757 & 0.00163 & & \\
\hline & 0.00012826 & 1053.756 & 40.38216 & 40.37533 & 0.00683 & & \\
\hline \multirow[t]{5}{*}{1} & 0.00015696 & 1056.68 & 56.63477 & 56.606285 & 0.028481 & 0.000157 & 1054.798 \\
\hline & 0.00015696 & 1053.064 & 57.62875 & 57.611656 & 0.01709 & & \\
\hline & 0.00015696 & 1052.973 & 58.63981 & 58.614258 & 0.025554 & & \\
\hline & 0.00015696 & 1055.63 & 59.65186 & 59.605309 & 0.046546 & & \\
\hline & 0.00015696 & 1055.645 & 60.65186 & 60.606445 & 0.04541 & & \\
\hline \multirow[t]{5}{*}{0.5} & 0.00017112 & 1053.739 & 82.18832 & 82.120773 & 0.067543 & 0.000171 & 1052.011 \\
\hline & 0.00017112 & 1053.631 & 84.19971 & 84.120605 & 0.079102 & & \\
\hline & 0.00017112 & 1049.898 & 86.17253 & 86.140625 & 0.031906 & & \\
\hline & 0.00017112 & 1052.121 & 88.18864 & 88.130371 & 0.058273 & & \\
\hline & 0.00017112 & 1050.667 & 90.20622 & 90.137535 & 0.068688 & & \\
\hline \multirow[t]{5}{*}{0.1} & 0.00024293 & 1048.211 & 96.75732 & 96.244629 & 0.512695 & 0.000243 & 1049.785 \\
\hline & 0.00024293 & 1051.138 & 106.7196 & 106.18359 & 0.53598 & & \\
\hline & 0.00024293 & 1050.457 & 116.8281 & 116.2041 & 0.62403 & & \\
\hline & 0.00024293 & 1048.338 & 126.8573 & 126.30095 & 0.55631 & & \\
\hline & 0.00024293 & 1050.779 & 136.7487 & 136.257 & 0.4917 & & \\
\hline
\end{tabular}

\begin{tabular}{|c|c|c|c|c|c|}
\hline \multicolumn{2}{|c|}{$10 \mathrm{~Hz}$} & \multicolumn{5}{|c|}{} \\
\cline { 1 - 2 } Cycle \# & P(lb-f) & A(in2) & & $\boldsymbol{\Delta}$ & GL \\
\hline 1 & 1052.76 & 10.75 & & 0.00011788 & 3.5 \\
\hline 2 & 1052.9 & 10.75 & & 0.00011788 & 3.5 \\
\hline 3 & 1052.64 & 10.75 & & 0.00011788 & 3.5 \\
\hline 4 & 1053.44 & 10.75 & & 0.00011788 & 3.5 \\
\hline 5 & 1050.58 & 10.75 & & 0.00011788 & 3.5 \\
\hline
\end{tabular}

\begin{tabular}{|c|c|c|l|l|}
\hline Cycle \# & $\sigma=P / A$ & $\varepsilon=\Delta-G L$ & $\begin{array}{l}{\left[E^{*}\right]=\sigma / \varepsilon} \\
(p s i)\end{array}$ & $\begin{array}{l}{\left[E^{*}\right]=\sigma / \varepsilon} \\
(\mathrm{GPa})\end{array}$ \\
\hline 1 & 97.931163 & $3.37 \mathrm{E}-05$ & 2907754 & 20.0344255 \\
\hline 2 & 97.944186 & $3.37 \mathrm{E}-05$ & 2908141 & 20.0370897 \\
\hline 3 & 97.92 & $3.37 \mathrm{E}-05$ & 2907423 & 20.0321418 \\
\hline 4 & 97.994419 & $3.37 \mathrm{E}-05$ & 2909632 & 20.0473661 \\
\hline 5 & 97.728372 & $3.37 \mathrm{E}-05$ & 2901733 & 19.9929392 \\
\hline
\end{tabular}

\begin{tabular}{|l|l|}
\hline Kpa & log KPa \\
\hline 20034425 & 7.301777 \\
\hline 20037090 & 7.301835 \\
\hline 20032142 & 7.301727 \\
\hline 20047366 & 7.302057 \\
\hline 19992939 & 7.300877 \\
\hline
\end{tabular}




\begin{tabular}{|c|c|c|c|c|c|}
\hline \multicolumn{2}{|c|}{$5 \mathbf{H z}$} & \multicolumn{5}{|l|}{} \\
\hline Cycle \# & P(lb-f) & A(in2) & & $\boldsymbol{\Delta}$ & GL \\
\hline 1 & 1055.8628 & 10.75 & & 0.00012826 & 3.5 \\
\hline 2 & 1053.8903 & 10.75 & & 0.00012826 & 3.5 \\
\hline 3 & 1051.3416 & 10.75 & & 0.00012826 & 3.5 \\
\hline 4 & 1053.0994 & 10.75 & & 0.00012826 & 3.5 \\
\hline 5 & 1053.7556 & 10.75 & & 0.00012826 & 3.5 \\
\hline
\end{tabular}

\begin{tabular}{|c|l|c|l|l|}
\hline Cycle \# & $\boldsymbol{\sigma}=\mathrm{P} / \mathrm{A}$ & $\boldsymbol{\varepsilon}=\Delta-\mathrm{GL}$ & $\begin{array}{l}{\left[\mathrm{E}^{*}\right]=\sigma / \varepsilon} \\
\text { (psi) }\end{array}$ & $\begin{array}{l}{\left[\mathrm{E}^{*}\right]=\sigma / \varepsilon} \\
\text { (GPa) }\end{array}$ \\
\hline 1 & 98.219795 & $3.66 \mathrm{E}-05$ & 2680331 & 18.4674825 \\
\hline 2 & 98.036307 & $3.66 \mathrm{E}-05$ & 2675324 & 18.4329827 \\
\hline 3 & 97.799219 & $3.66 \mathrm{E}-05$ & 2668854 & 18.3884049 \\
\hline 4 & 97.962735 & $3.66 \mathrm{E}-05$ & 2673316 & 18.4191495 \\
\hline 5 & 98.023777 & $3.66 \mathrm{E}-05$ & 2674982 & 18.4306267 \\
\hline
\end{tabular}

\begin{tabular}{|l|l|}
\hline$E(K p a)$ & $\begin{array}{l}\text { logE } \\
\text { (Kpa) }\end{array}$ \\
\hline 18467483 & 7.266408 \\
\hline 18432983 & 7.265596 \\
\hline 18388405 & 7.264544 \\
\hline 18419150 & 7.26527 \\
\hline 18430627 & 7.26554 \\
\hline
\end{tabular}

\begin{tabular}{|c|c|c|c|c|c|}
\hline \multicolumn{2}{|c|}{ 1HZ } & \multicolumn{5}{l|}{} \\
\hline Cycle \# & P(lb-f) & A(in2) & & $\Delta$ & GL \\
\hline 1 & 1056.6803 & 10.75 & & 0.00015696 & 3.5 \\
\hline 2 & 1053.0635 & 10.75 & & 0.00015696 & 3.5 \\
\hline 3 & 1052.9727 & 10.75 & & 0.00015696 & 3.5 \\
\hline 4 & 1055.6296 & 10.75 & & 0.00015696 & 3.5 \\
\hline 5 & 1055.6448 & 10.75 & & 0.00015696 & 3.5 \\
\hline
\end{tabular}

\begin{tabular}{|c|l|c|c|l|}
\hline Cycle \# & $\sigma=P / A$ & $\varepsilon=\Delta-G L$ & $\begin{array}{l}{\left[E^{*}\right]=\sigma / \varepsilon} \\
\text { (psi) }\end{array}$ & $\begin{array}{l}{\left[E^{*}\right]=\sigma / \varepsilon} \\
(\mathrm{GPa})\end{array}$ \\
\hline 1 & 98.295842 & $4.48 \mathrm{E}-05$ & 2191919 & 15.1023245 \\
\hline 2 & 97.959395 & $4.48 \mathrm{E}-05$ & 2184417 & 15.0506324 \\
\hline 3 & 97.950949 & $4.48 \mathrm{E}-05$ & 2184229 & 15.0493346 \\
\hline 4 & 98.198102 & $4.48 \mathrm{E}-05$ & 2189740 & 15.0873077 \\
\hline 5 & 98.199516 & $4.48 \mathrm{E}-05$ & 2189771 & 15.0875249 \\
\hline
\end{tabular}

\begin{tabular}{|l|l|}
\hline$E(K p a)$ & $\begin{array}{l}\text { logE } \\
\text { (Kpa) }\end{array}$ \\
\hline 15102325 & 7.179044 \\
\hline 15050632 & 7.177555 \\
\hline 15049335 & 7.177517 \\
\hline 15087308 & 7.178612 \\
\hline 15087525 & 7.178618 \\
\hline
\end{tabular}

\begin{tabular}{|c|r|c|l|c|c|}
\hline \multicolumn{2}{|c|}{$\mathbf{0 . 5 H z}$} & \multicolumn{5}{l|}{} \\
\hline Cycle \# & P(lb-f) & A(in2) & & $\boldsymbol{\Delta}$ & GL \\
\hline 1 & 1053.739 & 10.75 & & 0.00017112 & 3.5 \\
\hline 2 & 1053.6309 & 10.75 & & 0.00017112 & 3.5 \\
\hline 3 & 1049.8977 & 10.75 & & 0.00017112 & 3.5 \\
\hline 4 & 1052.1211 & 10.75 & & 0.00017112 & 3.5 \\
\hline 5 & 1050.667 & 10.75 & & 0.00017112 & 3.5 \\
\hline
\end{tabular}




\begin{tabular}{|c|c|c|c|c|}
\hline Cycle \# & $\sigma=P / A$ & $\varepsilon=\Delta-G L$ & $\begin{array}{l}{\left[E^{*}\right]=\sigma / \varepsilon} \\
\text { (psi) }\end{array}$ & $\begin{array}{l}{\left[\mathrm{E}^{*}\right]=\sigma / \varepsilon} \\
(\mathrm{GPa})\end{array}$ \\
\hline 1 & 98.022233 & 4.89E-05 & 2004868 & 13.8135401 \\
\hline 2 & 98.012177 & 4.89E-05 & 2004662 & 13.812123 \\
\hline 3 & 97.664902 & $4.89 \mathrm{E}-05$ & 1997559 & 13.7631842 \\
\hline 4 & 97.87173 & 4.89E-05 & 2001790 & 13.792331 \\
\hline 5 & 97.736465 & 4.89E-05 & 1999023 & 13.7732691 \\
\hline
\end{tabular}

\begin{tabular}{|l|r|}
\hline$E(K p a)$ & $\begin{array}{l}\text { logE } \\
\text { (Kpa) }\end{array}$ \\
\hline 13813540 & 7.140305 \\
\hline 13812123 & 7.14026 \\
\hline 13763184 & 7.138719 \\
\hline 13792331 & 7.139638 \\
\hline 13773269 & 7.139037 \\
\hline
\end{tabular}

\begin{tabular}{|c|c|c|c|c|c|}
\hline \multicolumn{2}{|c|}{$\mathbf{0 . 1 H z}$} & \multicolumn{5}{|l|}{} \\
\hline Cycle \# & P(lb-f) & A(in2) & & $\boldsymbol{\Delta}$ & GL \\
\hline 1 & 1048.2113 & 10.75 & & 0.00024293 & 3.5 \\
\hline 2 & 1051.1384 & 10.75 & & 0.00024293 & 3.5 \\
\hline 3 & 1050.4565 & 10.75 & & 0.00024293 & 3.5 \\
\hline 4 & 1048.3381 & 10.75 & & 0.00024293 & 3.5 \\
\hline 5 & 1050.7792 & 10.75 & & 0.00024293 & 3.5 \\
\hline
\end{tabular}

\begin{tabular}{|c|l|c|l|l|}
\hline Cycle \# & $\sigma=P / A$ & $\varepsilon=\Delta-G L$ & $\begin{array}{l}{\left[E^{*}\right]=\sigma / \varepsilon} \\
(p s i)\end{array}$ & $\begin{array}{l}{\left[E^{*}\right]=\sigma / \varepsilon} \\
\text { (GPa) }\end{array}$ \\
\hline 1 & 97.508028 & $6.94 \mathrm{E}-05$ & 1404854 & 9.67944291 \\
\hline 2 & 97.780316 & $6.94 \mathrm{E}-05$ & 1408777 & 9.70647247 \\
\hline 3 & 97.716884 & $6.94 \mathrm{E}-05$ & 1407863 & 9.70017564 \\
\hline 4 & 97.519823 & $6.94 \mathrm{E}-05$ & 1405024 & 9.68061381 \\
\hline 5 & 97.746902 & $6.94 \mathrm{E}-05$ & 1408295 & 9.70315553 \\
\hline
\end{tabular}

\begin{tabular}{|c|r|}
\hline$E$ (Kpa) & $\begin{array}{l}\text { logE } \\
\text { (Kpa) }\end{array}$ \\
\hline 9679443 & 6.98585 \\
\hline 9706472 & 6.987061 \\
\hline 9700176 & 6.98678 \\
\hline 9680614 & 6.985903 \\
\hline 9703156 & 6.986913 \\
\hline
\end{tabular}


(4.4 degrees)

\begin{tabular}{|c|c|c|c|c|c|c|c|}
\hline Freq (Hz) & $\begin{array}{l}\text { Peak } \\
\text { Displ. } \\
\text { Values } \\
\text { (in) }\end{array}$ & $\begin{array}{c}\text { Peak } \\
\text { Load } \\
\text { Values } \\
\text { (lb-f) }\end{array}$ & $\begin{array}{l}\text { Peak Displ. } \\
\text { Time (secs) }\end{array}$ & $\begin{array}{l}\text { Peak Load } \\
\text { Time (secs) }\end{array}$ & $\begin{array}{l}\text { Phase } \\
\text { Shift } \\
\text { Values } \\
\text { (secs) }\end{array}$ & $\begin{array}{l}\text { Average } \\
\text { Displ. (in) }\end{array}$ & $\begin{array}{l}\text { Average } \\
\text { Load (Ib) }\end{array}$ \\
\hline \multirow[t]{5}{*}{10} & 0.001312 & 786.018 & 23.68799 & 23.683496 & 0.004492 & 0.001318 & 785.6944 \\
\hline & 0.001312 & 785.807 & 23.88613 & 23.783725 & 0.102408 & & \\
\hline & 0.001318 & 785.934 & 23.88835 & 23.883789 & 0.004559 & & \\
\hline & 0.001321 & 784.624 & 23.98975 & 23.884506 & 0.10524 & & \\
\hline & 0.001328 & 786.09 & 24.58398 & 23.683432 & 0.900552 & & \\
\hline \multirow[t]{5}{*}{5} & 0.001457 & 789.01 & 43.44541 & 43.241051 & 0.204359 & 0.001476 & 789.9646 \\
\hline & 0.001467 & 790.879 & 43.44756 & 43.419453 & 0.028106 & & \\
\hline & 0.001478 & 789.092 & 43.64746 & 43.641113 & 0.006348 & & \\
\hline & 0.001483 & 791.136 & 43.85352 & 43.839031 & 0.014485 & & \\
\hline & 0.001478 & 789.708 & 44.04883 & 44.040691 & 0.008137 & & \\
\hline \multirow[t]{5}{*}{1.} & 0.0016 & 787.836 & 59.7277 & 59.667156 & 0.060547 & 0.001632 & 789.1913 \\
\hline & 0.001621 & 789.945 & 60.7341 & 60.661133 & 0.072965 & & \\
\hline & 0.001632 & 789.07 & 61.72738 & 61.66325 & 0.064129 & & \\
\hline & 0.001651 & 789.442 & 62.72266 & 62.665039 & 0.057617 & & \\
\hline & 0.001655 & 789.664 & 63.73926 & 63.663414 & 0.075844 & & \\
\hline \multirow[t]{5}{*}{0.5} & 0.001624 & 787.673 & 130.1714 & 129.25864 & 0.91275 & 0.001718 & 788.637 \\
\hline & 0.001673 & 788.667 & 140.243 & 139.28027 & 0.96274 & & \\
\hline & 0.001718 & 789.232 & 150.1538 & 149.24219 & 0.91162 & & \\
\hline & 0.001765 & 789.452 & 160.2148 & 159.27197 & 0.94287 & & \\
\hline & 0.001808 & 788.162 & 169.5858 & 169.3143 & 0.271478 & & \\
\hline \multirow[t]{5}{*}{0.1} & 0.002158 & 789.339 & 180.1994 & 179.27409 & 0.9253 & 0.002245 & 788.4817 \\
\hline & 0.002201 & 787.215 & 190.4751 & 189.34912 & 1.12598 & & \\
\hline & 0.002246 & 789.297 & 200.18 & 199.27116 & 0.90886 & & \\
\hline & 0.002293 & 788.67 & 210.12 & 209.29868 & 0.82128 & & \\
\hline & 0.002327 & 787.888 & 220.0776 & 219.30112 & 0.77652 & & \\
\hline \multicolumn{6}{|c|}{$10 \mathrm{~Hz}$} & & \\
\hline Cycle \# & $P(l b-f)$ & $A($ in2) & & $\Delta$ & GL & & \\
\hline 1 & 786.0178 & 10.75 & & 0.00010984 & 3.5 & & \\
\hline 2 & 785.807 & 10.75 & & 0.00010984 & 3.5 & & \\
\hline 3 & 785.9337 & 10.75 & & 0.00010984 & 3.5 & & \\
\hline 4 & 784.6235 & 10.75 & & 0.00010984 & 3.5 & & \\
\hline 5 & 786.0903 & 10.75 & & 0.00010984 & 3.5 & & \\
\hline Cycle \# & $\sigma=P / A$ & $\varepsilon=\Delta-G L$ & $\begin{array}{l}{\left[E^{*}\right]=\sigma / \varepsilon} \\
\text { (psi) }\end{array}$ & \begin{tabular}{|l|}
{$\left[\mathrm{E}^{*}\right]=\sigma / \varepsilon$} \\
$(\mathrm{GPa})$ \\
\end{tabular} & & Kpa & $\log \mathrm{KPa}$ \\
\hline 1 & 73.11793 & 3.1E-05 & 2329936 & \begin{tabular}{|l|}
16.05325697 \\
\end{tabular} & & 16053257 & 7.205563 \\
\hline 2 & 73.09833 & 3.1E-05 & 2329311 & \begin{tabular}{|l|l|}
16.04895271 \\
\end{tabular} & & 16048953 & 7.205447 \\
\hline 3 & 73.11011 & 3.1E-05 & 2329686 & \begin{tabular}{|l|}
16.05153914 \\
\end{tabular} & & 16051539 & 7.205517 \\
\hline 4 & \begin{tabular}{|l|}
72.98824 \\
\end{tabular} & 3.1E-05 & 2325803 & \begin{tabular}{|l|l|}
16.02478207 \\
\end{tabular} & & 16024782 & 7.204792 \\
\hline 5 & 73.12468 & 3.1E-05 & 2330151 & 16.05473788 & & 16054738 & 7.205603 \\
\hline
\end{tabular}




\begin{tabular}{|c|c|c|c|c|c|}
\hline \multicolumn{2}{|c|}{$\mathbf{5 H z}$} & \multicolumn{5}{|l|}{} \\
\cline { 1 - 2 } Cycle \# & P(lb-f) & A(in2) & & $\boldsymbol{\Delta}$ & GL \\
\hline 1 & 789.0098 & 10.75 & & 0.00012303 & 3.5 \\
\hline 2 & 790.8788 & 10.75 & & 0.00012303 & 3.5 \\
\hline 3 & 789.0916 & 10.75 & & 0.00012303 & 3.5 \\
\hline 4 & 791.1356 & 10.75 & & 0.00012303 & 3.5 \\
\hline 5 & 789.7075 & 10.75 & & 0.00012303 & 3.5 \\
\hline
\end{tabular}

\begin{tabular}{|c|l|c|c|c|}
\hline Cycle \# & $\sigma=\mathrm{P} / \mathrm{A}$ & $\varepsilon=\Delta-\mathrm{GL}$ & $\begin{array}{l}{\left[\mathrm{E}^{*}\right]=\sigma / \varepsilon} \\
(\mathrm{psi})\end{array}$ & $\begin{array}{l}{\left[\mathrm{E}^{*}\right]=\sigma / \varepsilon} \\
(\mathrm{GPa})\end{array}$ \\
\hline 1 & 73.39626 & $3.5 \mathrm{E}-05$ & 2088029 & 14.38652091 \\
\hline 2 & 73.57012 & $3.5 \mathrm{E}-05$ & 2092975 & 14.42059867 \\
\hline 3 & 73.40387 & $3.5 \mathrm{E}-05$ & 2088245 & 14.38801096 \\
\hline 4 & 73.59401 & $3.5 \mathrm{E}-05$ & 2093655 & 14.4252807 \\
\hline 5 & 73.46116 & $3.5 \mathrm{E}-05$ & 2089876 & 14.39924233 \\
\hline
\end{tabular}

\begin{tabular}{|l|l|}
\hline$E(K p a)$ & $\begin{array}{l}\text { logE } \\
\text { (Kpa) }\end{array}$ \\
\hline 14386521 & 7.157956 \\
\hline 14420599 & 7.158983 \\
\hline 14388011 & 7.158001 \\
\hline 14425281 & 7.159124 \\
\hline 14399242 & 7.15834 \\
\hline
\end{tabular}

\begin{tabular}{|c|c|c|l|c|c|}
\hline \multicolumn{2}{|c|}{ 1HZ } & \multicolumn{5}{l|}{} \\
\cline { 1 - 2 } Cycle \# & P(lb-f) & A(in2) & & $\Delta$ & GL \\
\hline 1 & 787.8361 & 10.75 & & 0.00013598 & 3.5 \\
\hline 2 & 789.9454 & 10.75 & & 0.00013598 & 3.5 \\
\hline 3 & 789.0696 & 10.75 & & 0.00013598 & 3.5 \\
\hline 4 & 789.4418 & 10.75 & & 0.00013598 & 3.5 \\
\hline 5 & 789.6637 & 10.75 & & 0.00013598 & 3.5 \\
\hline
\end{tabular}

\begin{tabular}{|c|c|c|c|l|}
\hline Cycle \# & $\sigma=P / A$ & $\varepsilon=\Delta-G L$ & $\begin{array}{l}{\left[E^{*}\right]=\sigma / \varepsilon} \\
\text { (psi) }\end{array}$ & $\begin{array}{l}{\left[E^{*}\right]=\sigma / \varepsilon} \\
\text { (GPa) }\end{array}$ \\
\hline 1 & 73.28708 & $3.9 \mathrm{E}-05$ & 1886311 & 12.99668028 \\
\hline 2 & 73.4833 & $3.9 \mathrm{E}-05$ & 1891361 & 13.03147689 \\
\hline 3 & 73.40183 & $3.9 \mathrm{E}-05$ & 1889264 & 13.01702926 \\
\hline 4 & 73.43644 & $3.9 \mathrm{E}-05$ & 1890155 & 13.02316817 \\
\hline 5 & 73.45709 & $3.9 \mathrm{E}-05$ & 1890686 & 13.02682928 \\
\hline
\end{tabular}

\begin{tabular}{|l|l|}
\hline$E(K p a)$ & $\begin{array}{l}\text { logE } \\
\text { (Kpa) }\end{array}$ \\
\hline 12996680 & 7.113832 \\
\hline 13031477 & 7.114994 \\
\hline 13017029 & 7.114512 \\
\hline 13023168 & 7.114717 \\
\hline 13026829 & 7.114839 \\
\hline
\end{tabular}

\begin{tabular}{|c|c|c|l|c|c|}
\hline \multicolumn{2}{|c|}{$\mathbf{0 . 5 H z}$} & \multicolumn{5}{l|}{} \\
\hline Cycle \# & P(lb-f) & A(in2) & & $\boldsymbol{\Delta}$ & GL \\
\hline 1 & 787.6733 & 10.75 & & 0.00014313 & 3.5 \\
\hline 2 & 788.6665 & 10.75 & & 0.00014313 & 3.5 \\
\hline 3 & 789.2318 & 10.75 & & 0.00014313 & 3.5 \\
\hline 4 & 789.4517 & 10.75 & & 0.00014313 & 3.5 \\
\hline 5 & 788.1617 & 10.75 & & 0.00014313 & 3.5 \\
\hline
\end{tabular}




\begin{tabular}{|c|l|c|c|l|}
\hline Cycle \# & $\sigma=P / A$ & $\varepsilon=\Delta-G L$ & $\begin{array}{l}{\left[E^{*}\right]=\sigma / \varepsilon} \\
\text { (psi) }\end{array}$ & $\begin{array}{l}{\left[\mathrm{E}^{*}\right]=\sigma / \varepsilon} \\
\text { (GPa) }\end{array}$ \\
\hline 1 & 73.27193 & $4.1 \mathrm{E}-05$ & 1791736 & 12.34506366 \\
\hline 2 & 73.36433 & $4.1 \mathrm{E}-05$ & 1793996 & 12.36063022 \\
\hline 3 & 73.41691 & $4.1 \mathrm{E}-05$ & 1795281 & 12.36948928 \\
\hline 4 & 73.43737 & $4.1 \mathrm{E}-05$ & 1795782 & 12.37293683 \\
\hline 5 & 73.31737 & $4.1 \mathrm{E}-05$ & 1792847 & 12.3527192 \\
\hline
\end{tabular}

\begin{tabular}{|l|l|}
\hline$E(K p a)$ & $\begin{array}{l}\text { logE } \\
(\mathrm{Kpa})\end{array}$ \\
\hline 12345064 & 7.091493 \\
\hline 12360630 & 7.092041 \\
\hline 12369489 & 7.092352 \\
\hline 12372937 & 7.092473 \\
\hline 12352719 & 7.091763 \\
\hline
\end{tabular}

\begin{tabular}{|c|c|c|c|c|c|}
\hline \multicolumn{2}{|c|}{$\mathbf{0 . 1 H z}$} & \multicolumn{5}{|l|}{} \\
\hline Cycle \# & $\mathbf{P}($ lb-f) & A(in2) & & $\boldsymbol{\Delta}$ & GL \\
\hline 1 & 789.3389 & 10.75 & & 0.00018709 & 3.5 \\
\hline 2 & 787.2152 & 10.75 & & 0.00018709 & 3.5 \\
\hline 3 & 789.2972 & 10.75 & & 0.00018709 & 3.5 \\
\hline 4 & 788.6696 & 10.75 & & 0.00018709 & 3.5 \\
\hline 5 & 787.8879 & 10.75 & & 0.00018709 & 3.5 \\
\hline
\end{tabular}

\begin{tabular}{|c|c|c|c|l|}
\hline Cycle \# & $\sigma=P / A$ & $\varepsilon=\Delta-G L$ & $\begin{array}{l}{\left[E^{*}\right]=\sigma / \varepsilon} \\
(\mathbf{p s i})\end{array}$ & $\begin{array}{l}{\left[E^{*}\right]=\sigma / \varepsilon} \\
\text { (GPa) }\end{array}$ \\
\hline 1 & 73.42687 & $5.3 E-05$ & 1373615 & 9.464204722 \\
\hline 2 & 73.22932 & $5.3 E-05$ & 1369919 & 9.438741953 \\
\hline 3 & 73.42299 & $5.3 E-05$ & 1373542 & 9.463704857 \\
\hline 4 & 73.36461 & $5.3 E-05$ & 1372450 & 9.456179668 \\
\hline 5 & 73.2919 & $5.3 E-05$ & 1371090 & 9.446807293 \\
\hline
\end{tabular}

\begin{tabular}{|c|l|}
\hline$E$ (Kpa) & $\begin{array}{l}\text { logE } \\
\text { (Kpa) }\end{array}$ \\
\hline 9464205 & 6.976084 \\
\hline 9438742 & 6.974914 \\
\hline 9463705 & 6.976061 \\
\hline 9456180 & 6.975716 \\
\hline 9446807 & 6.975285 \\
\hline
\end{tabular}


(21.1 degrees)

\begin{tabular}{|c|c|c|c|c|c|c|c|}
\hline Freq $(\mathrm{Hz})$ & $\begin{array}{l}\text { Peak } \\
\text { Displ. } \\
\text { Values } \\
\text { (in) }\end{array}$ & $\begin{array}{l}\text { Peak } \\
\text { Load } \\
\text { Values } \\
\text { (lb-ft) }\end{array}$ & $\begin{array}{l}\text { Peak Displ. } \\
\text { Time (secs) }\end{array}$ & $\begin{array}{l}\text { Peak Load } \\
\text { Time (secs) }\end{array}$ & $\begin{array}{l}\text { Phase } \\
\text { Shift } \\
\text { Values } \\
\text { (secs) }\end{array}$ & $\begin{array}{l}\text { Average } \\
\text { Displ. (in) }\end{array}$ & $\begin{array}{l}\text { Average } \\
\text { Load (Ib) }\end{array}$ \\
\hline \multirow[t]{5}{*}{10} & 0.001546 & 283.3735 & 20.6154 & 20.609213 & 0.006185 & 0.00155 & 282.89 \\
\hline & 0.001548 & 282.5074 & 20.7207 & 20.710938 & 0.009765 & & \\
\hline & 0.00155 & 283.1159 & 20.81999 & 20.809246 & 0.010742 & & \\
\hline & 0.00155 & 281.9168 & 20.91911 & 20.911133 & 0.007976 & & \\
\hline & 0.001554 & 283.5365 & 21.02035 & 21.009604 & 0.010742 & & \\
\hline \multirow[t]{5}{*}{5} & 0.0019 & 297.8737 & 40.18766 & 40.166016 & 0.021648 & 0.001912 & 298.0922 \\
\hline & 0.001907 & 298.5156 & 40.39014 & 40.365887 & 0.02425 & & \\
\hline & 0.001911 & 298.6231 & 40.58447 & 40.565918 & 0.018555 & & \\
\hline & 0.001916 & 297.5448 & 40.7889 & 40.766766 & 0.022136 & & \\
\hline & 0.001914 & 297.904 & 40.99007 & 40.967773 & 0.022301 & & \\
\hline \multirow[t]{5}{*}{1} & 0.002199 & 307.7705 & 56.66667 & 56.57943 & 0.087238 & 0.002225 & 307.695 \\
\hline & 0.002212 & 307.6576 & 57.6958 & 57.588379 & 0.107422 & & \\
\hline & 0.00223 & 307.6782 & 58.68473 & 58.586754 & 0.09798 & & \\
\hline & 0.002236 & 307.7156 & 59.70036 & 59.585777 & 0.114582 & & \\
\hline & 0.002249 & 307.653 & 60.68425 & 60.584637 & 0.099609 & & \\
\hline \multirow[t]{5}{*}{0.5} & 0.002507 & 313.5395 & 82.31332 & 82.071945 & 0.241371 & 0.002544 & 312.9323 \\
\hline & 0.002529 & 312.816 & 84.31609 & 84.117676 & 0.19841 & & \\
\hline & 0.002544 & 311.9343 & 86.30518 & 86.111816 & 0.19336 & & \\
\hline & 0.002561 & 313.5313 & 88.32195 & 88.078293 & 0.243652 & & \\
\hline & 0.00258 & 312.8406 & 90.3073 & 90.094727 & 0.21257 & & \\
\hline \multirow[t]{5}{*}{0.1} & 0.003142 & 316.324 & 177.1301 & 176.18864 & 0.94141 & 0.003228 & 316.2052 \\
\hline & 0.003185 & 316.3703 & 187.1123 & 186.2225 & 0.8898 & & \\
\hline & 0.003216 & 316.0776 & 197.1899 & 196.30014 & 0.8898 & & \\
\hline & 0.003287 & 316.2885 & 217.1776 & 216.2308 & 0.94678 & & \\
\hline & 0.003312 & 315.9654 & 227.1455 & 226.33073 & 0.81478 & & \\
\hline
\end{tabular}

\begin{tabular}{|c|c|c|c|c|c|}
\hline \multicolumn{2}{|c|}{$10 \mathrm{~Hz}$} & \multicolumn{1}{l|}{} \\
\cline { 1 - 2 } Cycle \# & P(lb-f) & A(in2) & & $\Delta$ & GL \\
\hline 1 & 283.3735 & 10.75 & & 0.00012914 & 3.5 \\
\hline 2 & 282.5074 & 10.75 & & 0.00012914 & 3.5 \\
\hline 3 & 283.1159 & 10.75 & & 0.00012914 & 3.5 \\
\hline 4 & 281.9168 & 10.75 & & 0.00012914 & 3.5 \\
\hline 5 & 283.5365 & 10.75 & & 0.00012914 & 3.5 \\
\hline
\end{tabular}

\begin{tabular}{|c|l|c|l|l|}
\hline Cycle \# & $\sigma=P / A$ & $\varepsilon=\Delta-G L$ & $\begin{array}{l}{\left[E^{*}\right]=\sigma / \varepsilon} \\
\text { (psi) }\end{array}$ & $\begin{array}{l}{\left[\mathrm{E}^{*}\right]=\sigma / \varepsilon} \\
\text { (GPa) }\end{array}$ \\
\hline 1 & 26.36033 & $3.69 \mathrm{E}-05$ & 714404.3 & 4.92224587 \\
\hline 2 & 26.27976 & $3.69 \mathrm{E}-05$ & 712220.7 & 4.9072007 \\
\hline 3 & 26.33636 & $3.69 \mathrm{E}-05$ & 713754.8 & 4.91777027 \\
\hline 4 & 26.22481 & $3.69 \mathrm{E}-05$ & 710731.7 & 4.89694118 \\
\hline 5 & 26.37549 & $3.69 \mathrm{E}-05$ & 714815.2 & 4.92507703 \\
\hline
\end{tabular}

\begin{tabular}{|l|l|}
\hline Kpa & $\operatorname{log~KPa}$ \\
\hline 4922246 & 6.692163 \\
\hline 4907201 & 6.690834 \\
\hline 4917770 & 6.691768 \\
\hline 4896941 & 6.689925 \\
\hline 4925077 & 6.692413 \\
\hline
\end{tabular}




\begin{tabular}{|c|c|c|c|c|c|}
\hline \multicolumn{2}{|c|}{$5 \mathrm{~Hz}$} & \multicolumn{5}{l|}{} \\
\hline Cycle \# & P(lb-f) & A(in2) & & $\boldsymbol{\Delta}$ & GL \\
\hline 1 & 297.8737 & 10.75 & & 0.00015932 & 3.5 \\
\hline 2 & 298.5156 & 10.75 & & 0.00015932 & 3.5 \\
\hline 3 & 298.6231 & 10.75 & & 0.00015932 & 3.5 \\
\hline 4 & 297.5448 & 10.75 & & 0.00015932 & 3.5 \\
\hline 5 & 297.904 & 10.75 & & 0.00015932 & 3.5 \\
\hline
\end{tabular}

\begin{tabular}{|c|c|c|l|l|}
\hline Cycle \# & $\sigma=P / A$ & $\varepsilon=\Delta-G L$ & $\begin{array}{l}{\left[E^{*}\right]=\sigma / \varepsilon} \\
(p s i)\end{array}$ & $\begin{array}{l}{\left[E^{*}\right]=\sigma / \varepsilon} \\
(\mathrm{GPa})\end{array}$ \\
\hline 1 & 27.70918 & $4.55 \mathrm{E}-05$ & 608713.4 & 4.19403536 \\
\hline 2 & 27.76889 & $4.55 \mathrm{E}-05$ & 610025.2 & 4.20307368 \\
\hline 3 & 27.77889 & $4.55 \mathrm{E}-05$ & 610244.9 & 4.20458713 \\
\hline 4 & 27.67859 & $4.55 \mathrm{E}-05$ & 608041.4 & 4.18940546 \\
\hline 5 & 27.712 & $4.55 \mathrm{E}-05$ & 608775.4 & 4.1944624 \\
\hline
\end{tabular}

\begin{tabular}{|l|l|}
\hline $\mathbf{E}(\mathrm{Kpa})$ & $\begin{array}{l}\text { logE } \\
\text { (Kpa) }\end{array}$ \\
\hline 4194035 & 6.622632 \\
\hline 4203074 & 6.623567 \\
\hline 4204587 & 6.623723 \\
\hline 4189405 & 6.622152 \\
\hline 4194462 & 6.622676 \\
\hline
\end{tabular}

\begin{tabular}{|c|c|c|c|c|c|}
\hline \multicolumn{2}{|c|}{ 1HZ } & \multicolumn{5}{l|}{} \\
\cline { 1 - 2 } Cycle \# & P(lb-f) & A(in2) & & $\Delta$ & GL \\
\hline 1 & 307.7705 & 10.75 & & 0.00018544 & 3.5 \\
\hline 2 & 307.6576 & 10.75 & & 0.00018544 & 3.5 \\
\hline 3 & 307.6782 & 10.75 & & 0.00018544 & 3.5 \\
\hline 4 & 307.7156 & 10.75 & & 0.00018544 & 3.5 \\
\hline 5 & 307.653 & 10.75 & & 0.00018544 & 3.5 \\
\hline
\end{tabular}

\begin{tabular}{|c|l|l|l|l|}
\hline Cycle \# & $\sigma=P / A$ & $\varepsilon=\Delta-G L$ & $\begin{array}{l}{\left[E^{*}\right]=\sigma / \varepsilon} \\
(p s i)\end{array}$ & $\begin{array}{l}{\left[E^{*}\right]=\sigma / \varepsilon} \\
(\mathrm{GPa})\end{array}$ \\
\hline 1 & 28.62982 & $5.3 \mathrm{E}-05$ & 540356.6 & 3.72305677 \\
\hline 2 & 28.61931 & $5.3 \mathrm{E}-05$ & 540158.3 & 3.72169079 \\
\hline 3 & 28.62122 & $5.3 \mathrm{E}-05$ & 540194.4 & 3.72193926 \\
\hline 4 & 28.62471 & $5.3 \mathrm{E}-05$ & 540260.2 & 3.72239265 \\
\hline 5 & 28.61888 & $5.3 \mathrm{E}-05$ & 540150.1 & 3.7216343 \\
\hline
\end{tabular}

\begin{tabular}{|l|r|}
\hline$E$ (Kpa) & $\begin{array}{l}\text { logE } \\
\text { (Kpa) }\end{array}$ \\
\hline 3723057 & 6.5709 \\
\hline 3721691 & 6.57074 \\
\hline 3721939 & 6.570769 \\
\hline 3722393 & 6.570822 \\
\hline 3721634 & 6.570734 \\
\hline
\end{tabular}

\begin{tabular}{|c|r|c|c|c|c|}
\cline { 1 - 2 } \multicolumn{2}{|c|}{$\mathbf{0 . 5 H z}$} & \multicolumn{5}{l|}{} \\
\cline { 1 - 2 } Cycle \# & P(lb-f) & A(in2) & & $\boldsymbol{\Delta}$ & GL \\
\hline 1 & 313.5395 & 10.75 & & 0.00021201 & 3.5 \\
\hline 2 & 312.816 & 10.75 & & 0.00021201 & 3.5 \\
\hline 3 & 311.9343 & 10.75 & & 0.00021201 & 3.5 \\
\hline 4 & 313.5313 & 10.75 & & 0.00021201 & 3.5 \\
\hline 5 & 312.8406 & 10.75 & & 0.00021201 & 3.5 \\
\hline
\end{tabular}




\begin{tabular}{|c|c|c|c|c|}
\hline Cycle \# & $\sigma=P / A$ & $\varepsilon=\Delta-G L$ & $\begin{array}{l}{\left[E^{*}\right]=\sigma / \varepsilon} \\
(p s i)\end{array}$ & $\begin{array}{l}{\left[E^{*}\right]=\sigma / \varepsilon} \\
(\mathrm{GPa})\end{array}$ \\
\hline 1 & 29.16647 & $6.06 \mathrm{E}-05$ & 481503.6 & 3.31755965 \\
\hline 2 & 29.09916 & $6.06 \mathrm{E}-05$ & 480392.5 & 3.30990419 \\
\hline 3 & 29.01714 & $6.06 \mathrm{E}-05$ & 479038.4 & 3.30057451 \\
\hline 4 & 29.1657 & $6.06 \mathrm{E}-05$ & 481490.9 & 3.31747214 \\
\hline 5 & 29.10145 & $6.06 \mathrm{E}-05$ & 480430.3 & 3.3101648 \\
\hline
\end{tabular}

\begin{tabular}{|l|r|}
\hline$E(K p a)$ & $\begin{array}{l}\text { logE } \\
\text { (Kpa) }\end{array}$ \\
\hline 3317560 & 6.520819 \\
\hline 3309904 & 6.519815 \\
\hline 3300575 & 6.51859 \\
\hline 3317472 & 6.520807 \\
\hline 3310165 & 6.51985 \\
\hline
\end{tabular}

\begin{tabular}{|c|c|c|c|c|c|}
\hline \multicolumn{2}{|c|}{$\mathbf{0 . 1 H z}$} & \multicolumn{5}{l|}{} \\
\cline { 1 - 2 } Cycle \# & P(lb-f) & A(in2) & & A & GL \\
\hline 1 & 316.324 & 10.75 & & 0.00026903 & 3.5 \\
\hline 2 & 316.3703 & 10.75 & & 0.00026903 & 3.5 \\
\hline 3 & 316.0776 & 10.75 & & 0.00026903 & 3.5 \\
\hline 4 & 316.2885 & 10.75 & & 0.00026903 & 3.5 \\
\hline 5 & 315.9654 & 10.75 & & 0.00026903 & 3.5 \\
\hline
\end{tabular}

\begin{tabular}{|c|l|c|l|l|}
\hline Cycle \# & $\sigma=P / A$ & $\varepsilon=\Delta-G L$ & $\begin{array}{l}{\left[E^{*}\right]=\sigma / \varepsilon} \\
\text { (psi) }\end{array}$ & $\begin{array}{l}{\left[E^{*}\right]=\sigma / \varepsilon} \\
\text { (GPa) }\end{array}$ \\
\hline 1 & 29.42549 & $7.69 E-05$ & 382820.4 & 2.63763275 \\
\hline 2 & 29.42979 & $7.69 E-05$ & 382876.4 & 2.63801848 \\
\hline 3 & 29.40257 & $7.69 E-05$ & 382522.3 & 2.63557842 \\
\hline 4 & 29.42219 & $7.69 E-05$ & 382777.5 & 2.63733699 \\
\hline 5 & 29.39213 & $7.69 E-05$ & 382386.4 & 2.63464244 \\
\hline
\end{tabular}

\begin{tabular}{|l|l|}
\hline$E(K p a)$ & $\begin{array}{l}\text { logE } \\
\text { (Kpa) }\end{array}$ \\
\hline 2637633 & 6.421214 \\
\hline 2638018 & 6.421278 \\
\hline 2635578 & 6.420876 \\
\hline 2637337 & 6.421166 \\
\hline 2634642 & 6.420722 \\
\hline
\end{tabular}


(37.8 degrees)

\begin{tabular}{|c|c|c|c|c|c|c|c|}
\hline Freq $(\mathrm{Hz})$ & $\begin{array}{l}\text { Peak } \\
\text { Displ. } \\
\text { Values } \\
\text { (in) }\end{array}$ & $\begin{array}{l}\text { Peak } \\
\text { Load } \\
\text { Values } \\
\text { (lb-f) }\end{array}$ & $\begin{array}{l}\text { Peak Displ. } \\
\text { Time (secs) }\end{array}$ & $\begin{array}{l}\text { Peak Load } \\
\text { Time (secs) }\end{array}$ & $\begin{array}{l}\text { Phase } \\
\text { Shift } \\
\text { Values } \\
\text { (secs) }\end{array}$ & $\begin{array}{l}\text { Average } \\
\text { Displ. (in) }\end{array}$ & $\begin{array}{l}\text { Average } \\
\text { Load (lb) }\end{array}$ \\
\hline \multirow[t]{5}{*}{10} & 0.00093 & 107.36 & 22.27588 & 22.27002 & 0.005859 & 0.000931 & 107.5403 \\
\hline & 0.000929 & 107.47 & 22.38119 & 22.370117 & 0.011069 & & \\
\hline & 0.000932 & 107.6 & 22.46654 & 22.469238 & 0.002698 & & \\
\hline & 0.000929 & 107.57 & 22.58057 & 22.569012 & 0.011554 & & \\
\hline & 0.000936 & 107.7 & 22.68636 & 22.669434 & 0.016927 & & \\
\hline \multirow[t]{5}{*}{5} & 0.001069 & 105.48 & 41.8527 & 41.830078 & 0.022625 & 0.001071 & 105.9952 \\
\hline & 0.001069 & 105.54 & 42.03662 & 42.029949 & 0.006672 & & \\
\hline & 0.00107 & 106.49 & 42.23568 & 42.225586 & 0.010094 & & \\
\hline & 0.001072 & 106.43 & 42.45297 & 42.423016 & 0.029949 & & \\
\hline & 0.001072 & 106.04 & 42.65283 & 42.62484 & 0.027992 & & \\
\hline \multirow[t]{5}{*}{1} & 0.001209 & 105.8 & 58.34001 & 58.262207 & 0.077801 & 0.001218 & 105.7351 \\
\hline & 0.001209 & 106.42 & 59.35107 & 59.234703 & 0.116371 & & \\
\hline & 0.001222 & 105.42 & 60.50914 & 60.255859 & 0.253281 & & \\
\hline & 0.001222 & 105.55 & 61.35059 & 61.261395 & 0.089191 & & \\
\hline & 0.001229 & 105.5 & 62.35612 & 62.260742 & 0.095379 & & \\
\hline \multirow[t]{5}{*}{0.5} & 0.001332 & 104.46 & 83.9292 & 83.819992 & 0.109207 & 0.001345 & 104.8966 \\
\hline & 0.001341 & 105.15 & 85.979 & 85.801109 & 0.177895 & & \\
\hline & 0.001346 & 104.59 & 87.92806 & 87.814941 & 0.113121 & & \\
\hline & 0.001348 & 105.17 & 89.9624 & 89.756187 & 0.206215 & & \\
\hline & 0.001357 & 105.12 & 91.91179 & 91.764816 & 0.146973 & & \\
\hline \multirow[t]{5}{*}{0.1} & 0.00151 & 104.49 & 188.6564 & 188.229 & 0.42742 & 0.001524 & 104.86 \\
\hline & 0.00152 & 105.53 & 198.722 & 198.09473 & 0.62729 & & \\
\hline & 0.001522 & 104.4 & 208.6729 & 208.17693 & 0.49592 & & \\
\hline & 0.001531 & 105.45 & 218.7902 & 218.13933 & 0.65088 & & \\
\hline & 0.001538 & 104.44 & 228.6856 & 228.18994 & 0.49561 & & \\
\hline
\end{tabular}

\begin{tabular}{|c|c|c|c|c|c|}
\hline \multicolumn{2}{|c|}{$10 \mathrm{~Hz}$} & \multicolumn{5}{|l|}{} \\
\hline Cycle \# & P(lb-f) & A(in2) & & $\boldsymbol{\Delta}$ & GL \\
\hline 1 & 107.355 & 10.75 & & 0.00007761 & 3.5 \\
\hline 2 & 107.4738 & 10.75 & & 0.00007761 & 3.5 \\
\hline 3 & 107.6021 & 10.75 & & 0.00007761 & 3.5 \\
\hline 4 & 107.5662 & 10.75 & & 0.00007761 & 3.5 \\
\hline 5 & 107.7044 & 10.75 & & 0.00007761 & 3.5 \\
\hline
\end{tabular}

\begin{tabular}{|c|l|c|l|l|}
\hline Cycle \# & $\sigma=P / A$ & $\varepsilon=\Delta-G L$ & $\begin{array}{l}{\left[E^{*}\right]=\sigma / \varepsilon} \\
(p s i)\end{array}$ & $\begin{array}{l}{\left[E^{*}\right]=\sigma / \varepsilon} \\
(\mathrm{GPa})\end{array}$ \\
\hline 1 & 9.986513 & $2 \mathrm{E}-05$ & 450378.7 & 3.10310902 \\
\hline 2 & 9.997567 & $2 \mathrm{E}-05$ & 450877.2 & 3.10654381 \\
\hline 3 & 10.00949 & $2 \mathrm{E}-05$ & 451415.1 & 3.11024974 \\
\hline 4 & 10.00616 & $2 \mathrm{E}-05$ & 451264.7 & 3.10921349 \\
\hline 5 & 10.01901 & $2 \mathrm{E}-05$ & 451844.2 & 3.11320673 \\
\hline
\end{tabular}

\begin{tabular}{|l|l|}
\hline Kpa & log KPa \\
\hline 3103109 & 6.491797 \\
\hline 3106544 & 6.492277 \\
\hline 3110250 & 6.492795 \\
\hline 3109213 & 6.492651 \\
\hline 3113207 & 6.493208 \\
\hline
\end{tabular}




\begin{tabular}{|c|c|c|c|c|c|}
\hline \multicolumn{2}{|c|}{$5 \mathrm{~Hz}$} & \multicolumn{5}{|l|}{} \\
\cline { 1 - 2 } Cycle \# & P(lb-f) & A(in2) & & $\boldsymbol{\Delta}$ & GL \\
\hline 1 & 105.4805 & 10.75 & & 0.00008922 & 3.5 \\
\hline 2 & 105.5351 & 10.75 & & 0.00008922 & 3.5 \\
\hline 3 & 106.4927 & 10.75 & & 0.00008922 & 3.5 \\
\hline 4 & 106.4314 & 10.75 & & 0.00008922 & 3.5 \\
\hline 5 & 106.0365 & 10.75 & & 0.00008922 & 3.5 \\
\hline
\end{tabular}

\begin{tabular}{|c|c|c|c|c|}
\hline Cycle \# & $\sigma=P / A$ & $\varepsilon=\Delta-G L$ & $\begin{array}{l}{\left[E^{*}\right]=\sigma / \varepsilon} \\
(\mathbf{p s i})\end{array}$ & $\begin{array}{l}{\left[E^{*}\right]=\sigma / \varepsilon} \\
(\mathrm{GPa})\end{array}$ \\
\hline 1 & 9.812135 & $3 \mathrm{E}-05$ & 384913.7 & 2.6520556 \\
\hline 2 & 9.81722 & $3 \mathrm{E}-05$ & 385113.2 & 2.65342989 \\
\hline 3 & 9.906301 & $3 \mathrm{E}-05$ & 388607.7 & 2.67750723 \\
\hline 4 & 9.900599 & $3 \mathrm{E}-05$ & 388384 & 2.67596599 \\
\hline 5 & 9.86386 & $3 \mathrm{E}-05$ & 386942.8 & 2.66603616 \\
\hline
\end{tabular}

\begin{tabular}{|l|l|}
\hline$E(K p a)$ & $\begin{array}{l}\text { logE } \\
(\mathrm{Kpa})\end{array}$ \\
\hline 2652056 & 6.423583 \\
\hline 2653430 & 6.423808 \\
\hline 2677507 & 6.427731 \\
\hline 2675966 & 6.427481 \\
\hline 2666036 & 6.425866 \\
\hline
\end{tabular}

\begin{tabular}{|c|c|c|c|c|c|}
\hline \multicolumn{2}{|c|}{ 1Hz } & \multicolumn{5}{l|}{} \\
\hline Cycle \# & P(lb-f) & A(in2) & & $\Delta$ & GL \\
\hline 1 & 105.7992 & 10.75 & & 0.00010154 & 3.5 \\
\hline 2 & 106.4179 & 10.75 & & 0.00010154 & 3.5 \\
\hline 3 & 105.4159 & 10.75 & & 0.00010154 & 3.5 \\
\hline 4 & 105.5471 & 10.75 & & 0.00010154 & 3.5 \\
\hline 5 & 105.4956 & 10.75 & & 0.00010154 & 3.5 \\
\hline
\end{tabular}

\begin{tabular}{|c|c|c|c|l|}
\hline Cycle \# & $\sigma=P / A$ & $\varepsilon=\Delta-G L$ & $\begin{array}{l}{\left[E^{*}\right]=\sigma / \varepsilon} \\
(\mathbf{p s i})\end{array}$ & $\begin{array}{l}{\left[E^{*}\right]=\sigma / \varepsilon} \\
(\mathrm{GPa})\end{array}$ \\
\hline 1 & 9.84179 & $3 \mathrm{E}-05$ & 339248.4 & 2.33742155 \\
\hline 2 & 9.899335 & $3 \mathrm{E}-05$ & 341232 & 2.35108849 \\
\hline 3 & 9.806127 & $3 \mathrm{E}-05$ & 338019.1 & 2.32895176 \\
\hline 4 & 9.818333 & $3 \mathrm{E}-05$ & 338439.9 & 2.33185058 \\
\hline 5 & 9.813548 & $3 \mathrm{E}-05$ & 338274.9 & 2.33071412 \\
\hline
\end{tabular}

\begin{tabular}{|l|l|}
\hline $\mathrm{E}(\mathrm{Kpa})$ & $\begin{array}{l}\text { logE } \\
\text { (Kpa) }\end{array}$ \\
\hline 2337422 & 6.368737 \\
\hline 2351088 & 6.371269 \\
\hline 2328952 & 6.36716 \\
\hline 2331851 & 6.367701 \\
\hline 2330714 & 6.367489 \\
\hline
\end{tabular}

\begin{tabular}{|c|c|c|c|c|c|}
\hline \multicolumn{2}{|c|}{$\mathbf{0 . 5 H z}$} & \multicolumn{5}{l|}{} \\
\hline Cycle \# & P(lb-f) & A(in2) & & $\Delta$ & GL \\
\hline 1 & 104.4571 & 10.75 & & 0.00011206 & 3.5 \\
\hline 2 & 105.1452 & 10.75 & & 0.00011206 & 3.5 \\
\hline 3 & 104.5892 & 10.75 & & 0.00011206 & 3.5 \\
\hline 4 & 105.1671 & 10.75 & & 0.00011206 & 3.5 \\
\hline 5 & 105.1244 & 10.75 & & 0.00011206 & 3.5 \\
\hline
\end{tabular}




\begin{tabular}{|c|c|c|c|l|}
\hline Cycle \# & $\boldsymbol{\sigma}=\mathrm{P} / \mathrm{A}$ & $\boldsymbol{\varepsilon}=\Delta-\mathrm{GL}$ & $\begin{array}{l}{\left[\mathrm{E}^{*}\right]=\sigma / \varepsilon} \\
(\mathbf{p s i})\end{array}$ & $\begin{array}{l}{\left[\mathrm{E}^{*}\right]=\sigma / \varepsilon} \\
(\mathrm{GPa})\end{array}$ \\
\hline 1 & 9.716936 & $3 \mathrm{E}-05$ & 303494.3 & 2.09107563 \\
\hline 2 & 9.780945 & $3 \mathrm{E}-05$ & 305493.5 & 2.10485038 \\
\hline 3 & 9.72923 & $3 \mathrm{E}-05$ & 303878.3 & 2.09372128 \\
\hline 4 & 9.782983 & $3 \mathrm{E}-05$ & 305557.2 & 2.10528898 \\
\hline 5 & 9.77901 & $3 \mathrm{E}-05$ & 305433.1 & 2.10443399 \\
\hline
\end{tabular}

\begin{tabular}{|l|l|}
\hline $\mathrm{E}(\mathrm{Kpa})$ & $\begin{array}{l}\text { logE } \\
\text { (Kpa) }\end{array}$ \\
\hline 2091076 & 6.32037 \\
\hline 2104850 & 6.323221 \\
\hline 2093721 & 6.320919 \\
\hline 2105289 & 6.323312 \\
\hline 2104434 & 6.323135 \\
\hline
\end{tabular}

\begin{tabular}{|c|c|c|c|c|c|}
\hline \multicolumn{2}{|c|}{$\mathbf{0 . 1 H z}$} & \multicolumn{5}{l|}{} \\
\hline Cycle \# & P(lb-f) & A(in2) & & $\Delta$ & GL \\
\hline 1 & 104.4894 & 10.75 & & 0.00012702 & 3.5 \\
\hline 2 & 105.5274 & 10.75 & & 0.00012702 & 3.5 \\
\hline 3 & 104.4014 & 10.75 & & 0.00012702 & 3.5 \\
\hline 4 & 105.4458 & 10.75 & & 0.00012702 & 3.5 \\
\hline 5 & 104.4363 & 10.75 & & 0.00012702 & 3.5 \\
\hline
\end{tabular}

\begin{tabular}{|c|l|c|l|r|}
\hline Cycle \# & $\sigma=P / A$ & $\varepsilon=\Delta-G L$ & $\begin{array}{l}{\left[E^{*}\right]=\sigma / \varepsilon} \\
\text { (psi) }\end{array}$ & $\begin{array}{l}{\left[E^{*}\right]=\sigma / \varepsilon} \\
(\mathrm{GPa})\end{array}$ \\
\hline 1 & 9.719942 & 4E-05 & 267820.7 & 1.8452846 \\
\hline 2 & 9.816499 & 4E-05 & 270481.2 & 1.86361535 \\
\hline 3 & 9.711755 & 4E-05 & 267595.1 & 1.84373034 \\
\hline 4 & 9.808912 & 4E-05 & 270272.1 & 1.862175 \\
\hline 5 & 9.715004 & 4E-05 & 267684.6 & 1.84434703 \\
\hline
\end{tabular}

\begin{tabular}{|l|l|}
\hline$E$ (Kpa) & $\begin{array}{l}\text { logE } \\
\text { (Kpa) }\end{array}$ \\
\hline 1845285 & 6.266063 \\
\hline 1863615 & 6.270356 \\
\hline 1843730 & 6.265697 \\
\hline 1862175 & 6.27002 \\
\hline 1844347 & 6.265843 \\
\hline
\end{tabular}


Appendix - B

Material Test System (MTS)

810 Load Frame \& Environmental Chamber

Specifications 
$1.1 \quad 318.10 \mathrm{~B}-01$ Model 318.10B-01, $100 \mathrm{kN}$ (22,000 lbs) Load Unit 1

Nominal dynamic load rating: $+/-100 \mathrm{kN}(+/-22,000 \mathrm{lbs})$.

Test space:

- Width: $533 \mathrm{~mm}$ (21 inches).

- Height (with standard columns): $146 \mathrm{~mm}$ (5.75 inches) to $1308 \mathrm{~mm}$ (51.5 inches).

Overall height (with standard columns): $2540 \mathrm{~mm}$ (100 inches).

Base dimensions:

- Width: $844 \mathrm{~mm}$ (33.25 inches).

- Depth: $610 \mathrm{~mm}$ (24 inches).

1.1.1

22,000 lbs Actuator, 6 inch Stroke, 1 inch -14 Mounting

Threads 1

1.1.2 Position Transducer, $150 \mathrm{~mm}$ (6 inch) 1

1.1.3 Hydraulic Lifts (22 Kip 65 in) 1

1.1.4 Hydraulic Crosshead Locks (22 Kip 65 in) 1

1.1.5 Emergency Stop and Hydraulic Lift / Lock Controls 1

1.1.6 298.12

Off/Low/On Control

298.12 Hydraulic Service Manifold with

Close-coupled accumulators allowing maximum high frequency response of servovalve(s).

Maximum operating pressure: $21 \mathrm{MPa}$ (3000 psi).

Off/Low/High pressure control.

Slow pressure turn on.

Fast emergency unload for system depressurization.

1.1.7 Hydraulic Service Manifold Adapter 1

1.1.8 318.10 Crosshead 1

1.1.9 Columns for Standard Test Space 1

1.1.10 252.24G-04 252.24G-04, 10 gpm (37 lpm) 5 port High

Response Servovalve 1

1.1.11 493.25 Calibration performed at MTS. Full Range for

493.25. 1

English units of measure.

1.2 FlexTest SE Controller - PLUS 1

1.2.1 493.02 MTS Model 493.02 FlexTest SE 1-Channel Chassis 1

The MTS FlexTest SE digital controller is a flexible and easy-to-use servocontroller for general testing applications. 
FlexTest SE hardware is VME-based including an MVME processor to provide real-time closed-loop control. The controller includes one analog input for high level data signal or external program, three analog outputs, and four digital inputs and four digital outputs (one pair dedicated for interlock).

The Basic model can operate stand-alone (without PC) or with PC automation. A dedicated PC is included as a standard feature with the Plus model. The Plus model also features a higher performance controller processor, capable of update rates up to $6 \mathrm{KHz}$

The higher performance processor is available as an option on the Basic model controller. If a stand-alone controller is desired for low-cost initial use, and TestWorks 4 or other application software is anticipated in the future, the Basic model should be ordered with the $6 \mathrm{KHz}$ processor.

Capabilities include:

- Function generation of monotonic ramps and cyclic waveforms using sine, square and triangular shapes can be generated.

- Graphic color display with optional general purpose scope; meters, which provide digital displays of specified measurements.

- Auto zero, bumpless start, hydraulics on mode-switching.

- Ability to save and restore PID tuning settings.

- Adaptive controls compensation; Peak-Valley and Null Pacing.

\subsubsection{Multi-position Handle 1}

\subsection{MTS Model 493.25 Universal Conditioner 3}

Provides transducer conditioning for AC or DC transducers.

Normalized with an on board reference for easy portability of calibrations.

Low noise, low drift, high accuracy signal conditioning.

Computer control of range, transducer zero, excitation, filter.

Designed for full range calibrations.

Shunt calibration for $100 \%$ range.

Supports strain gage bridge completion.

Excitation loss detection.

Computer controlled limit detection.

Excitation frequency: $9.83 \mathrm{kHz}$.

\subsection{Analog input package for 4931}

Provides set of 6 auxiliary input channels for high level (+/-10V) analog signals which can be used for control and data acquisition.

Includes adapter supporting BNC connectors on six 'pig-tail' leads.

Limit of 1 module per controller.

\subsection{14 Two Stage Valve Driver 1}

Provides servovalve drive signal for 2-stage servovalves.

- Supports single or dual MTS Model 252 style servovalves. 
- Digitally controlled fault protection logic.

- 16 bit resolution on valve D/A.

1.2.6 E-Stop Cable, 25ft / 7.5m 1

1.2.7 Load Transducer ID Cable, PT, $5 \mathrm{ft} / 1.5 \mathrm{~m} \quad 1$

1.2.8 Transducer Cable, 25ft / 7.5m 2

1.2.9 HSM Cable, 298.12, 25ft / 7.5m 1

1.2.10 Single Servovalve Cable, $25 \mathrm{ft} / 7.5 \mathrm{~m} \quad 1$

1.2.11 Ground Cable, 25ft / 7.5m 1

1.2.12 LVDT Transducer ID Cable, $5 \mathrm{ft} / 1.5 \mathrm{~m} 1$

1.2.13 FlexTest SE PC Automation Kit 1

This kit includes the MTS computer referenced elsewhere in this quote. Installed on the computer is Model 793.00 Software and 100MBPS Ethernet network card / cable.

Enables use of Basic TestWare to setup and run cyclic and monotonic tests, and acquire and store test data.

\subsection{Compaq Pentium IV / 3.2 GHz 1}

Compaq/HP Pentium IV/3.2 GHz

512MB SDRAM Memory, 512KB L2 CACHE Memory.

40GB SMART III Ultra ATA/100 Hard Drive, 1.44MB Diskette Drive.

CD/RW, X48

Windows XP.

\subsubsection{7 inch Compaq Monitor SVGA 1}

\section{$1.4 \quad 793.00 \quad 793.00$ FlexTest SE Automation (PC) System Software Key 1}

MTS 793 System Software including:

- Station Builder Software -- Provides a software interface for reconfiguring the controller.

- Station Manager Software -- Provides the main user interface to the test station.

- Basic TestWare -- Basic TestWare (BTW) is a software application that allows the user to define, save and execute simple test procedures.

- Null Pacing -- Ensures that desired levels are achieved on initial pass without over-programming. Can be used to optimize performance to reproduce waveshape or to maximize test speed.

- Peak Valley Control (PVC) -- Corrects for peaks and mean levels in cyclic waveforms. PVC is our most popular and widely used compensation tool.

\subsubsection{FlexTest SE Maintenance, Enhancement, and Support (ME\&S)}


The FlexTest SE Maintenance, Enhancement, and Support (ME\&S) makes it easy and cost effective to keep pace with rapidly changing technologies.

ME\&S owners receive all software Updates (maintenance) and software Upgrades (enhancement) that become available after your initial purchase. During the life of the contract, ME\&S owners are authorized to contact MTS for live technical support.

Enhancements may include upgrades for previously purchased software options (e.g. improved editing and plotting for the Profile Editor option).

The ME\&S only covers new features that are included in the base system. New features that are sold as options with a new release are not included, but are available for an additional charge.

Coverage includes FlexTest SE and all applications and options delivered on the System Software Media (e.g. MPT). Coverage for additional applications is available at an additional charge.

\subsection{Service 1}

\subsubsection{MTS Installation and Commissioning 1}

MTS Installation and Commissioning Plan.

This items covers installation and commissioning per the MTS Installation and Commissioning Plan. See plan for details.

\subsection{Vented In-vessel Load Cell 25 kN (5.5 Kip) 1}

$25 \mathrm{kN}$ (5.5 Kip) force rating.

Air or silicon oil confining fluid use only.

Uses load channel signal conditioner from the Uniaxial Testing System

Requires (1) load calibration.

Cable, $7.6 \mathrm{~m}(25 \mathrm{ft}$.

\subsection{Model 651.34S LN2 Cooled Chamber Assembly 1}

MTS Model 651.34 Liquid Nitrogen cooled, mechanically heated chamber Temperature control from $-70^{\circ} \mathrm{C}$ up to $+100^{\circ} \mathrm{C}$ for asphalt testing. Please contact MTS for extended temperature range option.

Inside dimensions adequate for all Uniaxial Test Packages and the Model 655.04 Triaxial Cell: $305 \mathrm{~mm}$ wide $\times 610 \mathrm{~mm}$ high $\times 508 \mathrm{~mm}$ deep

Temperature controller with PID control algorithms for manual or software command of temperature set point. Stability, $\pm 0.2^{\circ} \mathrm{C}$ with control and readout $R T D$ on the specimen surface.

"U" Plugs for easy removal from load frame test space

Sight window in front door with interior lighting 
Solenoid controlled LN2 regulator and flexible hose for connection to customer-supplied LN2 container

Cart for 810 Load Unit

Electrical power requirements: $220 \mathrm{VAC}, 30 \mathrm{~A}, 60 \mathrm{~Hz}, 1$ Phase

\subsection{Feed trough cables for triaxial cell 5}

complete with limo connectors on one end and PT connectors on the other end. Length is 15 feet or more. Specifically designed to work with feed throughs of a triaxial cell.

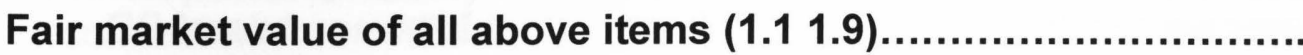
Call for Quote.

2 Options for 810 System

2.1.1 661.20E-03 661.20E-03 Axial Load Cell 1

2.1.2 1 inch -14 Load Cell Mounting Hardware 1

2.1.3 493.25 Calibration performed at MTS. Full Range for 493.25. 1

3 Options for Spare Parts and Consumables

3.1 Actuator Seal Kit, 318.10 Load Frame, 100 kN (22 kip) 1

Actuator Seal Kit, 318.10 Load Frame, 100 kN (22 kip)

- Non-Hydrostatic bearing

NOTE: The prices quoted above are expressed in Canadian dollars, unless otherwise noted. Prices do not include any local, state, or federal taxes, if applicable.

\section{Standard Project Engineering and Services}

\section{Documentation}

MTS supplies one set of documentation. Documentation is supplied on $\mathrm{CD}$; paper copies are also provided for some items. Depending on the system configuration, documentation consists of some or all of the following: 


\section{Software Information}

Includes descriptions of some or all of the following, as appropriate for the system: System Controller software, Test Definition software, Data Analysis software and other software tools.

\section{Operation Information}

Includes system operating instructions and information.

\section{Reference Information}

Pertinent system drawings, parts lists, and product information manuals.

Note: For MTS Minneapolis based servocontrolled systems, the documentation is supplied in pdf format on a browser-based CD. Paper copies of the System Reference manual are available on request for an additional fee.

\section{Vendor Manuals}

As received by MTS for equipment such as personal computers.

\section{Customer Responsibilities}

\section{Facility Requirements}

The customer should perform a detailed review of the machine specifications to assure that the facility where the machine will be installed has an appropriate sized dock to accommodate the dimensions of the MTS system being purchased. The path that the system will take to it's final destination should be measured to verify that the entry into the building, any doorways, elevators, or stairways that the machine must travel through, will accommodate the dimensions of the purchased MTS system. The customer should have appropriate moving equipment available to position the machine. Please pay close attention to the forklift handling instructions that accompany the shipment. 


\section{Equipment \& Personnel}

The customer will provide suitable equipment and personnel to unload and set in place all items in the contract, prior to the arrival of the MTS installation engineer. It is the customer's responsibility to ensure the system is handled and manipulated per the packing instructions.

\section{Power}

Electrical power for MTS supplied equipment will be provided by the customer. This electrical supply should be free from power transients caused by other equipment on the circuit. This includes appropriate electrical power for the hydraulic power supply (HPS) as well as a fused disconnect when an HPS is purchased. The desired HPS voltage must be specified at the time of the order.

\section{Water}

If a hydraulic power supply with a water to oil heat exchanger or watercooled accessories are purchased, a cooling water supply and drain of sufficient capacity are required. The cooling water lines shall be provided and connected by the customer.

\section{Environment}

Environmental requirements are indicated in the associated product literature. If purchased, the hydraulic power supply will require a room with adequate ventilation to ensure the maximum temperature for the room does not exceed 104 degree $F$ ( 40 degree $C$ ). The electronic components and computer equipment should be located in a suitable environment with respect to temperature, humidity, and dust.

\section{Specimens}

For installation, demonstration, and training, the customer will provide suitable specimens and other materials appropriate for use with the equipment described in this quotation.

\section{Accreditation}

MTS North American Field Service is accredited by the American Association of Laboratory Accreditation (A2LA) to deliver on-site calibrations in conformance to ISO/IEC 17025. Our Certificate number is 1145.01. The accreditation covers the specific calibrations listed on the 
agreed Scope of Accreditation, available on the A2LA website, www.a2la.org. Our calibration service meets the requirements of ISO/IEC 17025, ANSI/NCSL Z540-1, and ISO 10012-1. All systems used for accredited testing must be calibrated on site at the time of installation by an accredited calibration entity.

For systems installed outside North America, please contact the local MTS Field Service office for information concerning accredited calibration services.

\section{Warranty}

MTS warrants equipment of its manufacture to be free of defects in materials and workmanship for a period of 12 months after shipment from its plant or 12 months from completion of commissioning at your site if MTS installs the equipment. MTS allows a maximum of 3 months for transit; the warranty shall not exceed 15 months from shipment in any case. MTS shall, at its option, repair or replace free of charge within the warranty period any components or assemblies supplied by MTS which prove to be defective in workmanship or materials, subject to the following:

MTS reserves the right to request the prepaid return of such defective items to its plant for inspection and evaluation.

Expendable items (oil, lamps, seals, filters, etc.) and items subject to normal wear and/or replacement, will not be covered under warranty if their failure is the result of normal wear. Re-calibration of transducers is not covered by this warranty.

MTS reserves the right to reject those claims for warranty where it is determined that failure is caused by Buyer made modifications, improper maintenance, misuse or abuse of the equipment.

This warranty is extended only to the original Buyer of the equipment.

Items supplied by MTS but not of its manufacture (computers, oscilloscopes, commercial software packages, etc.) carry the original manufacturer's warranty which is passed on to the customer who is responsible to deal directly with the manufacturer on warranty issues. 
MTS Integrated Software, MTS will provide telephone consultation and strive to correct errors brought to its attention for the period of the warranty.

This warranty is expressly in lieu of all other warranties expressed or implied, statutory or otherwise, including any implied warranty of merchantability or fitness or suitability for a particular purpose. No warranties are expressed or implied which extend beyond the description of the face hereof. In no event shall MTS be liable to the Buyer for collateral, indirect, incidental or consequential damages of any kind.

MTS assumes no liability for damages arising from the use of the equipment by the buyer or any third party. By purchasing MTS equipment, the Buyer assumes all liability for any damages of any kind which may result from its use or misuse by the Buyer, Buyer's employees, agents, contractors or any other third party unknown to MTS or the Buyer, including damages due to failure of the equipment.

MTS Limited Warranties is the over-ruling document in the event of a conflict or misunderstanding and is incorporated by this reference. 


\section{REFERENCES}

AASHTO, "Standard Method of Test for Determining Dynamic Modulus of Hot Mix Asphalt Concrete Mixtures", Designation: TP 62-03, (2003)

Asphalt Materials, Mixture Design, and Construction. "NAPA Education Foundation, Second Edition, (1996).

Asphalt Institute "Superpave, Performance Graded Asphalt Binder Specification and Testing" Superpave Series No 1, (SP-1), Asphalt Institute, Lexington, Kentucky (2003).

ASTM D3496-99 "Standard Practice for Preparation of Bituminous Mixture Specimens for Dynamic Modulus Testing" (2005).

ASTM D3497-79 "Standard Test Method for Dynamic Modulus of Asphalt Mixtures (2003).

Balmer, G.G. "Pavement Texture: Its Significance and Development" Transportation Research Board, Transportation Research Record 666, (1978).

Bhasin, A., Button, J.W., Chowdhury, A., Chowdhury, A., "Evaluation of Simple Performance Tests on HMA Mistures" Project Summary Report Texas Transportation Institute. (2005).

Brown R., Kandhal P. and Zhang Z. "performance Testing for Hot Mix Asphalt, Executive Summary", National Center for Asphalt Technology, NCAT Report No. 2001-05A, November (2001).

Brown, E.R., and S.A. Cross. "A National Study of Rutting in Hot Mix Asphalt (HMA) Pavements.” NCAT Report No.92-5, (1992).

Brown, E.R., Kandhal, P.S., Zhang, J., "Performance Testing for Hot Mix Asphalt"

Hills, J.F. "The Creep of Asphalt Concrete Mixes." Journal of the Institute of Petroleum, (1973). 
Mallick, R.B, R.Ahlrich, and E.R. Brown. "Potential of Dynamic Creep to Predict Rutting." ASTM SPT (1995).

McGennis, R.B., R.M. Anderson, T.W. Kennedy, and M. Solaimanian. "Background of Superpave Asphalt Mixture Design and Analysis" Pub No.FHWA-SA-95-003, (1994).

Mehta, Y.A, and Sukurmaran, B., "Investigation of New Devices for Use in Determining Mechanistic Properties and Performance" SPR\# 0092-03-15 (2005).

Ministry of Transportation "Pavement Design and Rehabilitation Manual SDO90-01" (1990).

Nahass, N. C. Jaques, B "Polymer Modified Asphalts for High Performance Hot Mix Pavement Binders", J. Assoc. of Aspahlt Paving Technology (1990).

National Center for Asphalt Technology (2001).

National Cooperative Highway Research Program, "Accelerated Laboratory Rutting Tests: Evaluation of the APA" NCHRP Report 508 (2003).

National Cooperative Highway Research Program, "Guide for MechanicalEmpirical Design of New and Rehabilitated Pavement Structures", NCHRP (2004).

National Cooperative Highway Research Program, "Relationship of Superpave Gyratory Compaction Properties to HMA Rutting Behavior", NCHRP (2002).

National Cooperative Highway Research Program, "Simple Performance Tester for Superpave Mix Design: First Article Development and Evaluation", NCHRP Report 513 (2003).

National Cooperative Highway Research Program, "Simple Performance Tester for Superpave Mix Design: Summary of Recommended Methods and Database", NCHRP Report 547 (2005).

National Cooperative Highway Research Program, "Simple Performance Tester for Superpave Mix Design”, NCHRP Report 513 (2001). 
Nevelt, G., and H. Thanfold. "Evaluation of the Resistance to Deformation of Different Road Structures and Asphalt Mixtures Determined in the Pavement Rutting Tester," Proceeding of the Association of Asphalt Paving Technologists, Vol 57, (1988).

Ontario Provincial Standard Specification "Air Voids Mix Design Criteria" (2002).

Powell R.B. "Laboratory Performance Testing for the NCAT Pavement Test Track", Transportation Research Board, 2003.

Prithvi S. Kandahal and L. Allen Cooley, Jr "Evaluation of Permanent Deformation of Asphalt Mixtures Using Loaded Wheel Tester", NCHRP Report 513 (2003).

Ramswamy, S.D. and Aziz, M.A, "Effect of Filler Type and Shape of Aggregates on the Stability of Bituminous Mixes", Road Engineering Association of Asia and Australia 3 (1983).

Rosener, John C., James G.Ghehovits and Gene R. Morris., "Fly Ash as a Mineral Filler and Anti Stripping Agent for Asphalt Concrete", Proceeding of the Sixth International Ash Utilization Symposium. Vol 1, Washington (1982).

Strategic Highway research Program, "The SUPERPAVE Mix Design System Manual of Specifications, test Methods, and Practices". National research Council (1994).

Suhaibani, A.A, Mudaiheem J.A. "Effect of Filler Type and Content on Properties of Aspahlt Concrete Mixes" American Society for Testing and Material, Philadelphia, (1992).

Suheibani, A.R.S, "The use of Fly Ash as an Asphalt Extender," University of Michigan (1986).

Terrel, R.L., and S. Al-Swailimi. Water Sensitivity of Asphalt Aggregate Mixes: Test Selection." SHRP-A-403. National Research Council. Washington, (1994). 
Transportation Research Circular Mum E-C068 Transportation research Board (2004).

White T., Hua J. and Galal K. "Analysis of Acceleration Pavement Tests", Transportation Research Board (2003).

Witczak, M.W, "Development of a Master Curve (E*) Database for Lime Modified Asphaltic Mixtures." ASU (2004).

Zimmer, Frank V. "Fly Ash as Bituminous Filler", Proceeding of the Second Ash Utilization Symposium, No. 8488, Pittsburgh, Pennsylvania (1970). 